Supplement of Geosci. Commun., 3, 291-302, 2020

https://doi.org/10.5194/gc-3-291-2020-supplement

(C) Author(s) 2020. This work is distributed under

the Creative Commons Attribution 4.0 License.

(c) (1)

Supplement of

\title{
The human side of geoscientists: comparing geoscientists' and non-geoscientists' cognitive and affective responses to geology
}

Anthea Lacchia et al.

Correspondence to: Anthea Lacchia (anthea.lacchia@icrag-centre.org)

The copyright of individual parts of the supplement might differ from the CC BY 4.0 License. 


\section{Subsurface}

Please sketch the ground under your feet down to any depth within the Earth/beneath the ground 


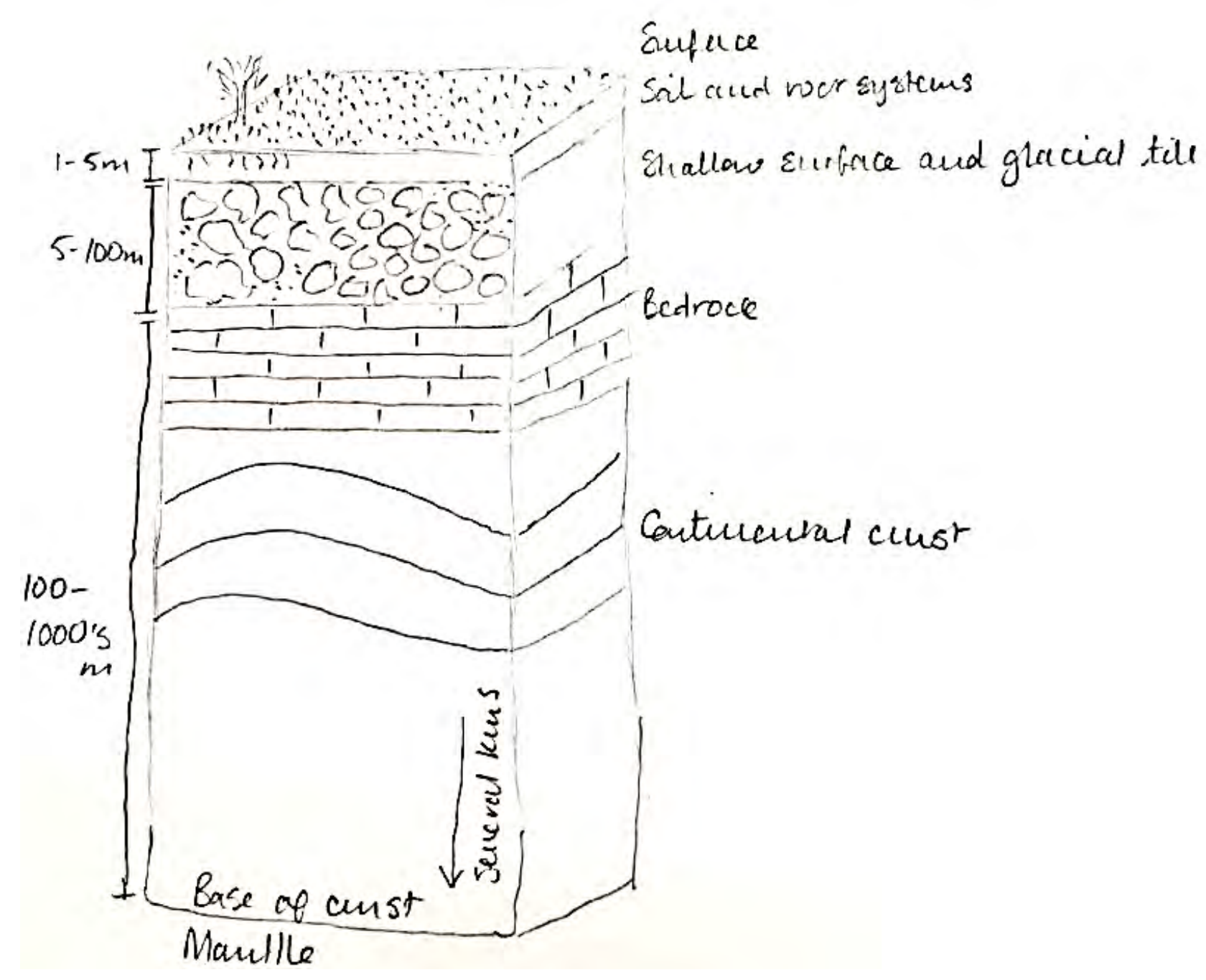

Expert 


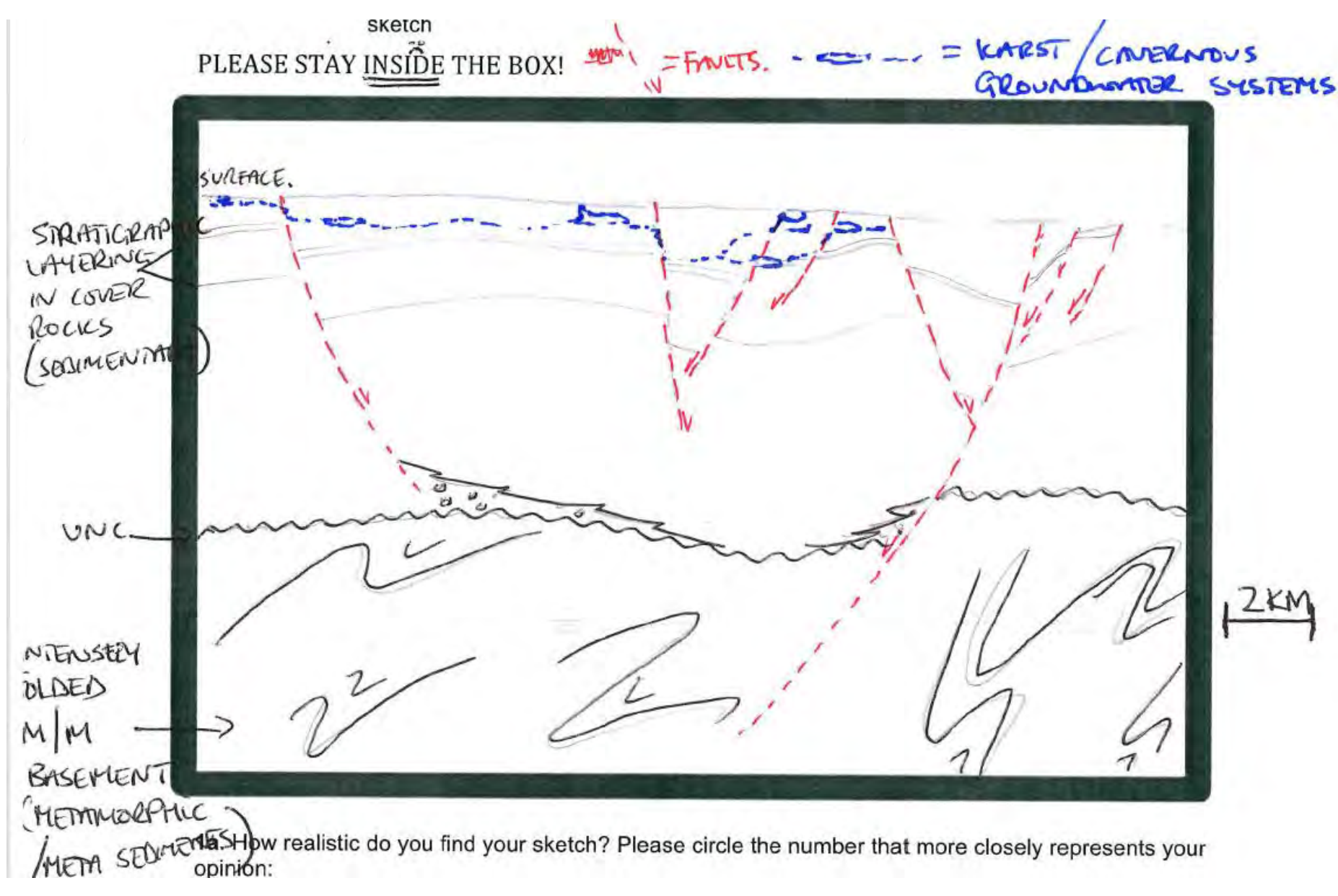




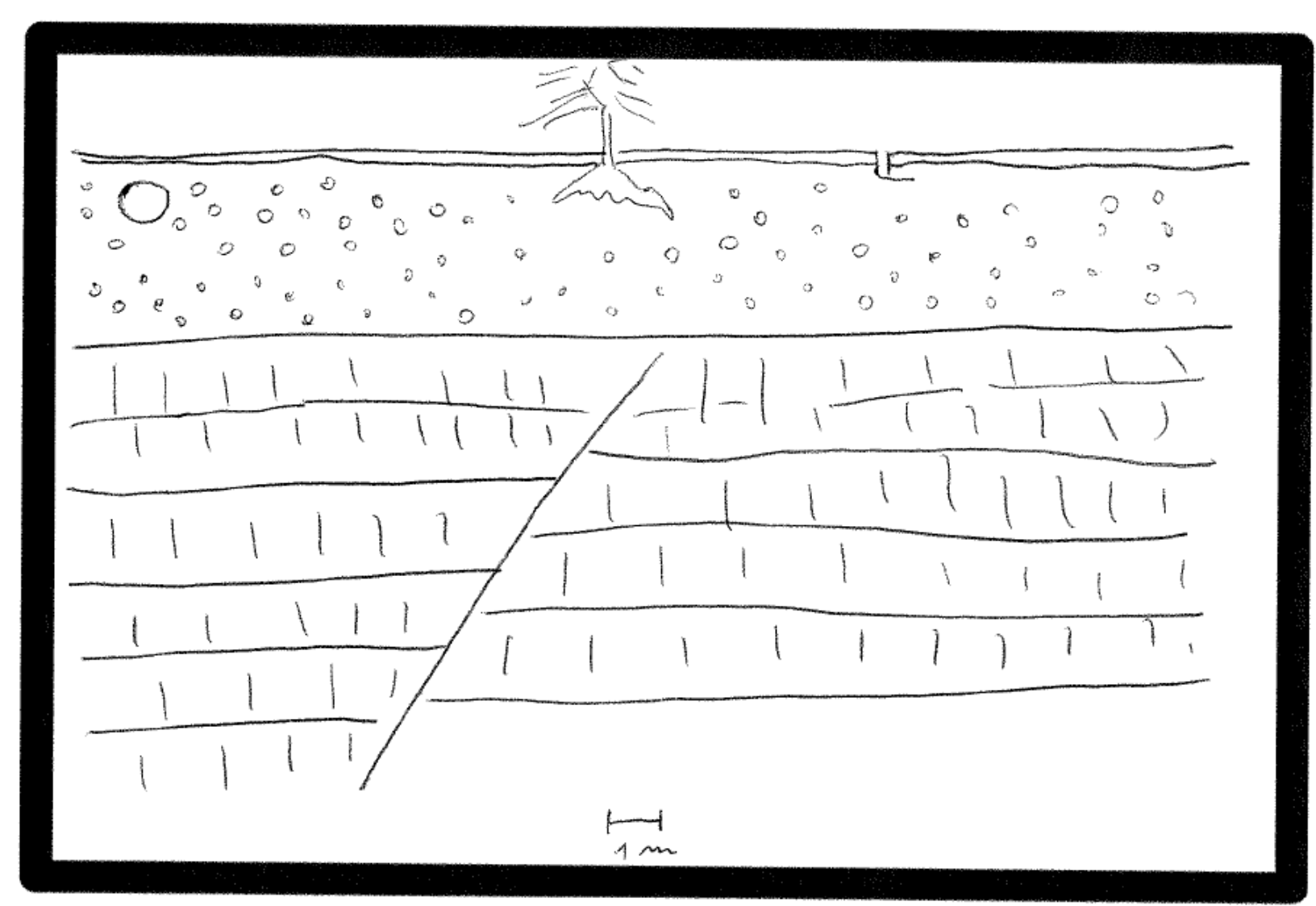




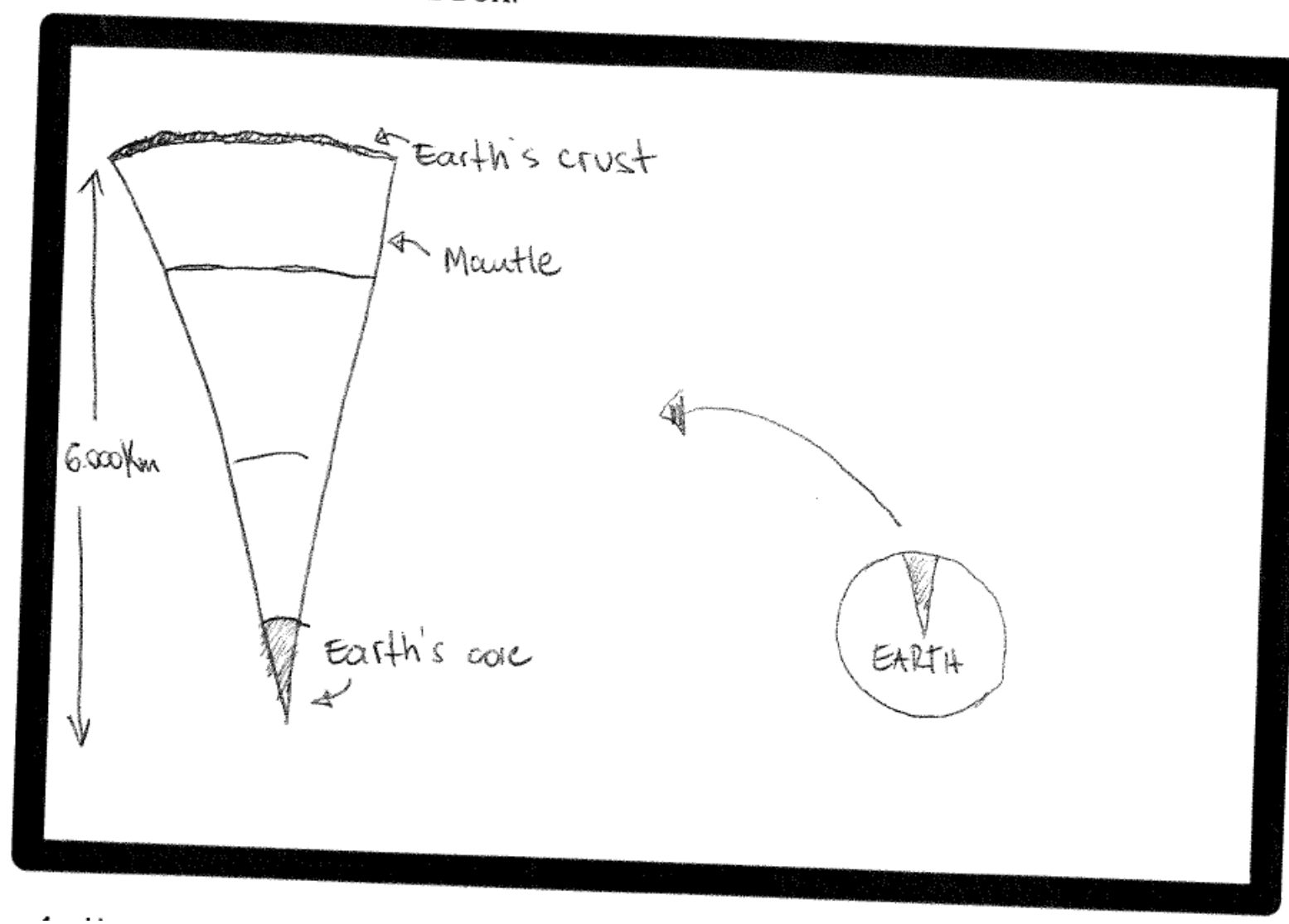




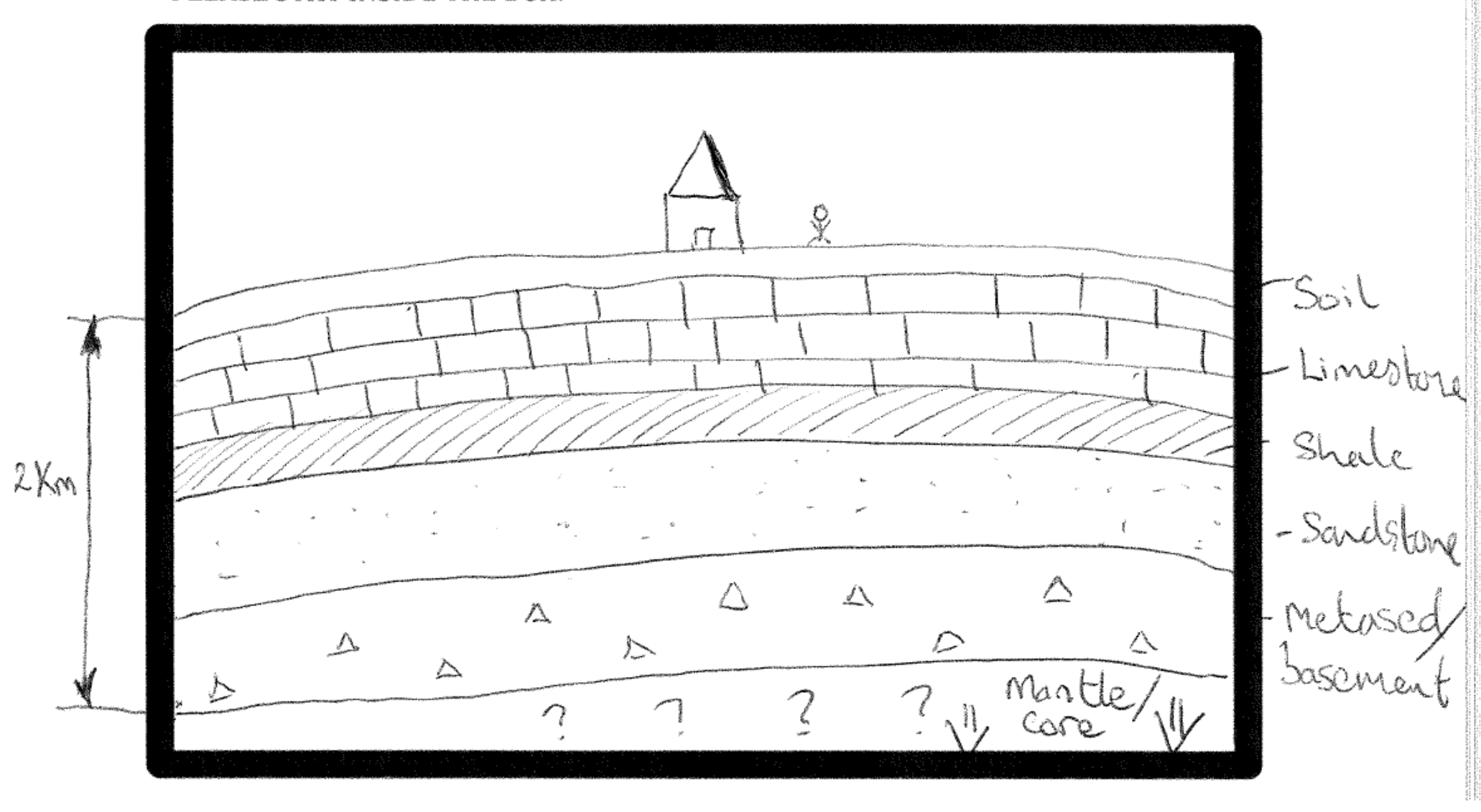




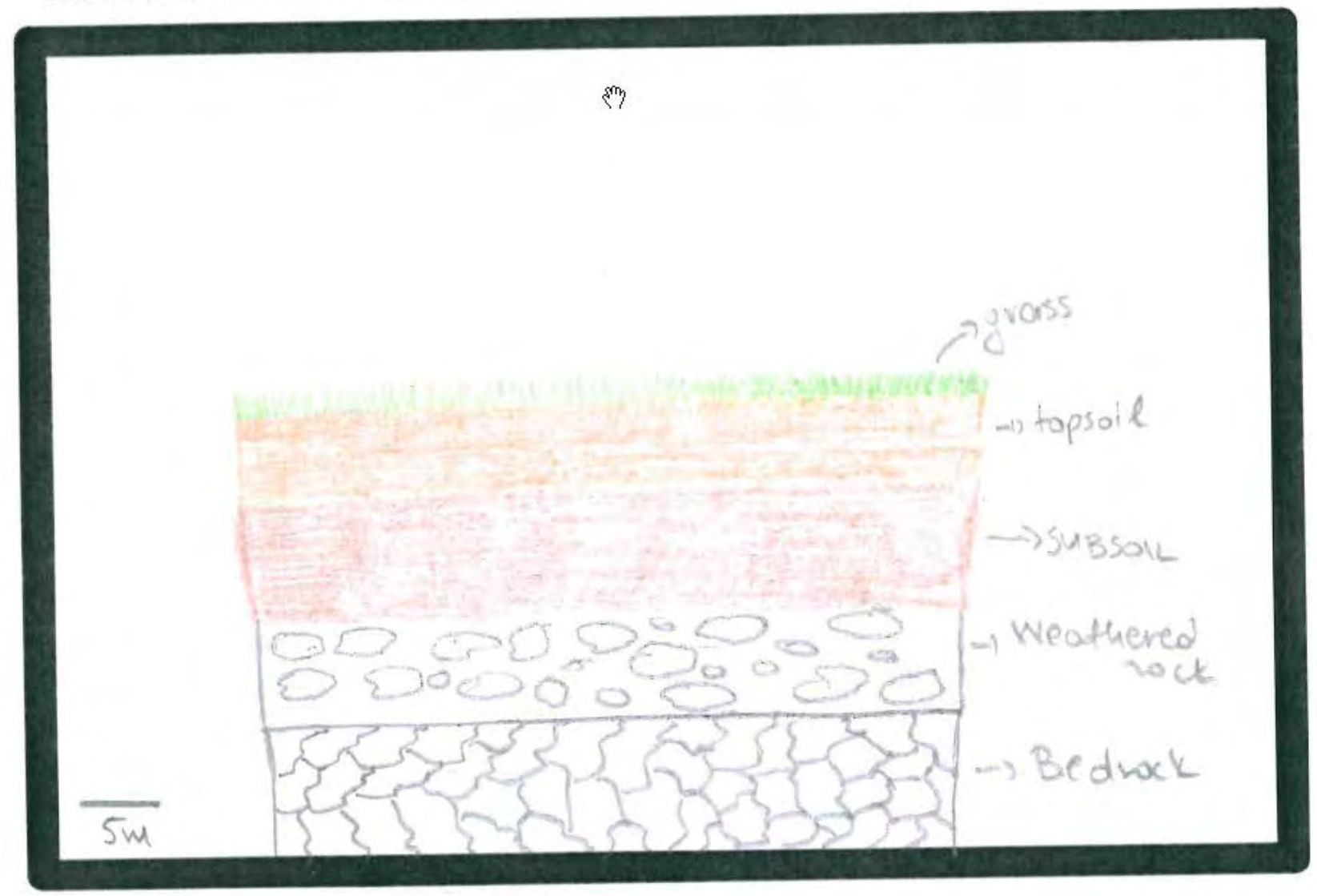




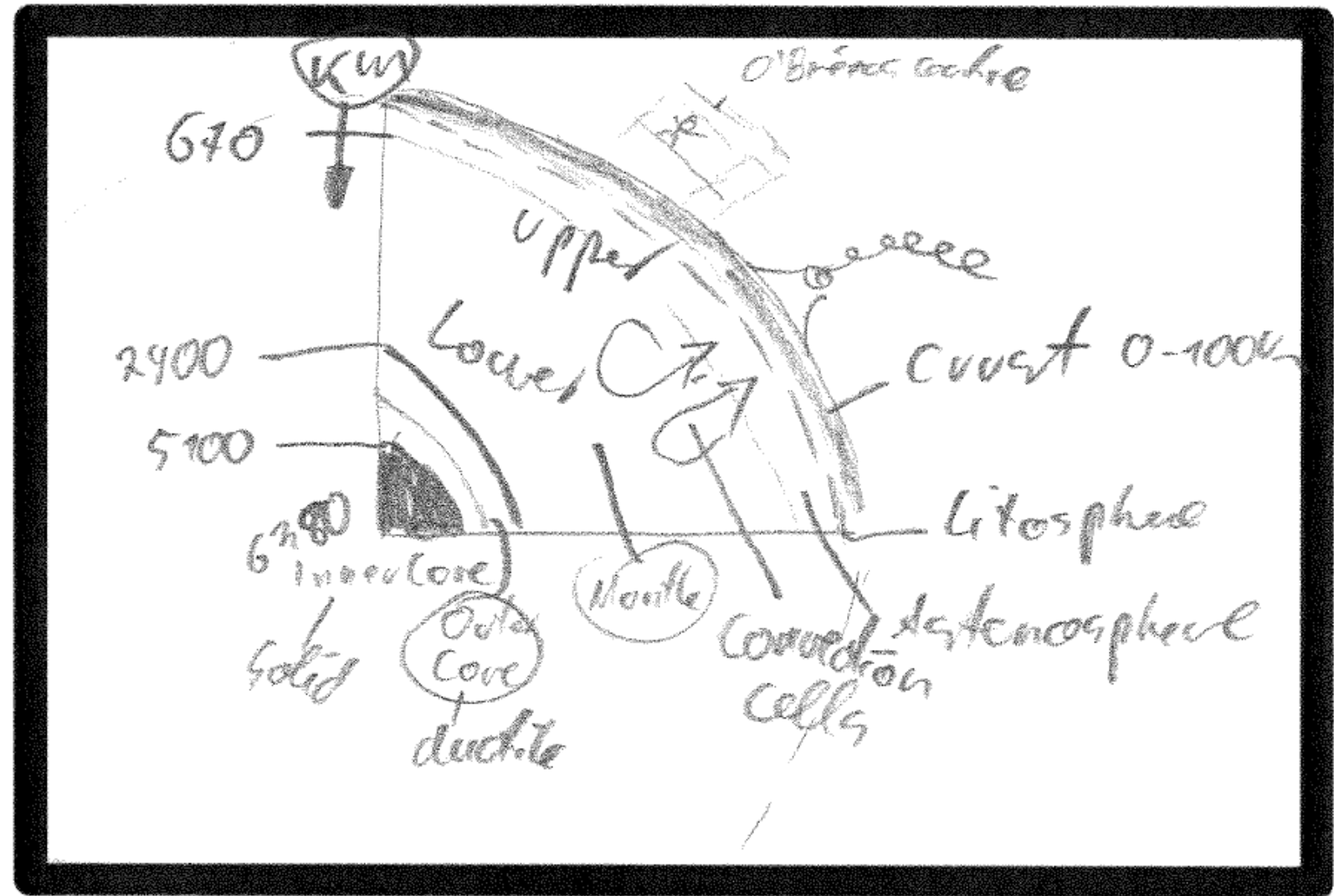




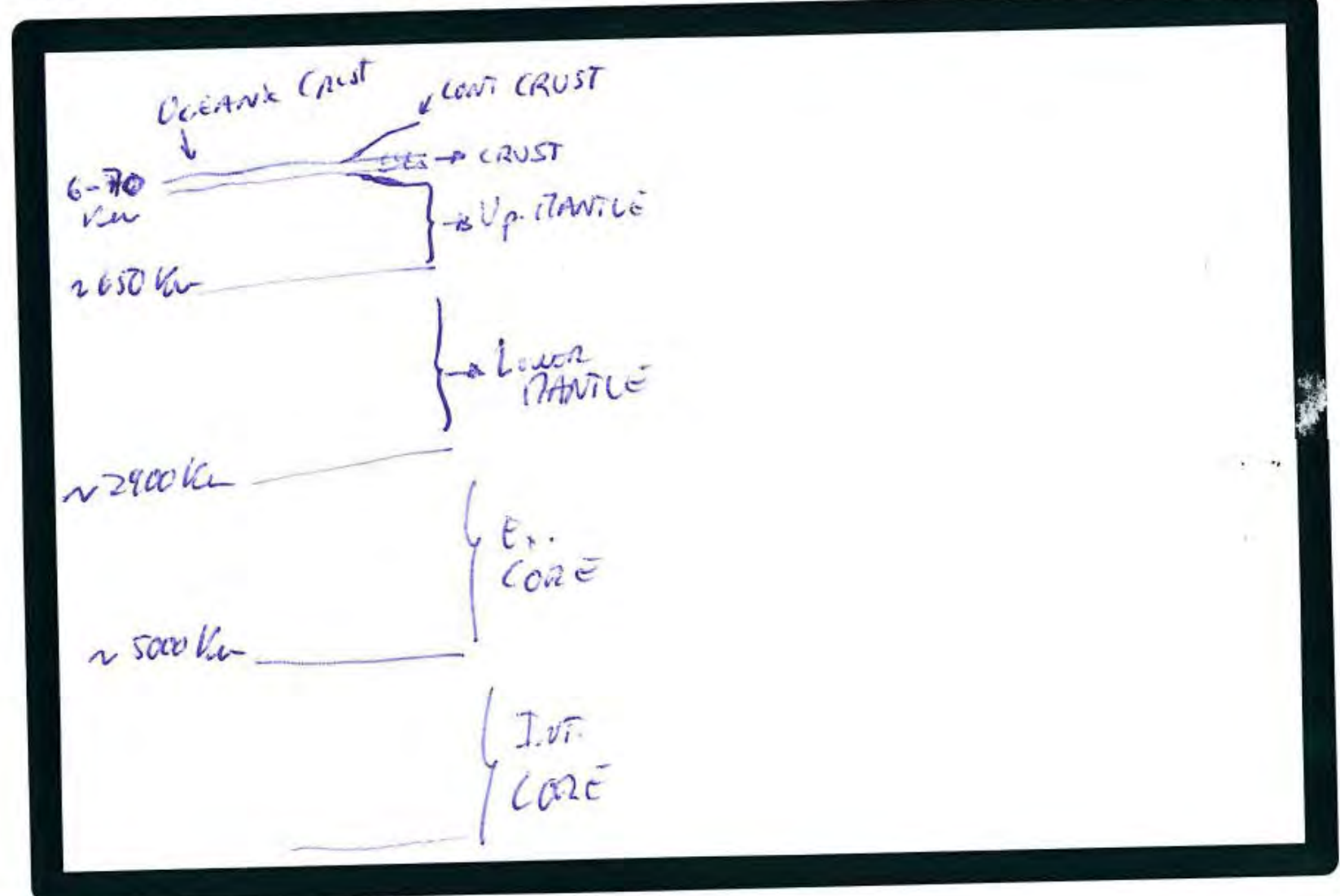




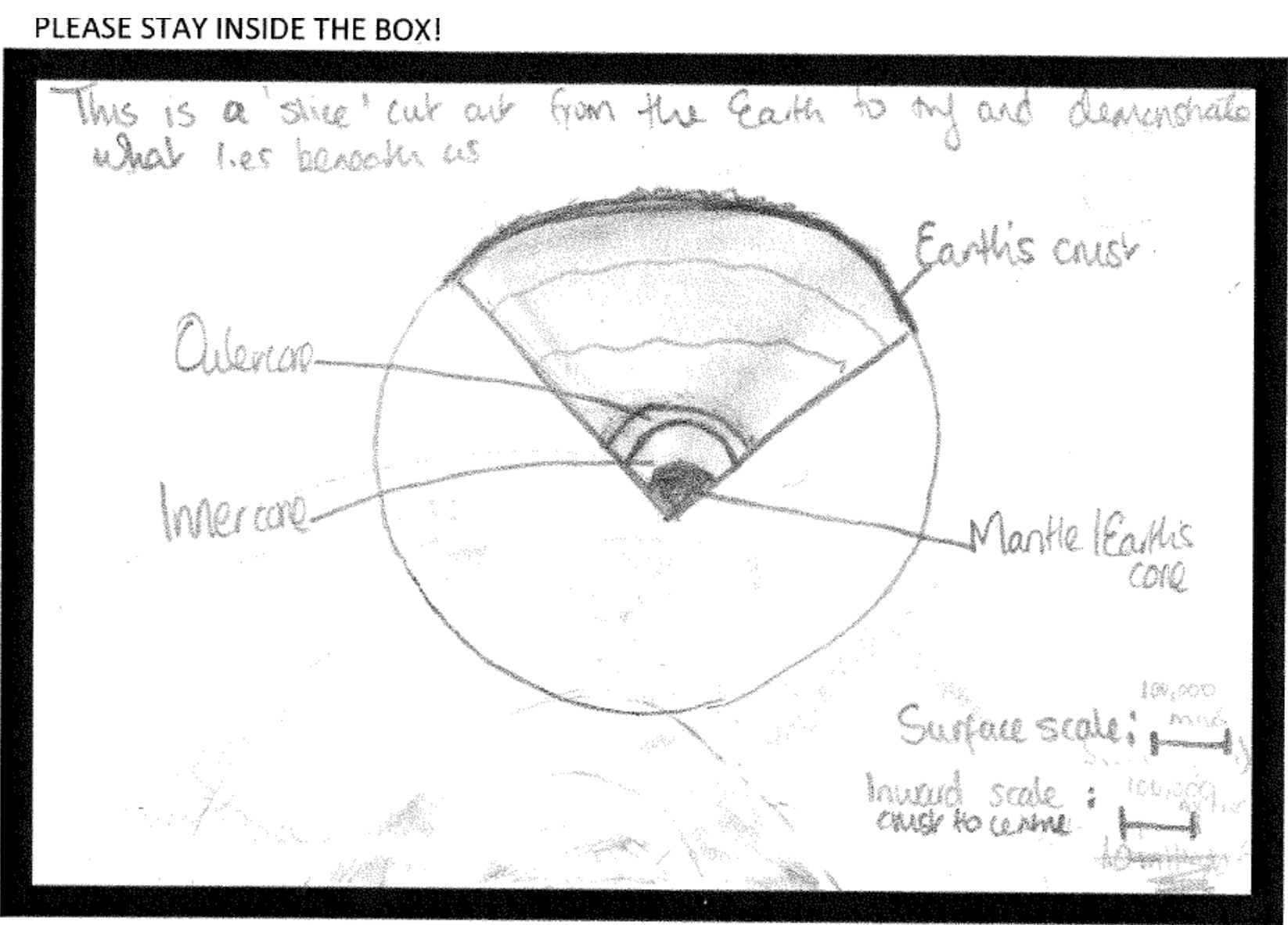


PLEASE STAY INSIDE THE BOX!

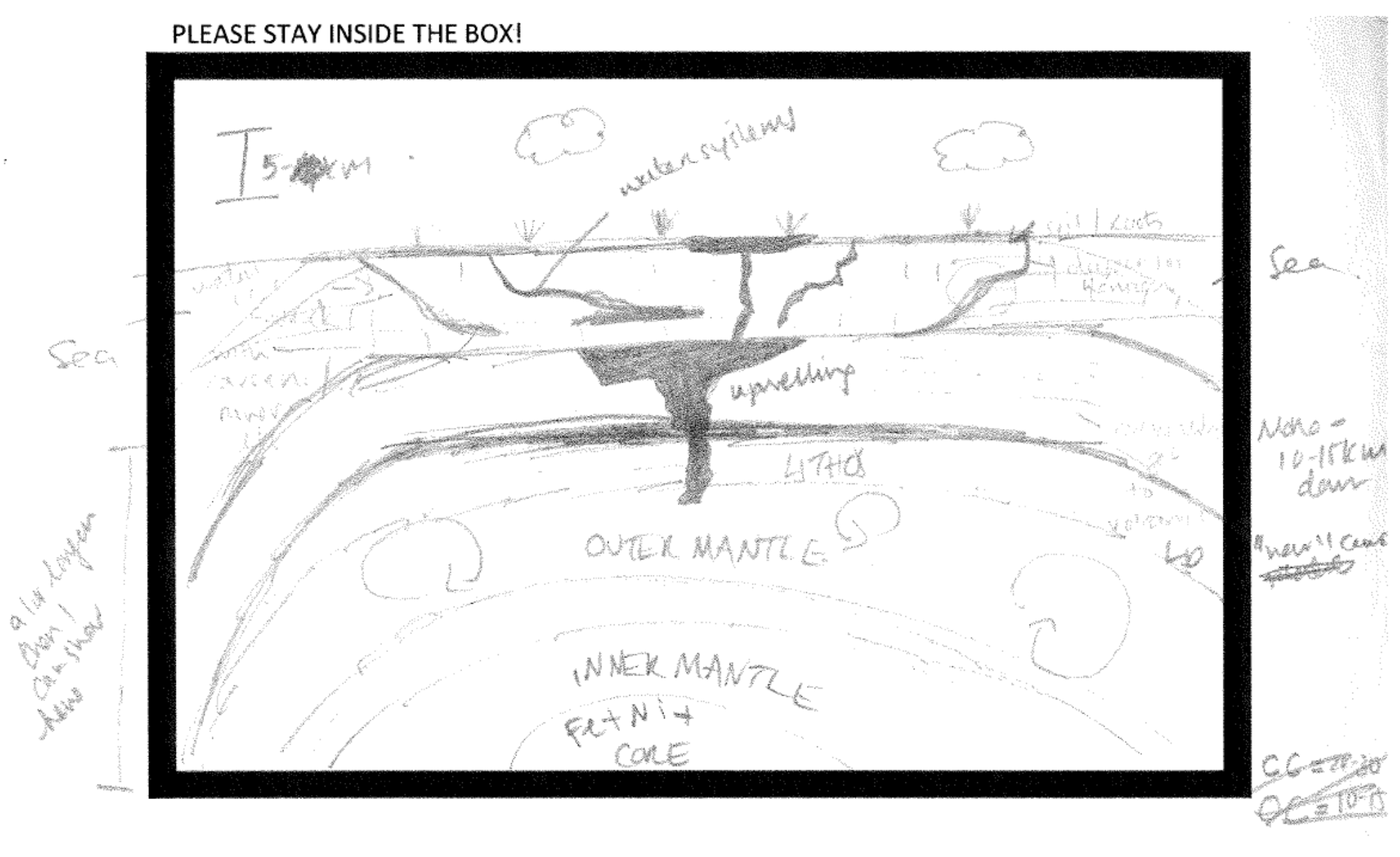




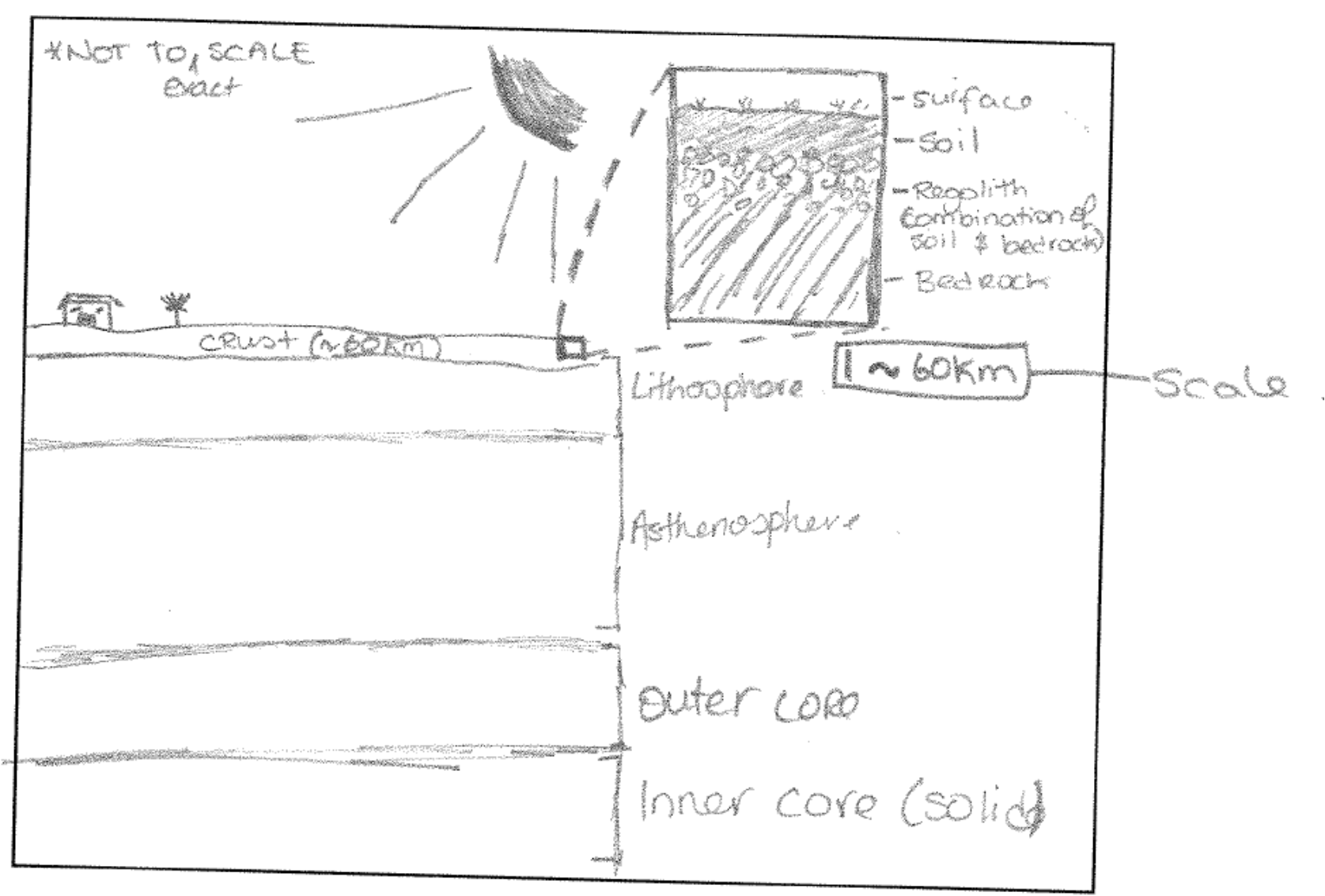

Expert 
PLEASE STAY INSIDE THE BOX!

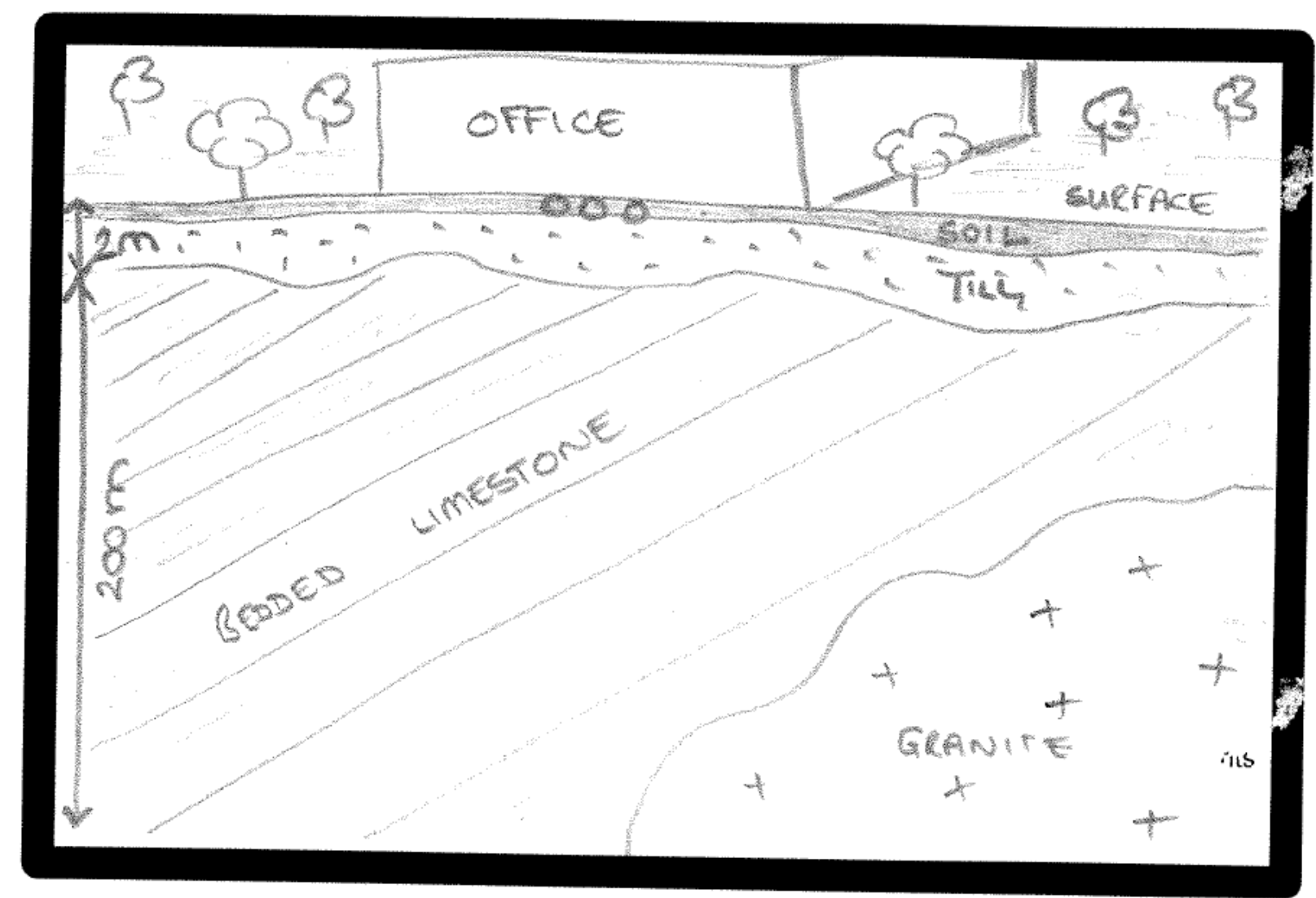


PLEASE STAY INSIDE THE BOX!

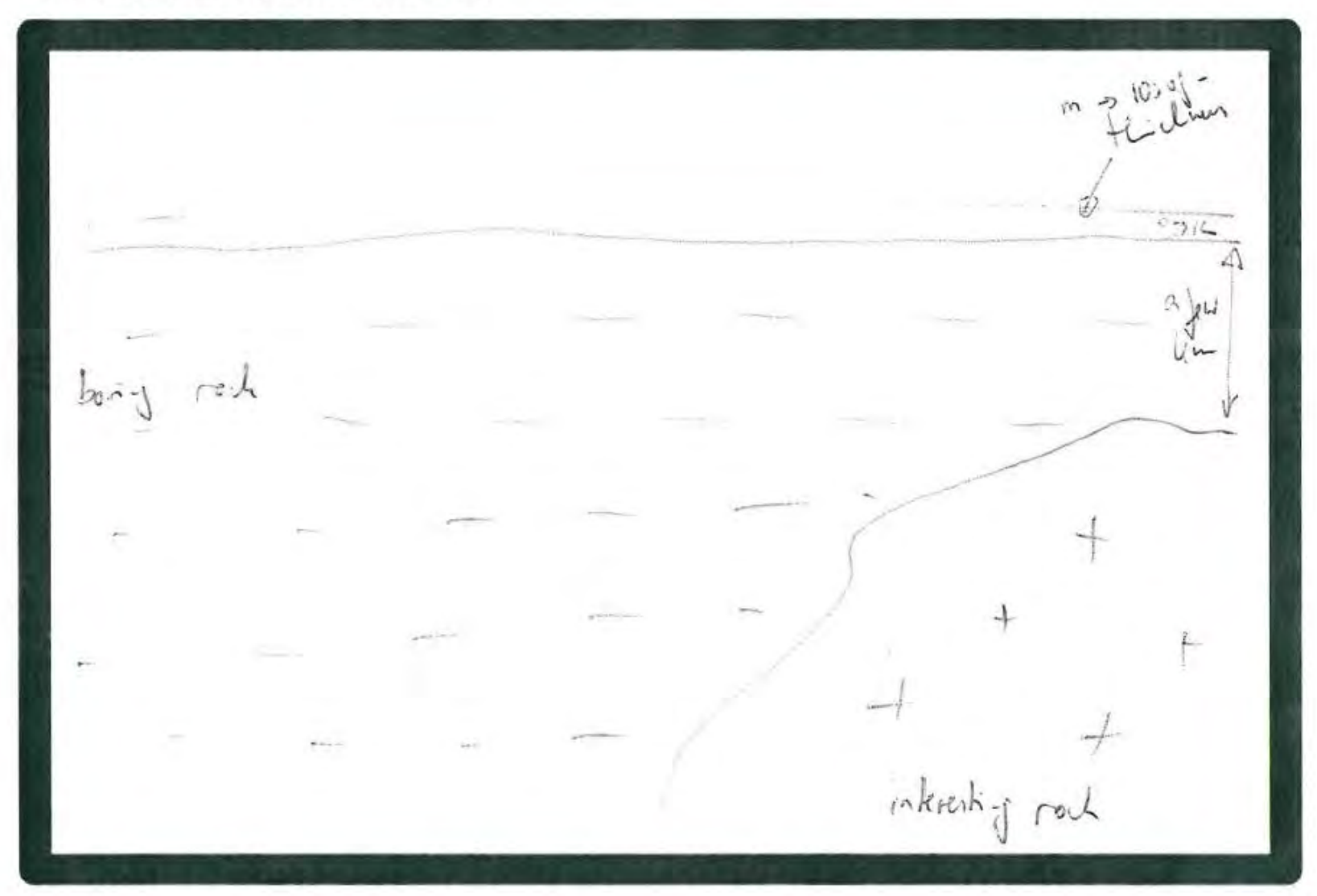


PLEASE STAY INSIDE THE BOX!

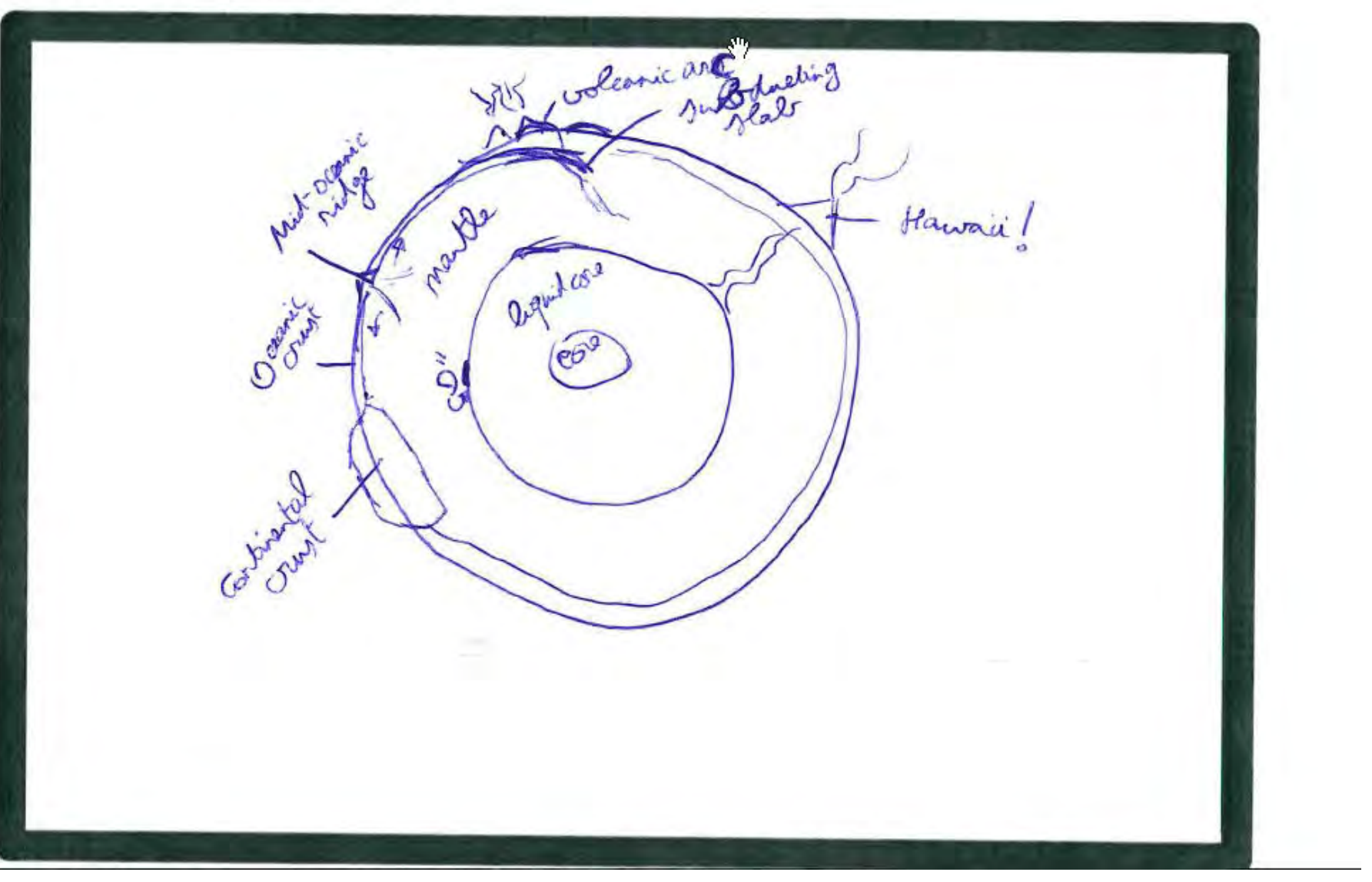




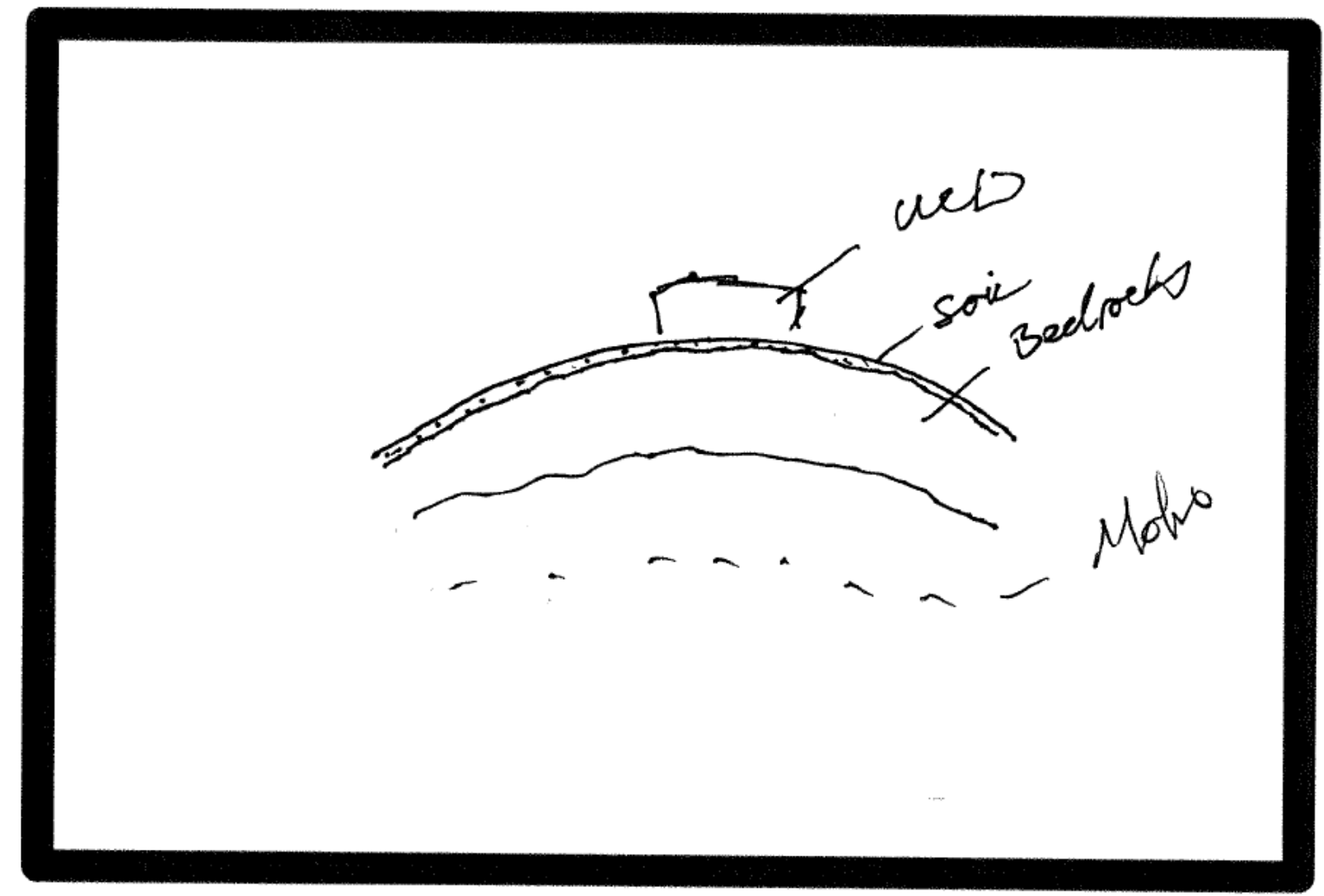




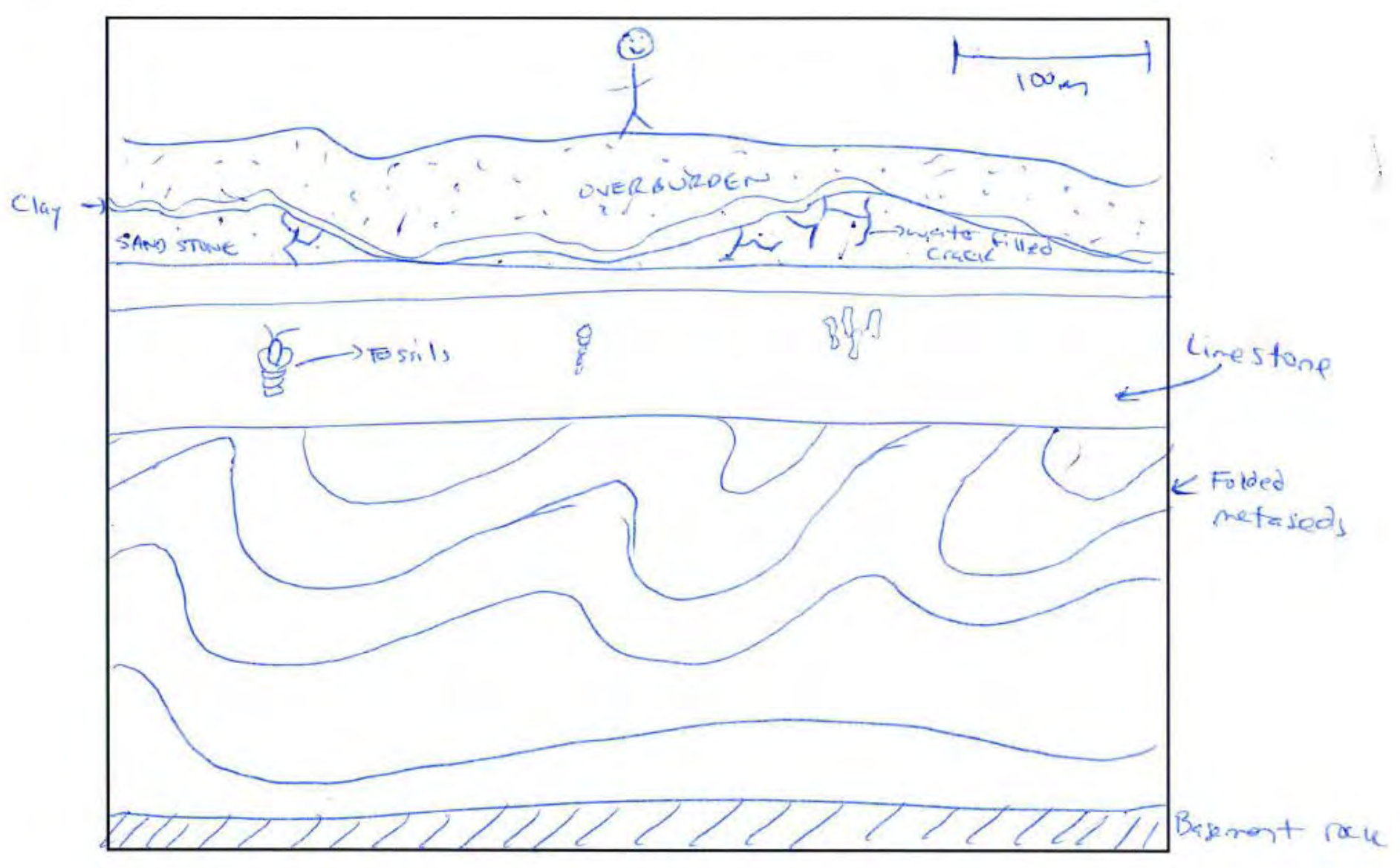

Expert 
PLEASE STAY INSIDE THE BOX!

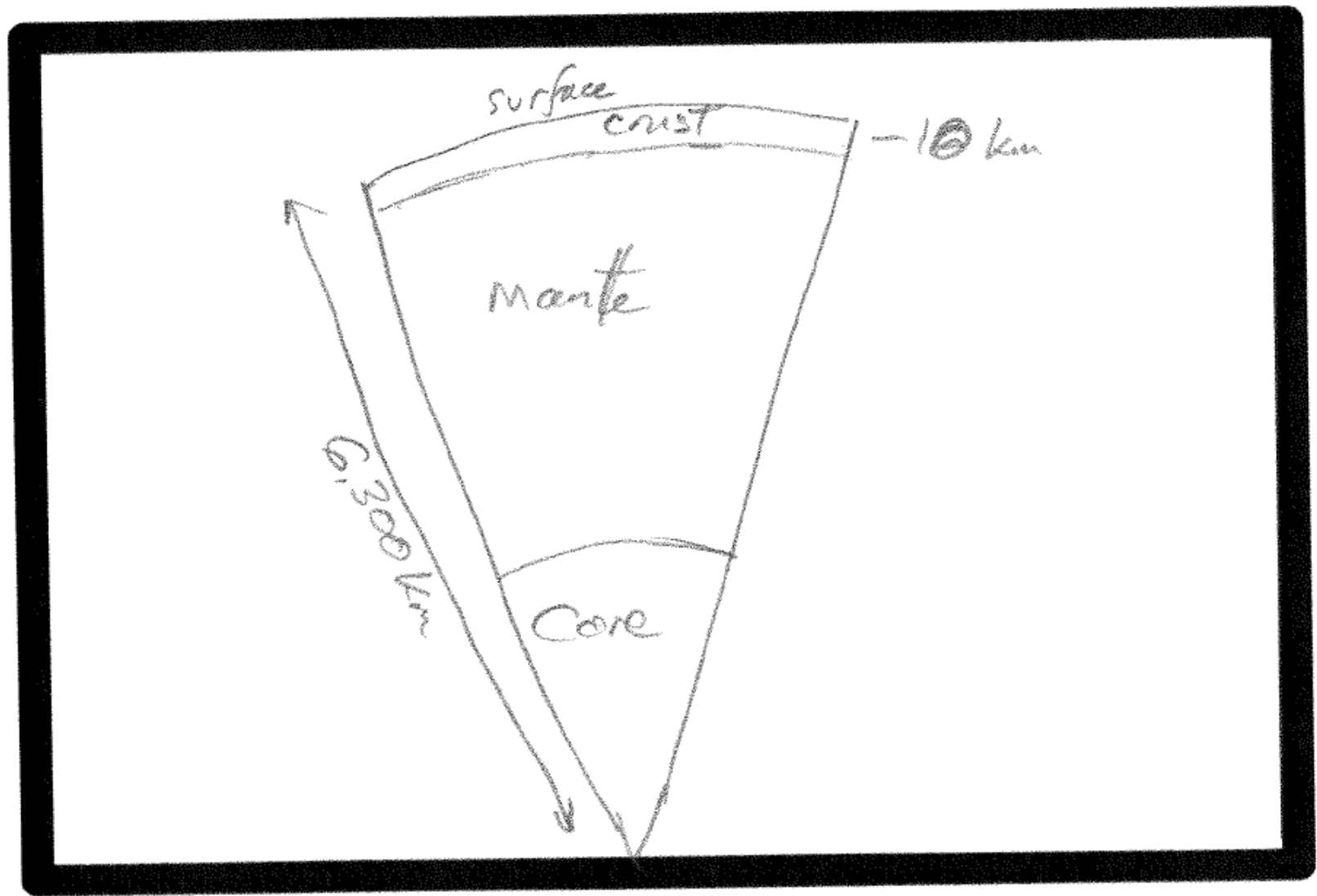


PLEASE STAY INSIDE THE BOX!

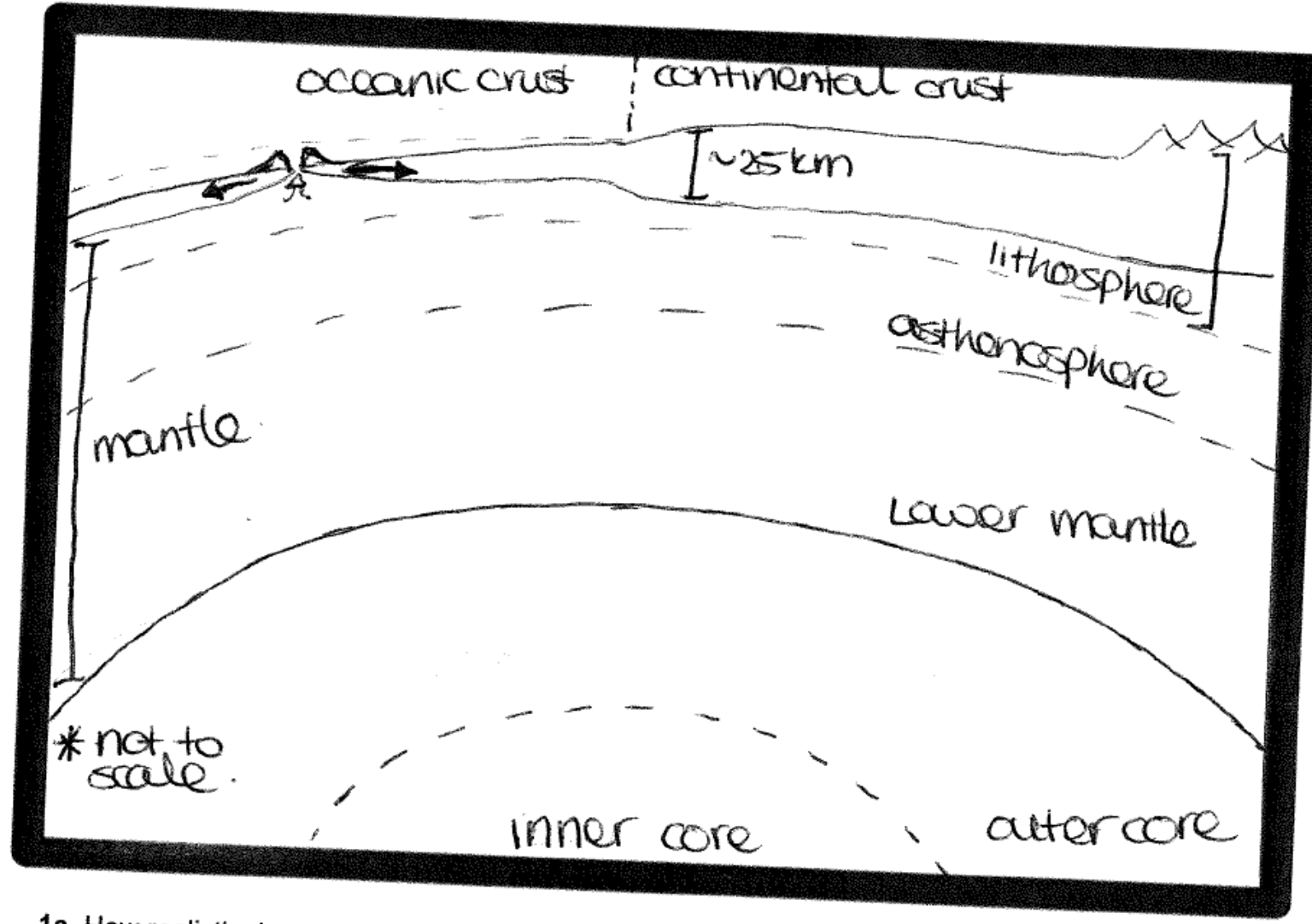


PLEASE STAY INSIDE THE BOX!

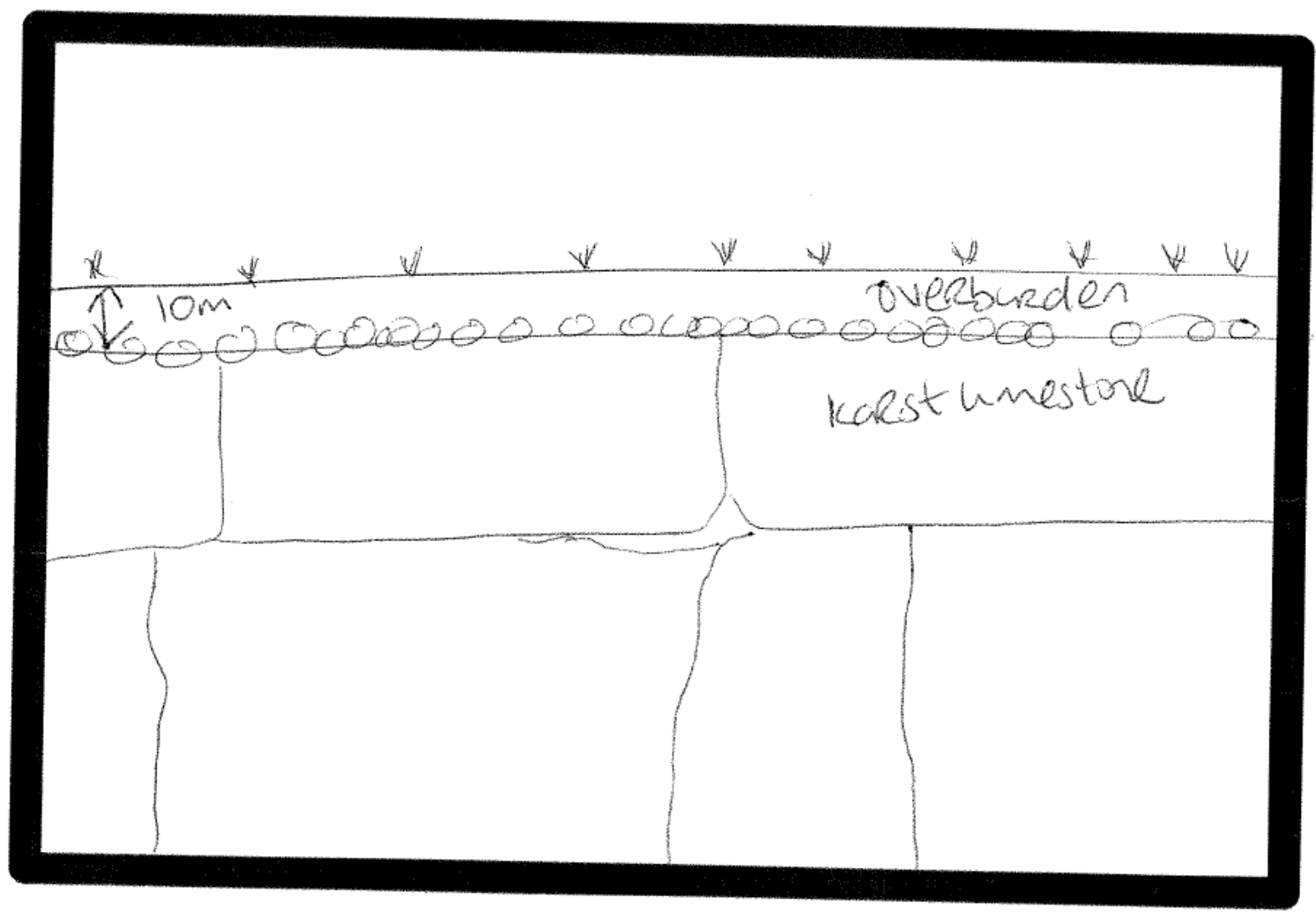




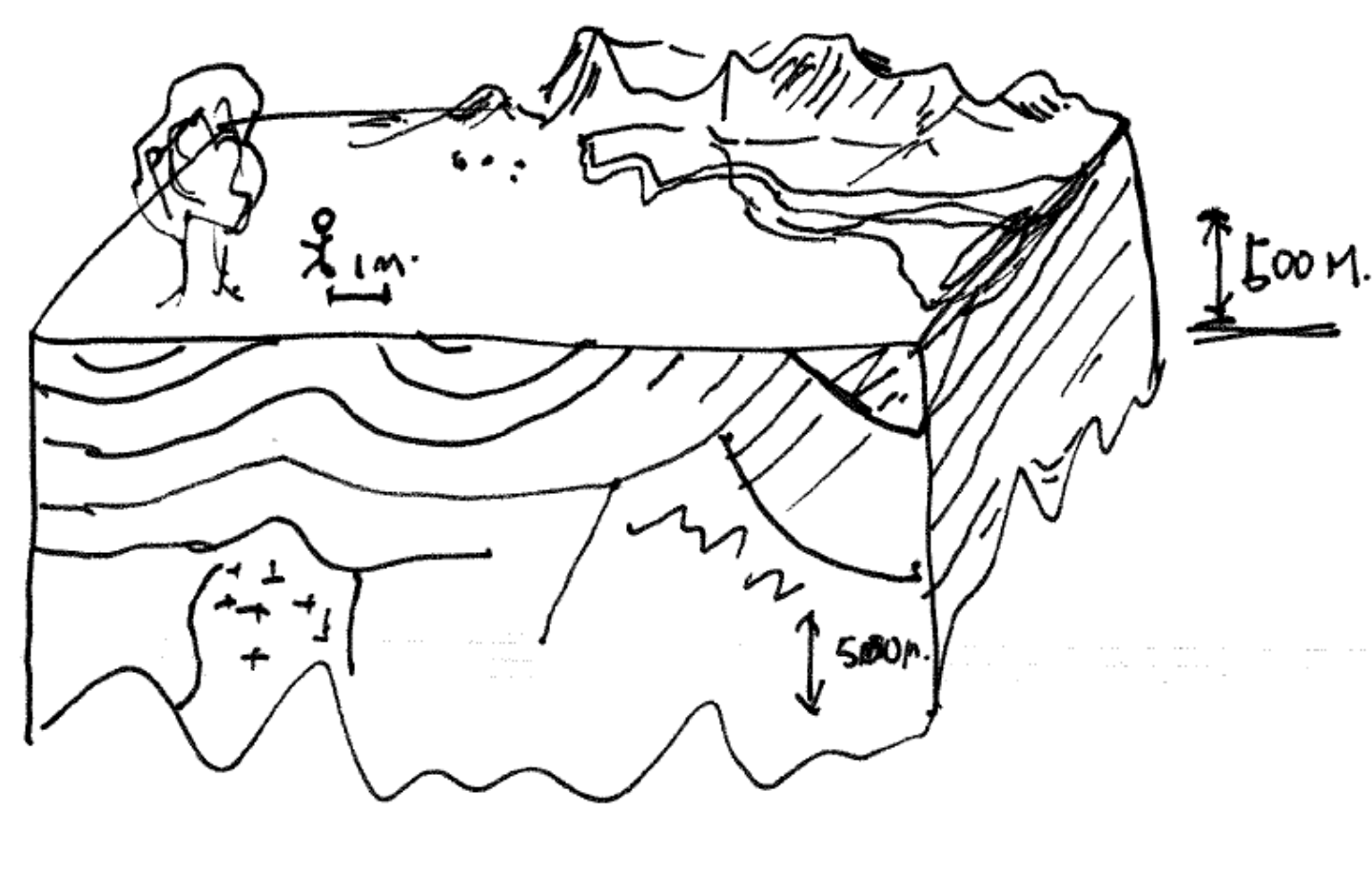




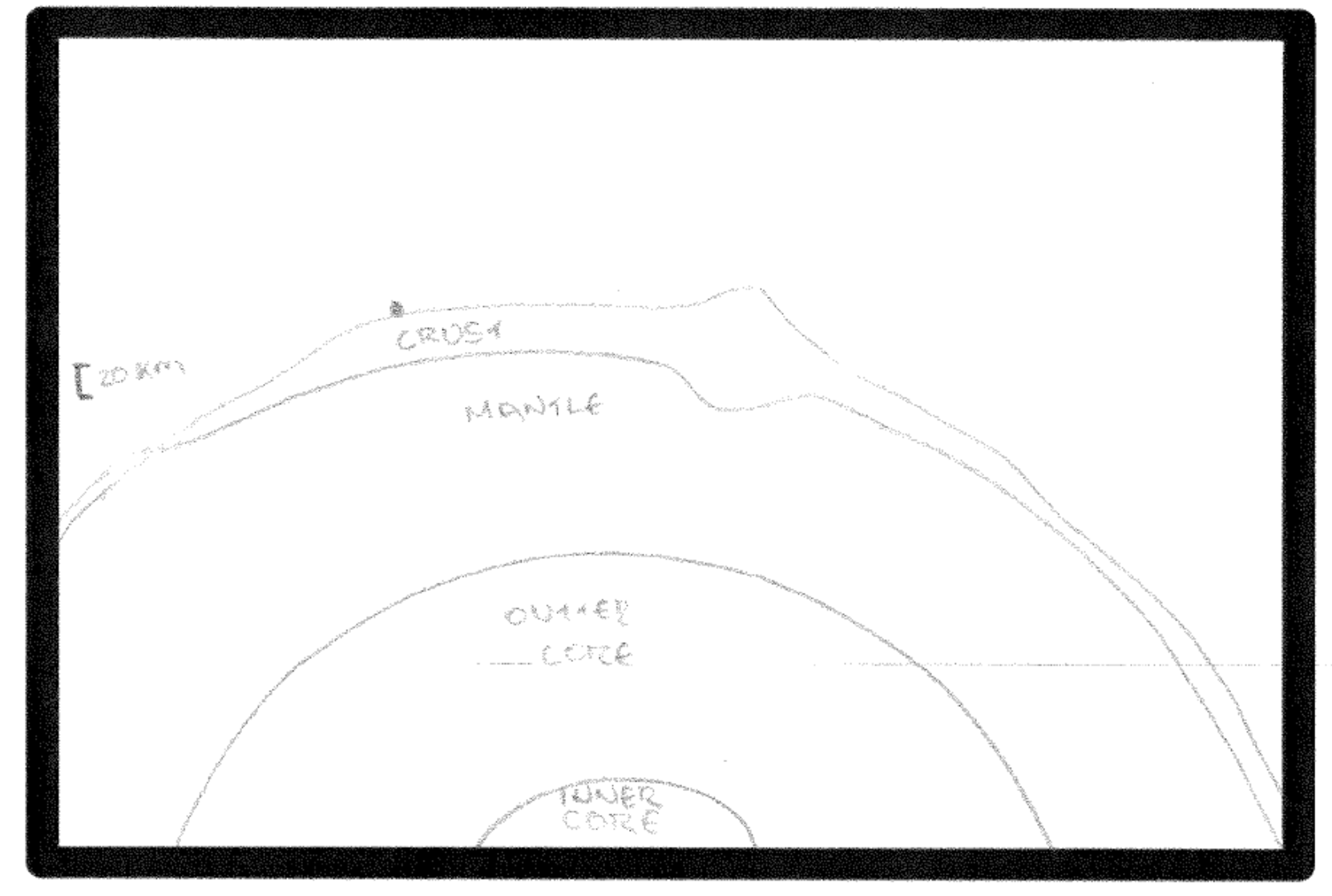


PLEASE STAY INSIDE THE BOX!

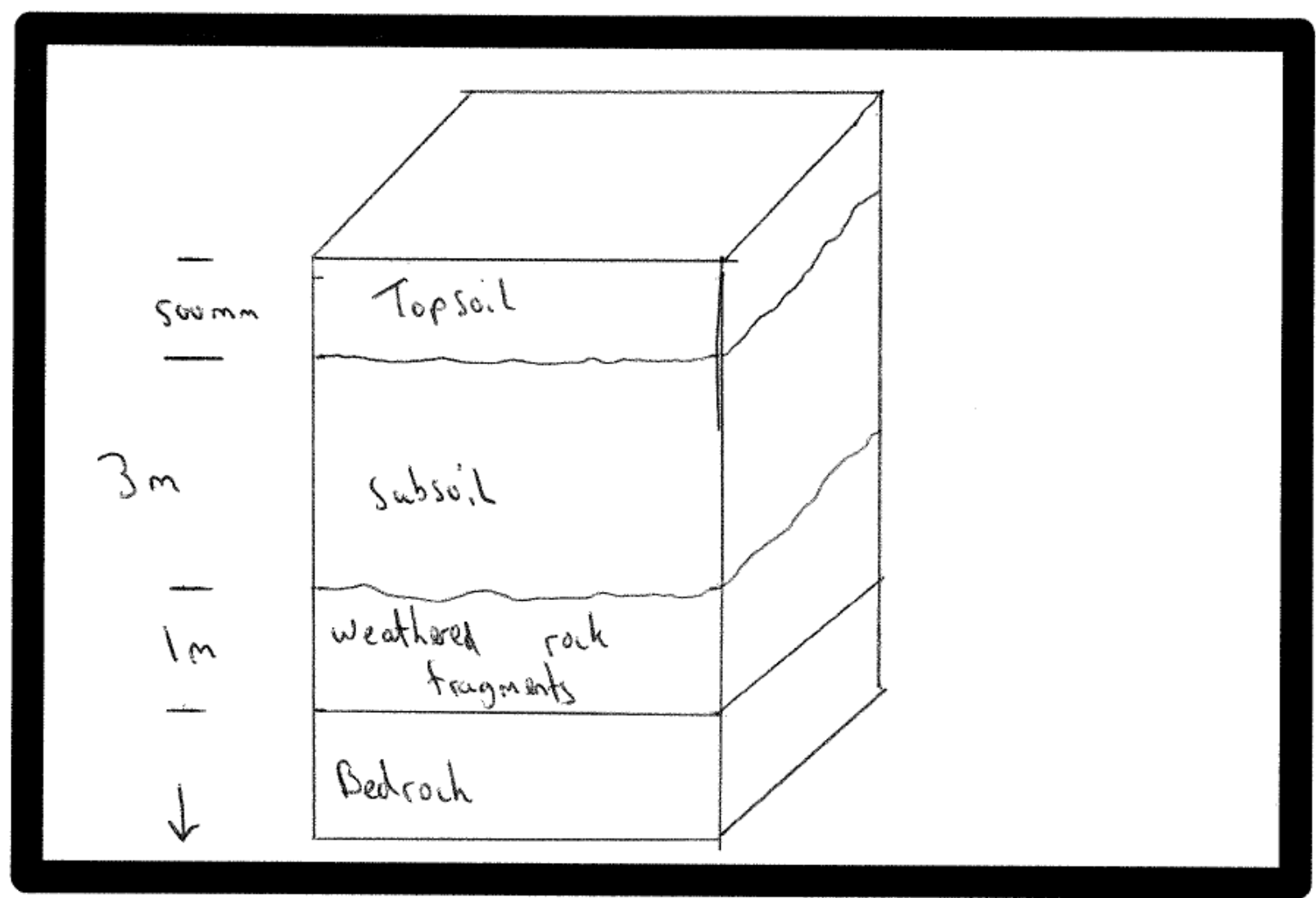




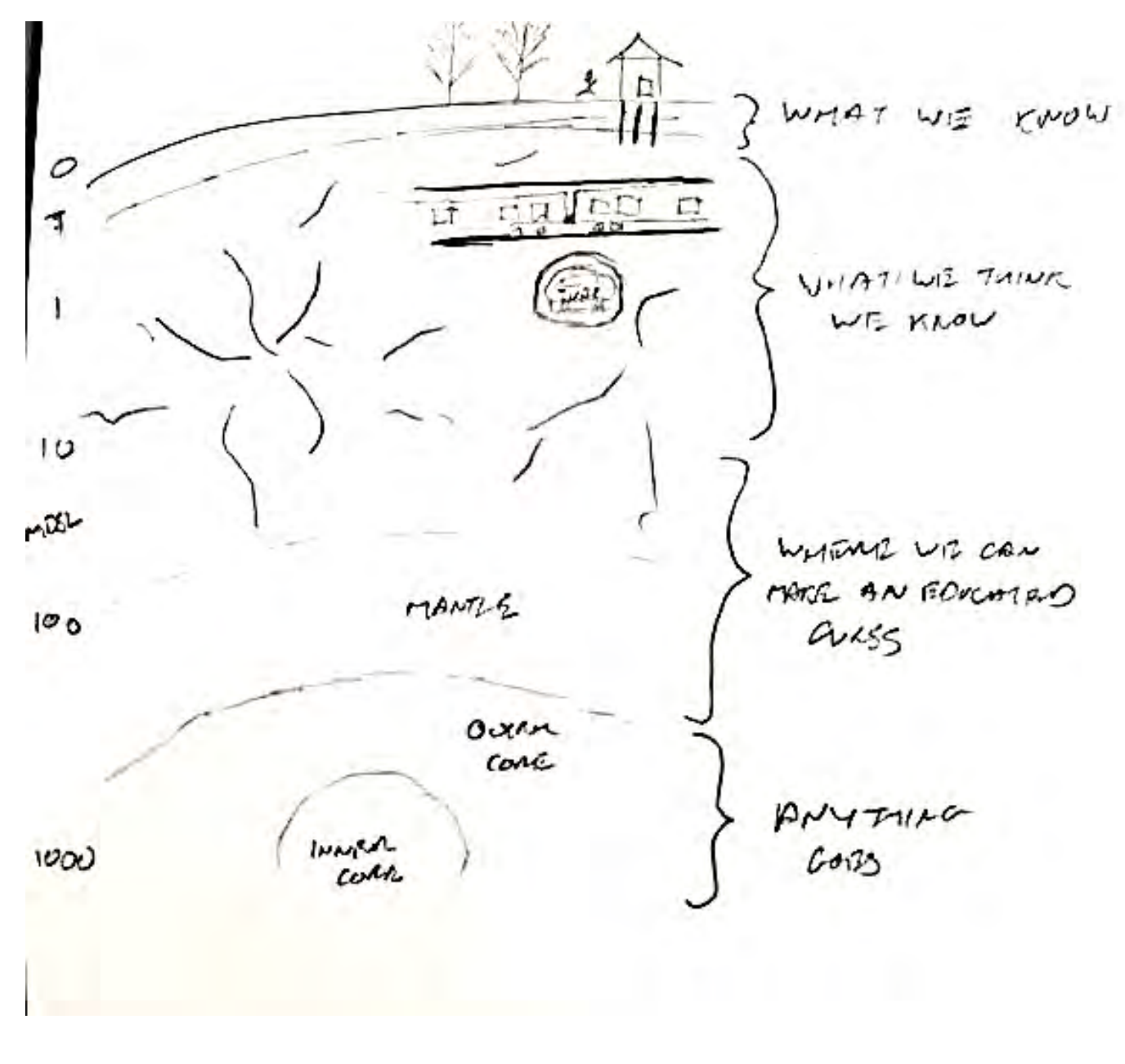




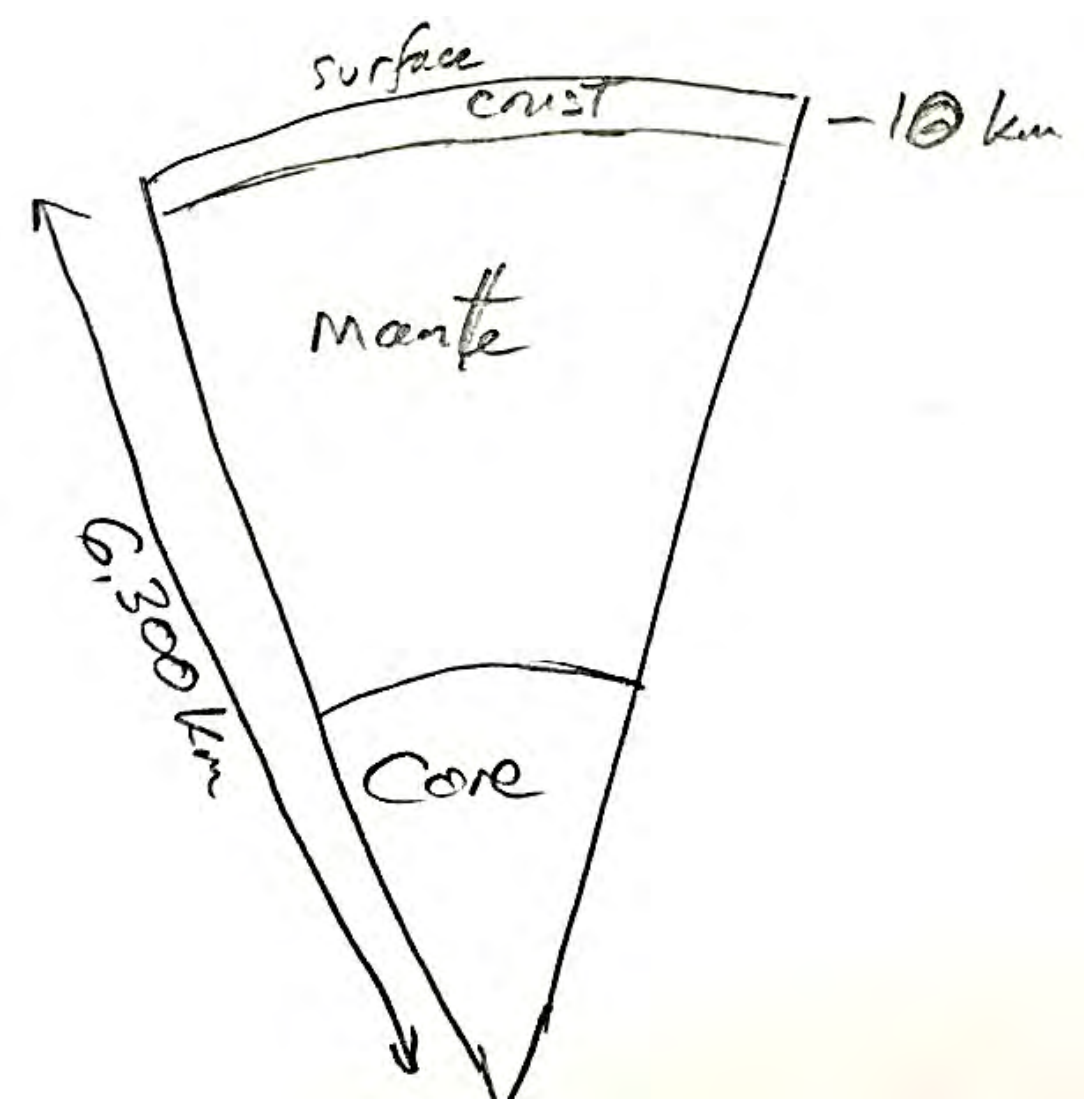

Expert 


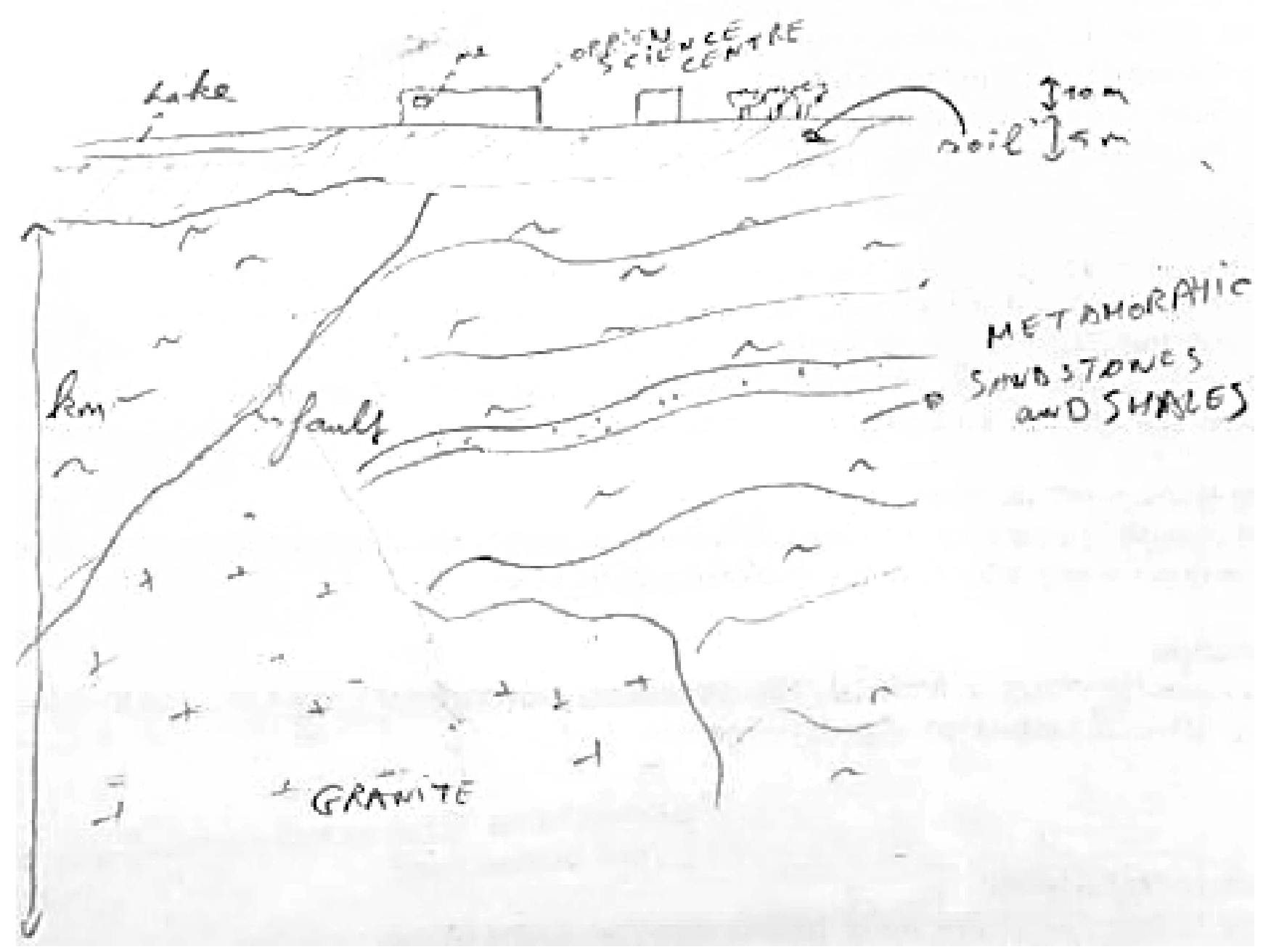

Expert 
$\downarrow$ Ceramictile $5 \mathrm{~mm}$

$\rightarrow$ Concrete $150 \mathrm{~mm}$

$\rightarrow$ Clear. Soil. Stone $450 \mathrm{~mm}$.

- Stone, Rock. Clay $2 \mathrm{~m}$.

$$
\text { ???? }
$$

Non-expert 


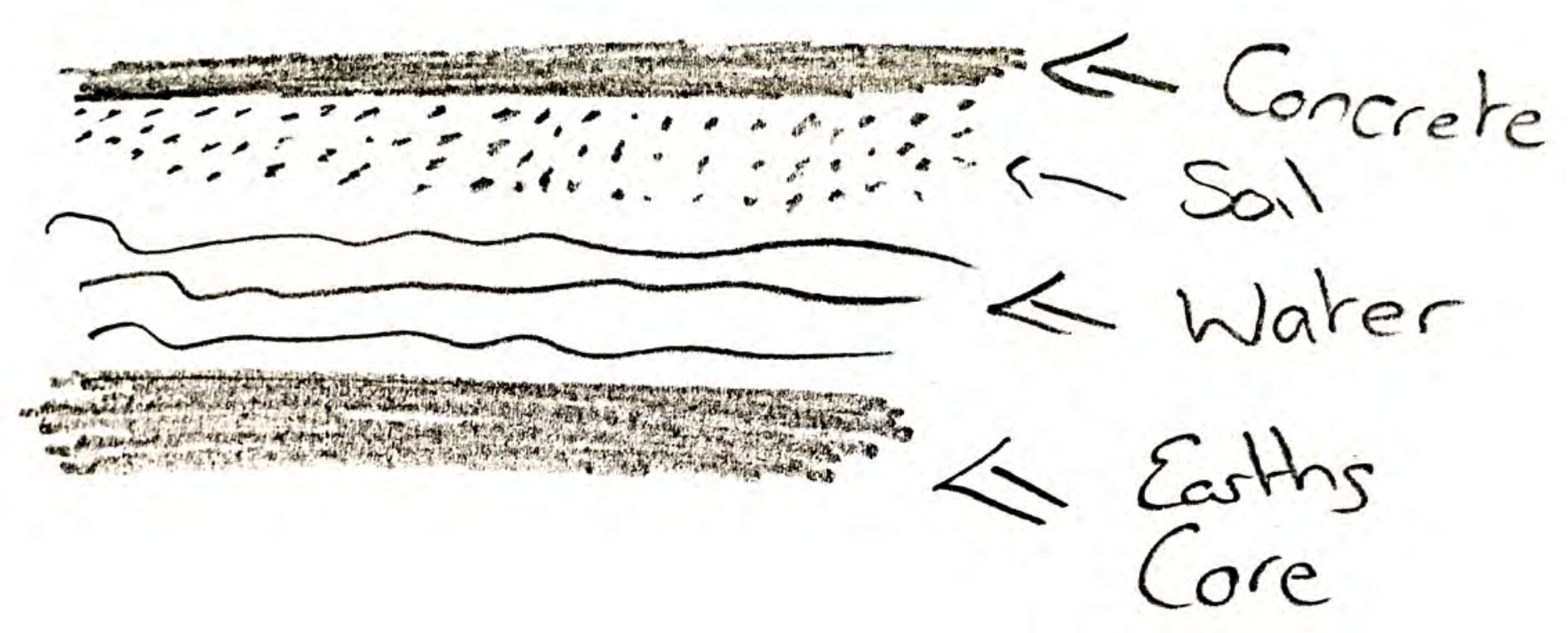

Non-expert 


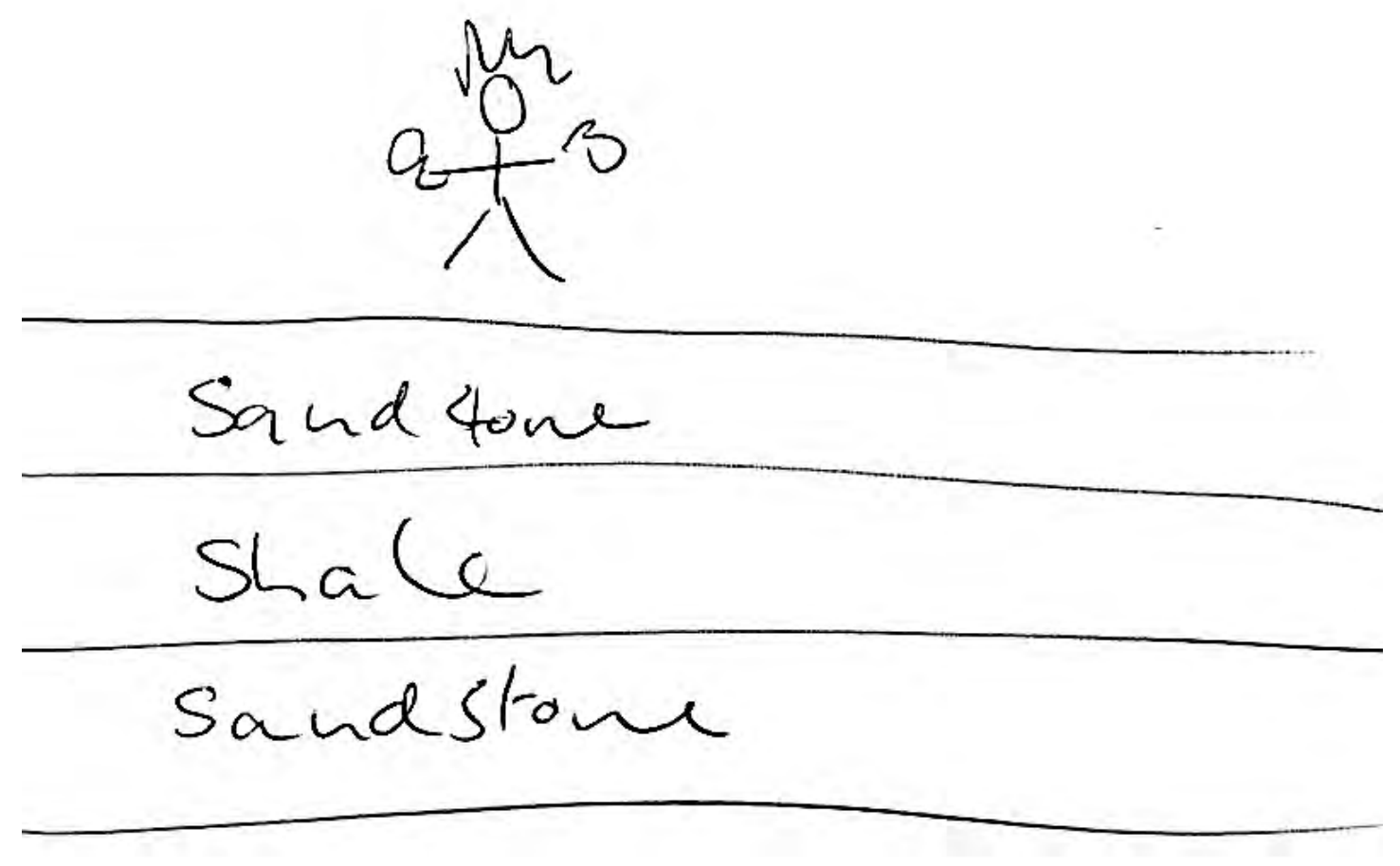

Non-expert 


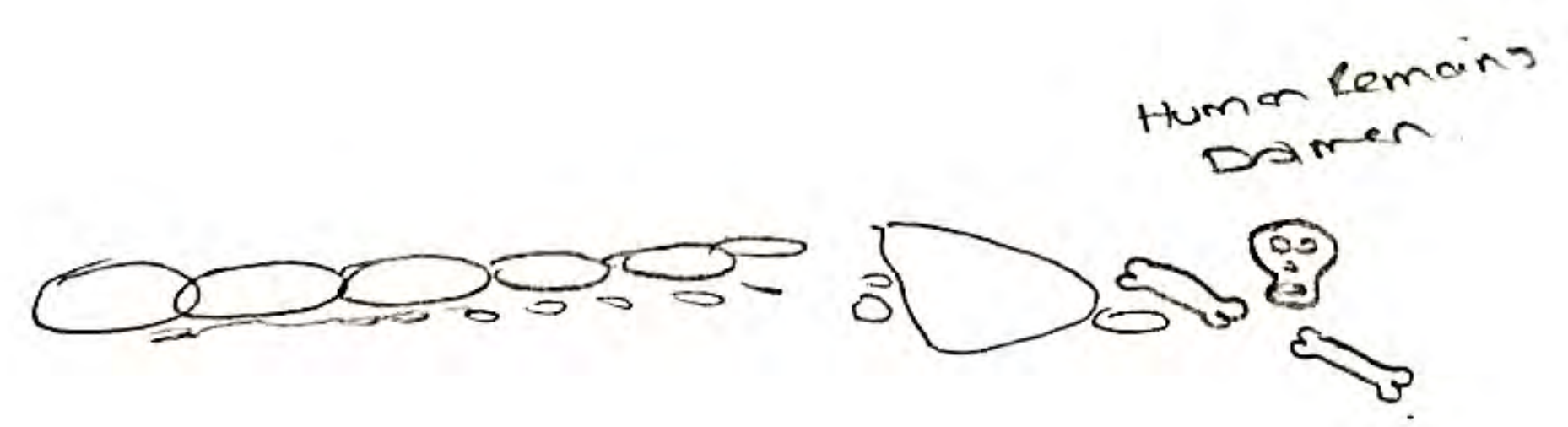

Non-expert 
sketch

PLEASE STAY INSIDE THE BOX!

CONCREATE FlOod

Twew SLate
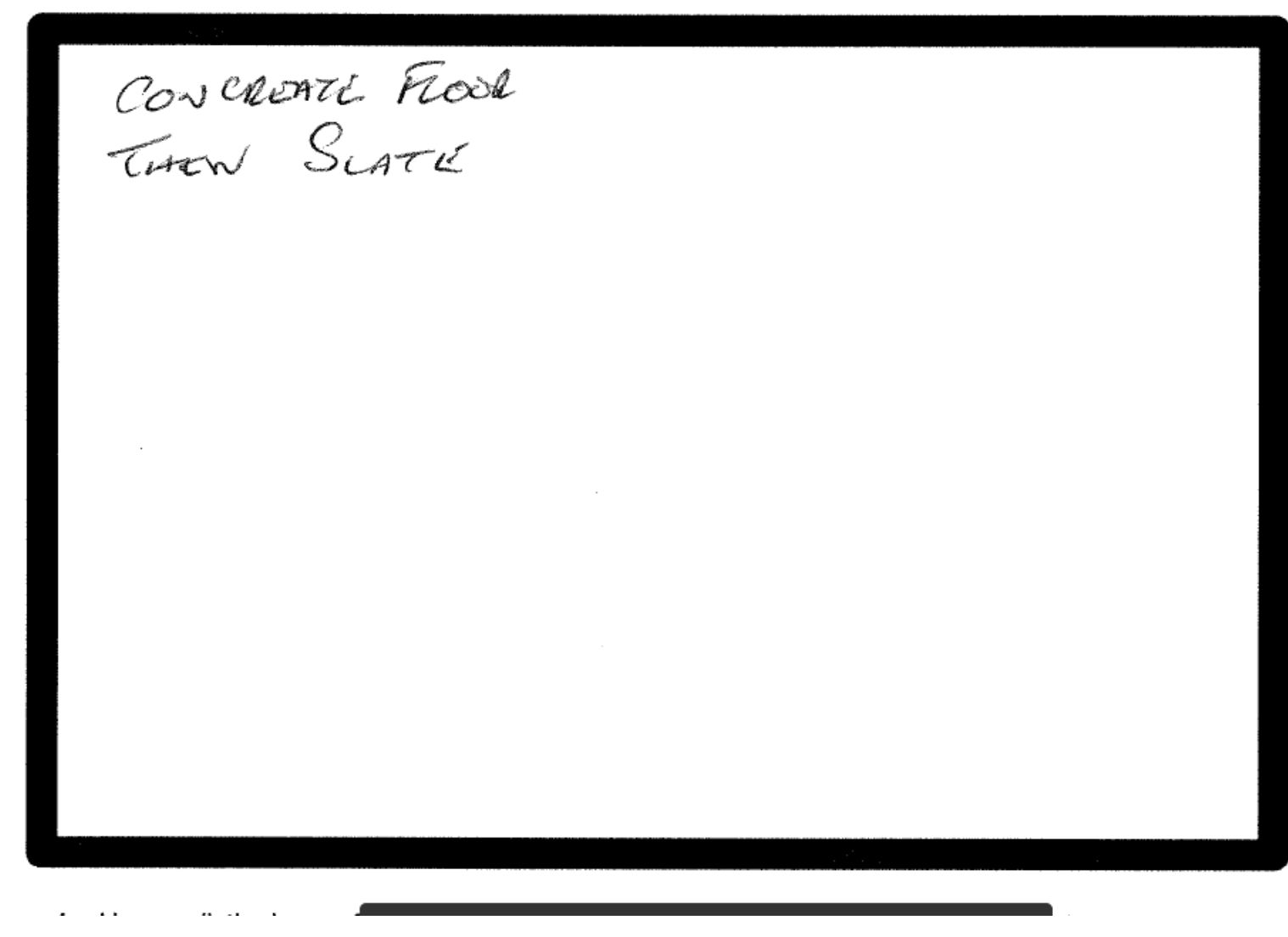
PLEASE STAY INSIDE THE BOX!

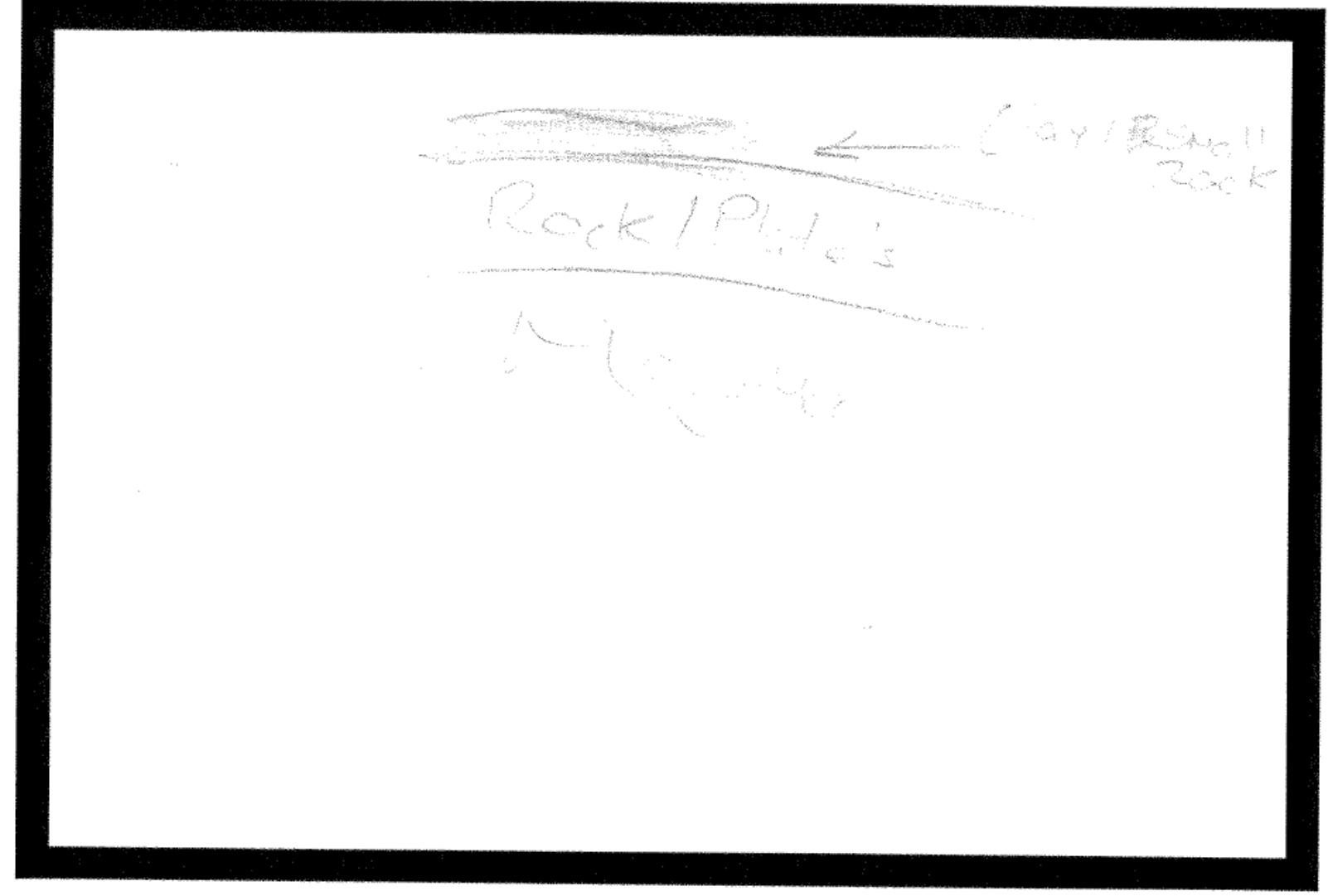




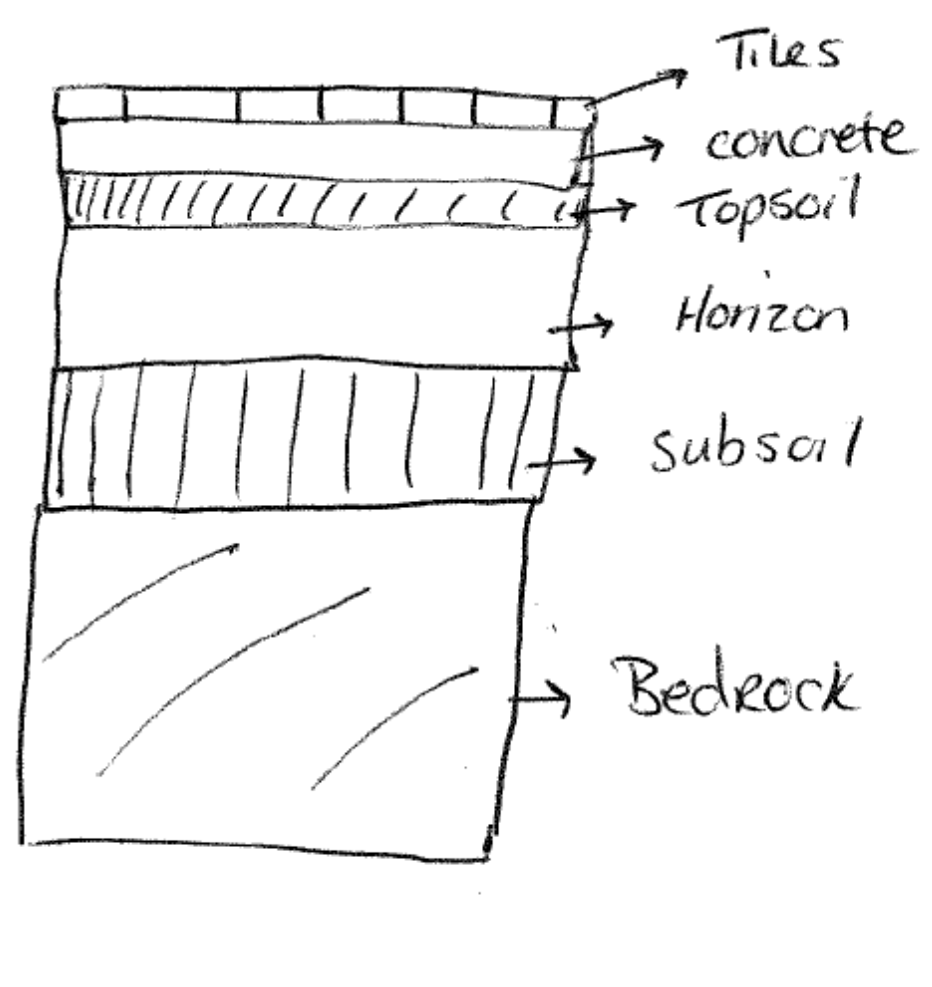




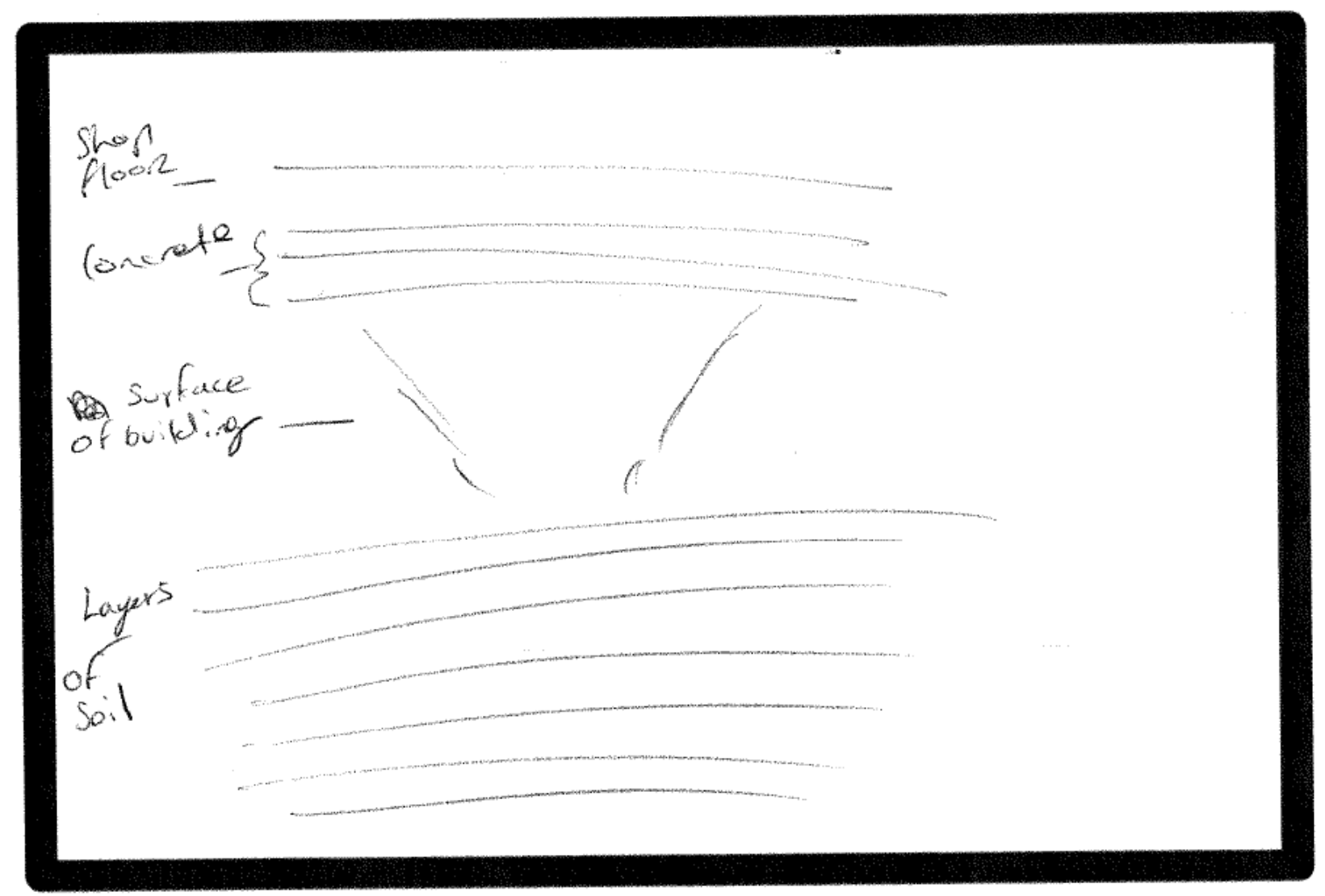




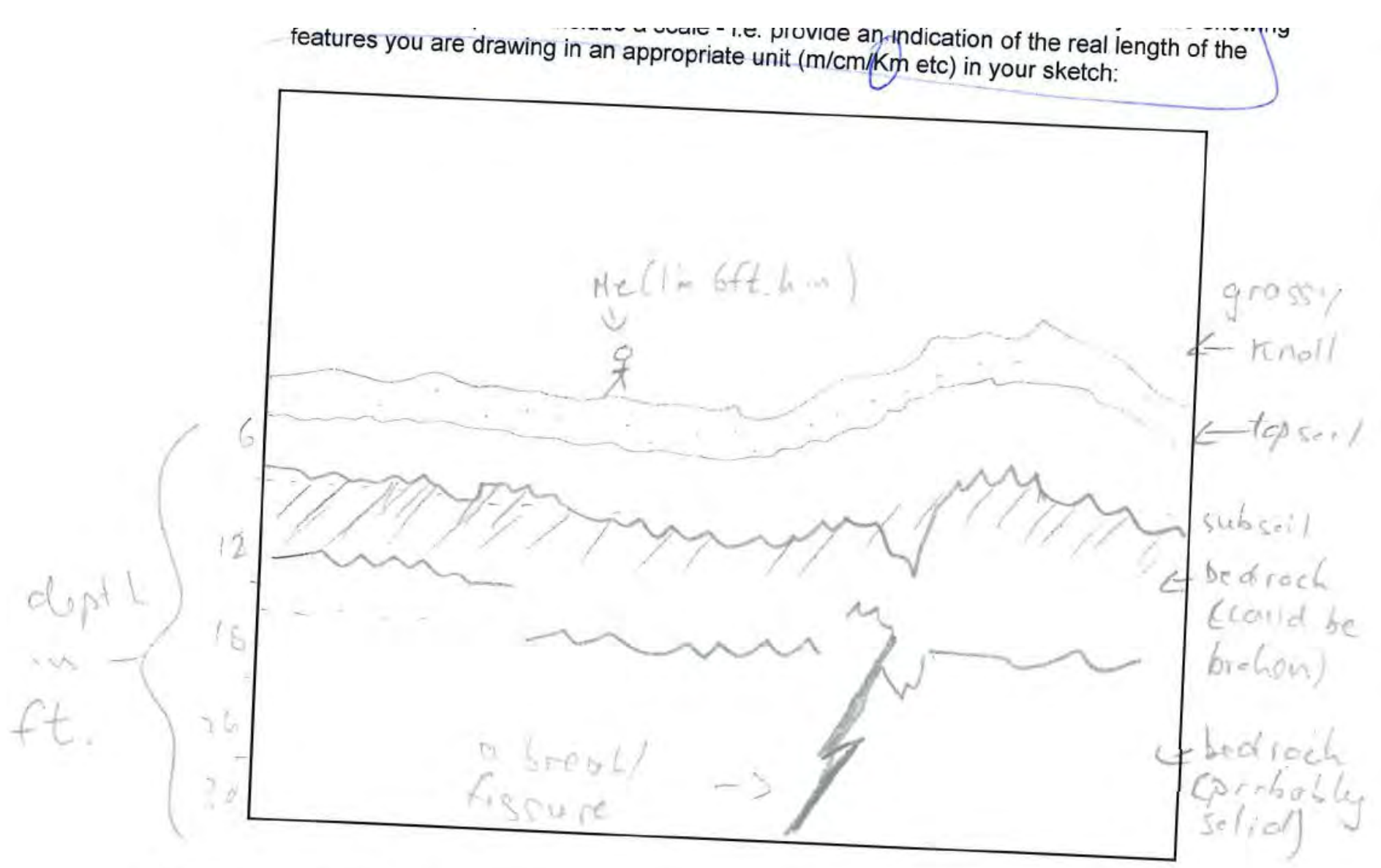

1a. How realictin No un . s:-A. 


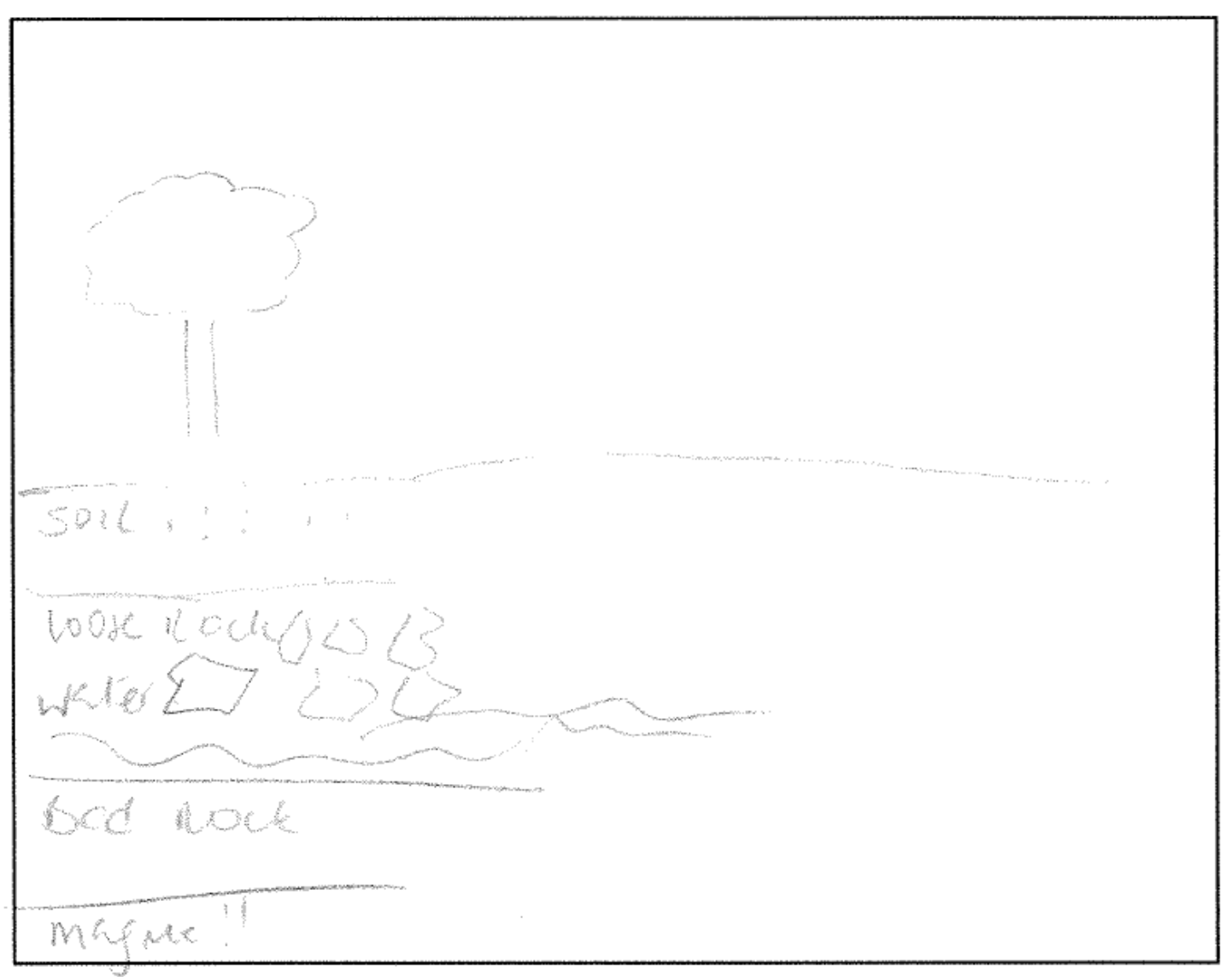


PLEASE STAY INSIDE THE BOX!

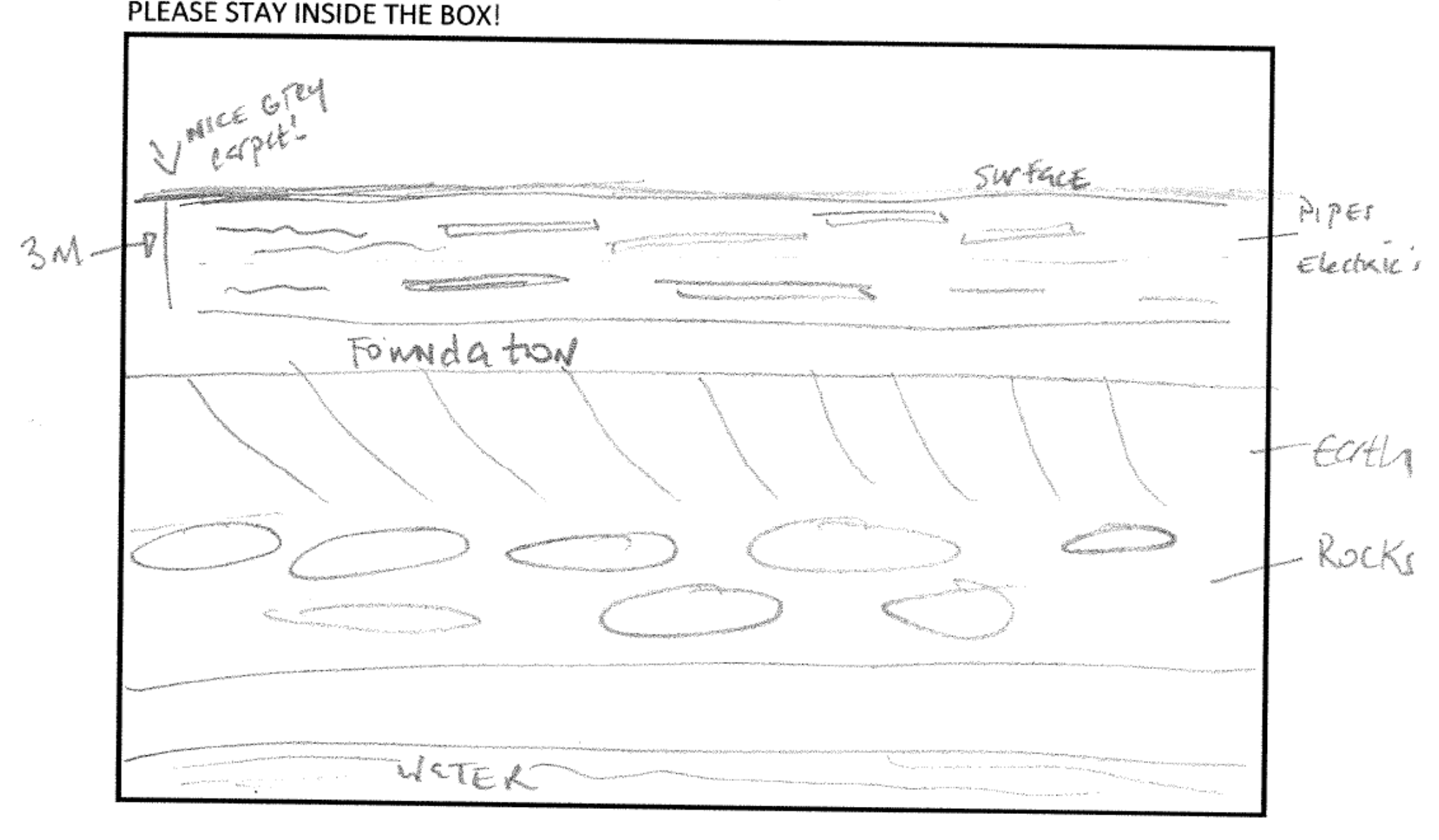

Non-expert 
PLEASE STAY INSIDE THE BOX!

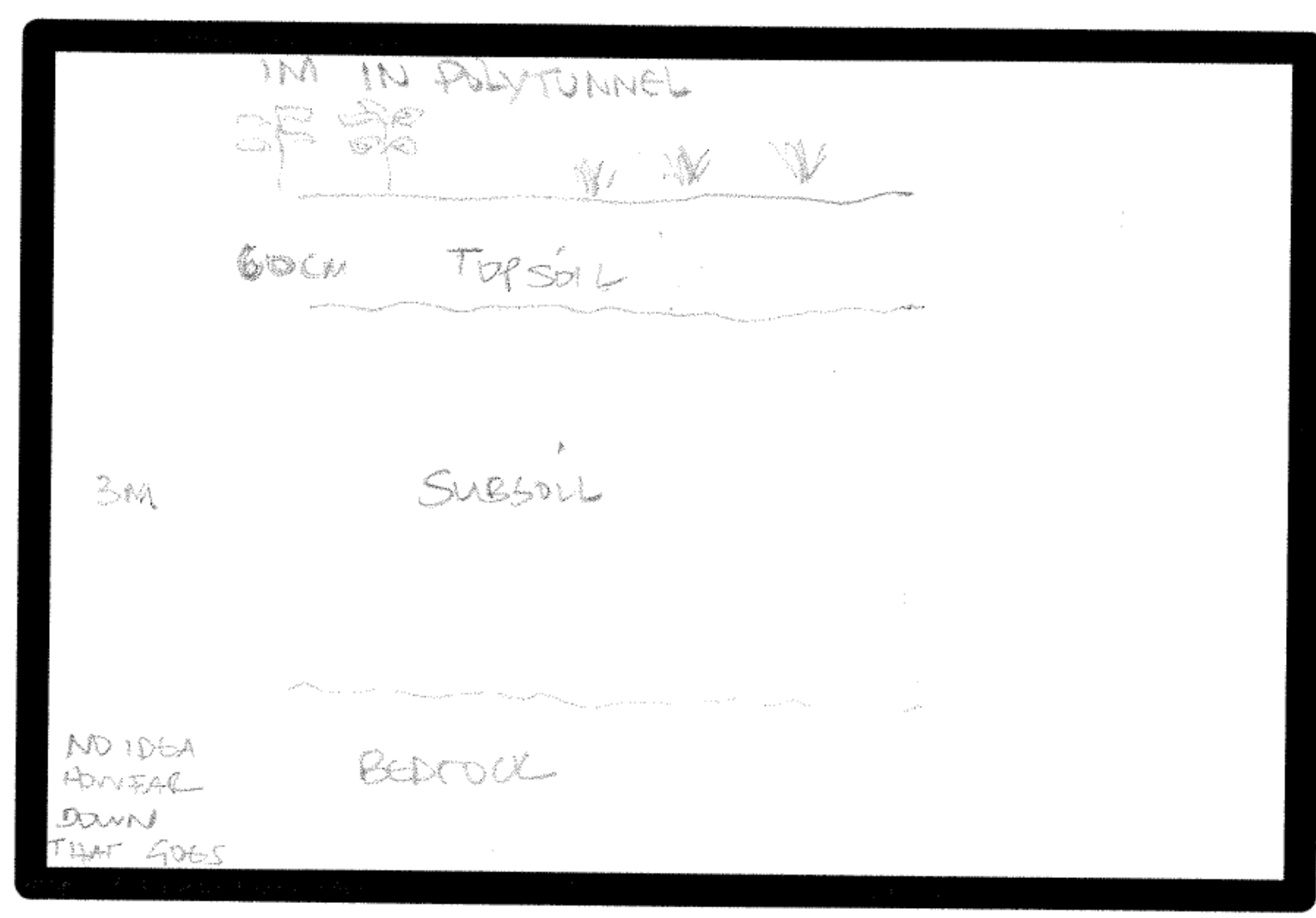




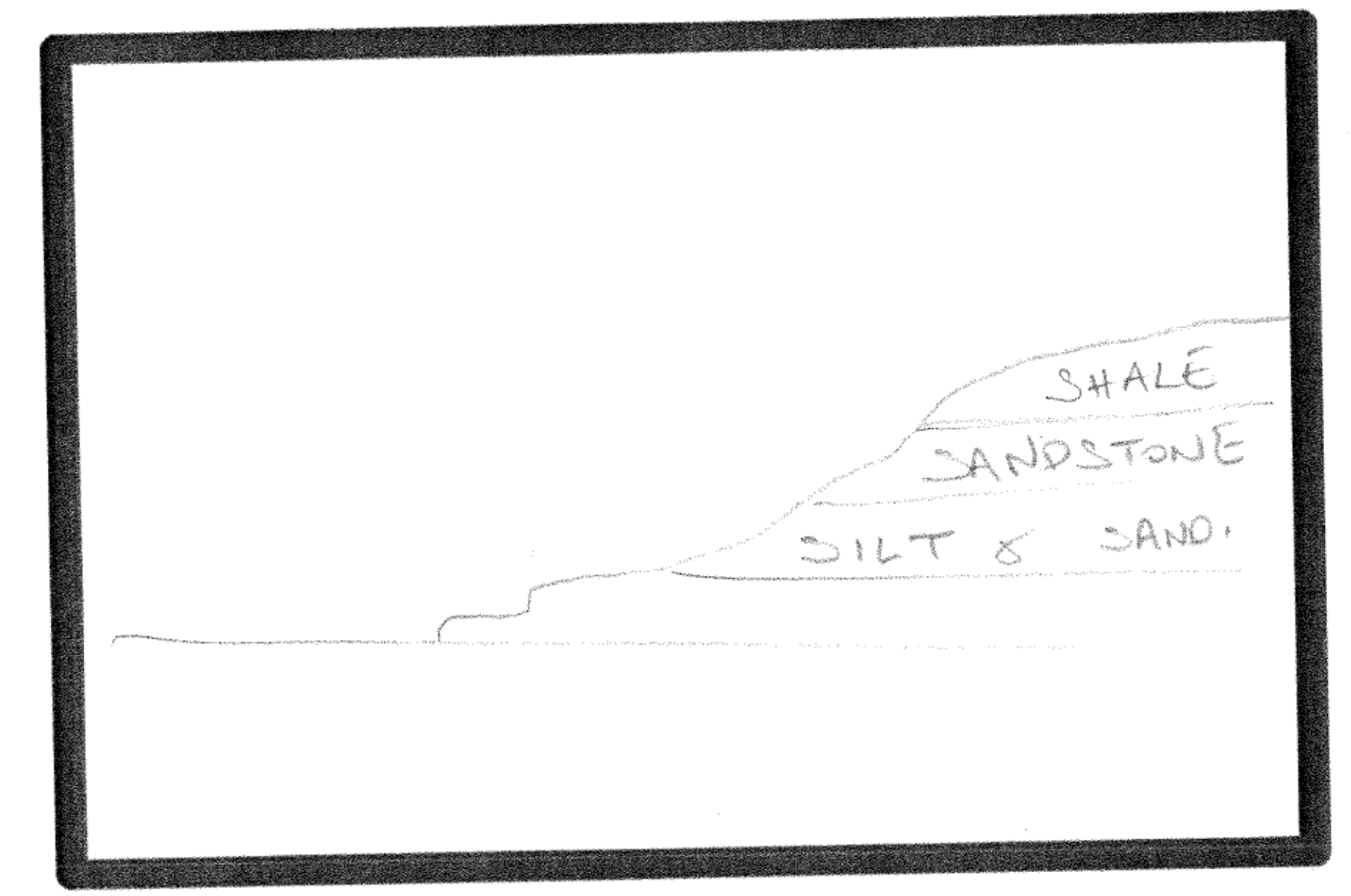


sketch

PLEASE STAY INSIDE THE BOX!

CONCREATE FlOod

Twew SLate
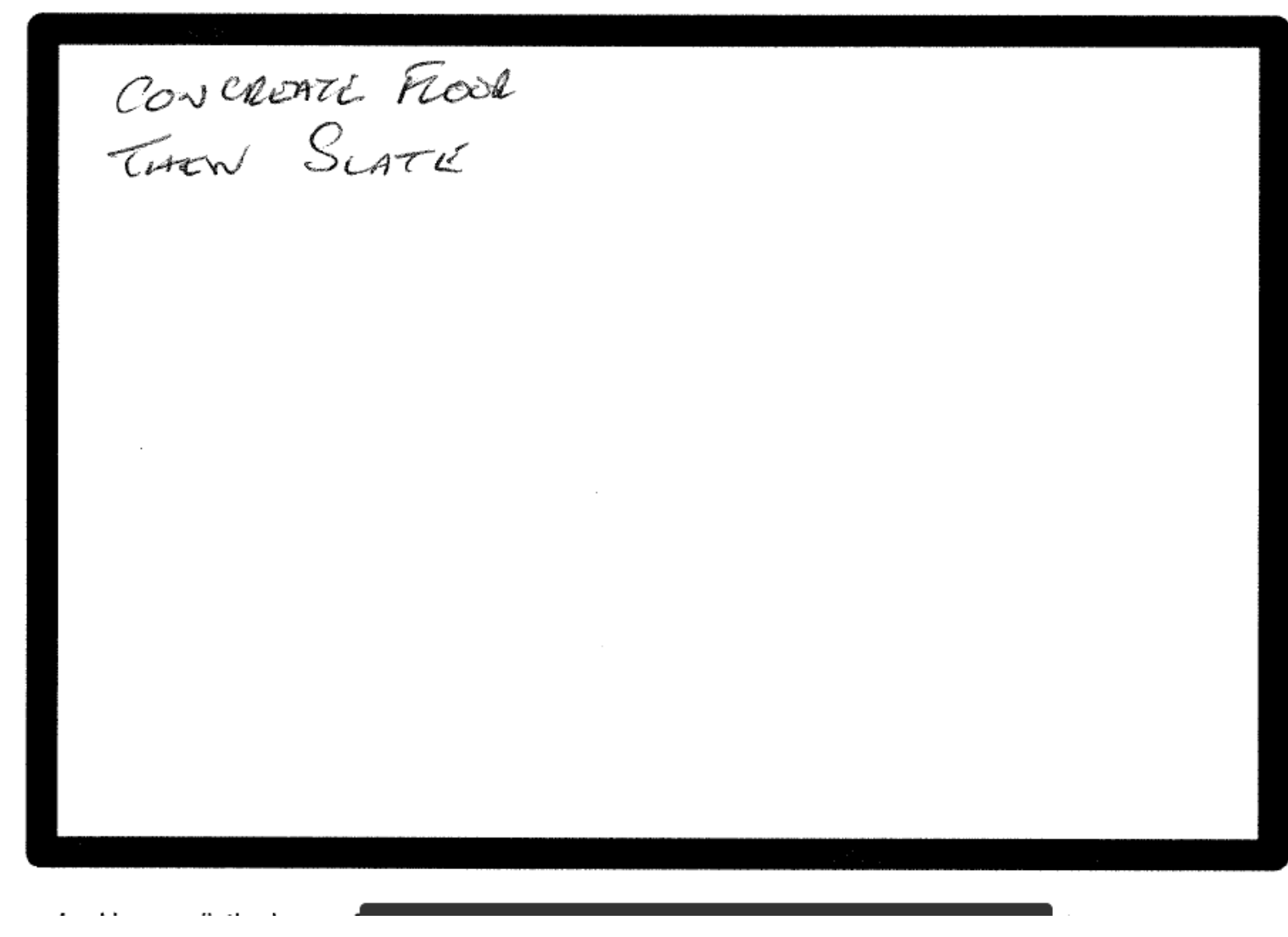
PLEASE STAY INSIDE THE BOX!

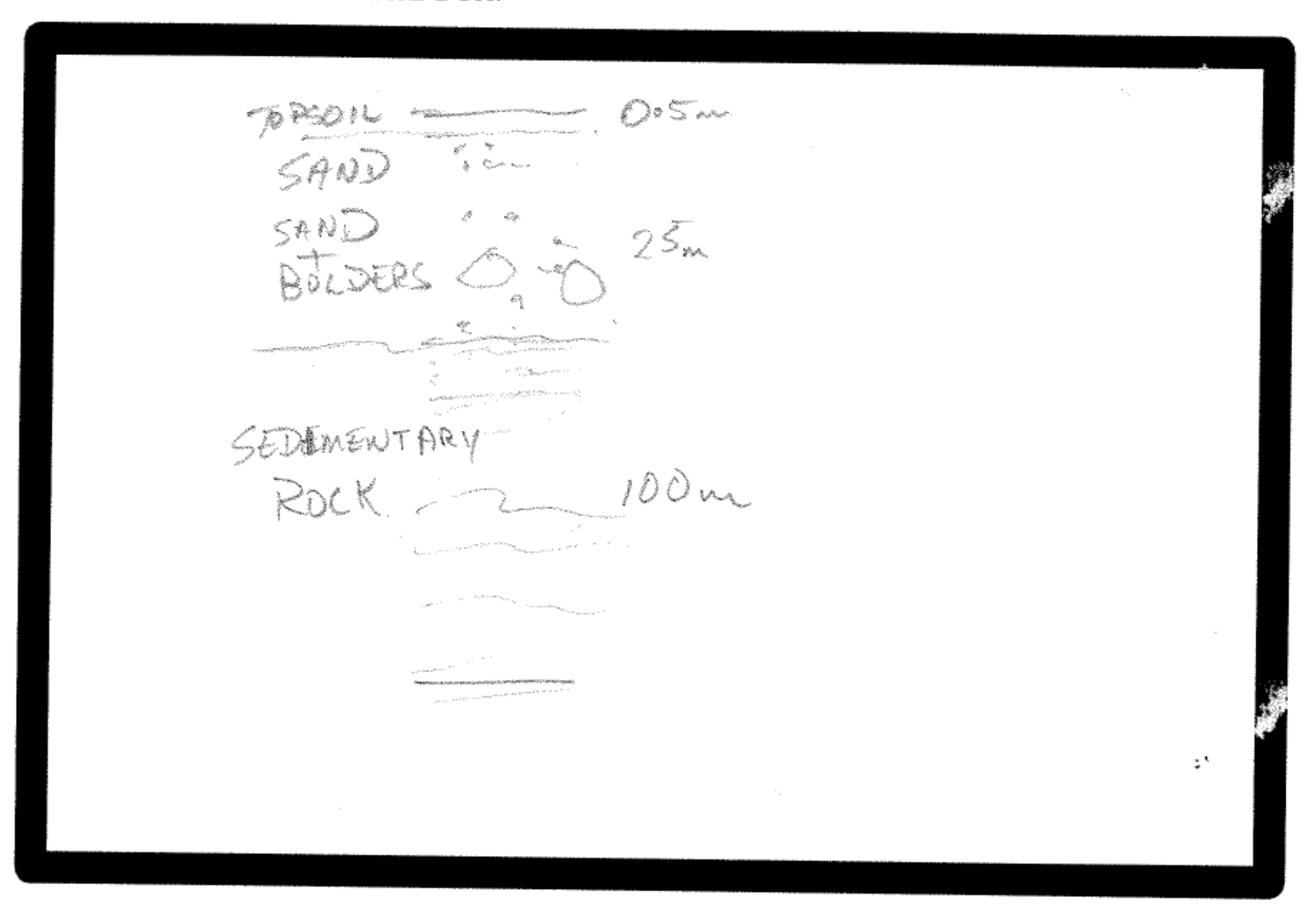


PLEASE STAY INSIDE THE BOX!

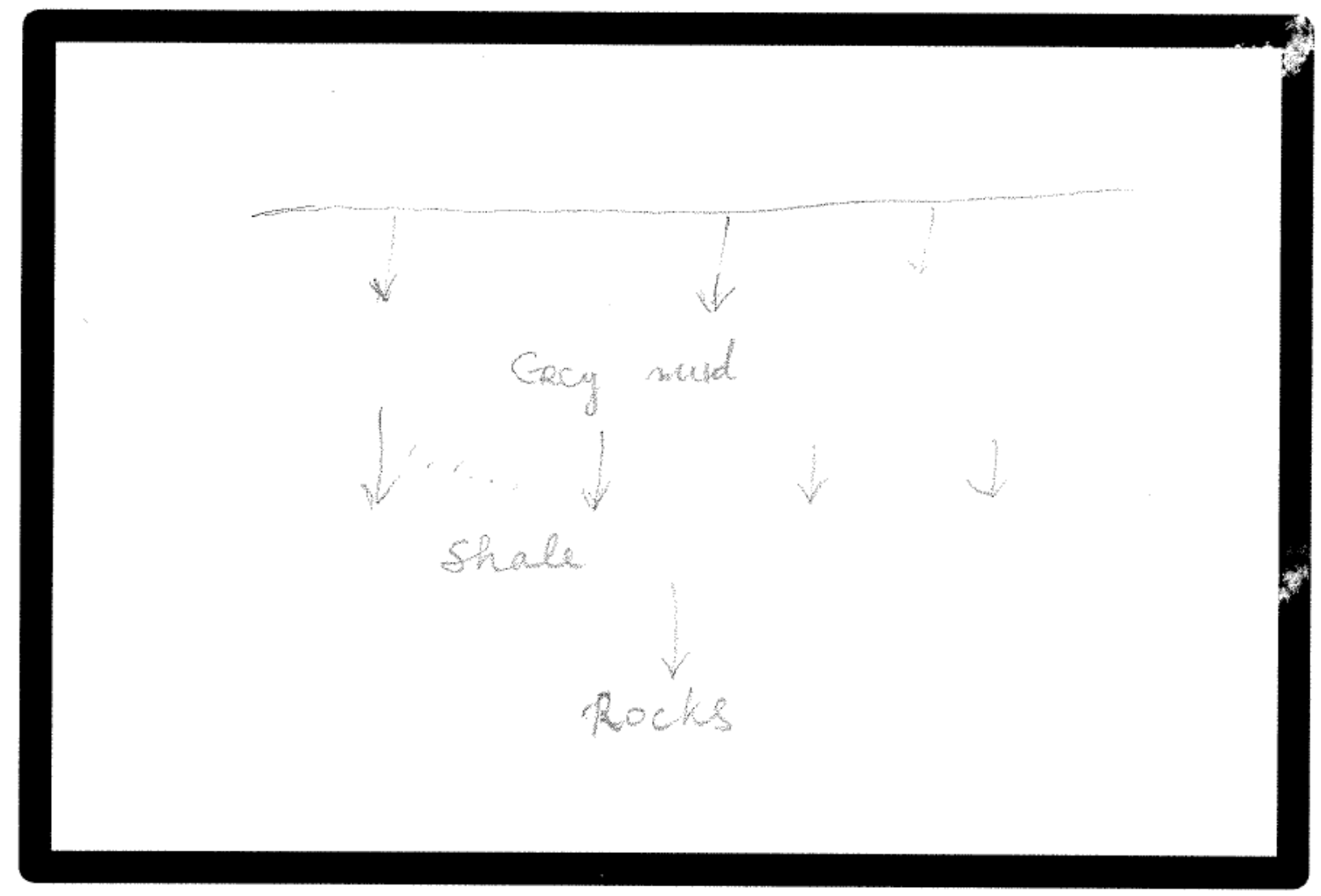




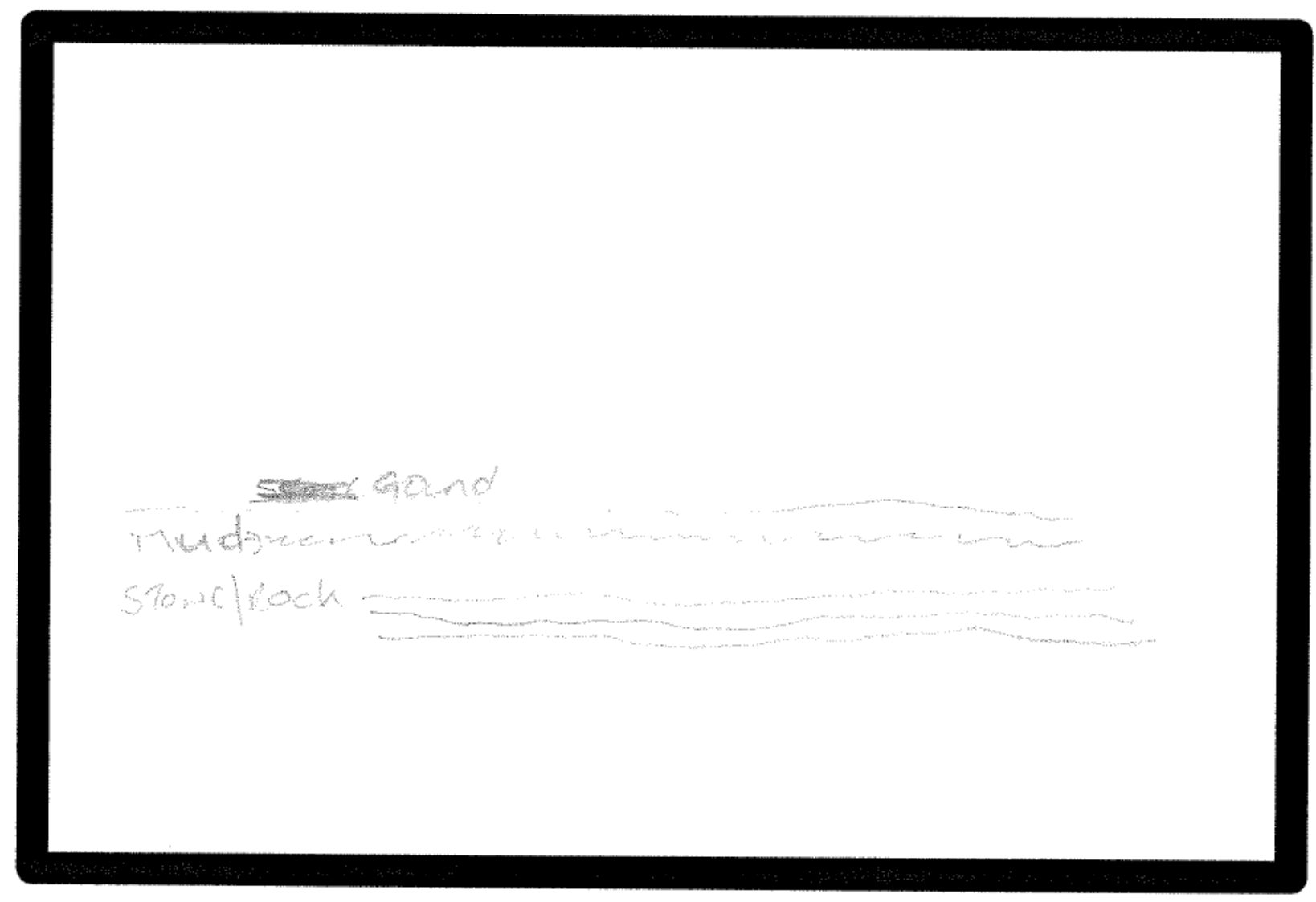




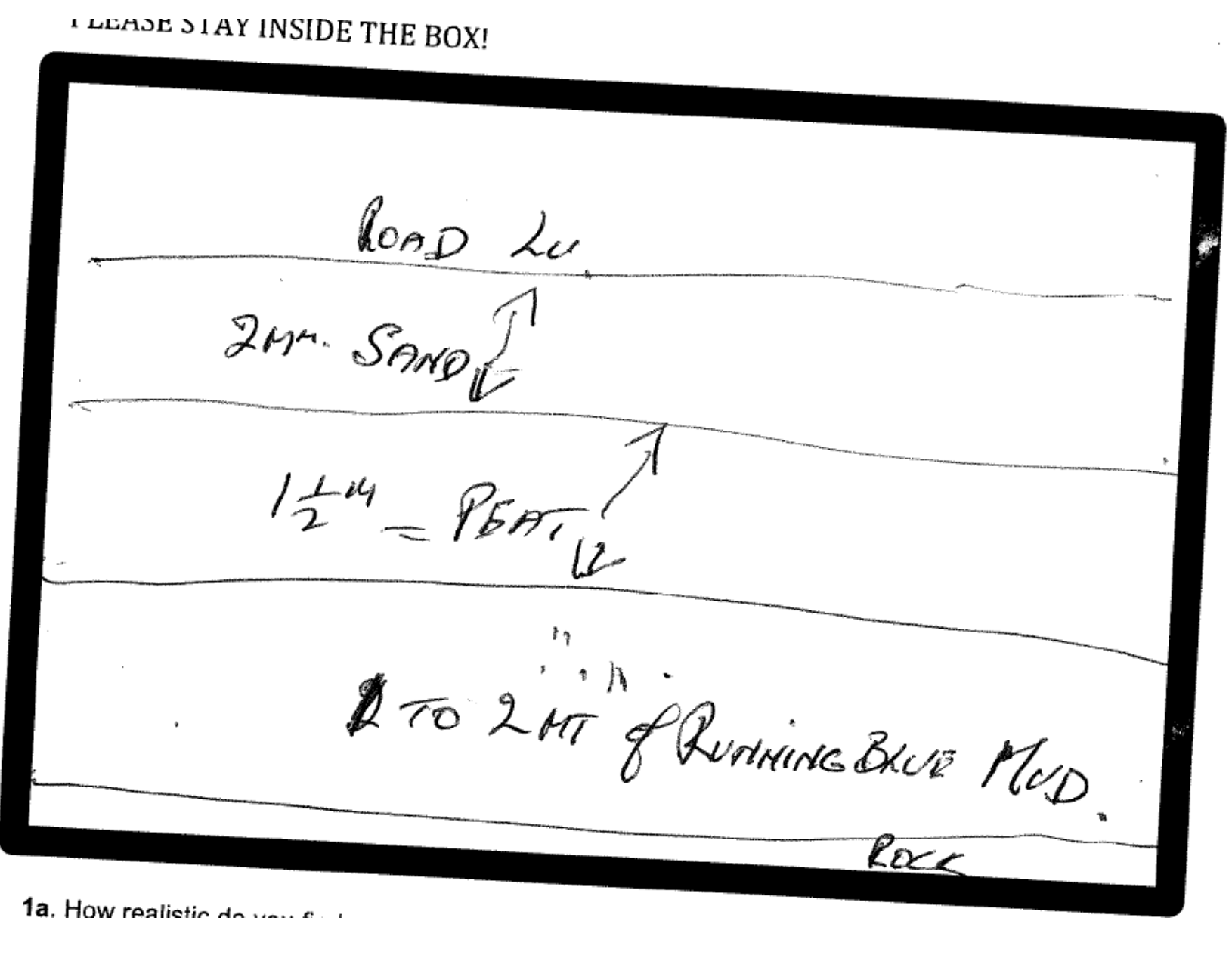




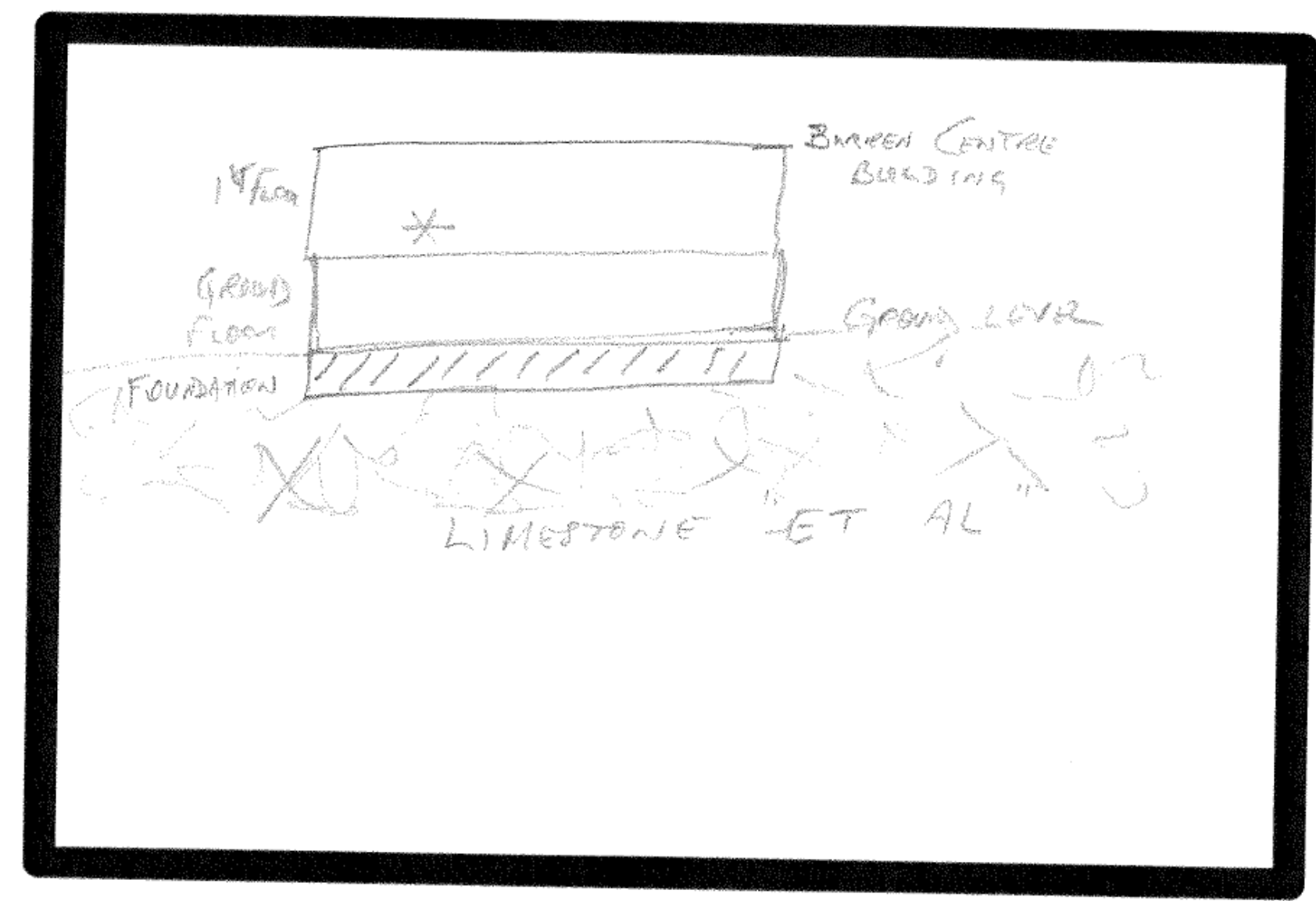




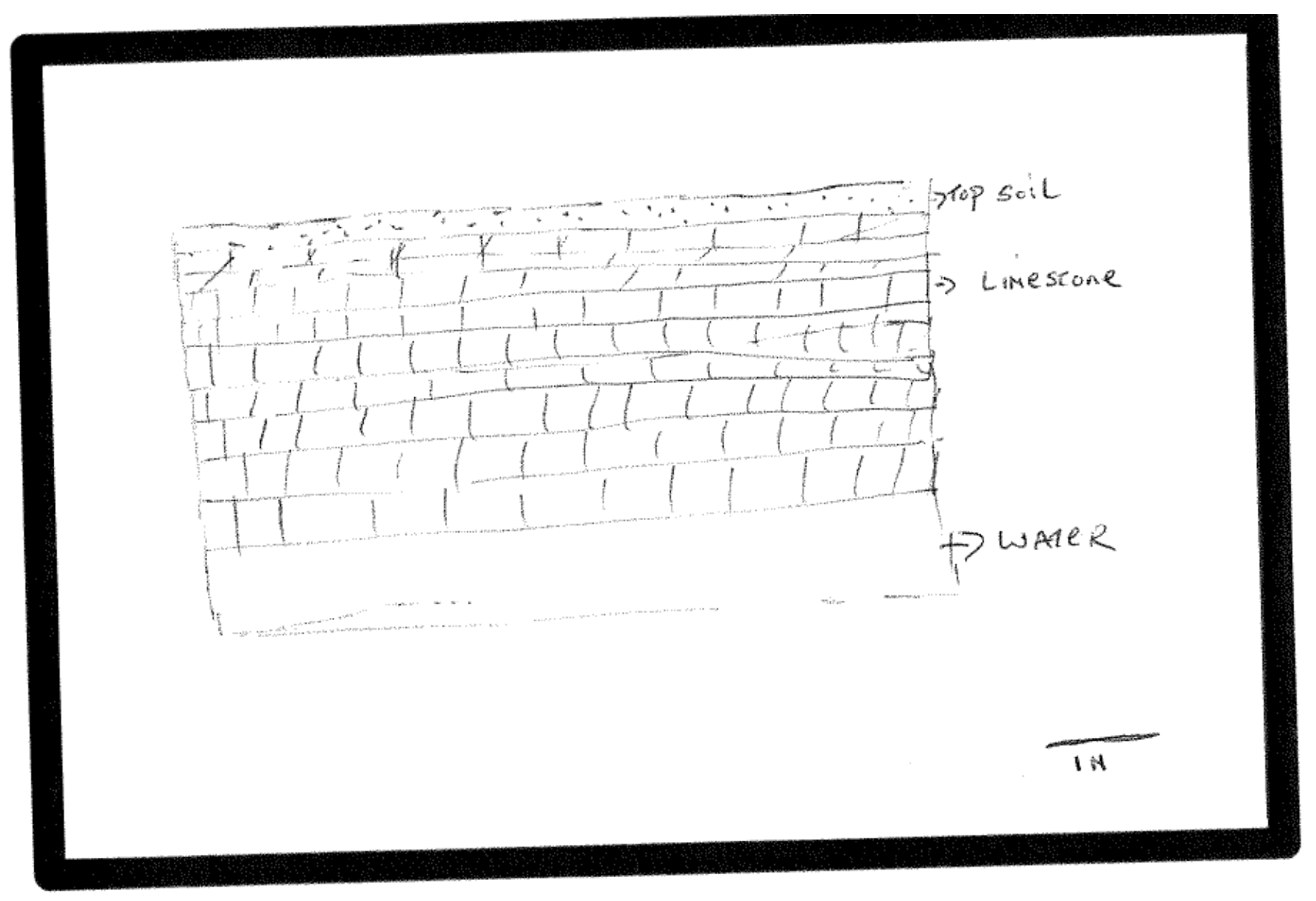




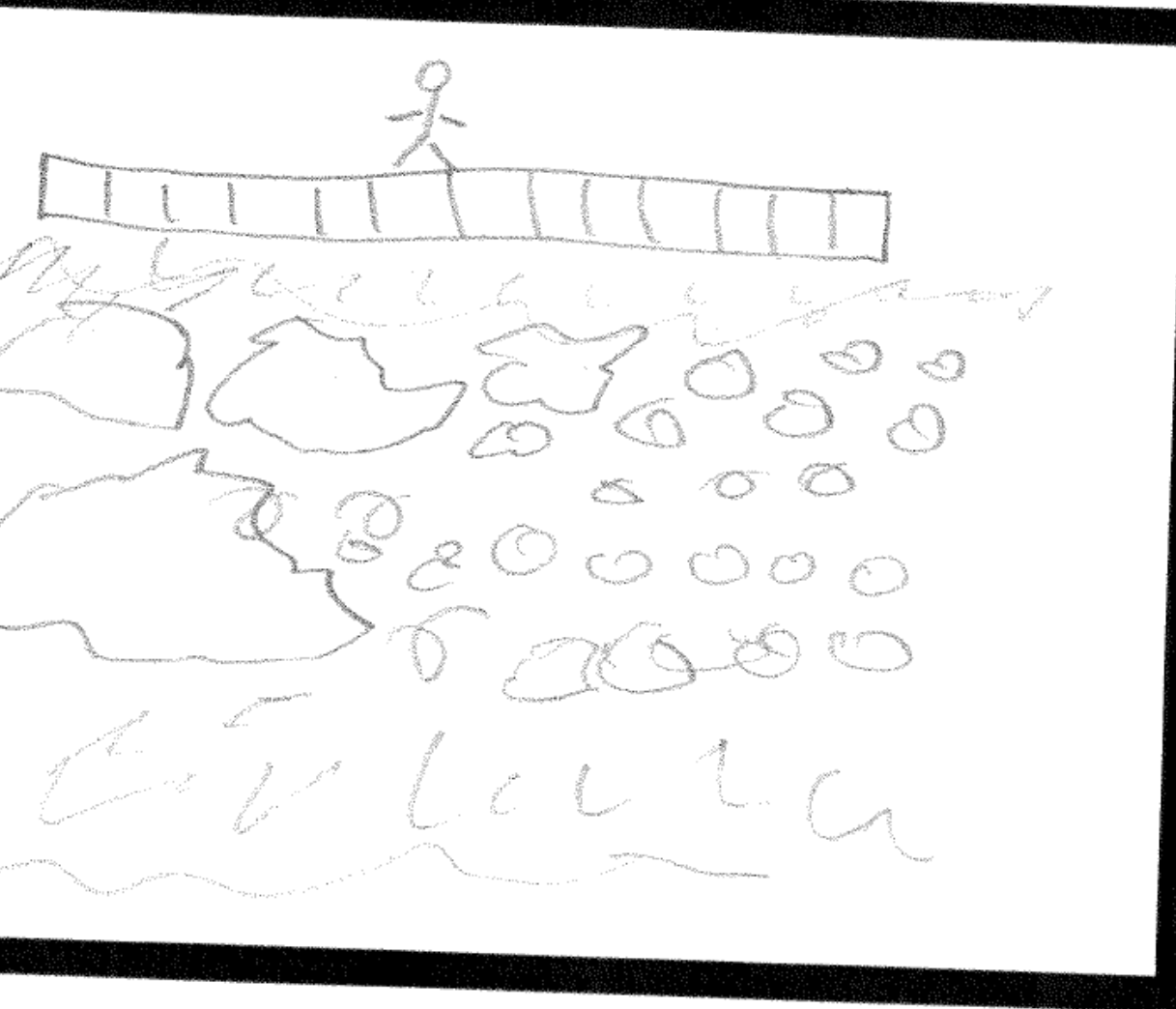


PLEASE STAY INSIDE THE BOX!

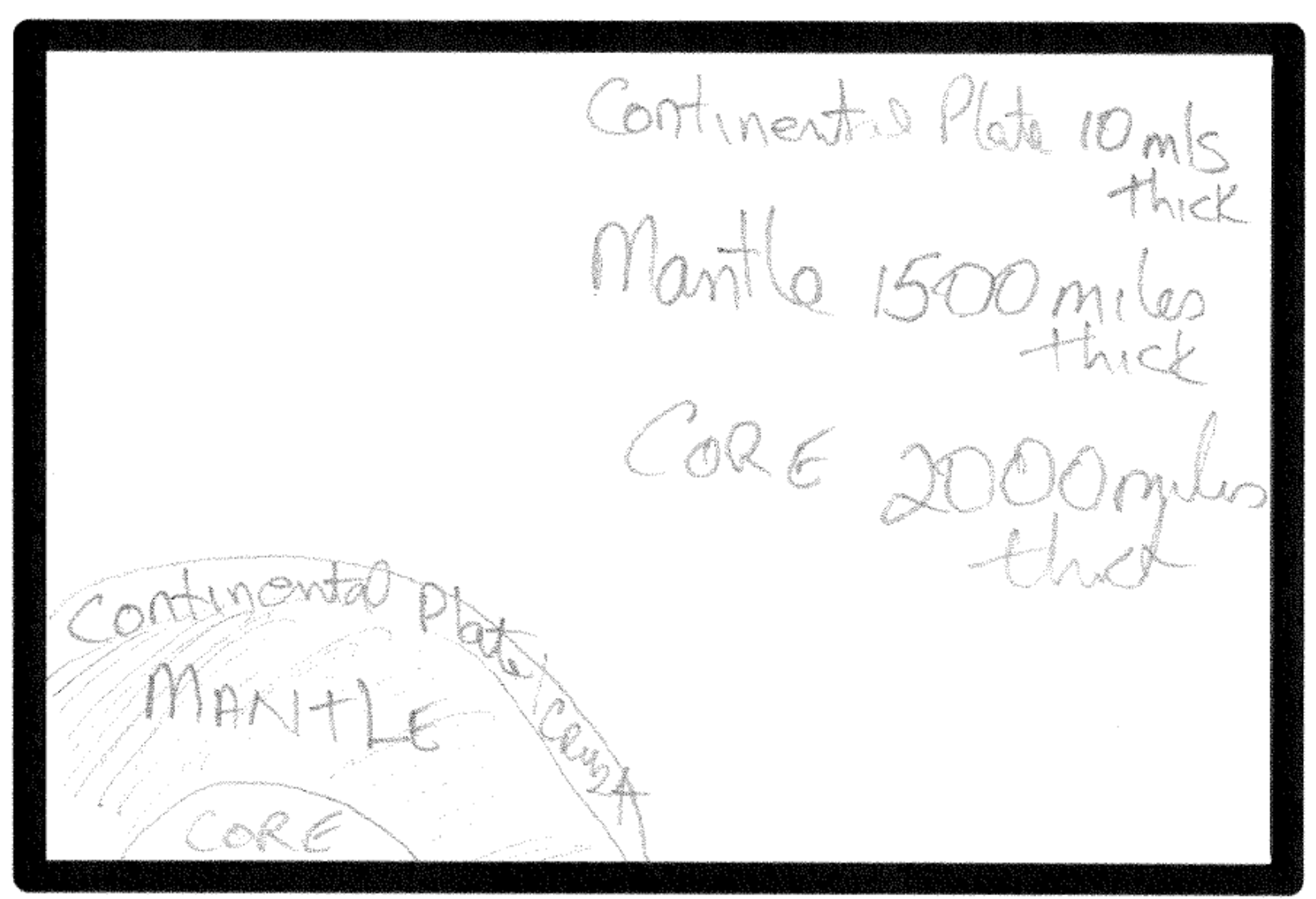



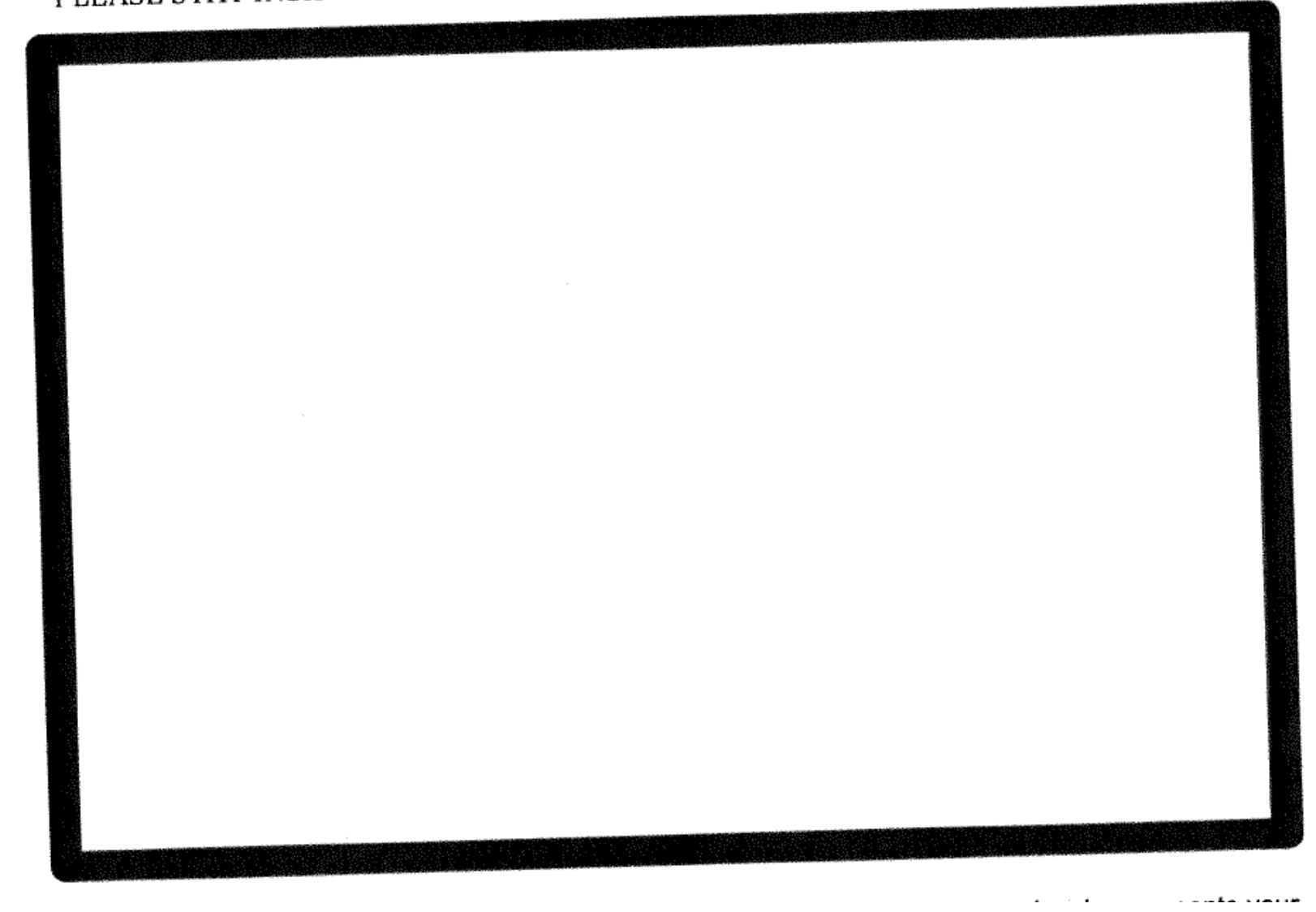


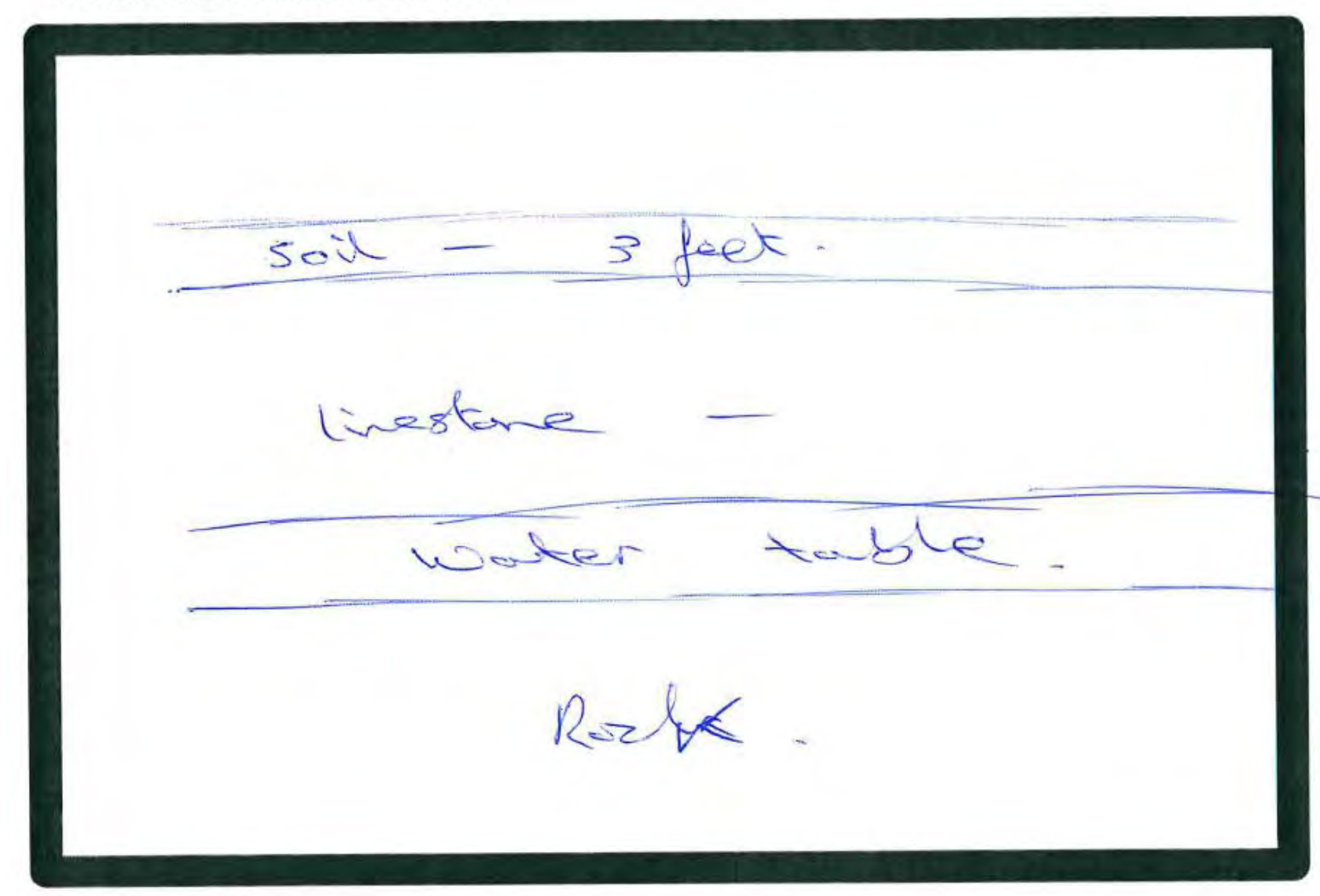


PLEASE STAY INSIDE THE BOX!

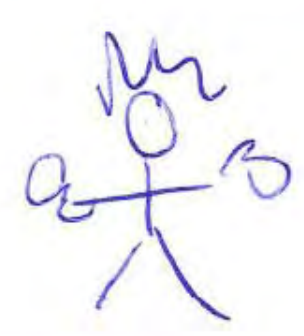

Sand tome

$$
\text { shale }
$$

Sand stow

Non-expert 
PLEASE STAY INSIDE THE BOX!

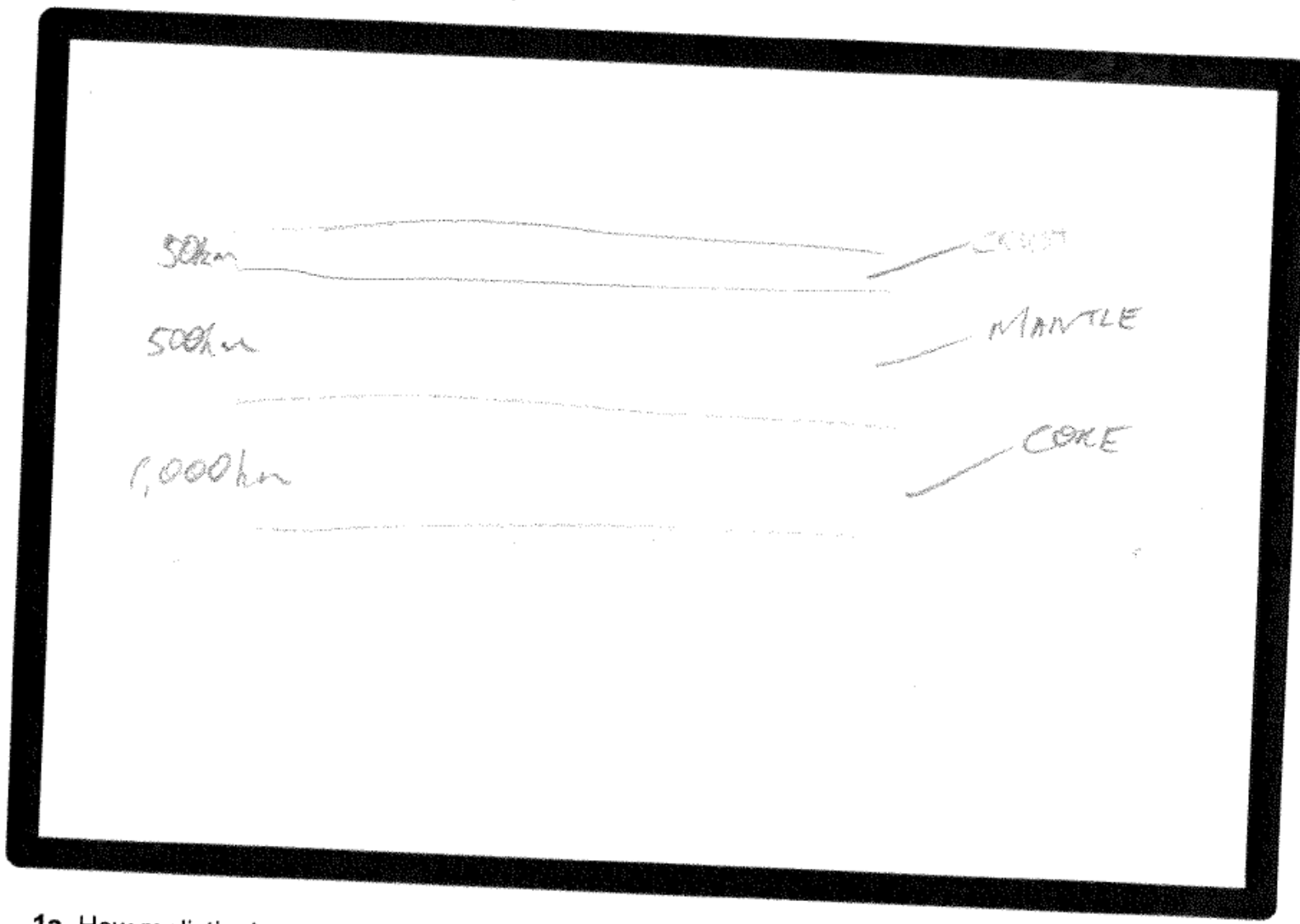


PLEASE STAY INSIDE THE BOX!

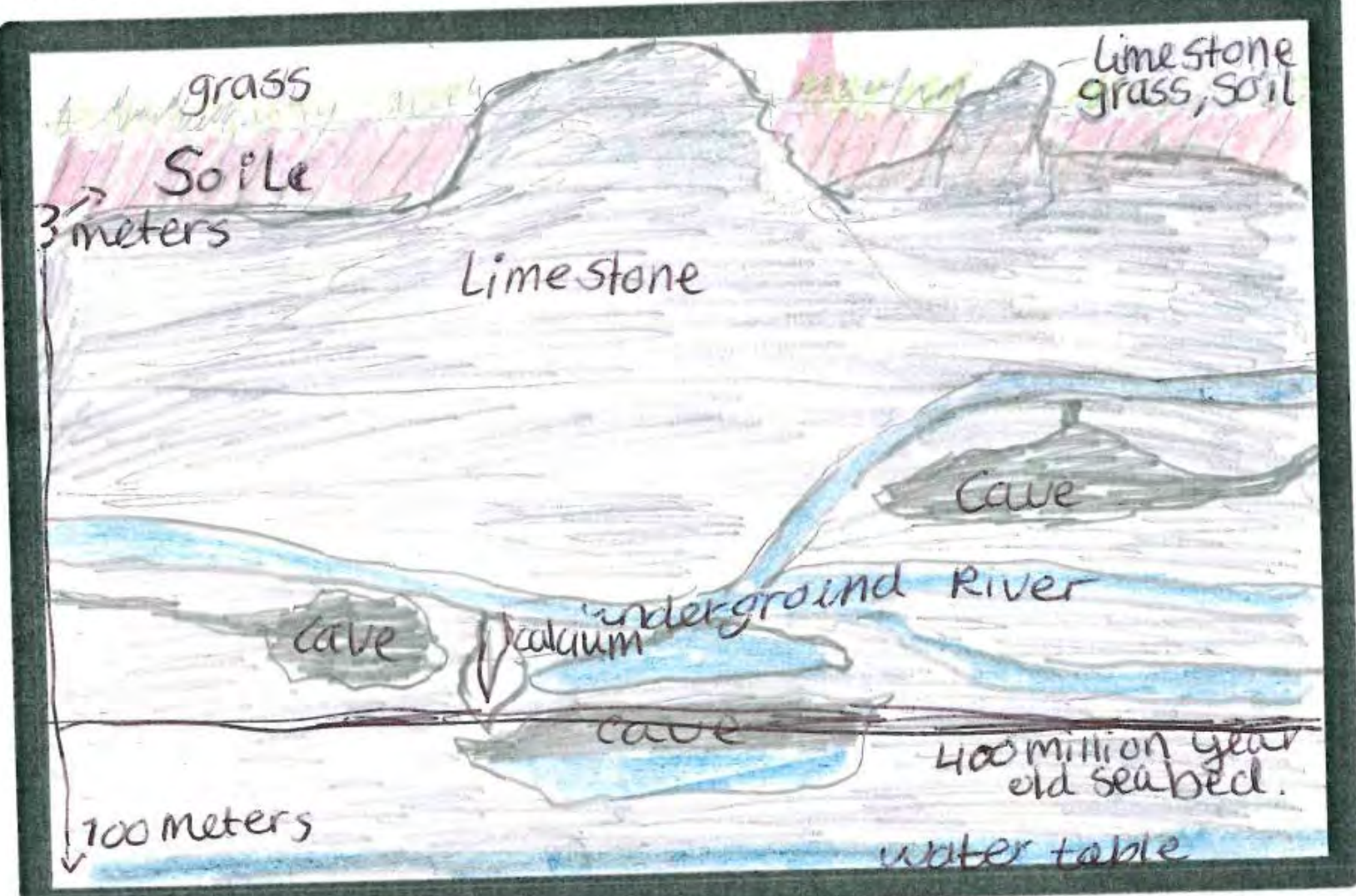


PLEASE STAY INSIDE THE BOX!

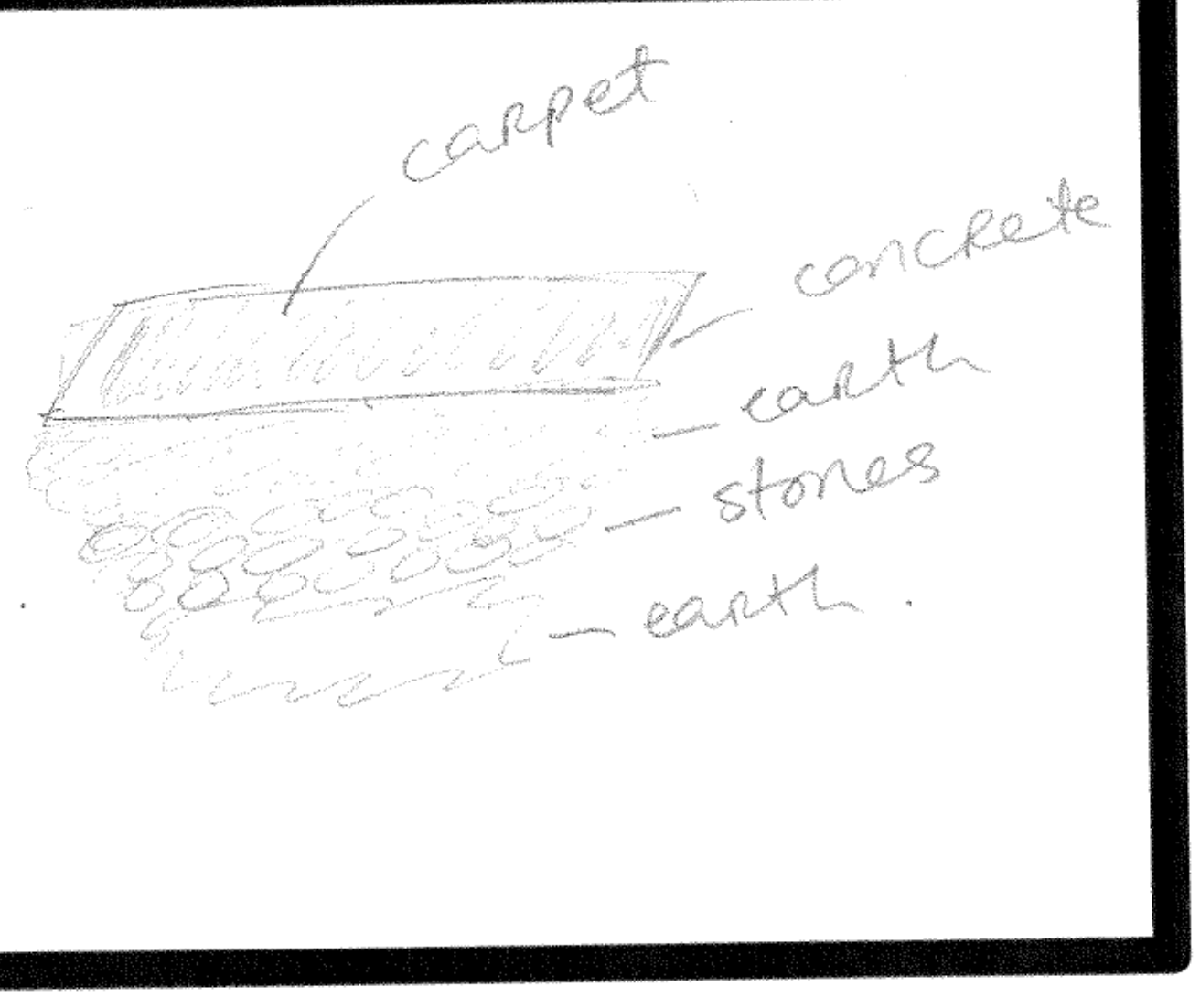

Non-expert 
PLEASE STAY INSIDE THE BOX!

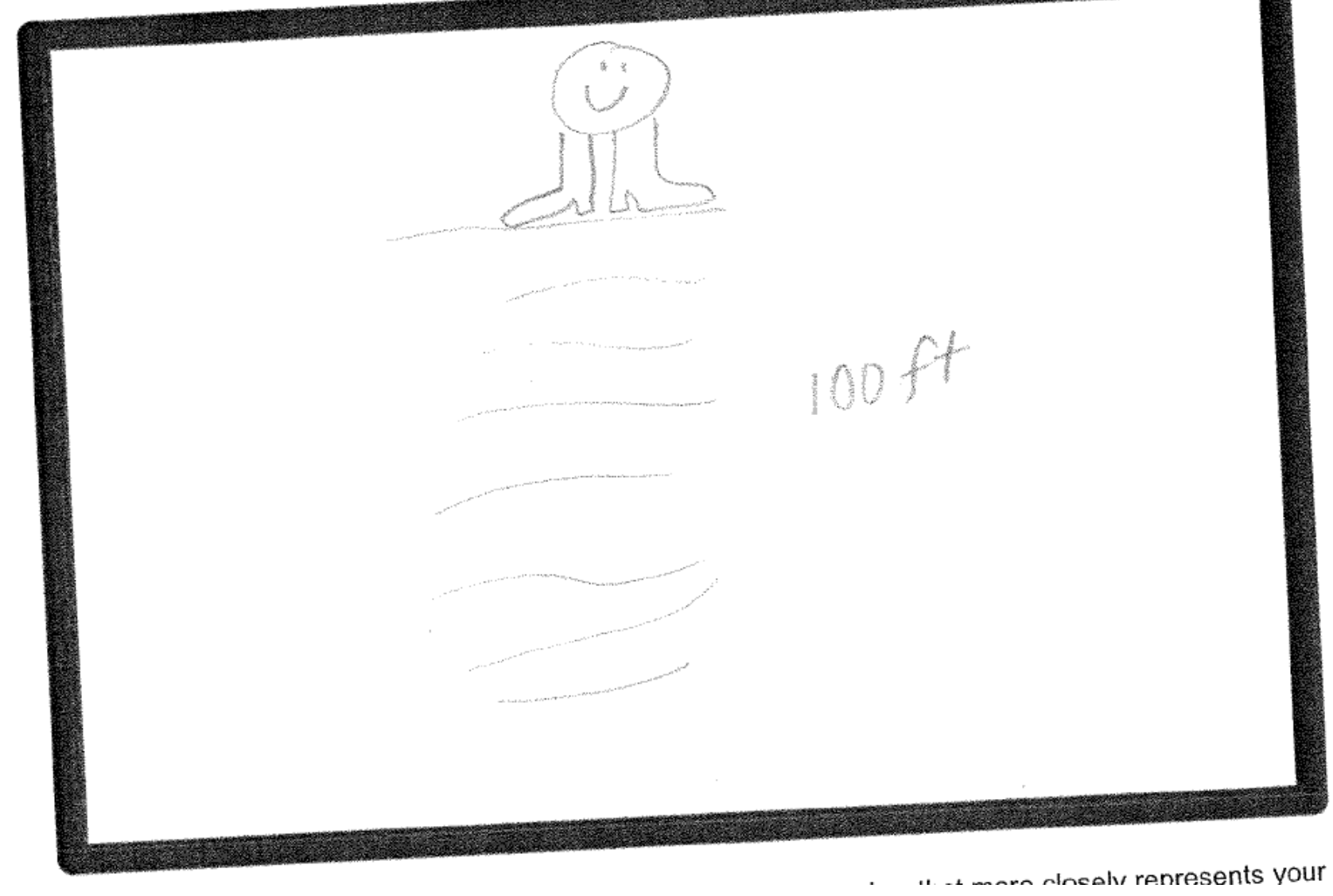


PLEASE STAY INSIDE THE BOX!

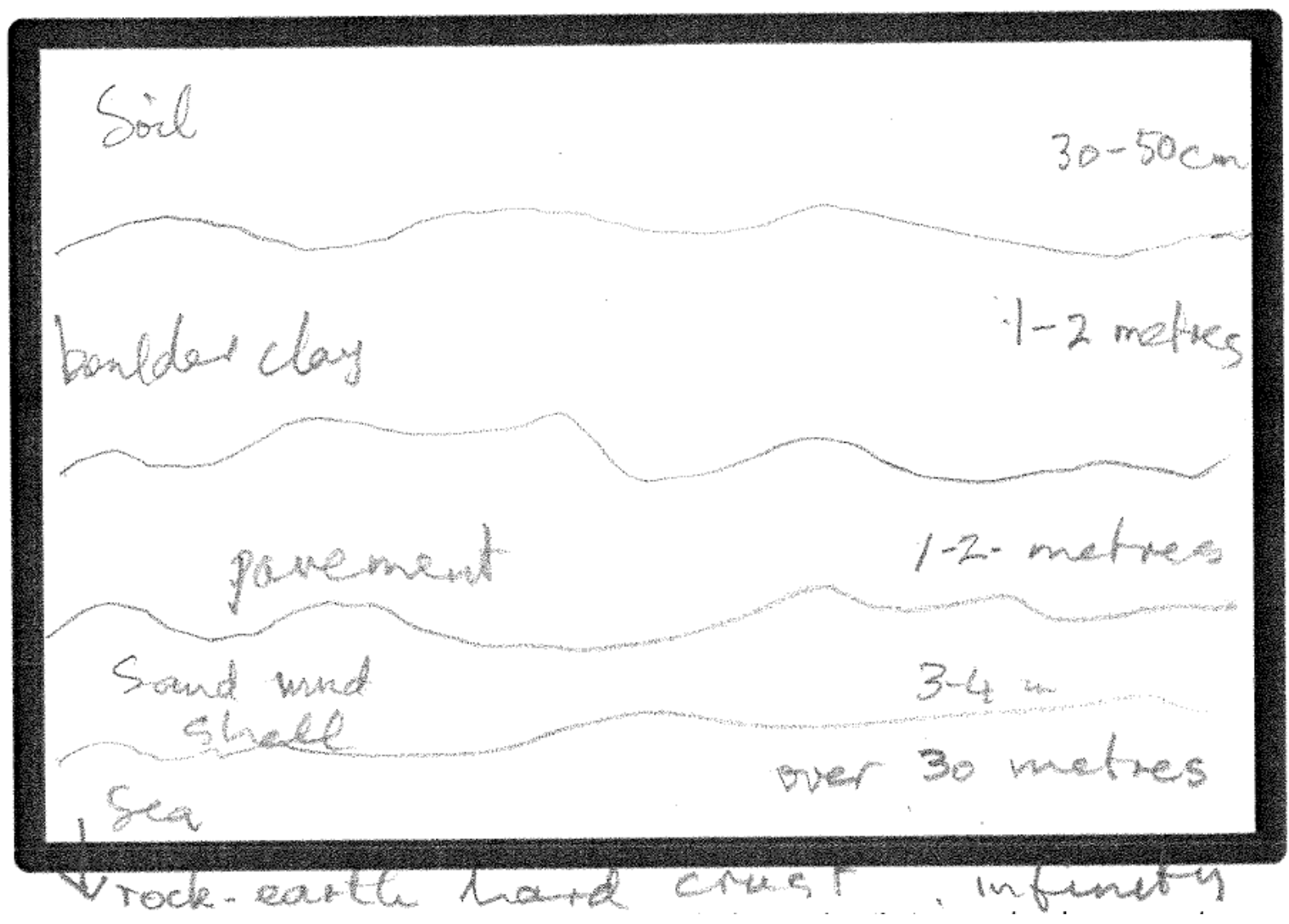


PLEASE STAY INSIDE THE BOX!

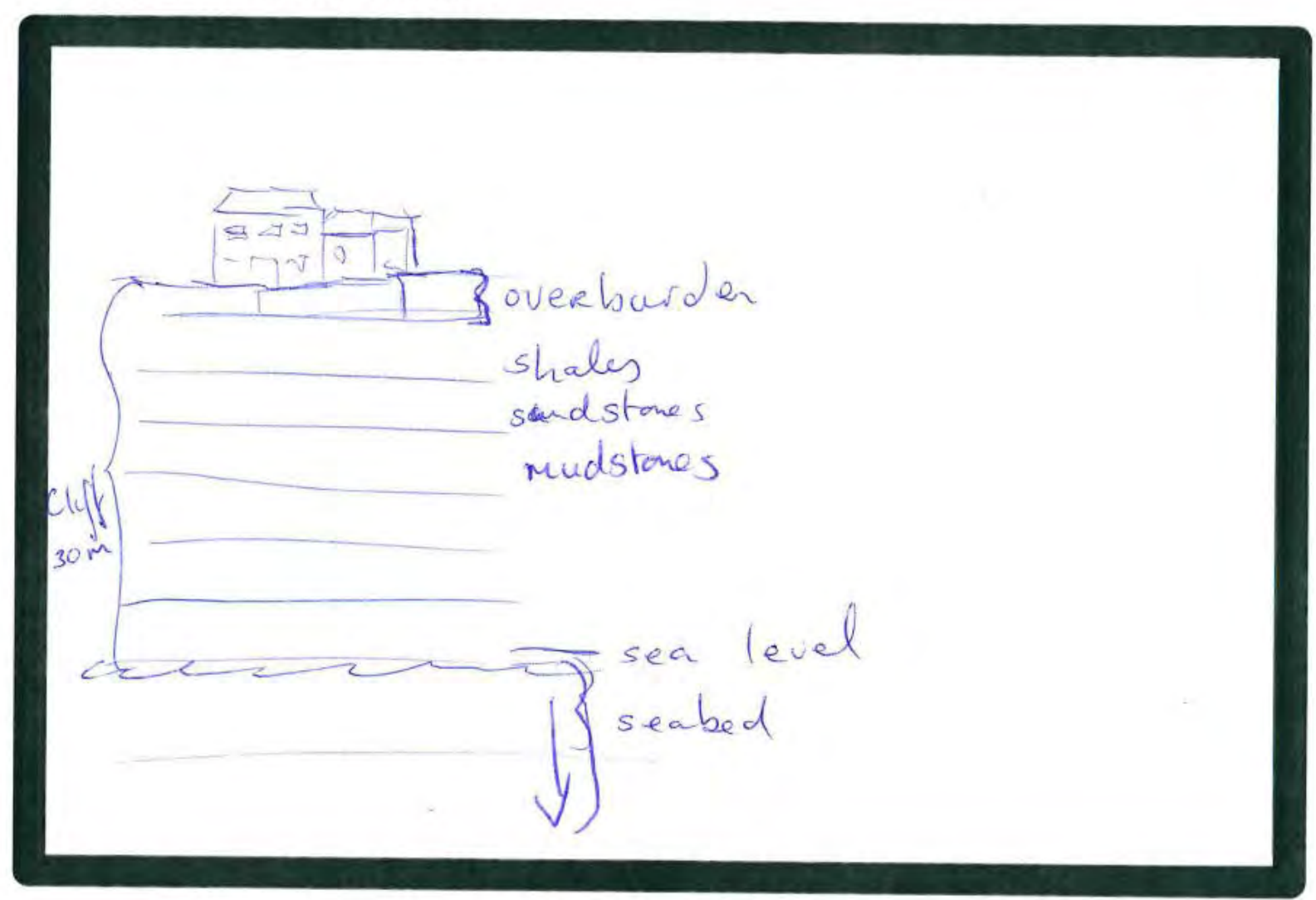


PLEASE STAY INSIDE THE BOX!

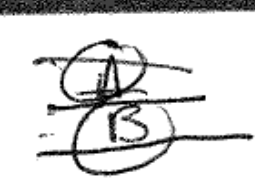

(c)

-
(A) TILES $50 \mathrm{~mm}$

(B) CONCRETElsowm

(C) LIMESTNE vanies

im to 100m $t$

Non-expert 
PLEASE STAY INSIDE THE BOX!

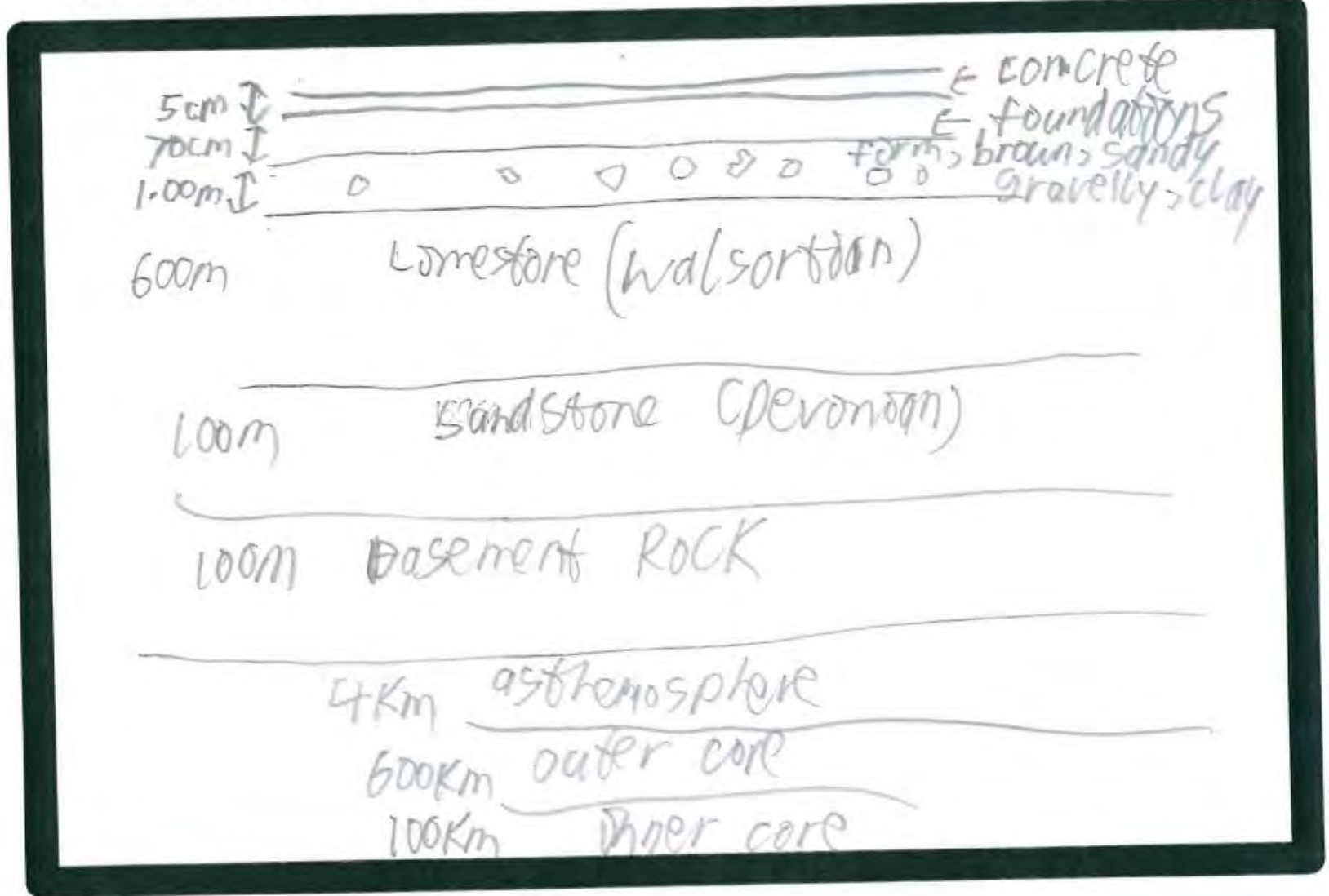


PLEASE STAY INSIDE THE BOX!

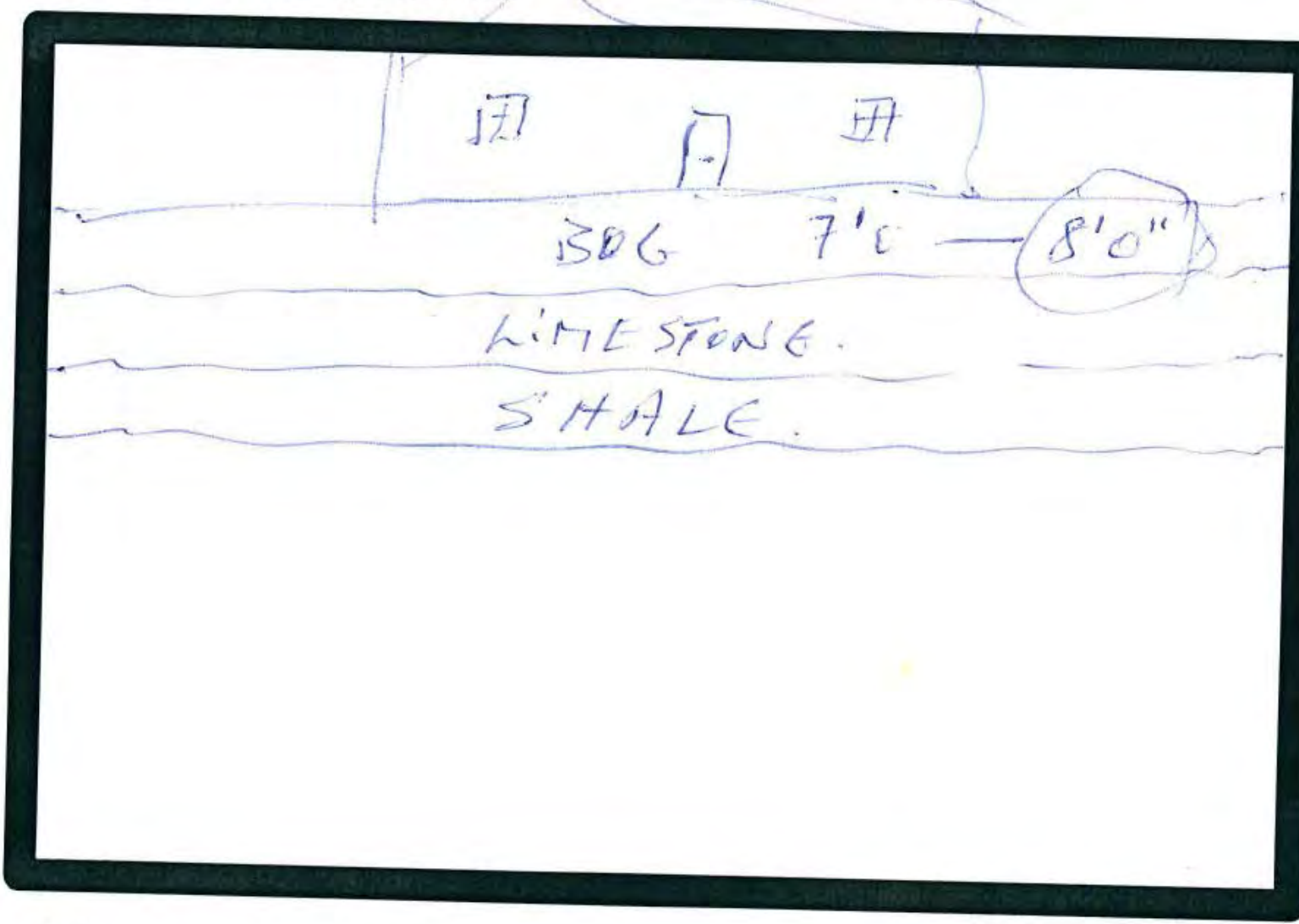




\section{PLEASE STAY INSIDE THE BOX!}
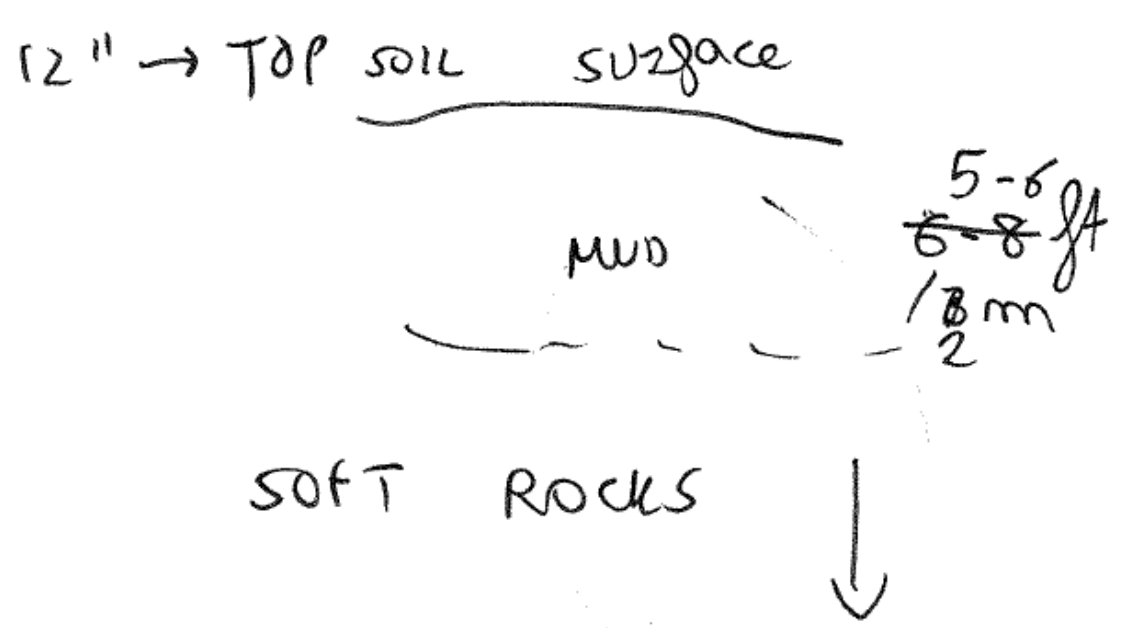

* TYPES

Honder Rock 
PLEASE STAY INSIDE THE BOX!

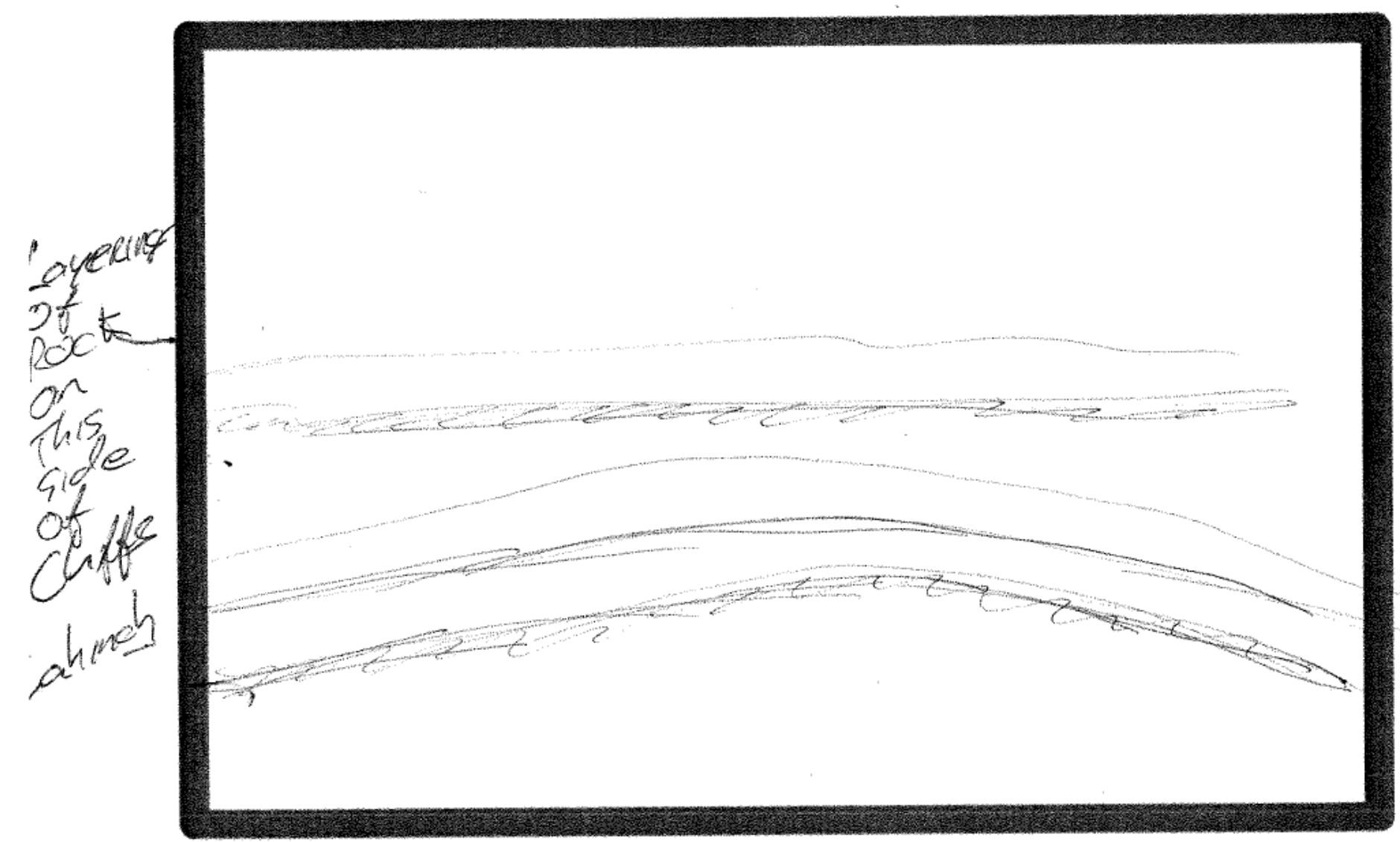




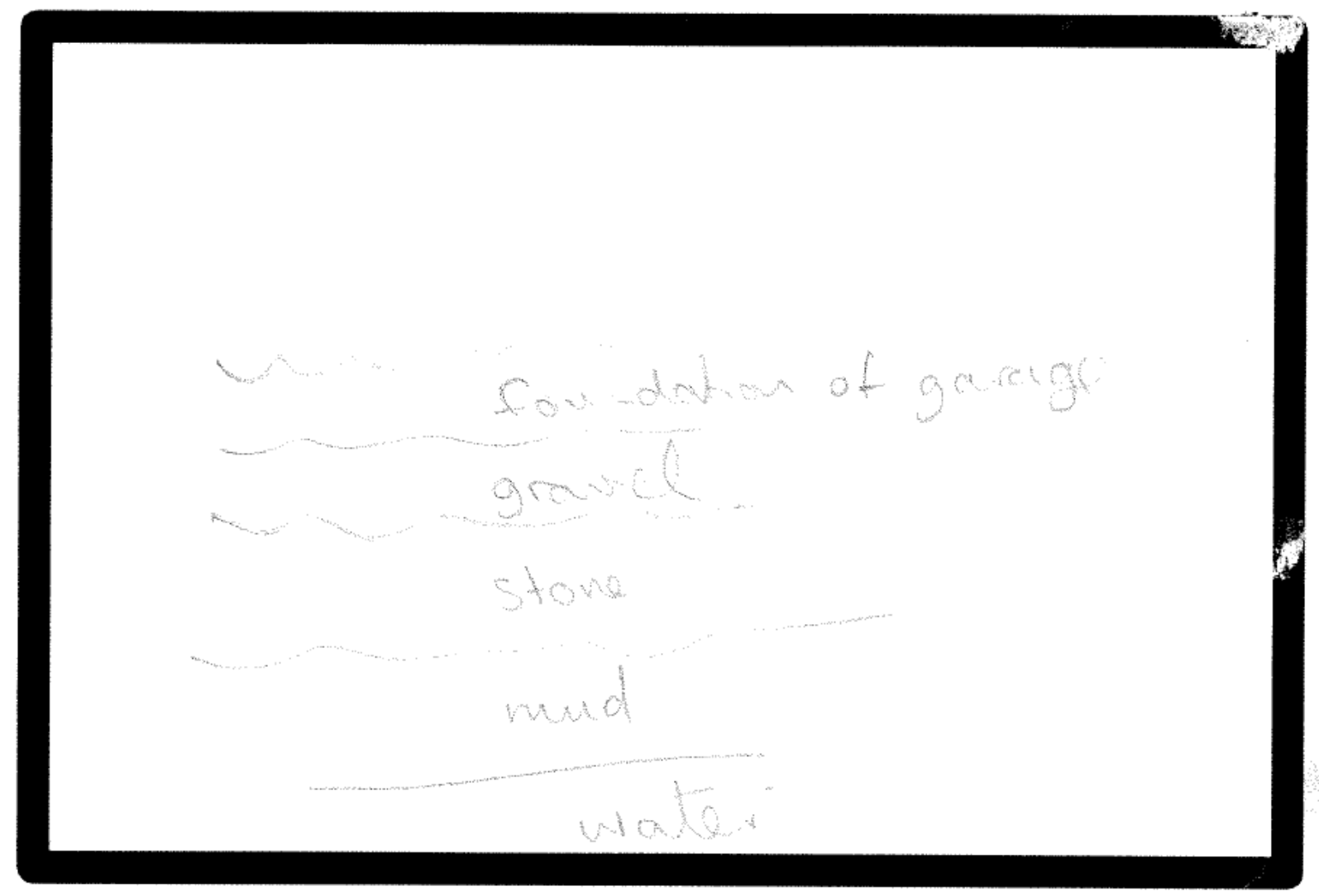




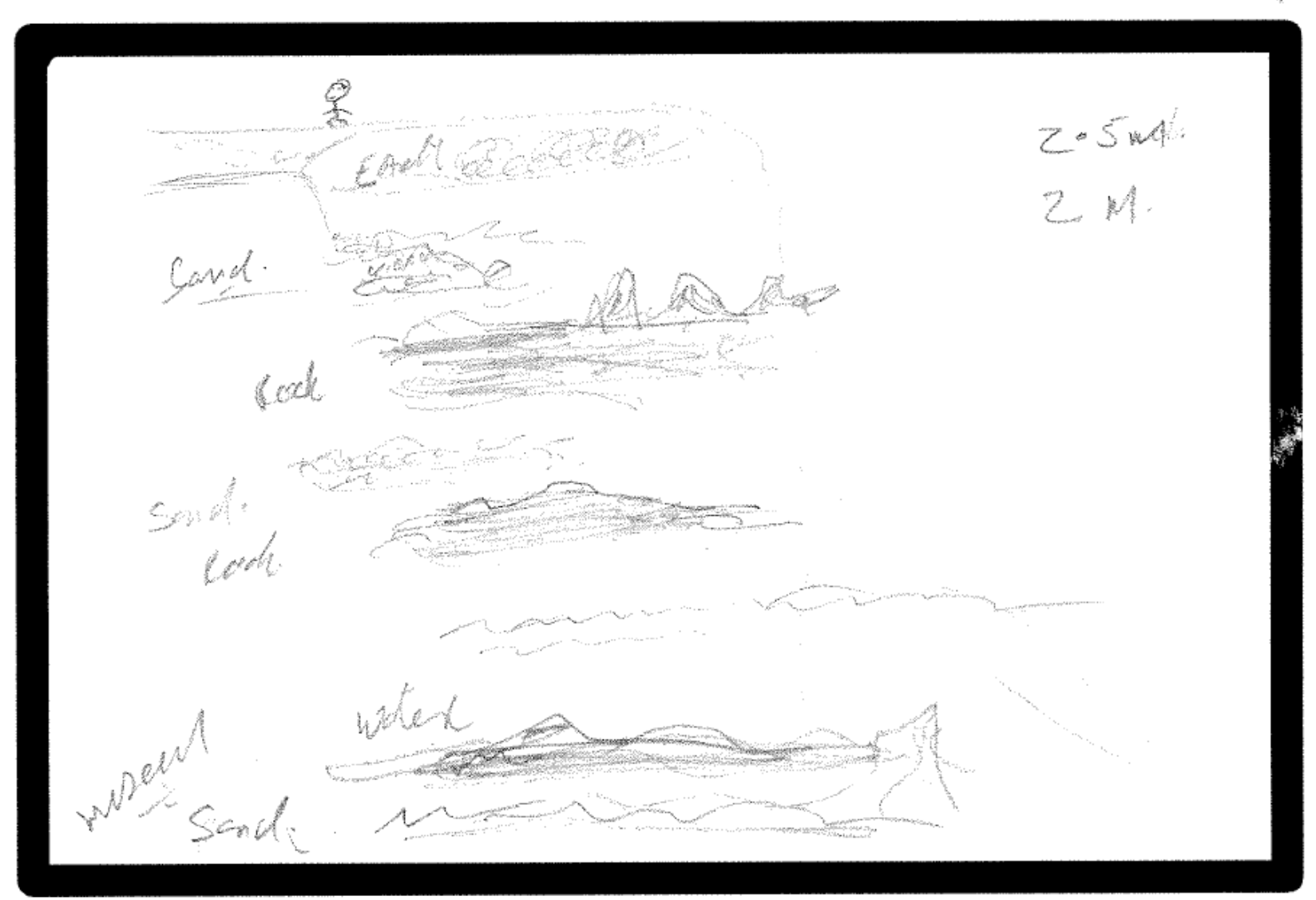




\section{Drilling}

Imagine a company is interested in drilling a hole in the ground through the rock in Co. Clare. Please sketch what the drilling process would look like 


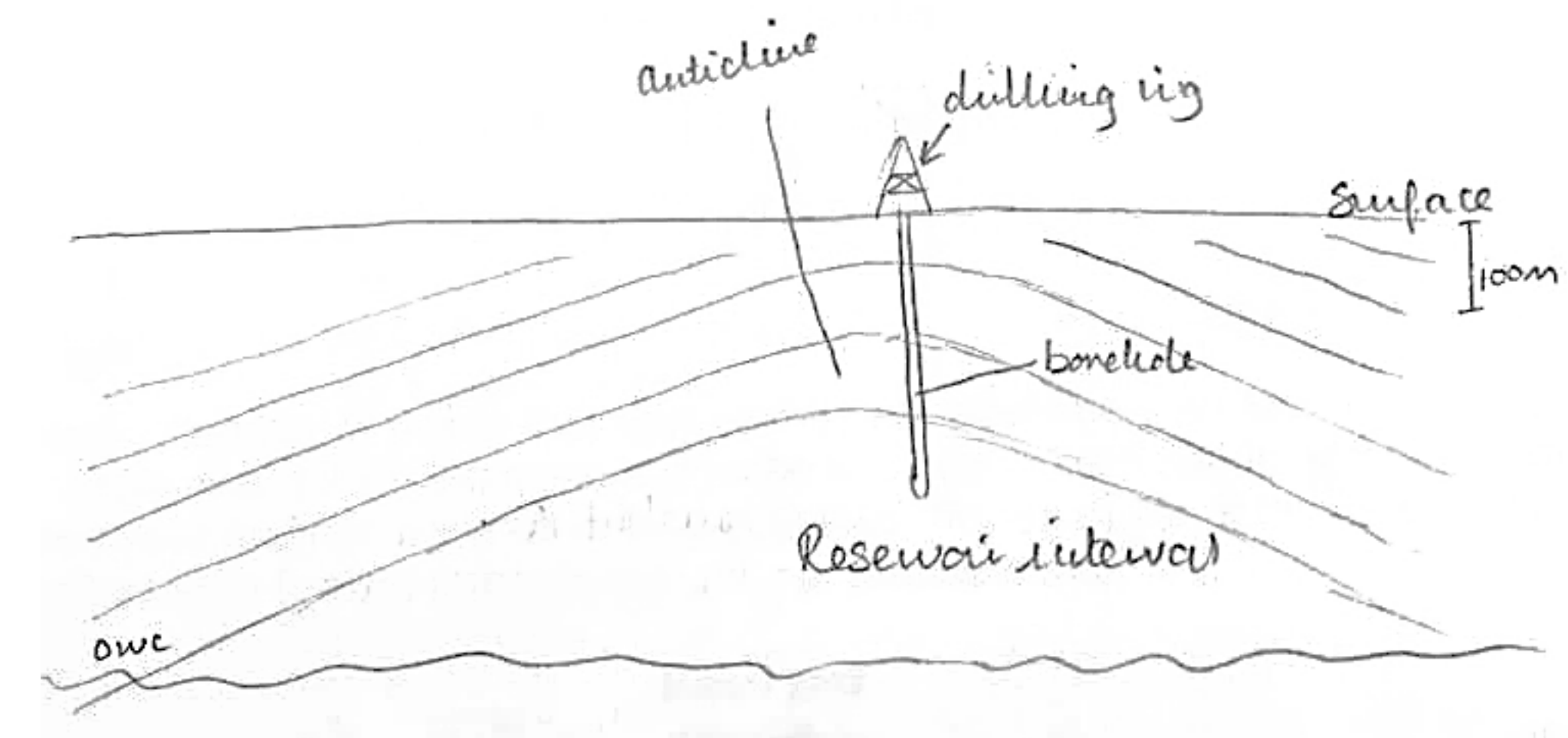

Expert 
PLEASE STAY INSIDE THE BUX!

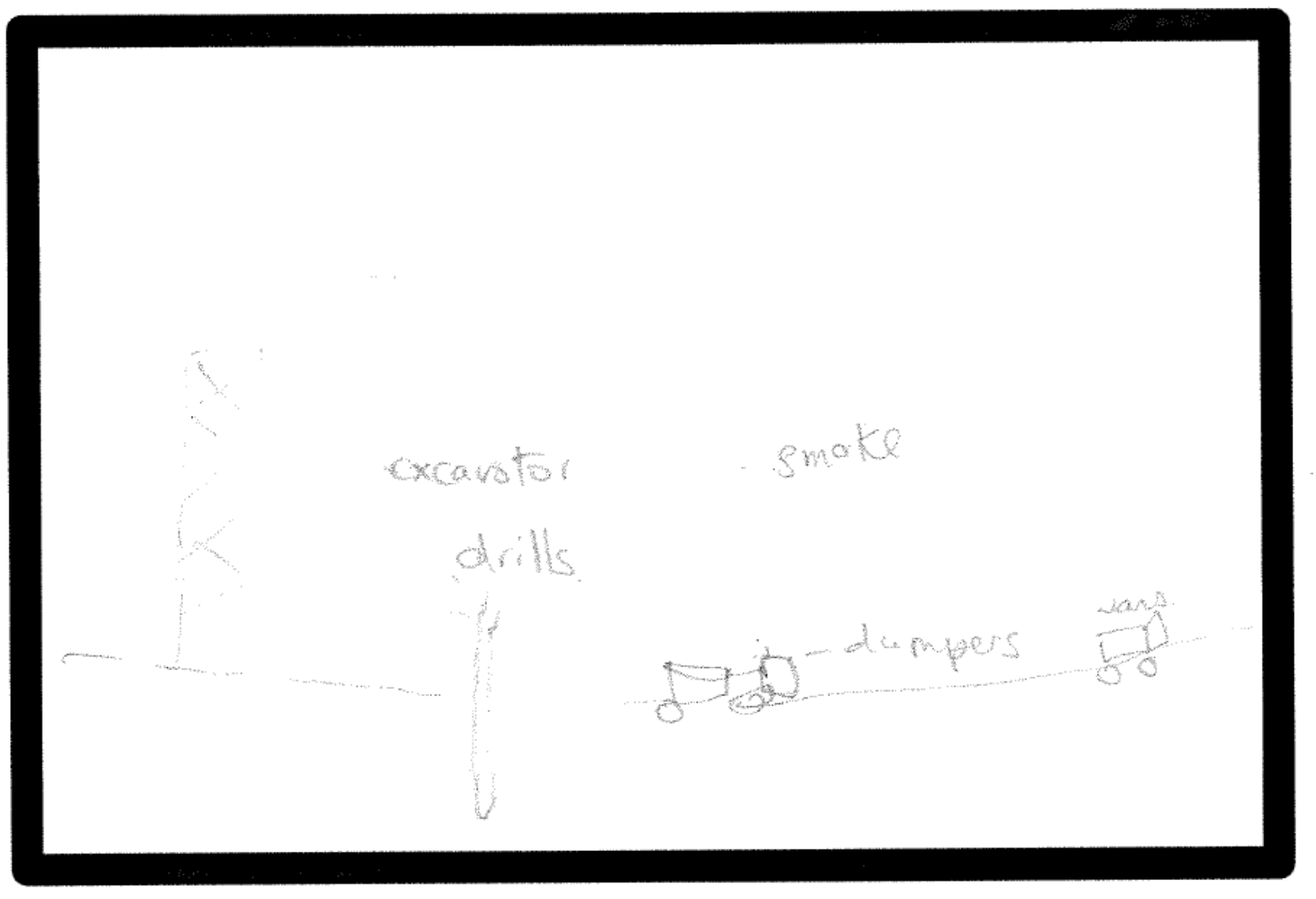




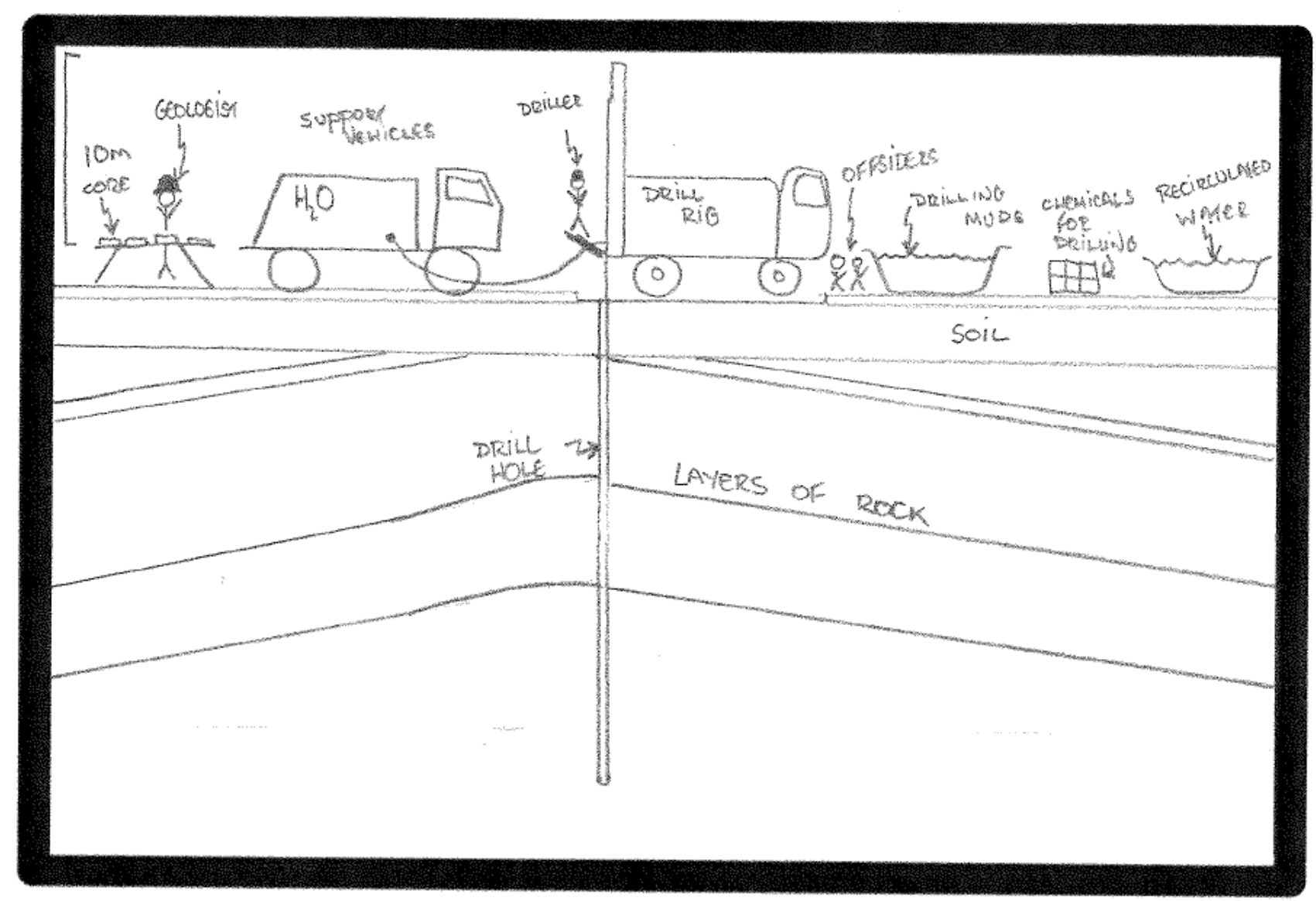


PLEASE STAY INSIDE THE BOX!

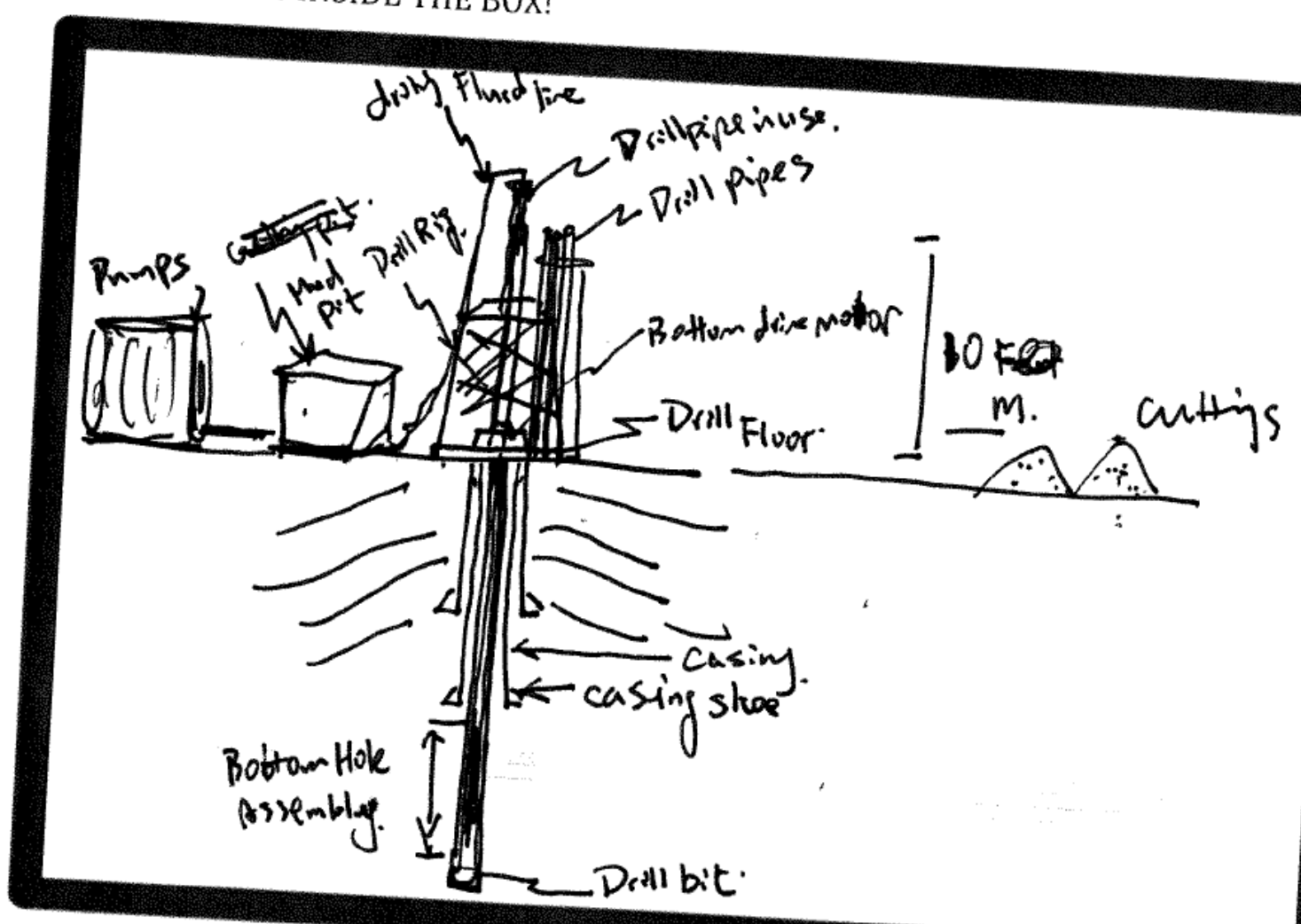

2a. How realistic do you find your sketch? Ploann 
PLEASE SIAY INSIDE THE BOX!

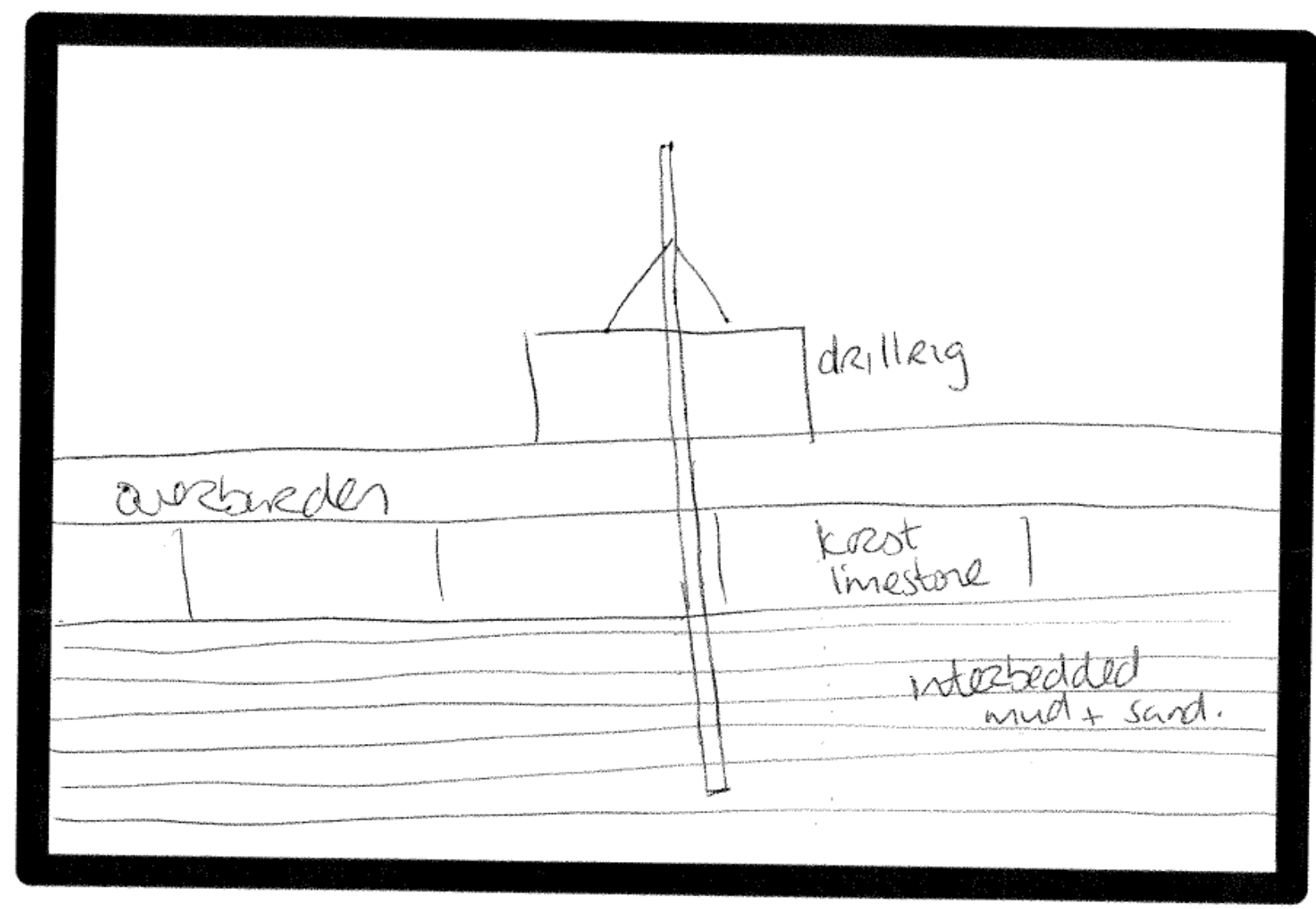


PLEASE STAY INSIDE THE BOX!

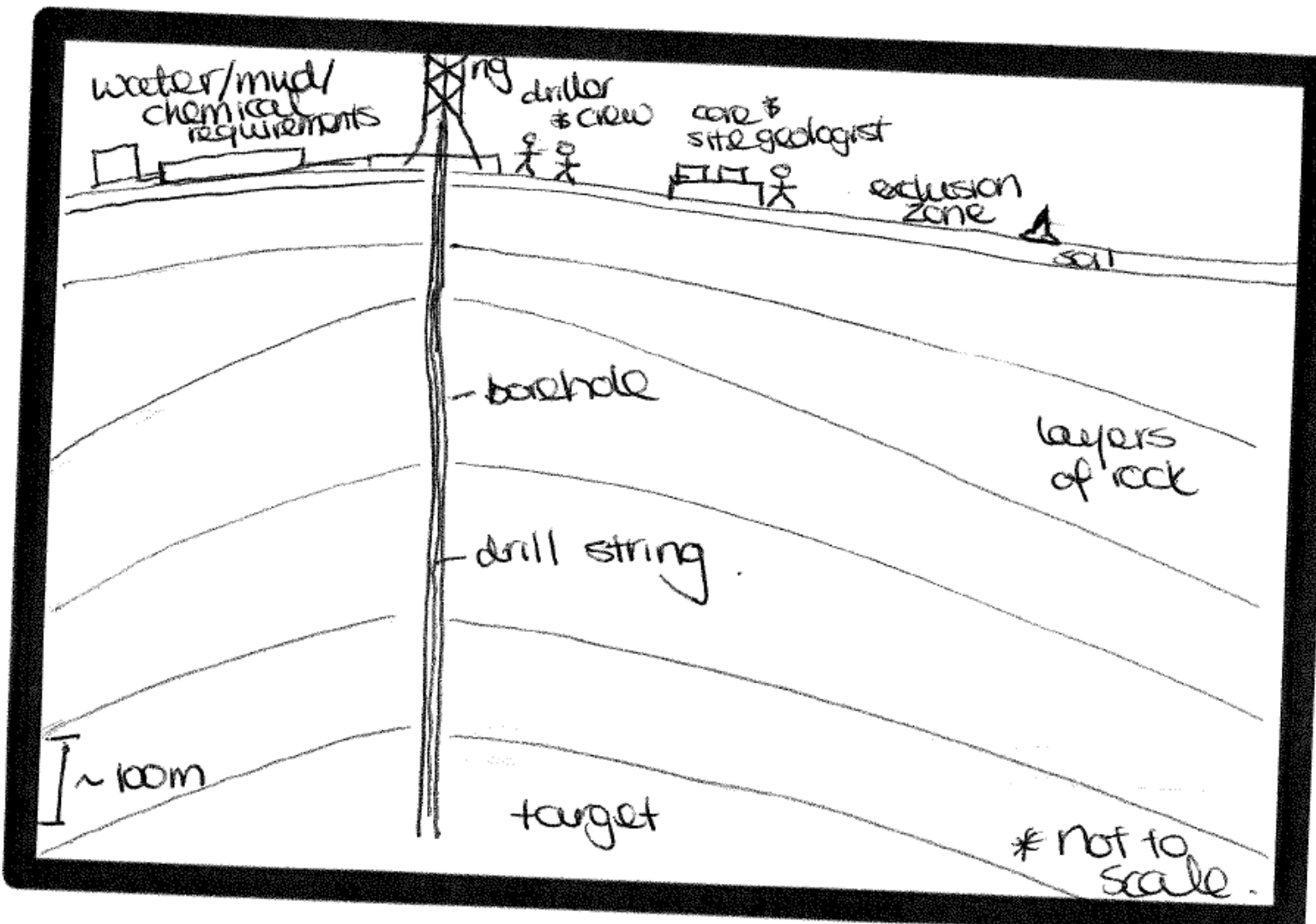




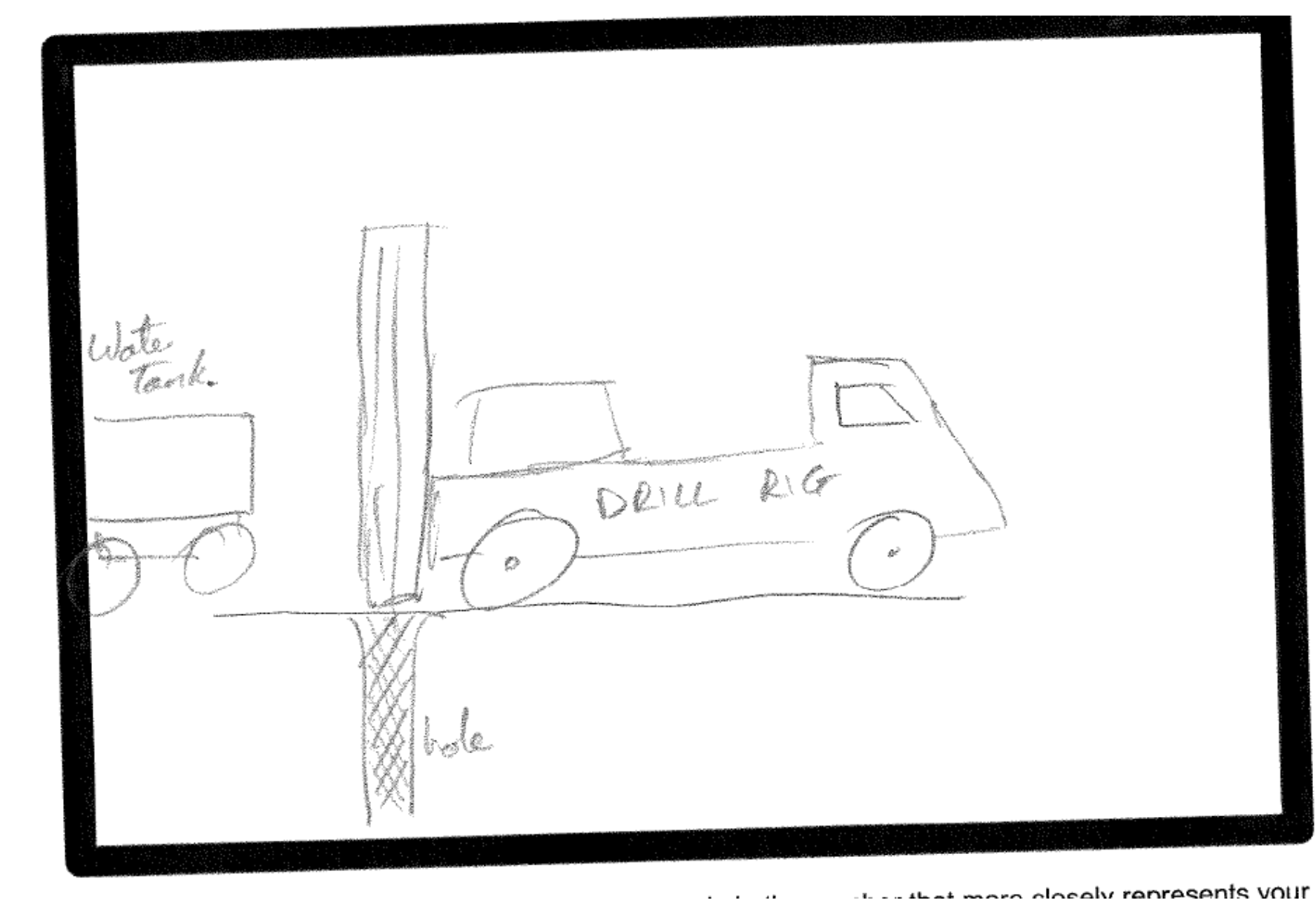




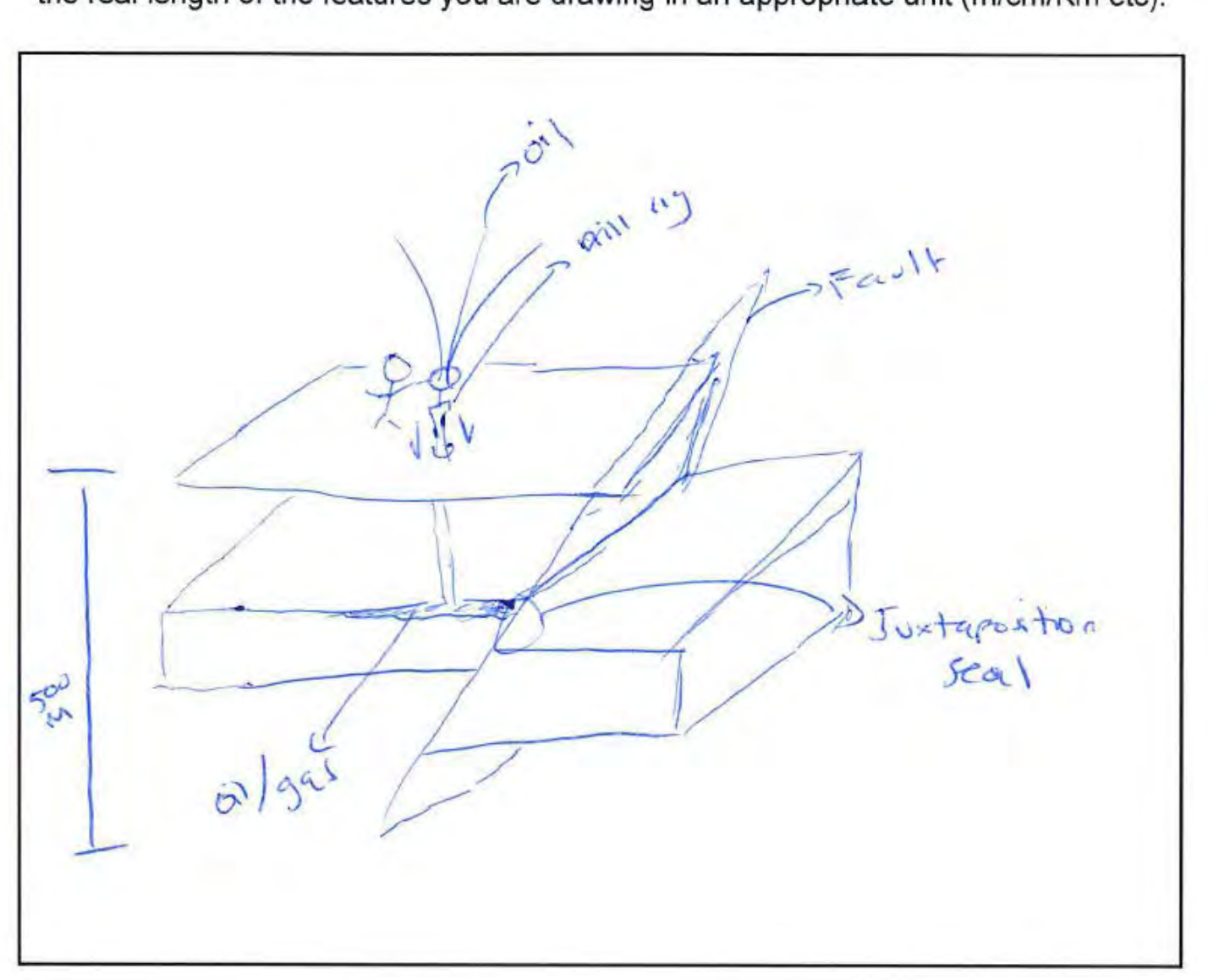

Expert 


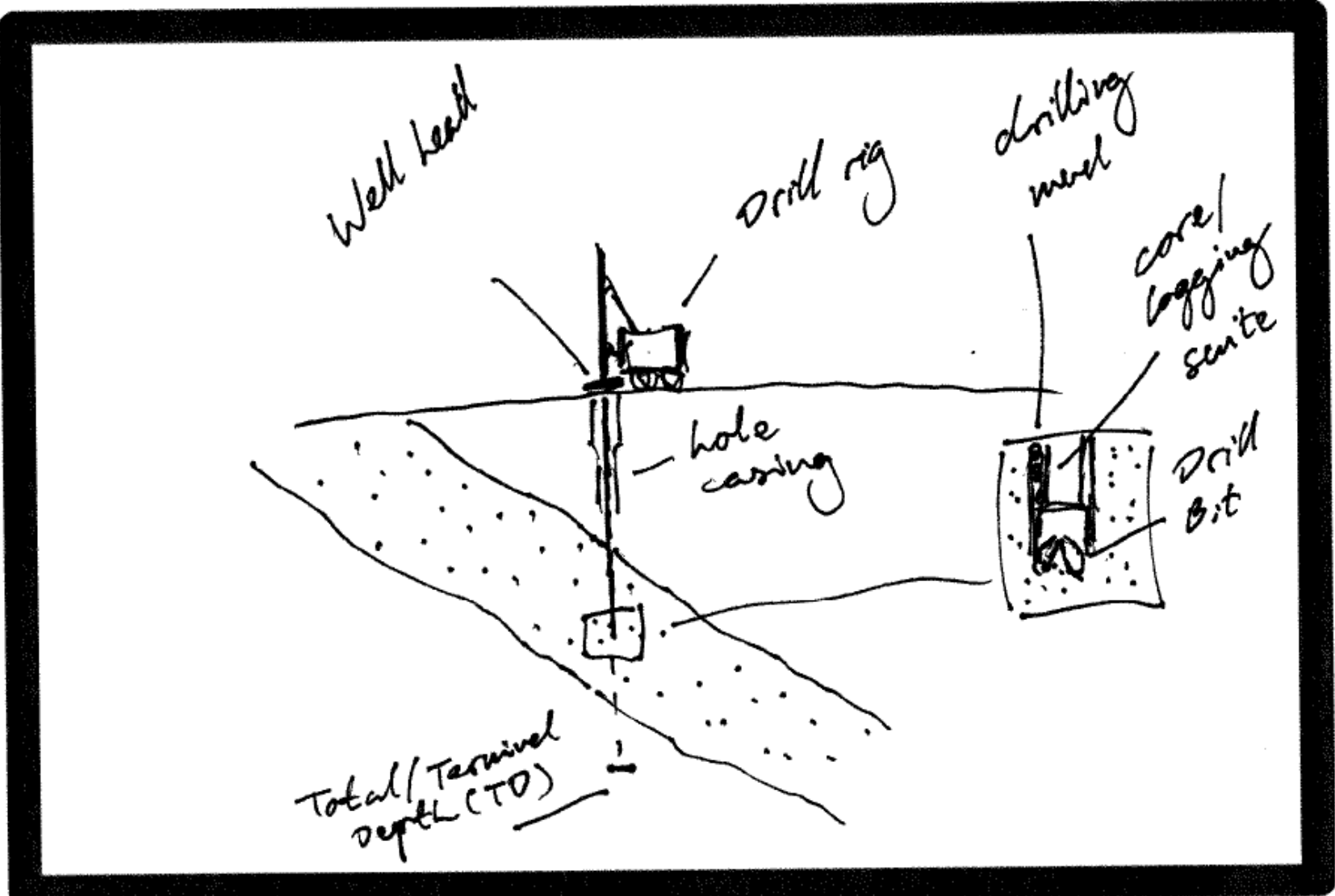




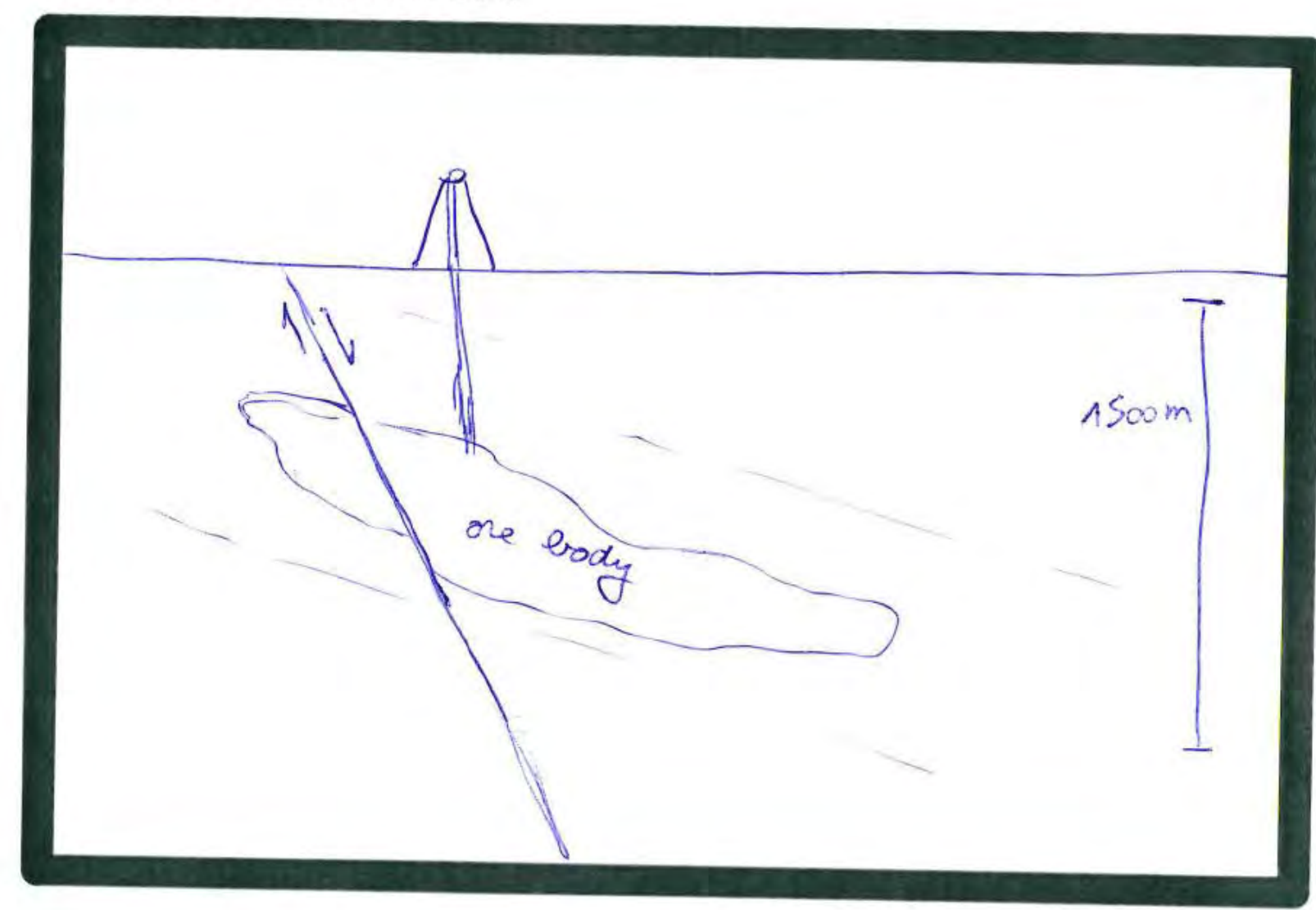




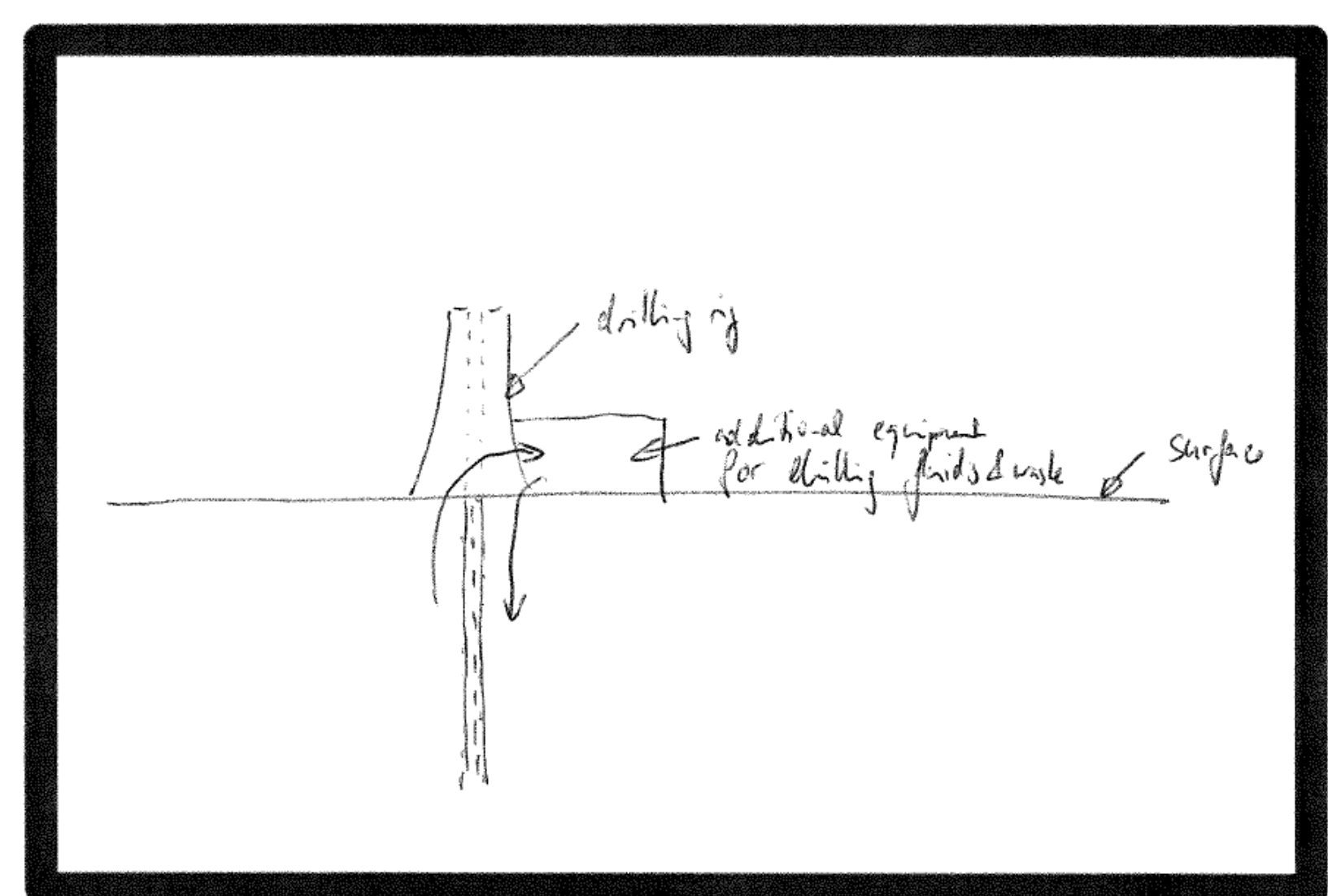




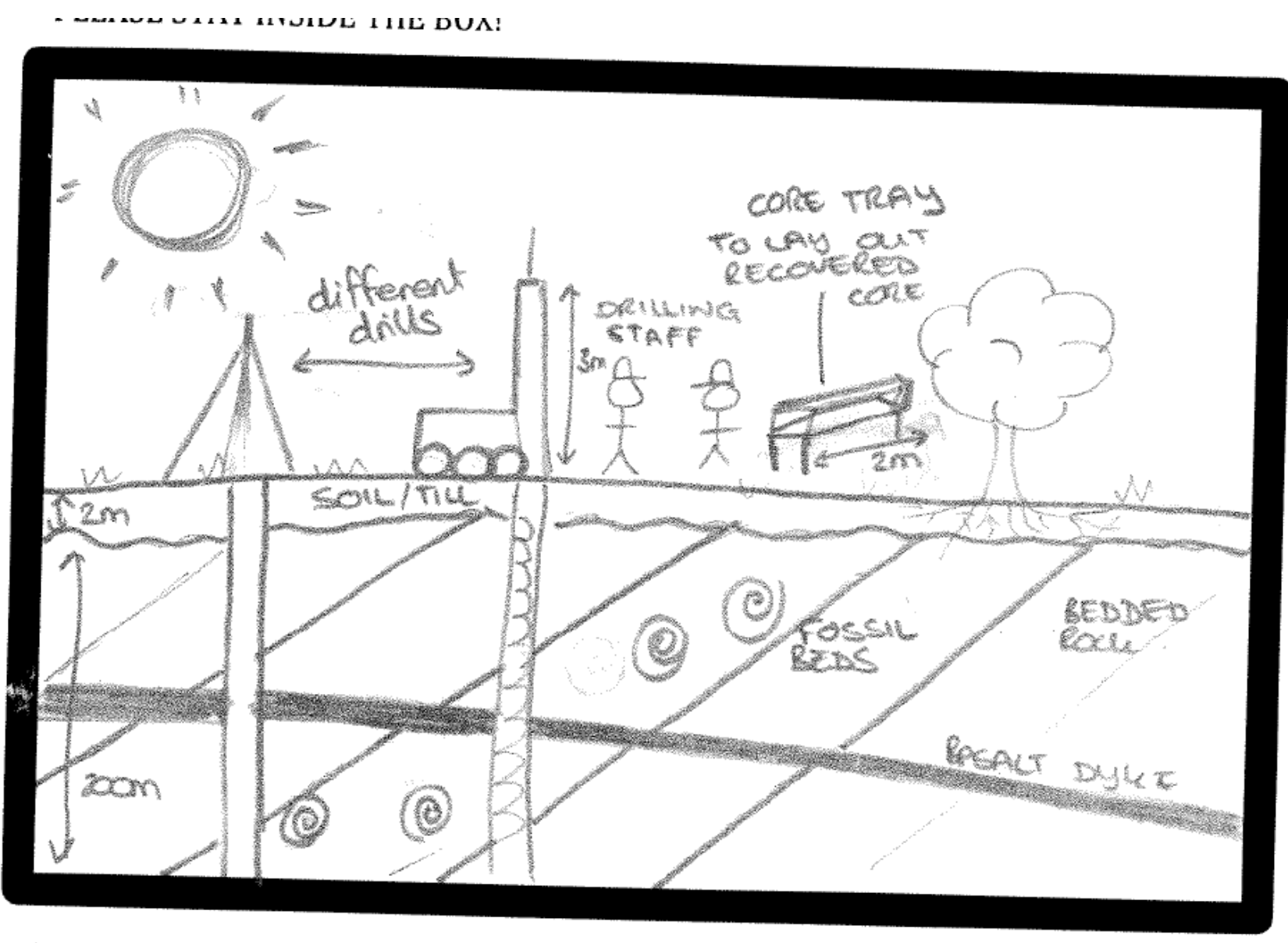




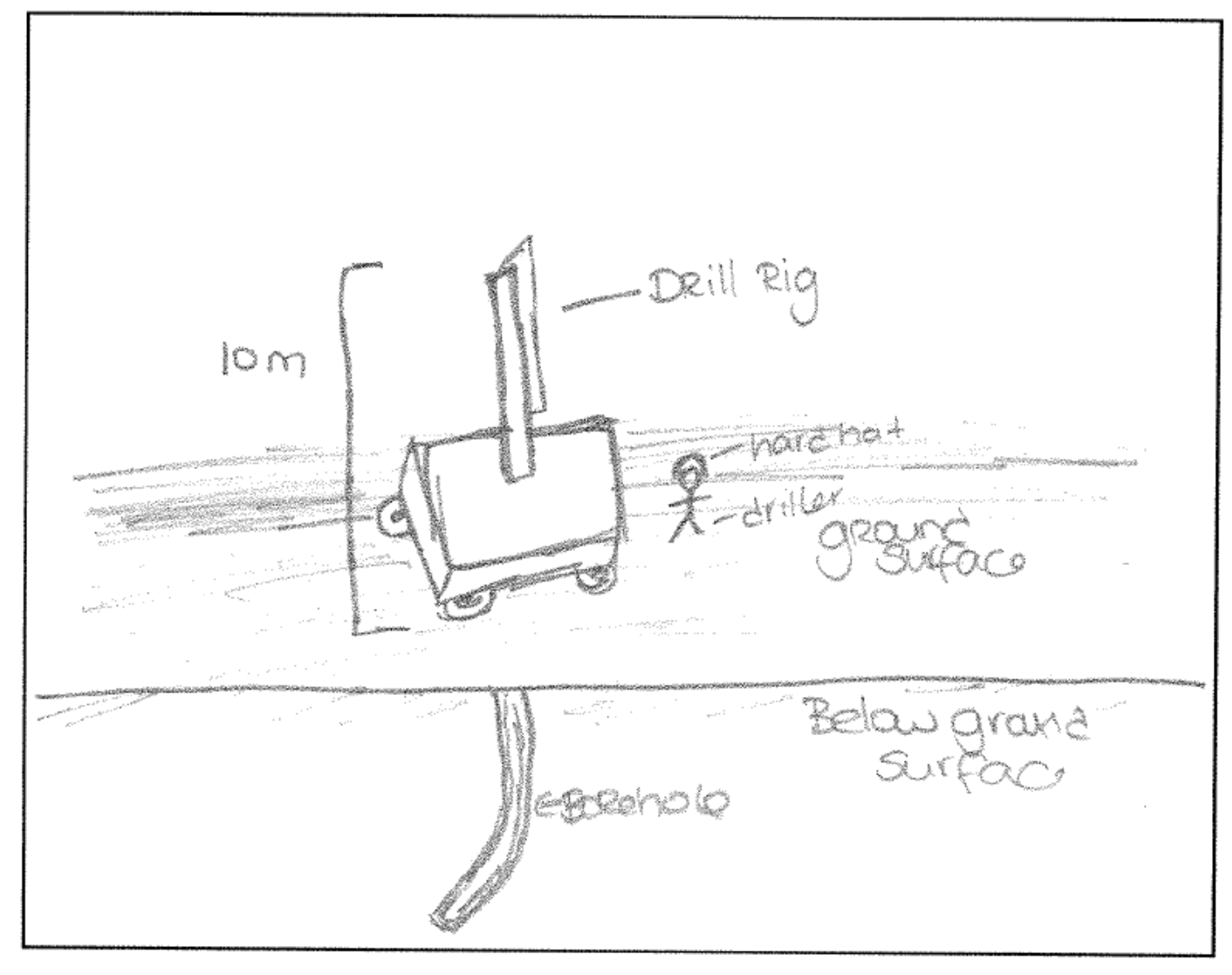




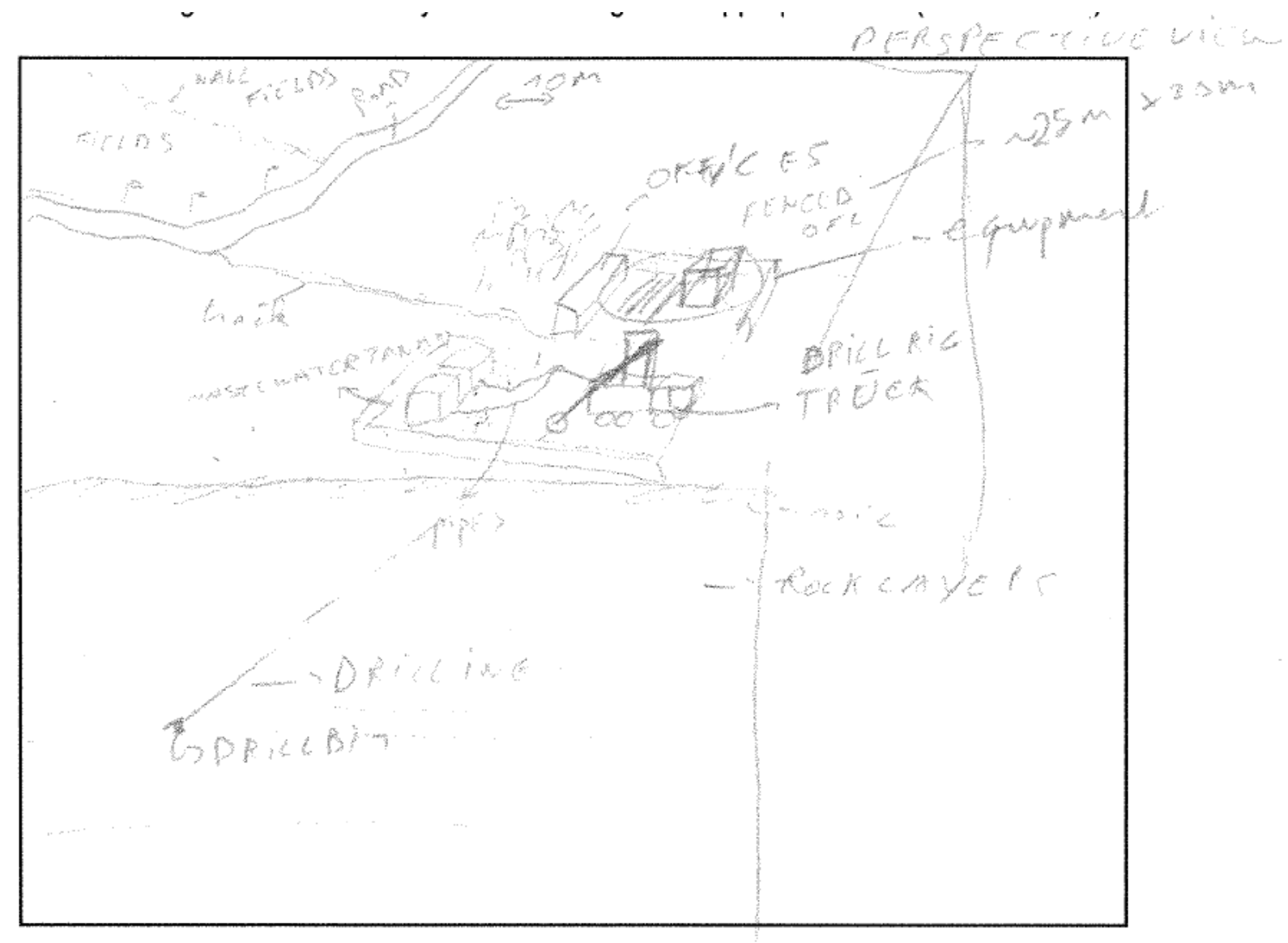

Expert 
PLEASE STAY INSIDE THE BOX!

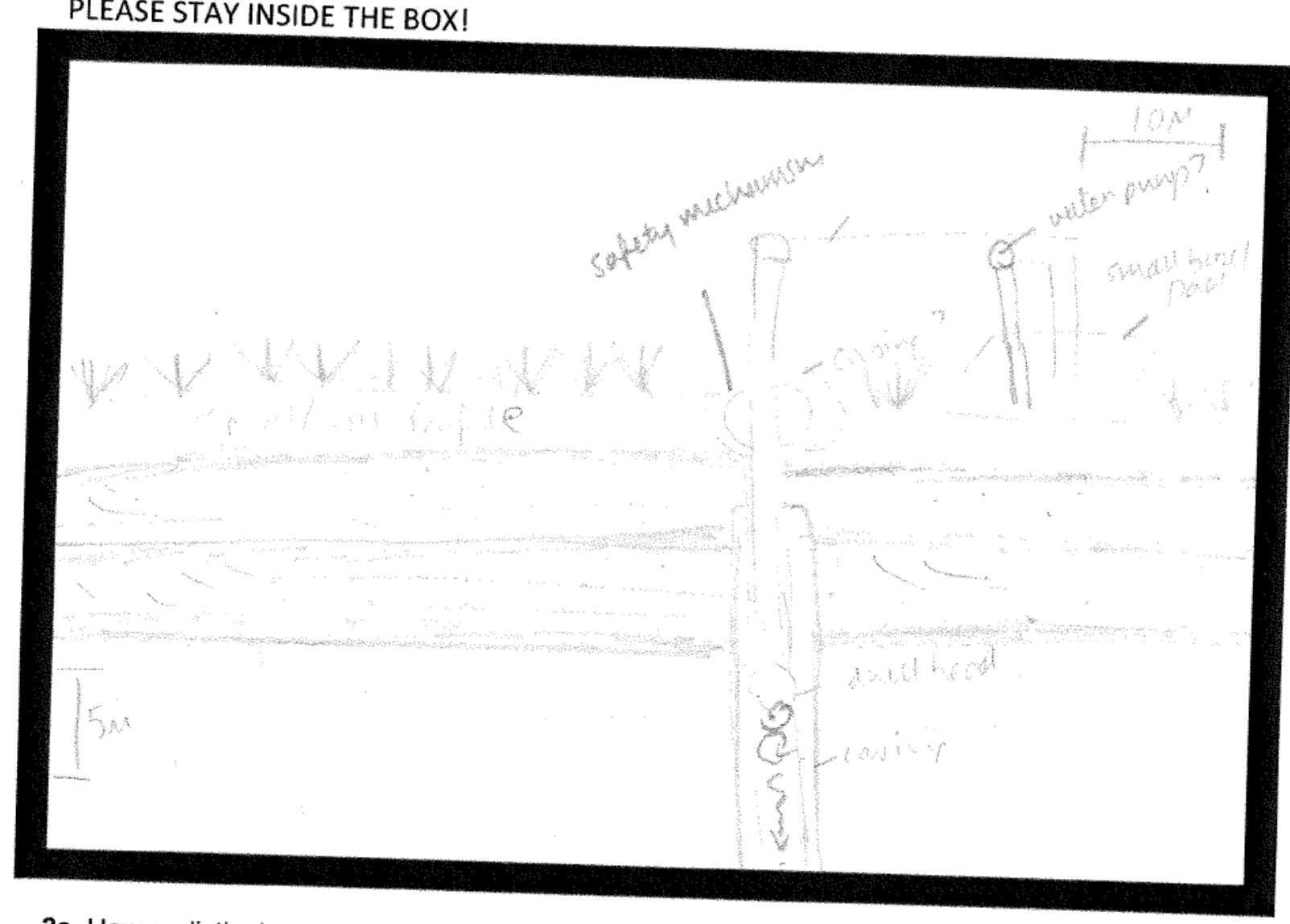

2n Ua... -..--1:-1: 1 
3a Hnw roalictin do unu find ........ - - ...... 
PLEASE STAY INSIDE THE BOX!

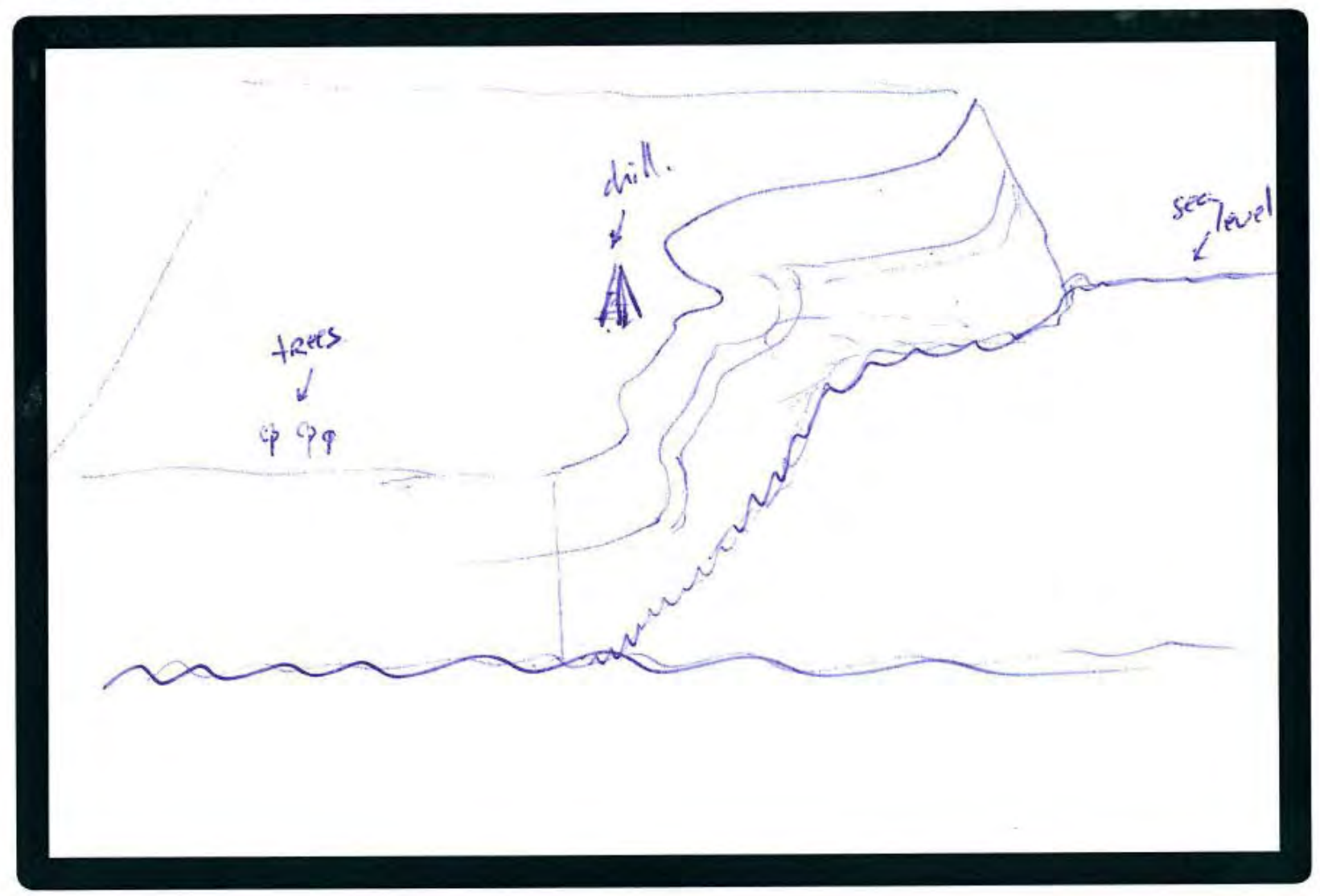


PLEASE STAY INSIDE THE BOX!

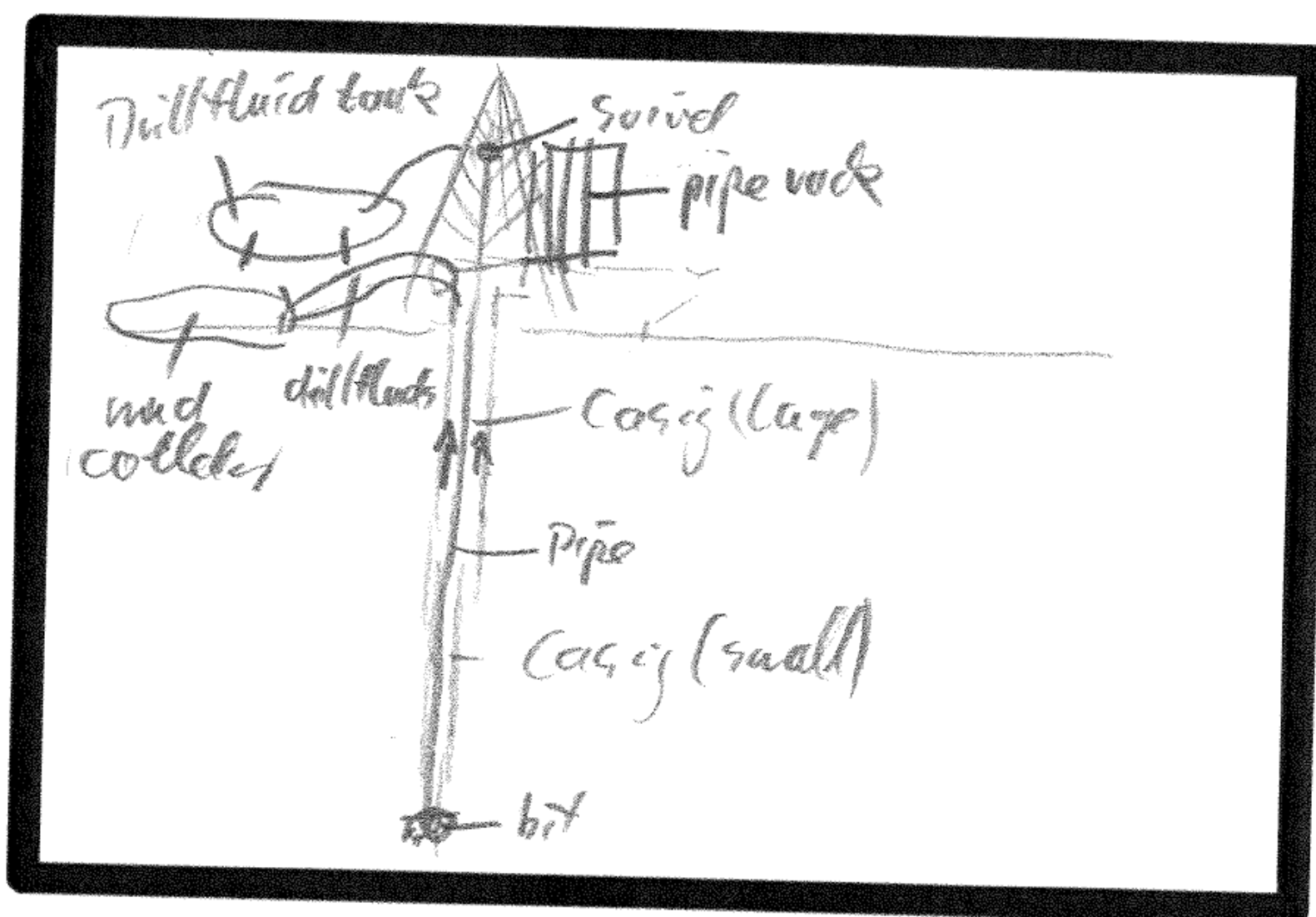




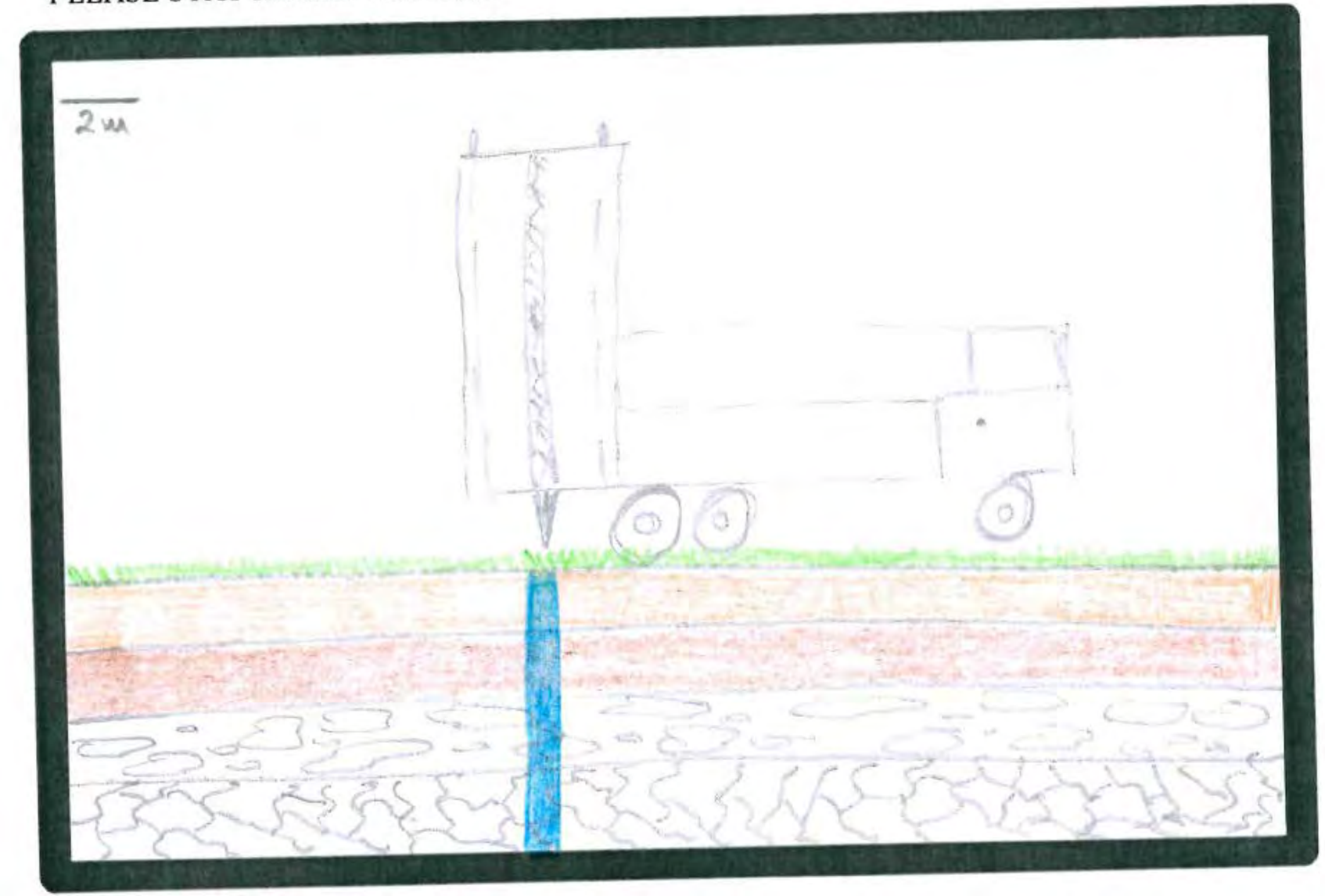


PLEASE STAY INSIDE THE BOX!

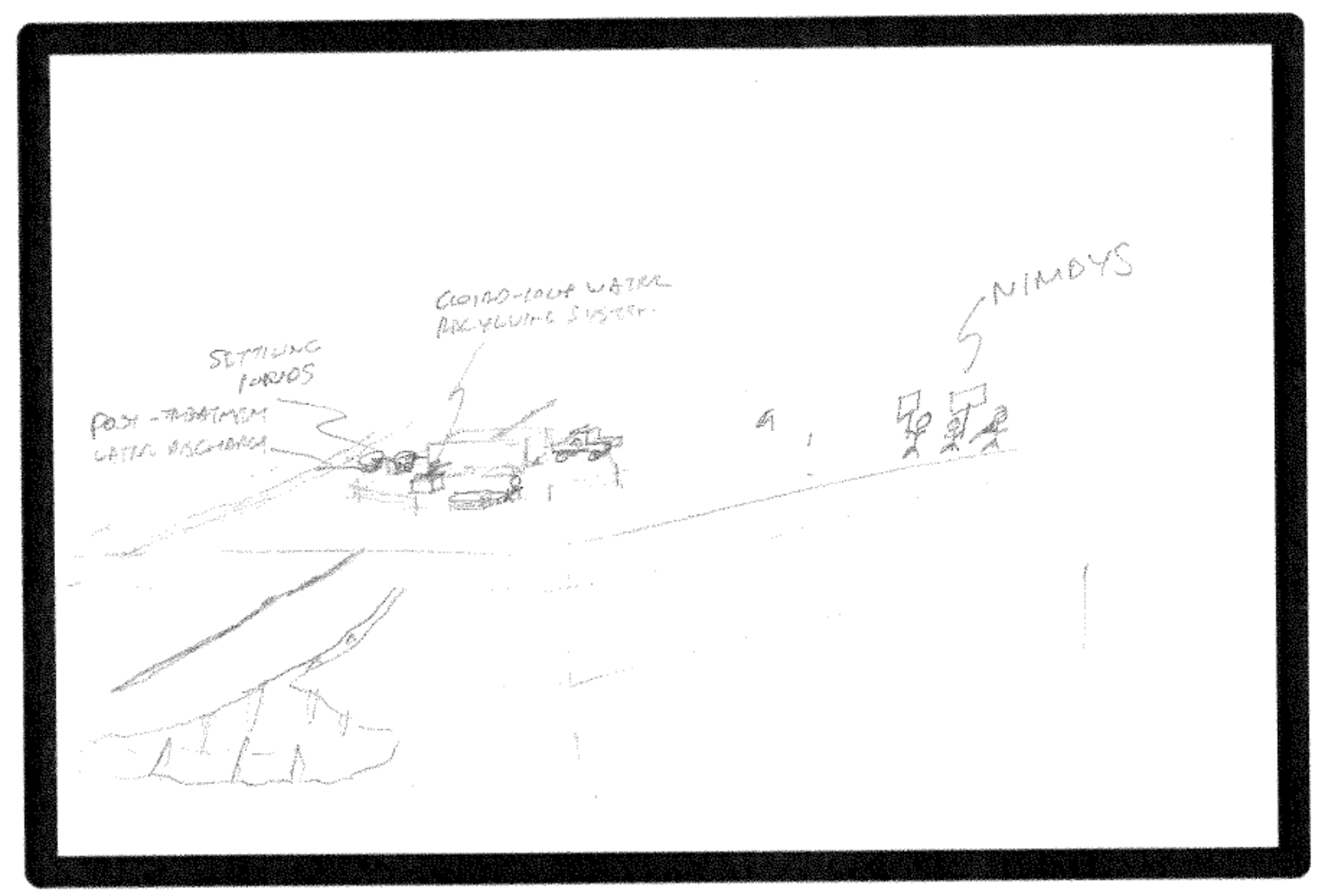


PLEASE STAY INSIDE THE BOX!

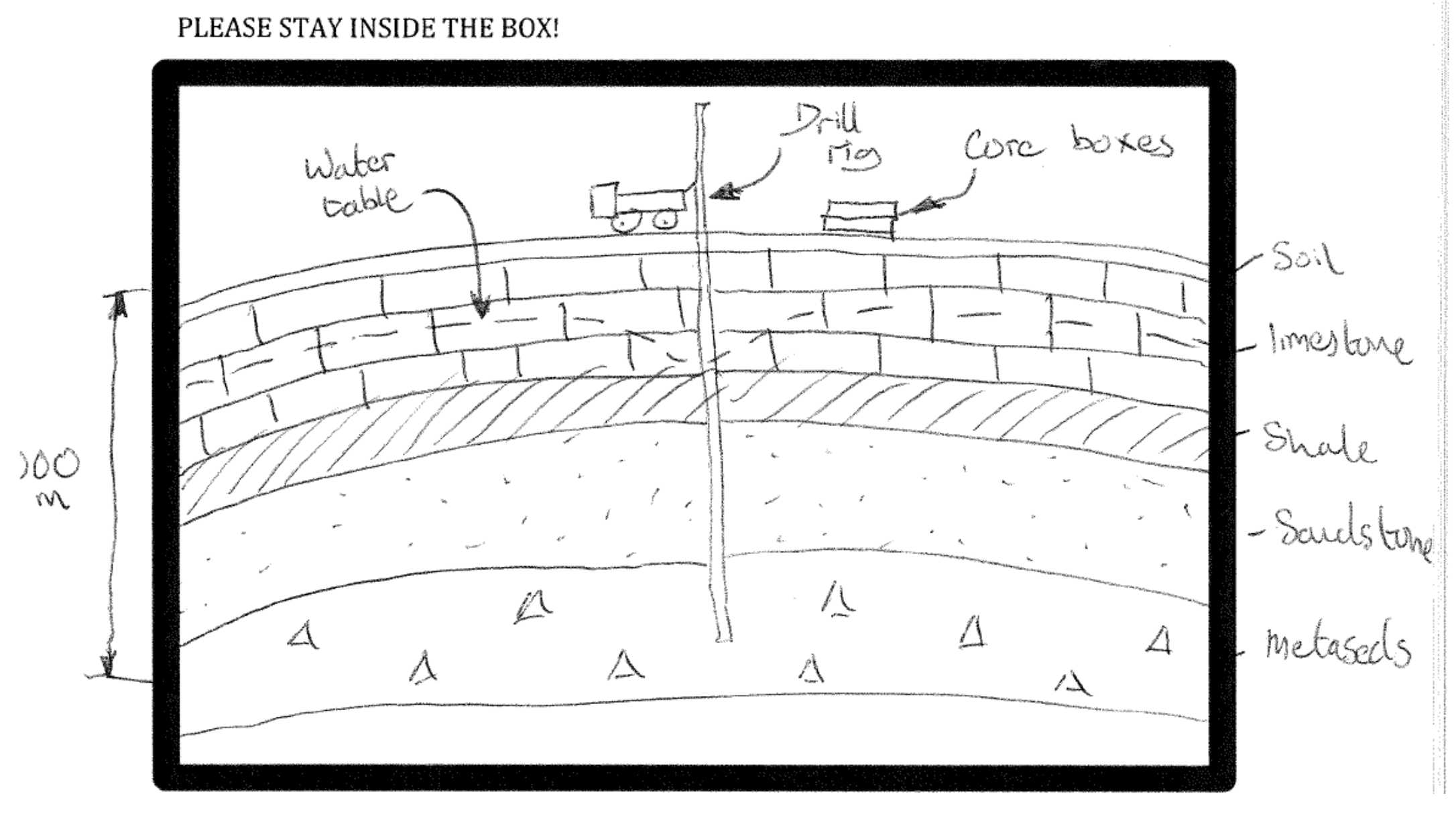


PLEASE STAY INSIDE THE BOX!

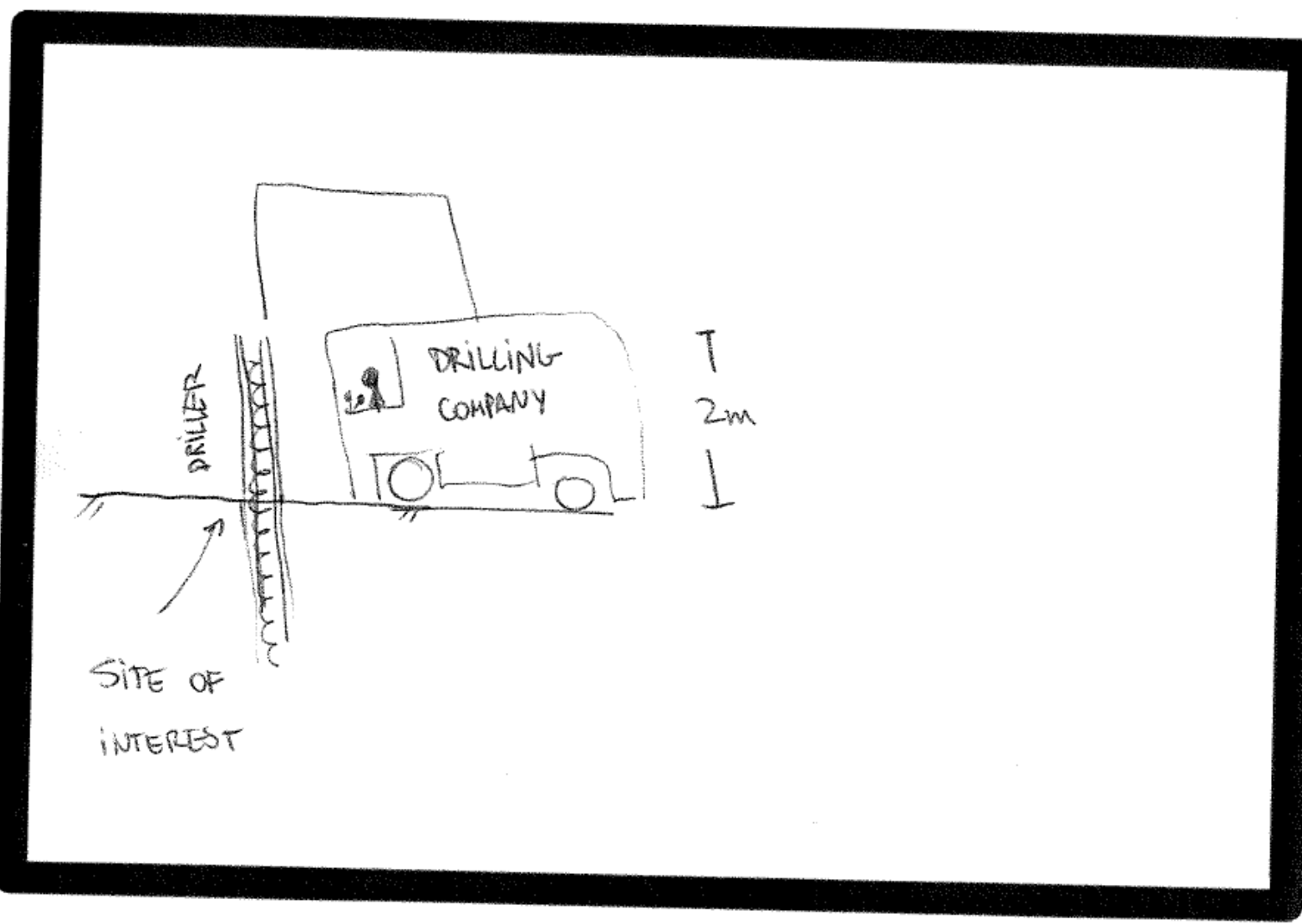


PLEASE STAY INSIDE THE BOX!

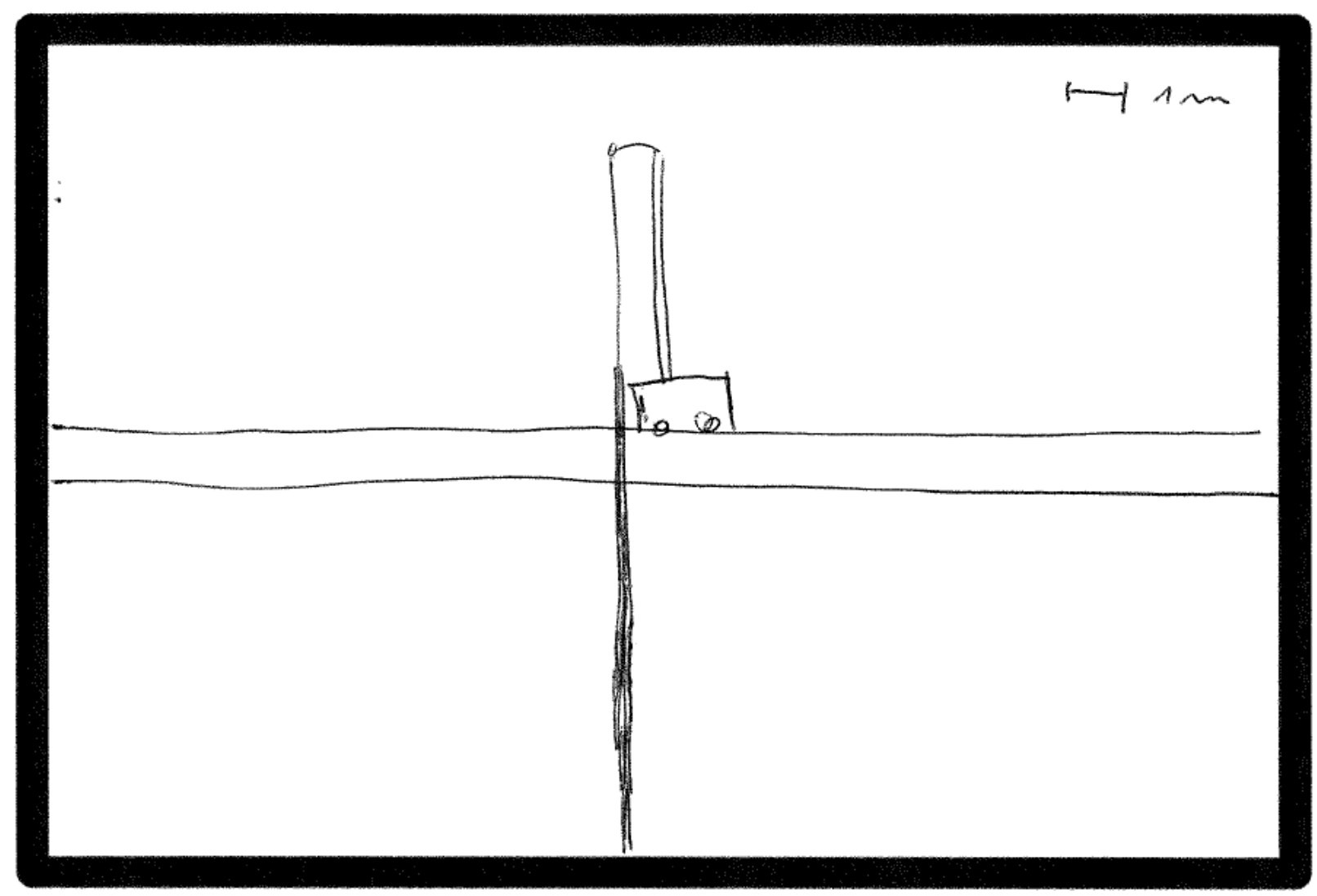


PLEASE STAY INSIDE THE BOX!

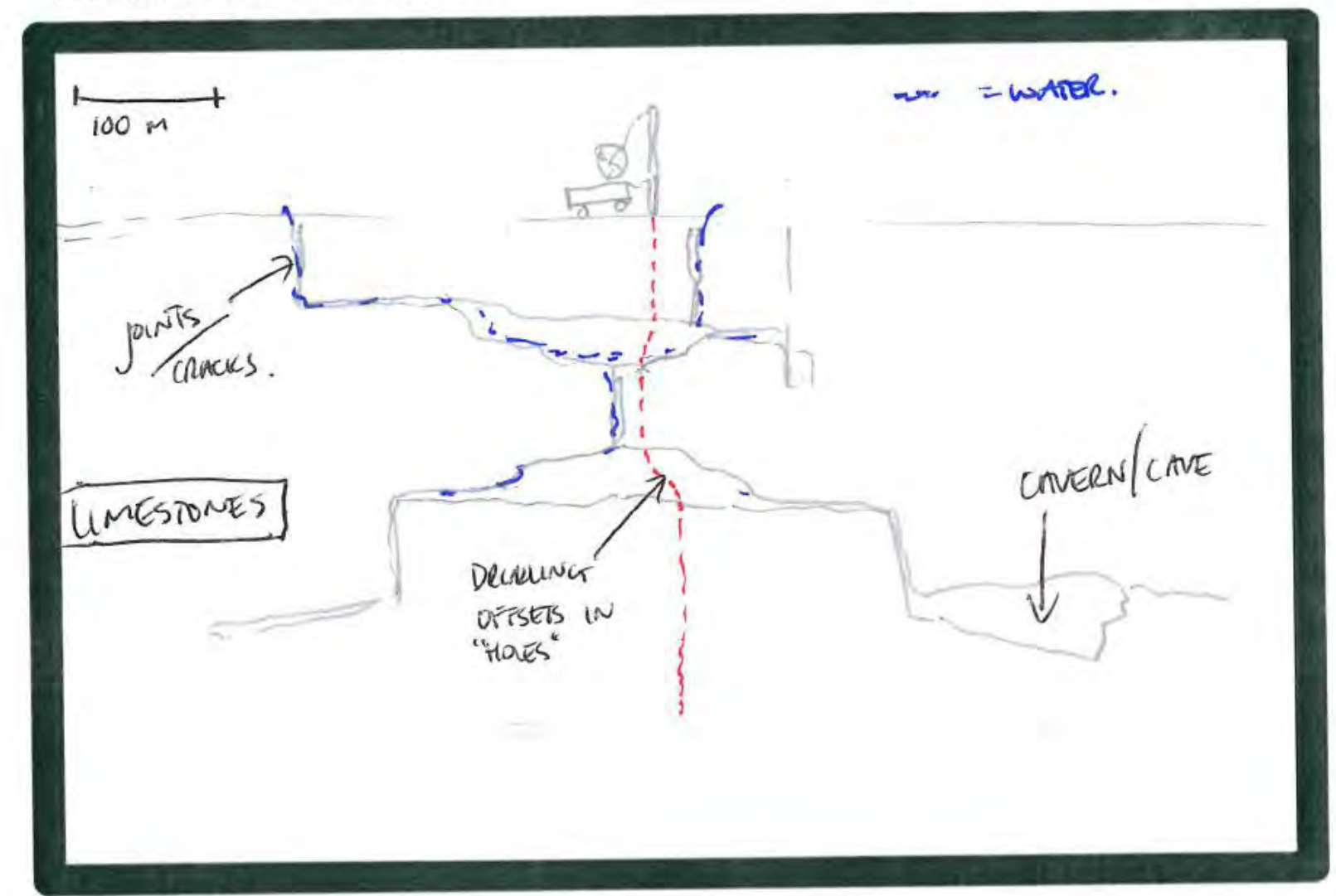




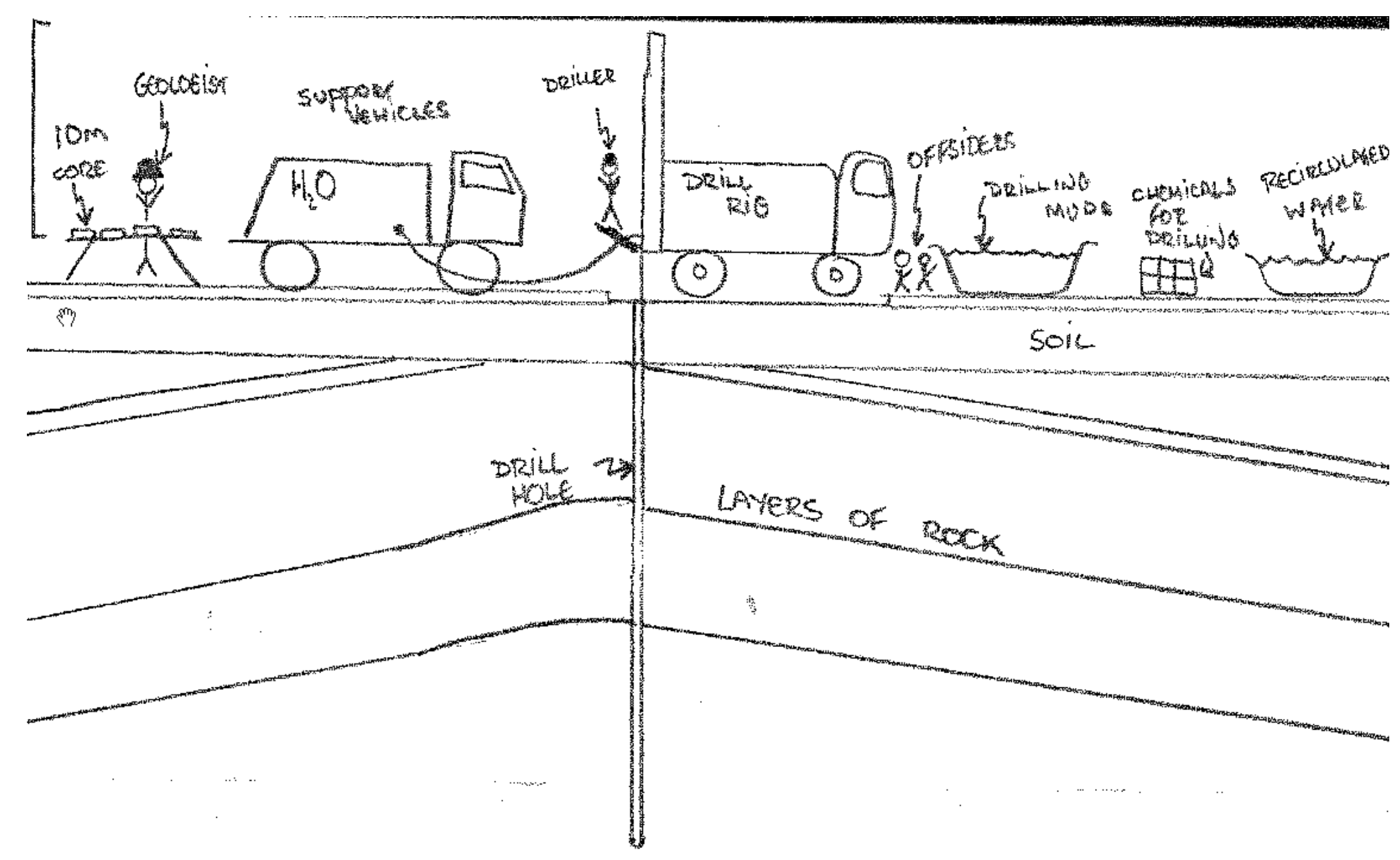

Expert 


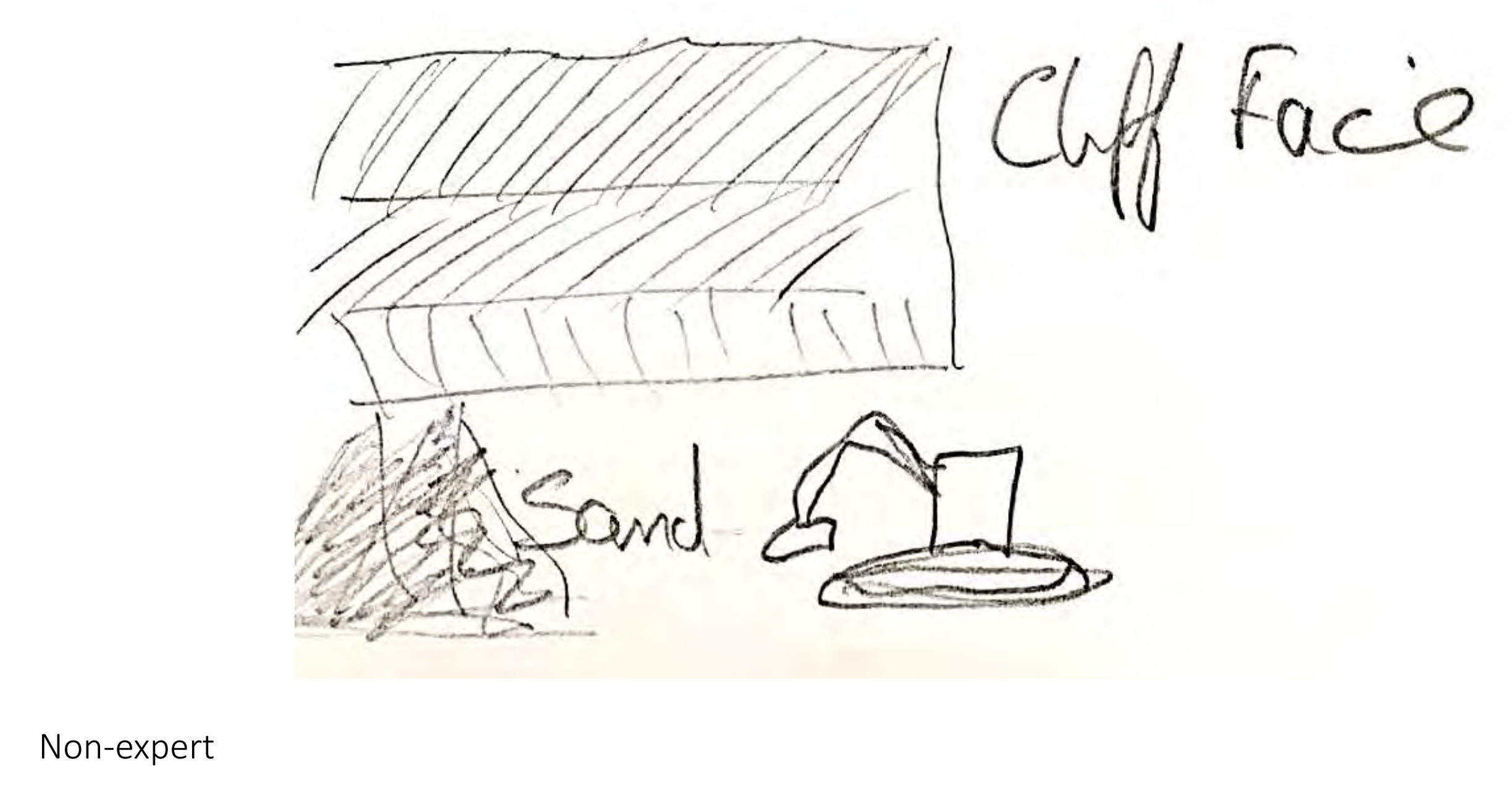




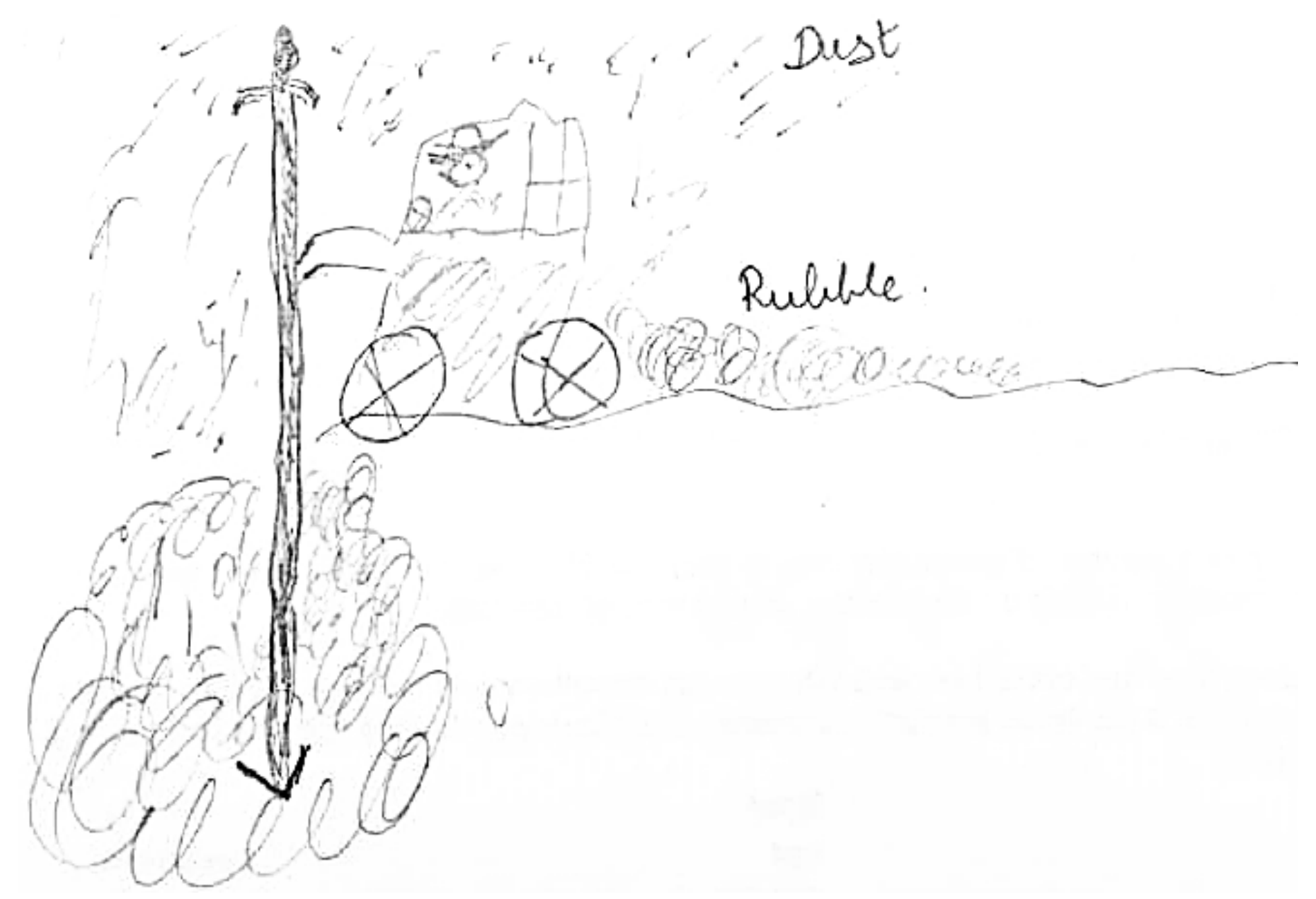

Non-expert 
<smiles>Cc1cc(C)c(C)c(C)c1C</smiles> 


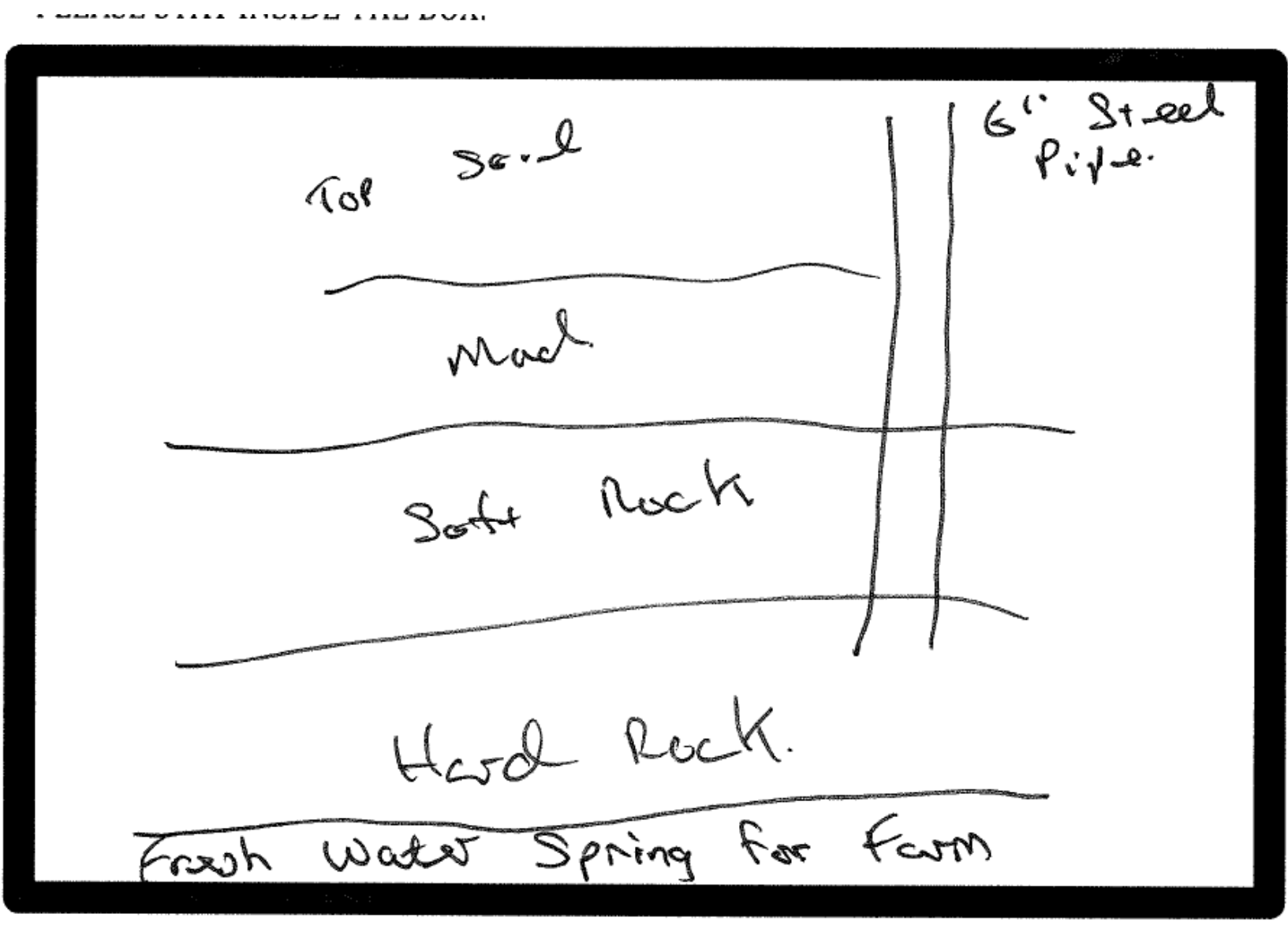




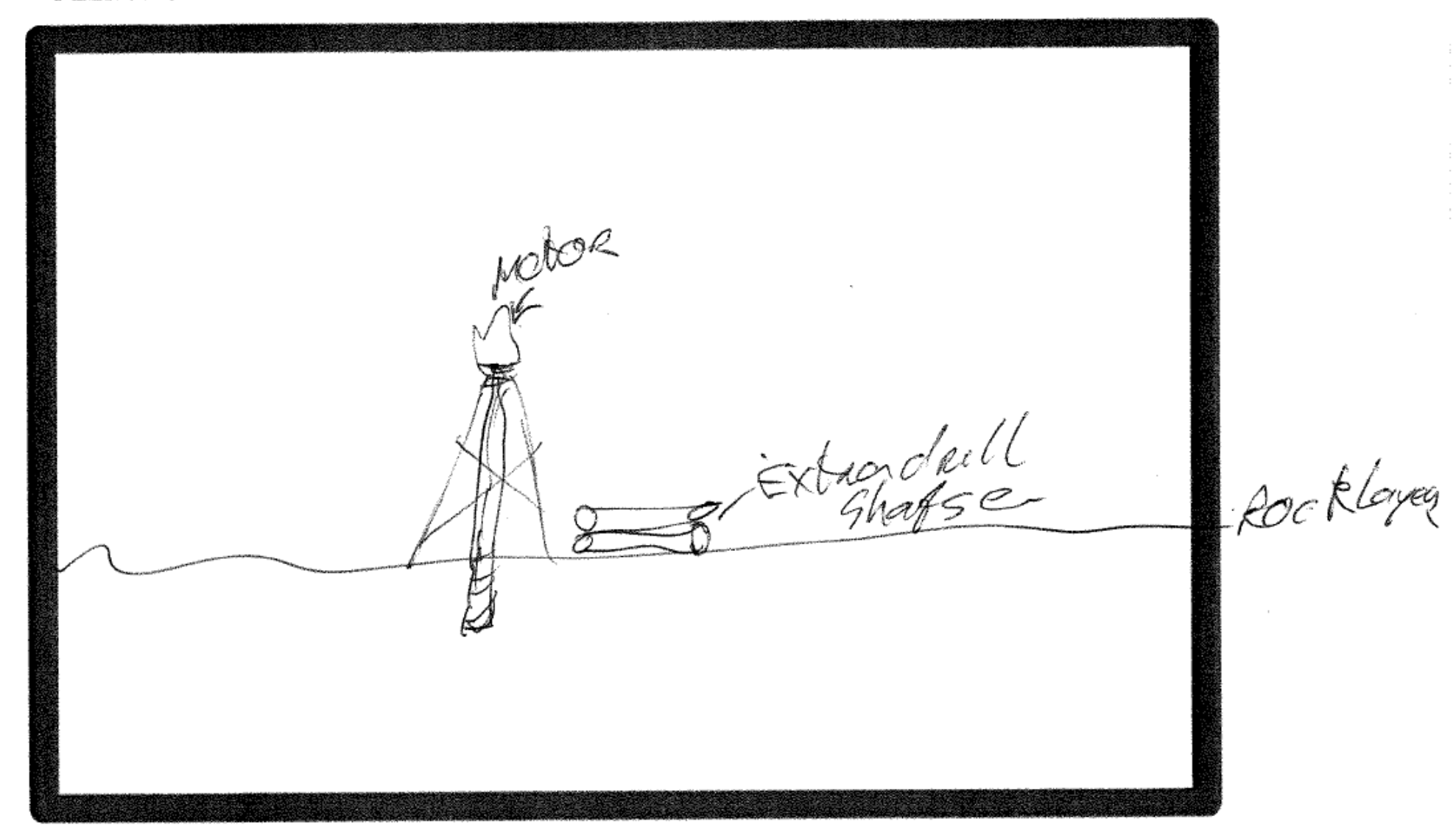


PLEASE STAY INSIDE THE BOX!

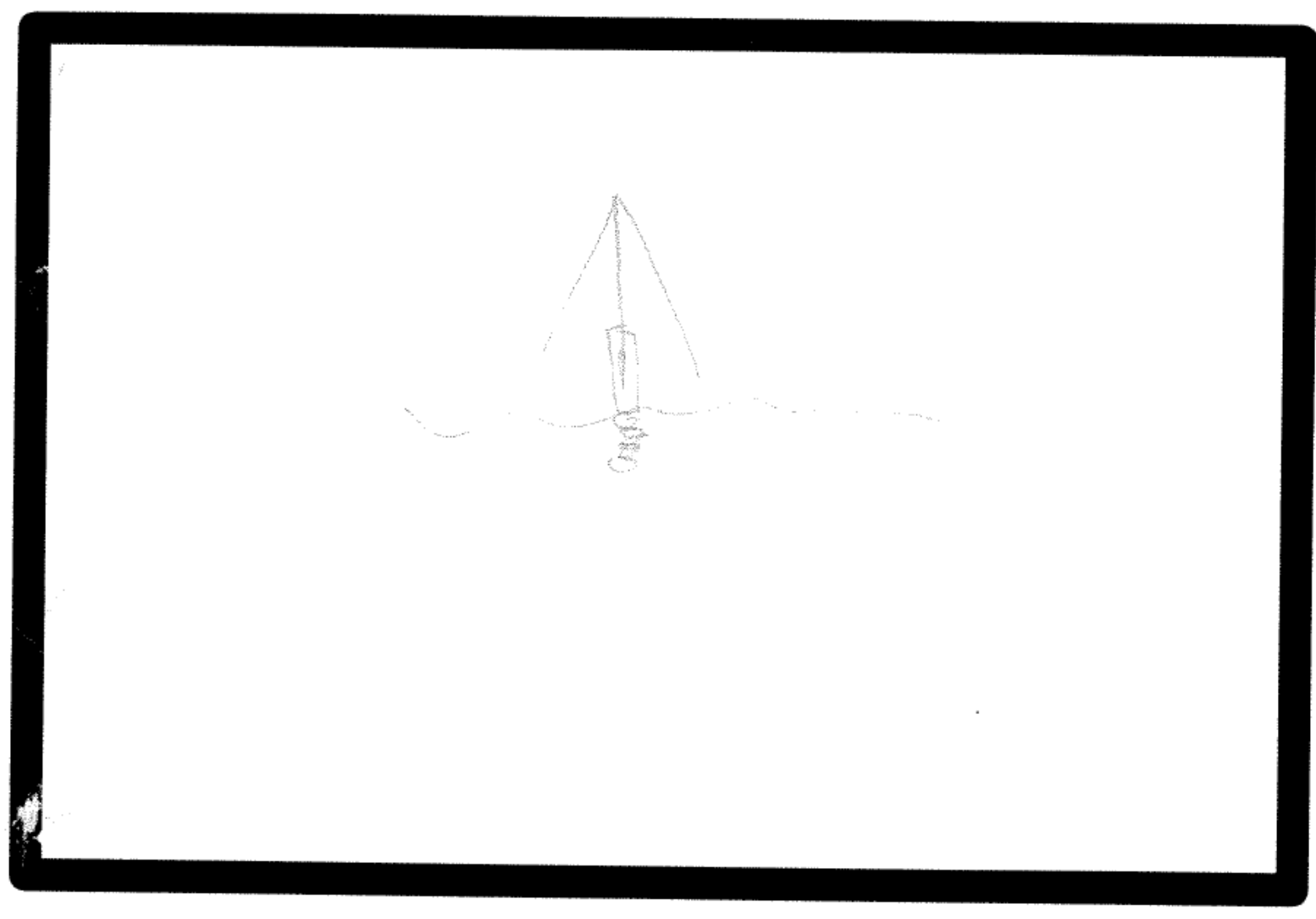


PLEASE STAY INSIDE THE BOX!

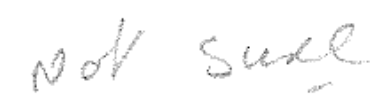


PLEASE STAY INSIDE THE BOX!

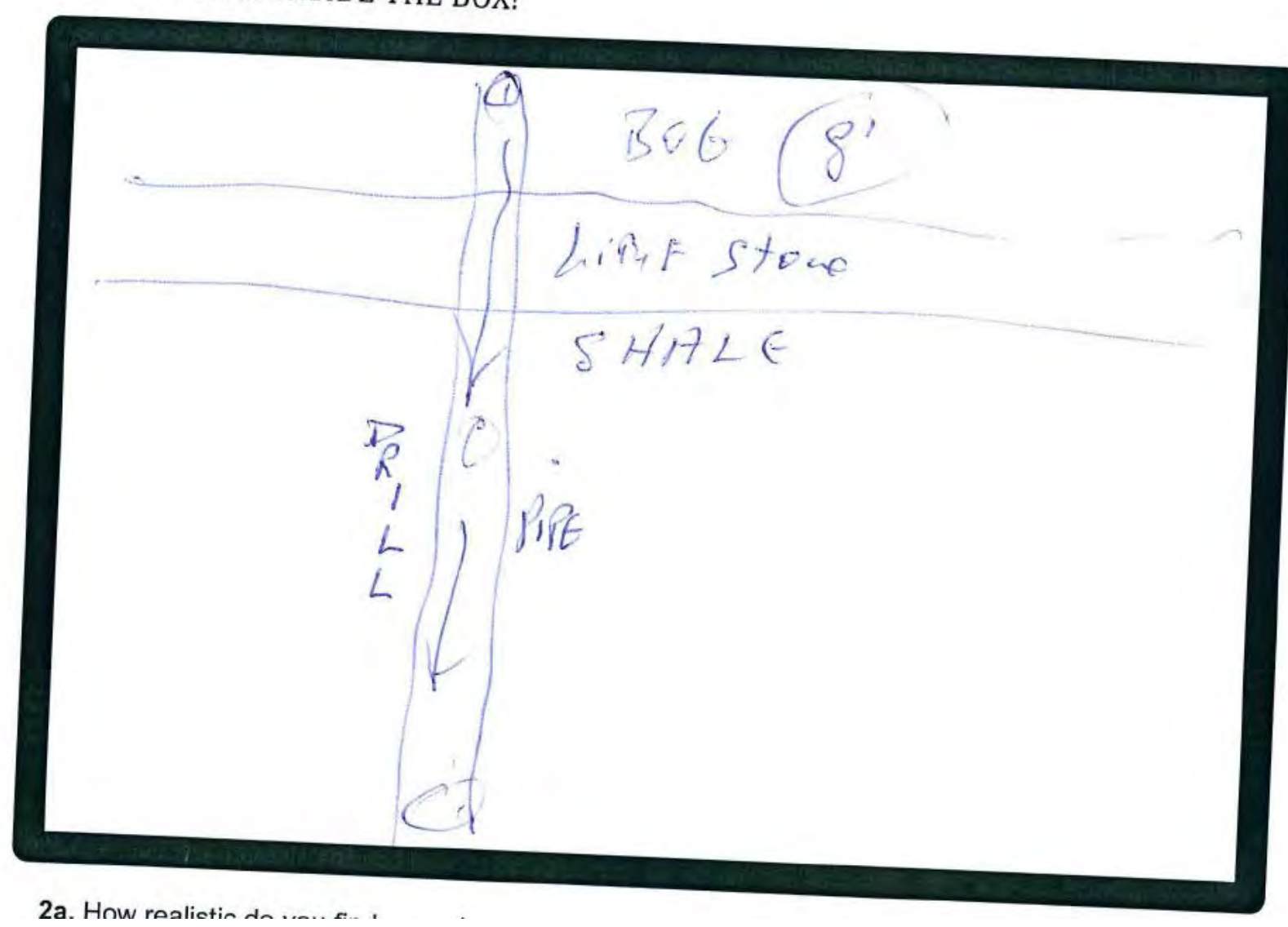


PLEASE STAY INSIDE THE BOX!

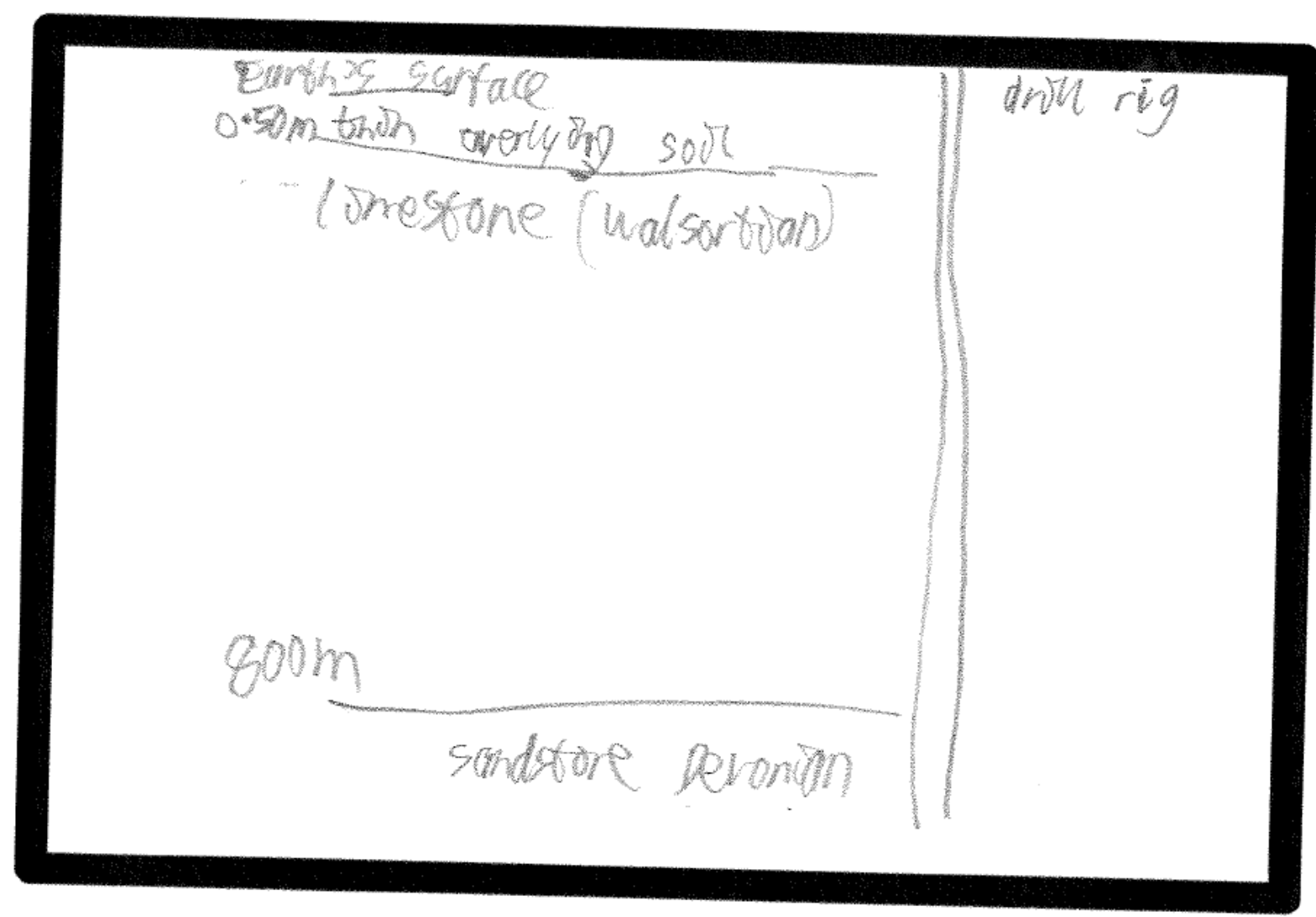


PLEASE STAY INSIDE THE BOX! DQI UL

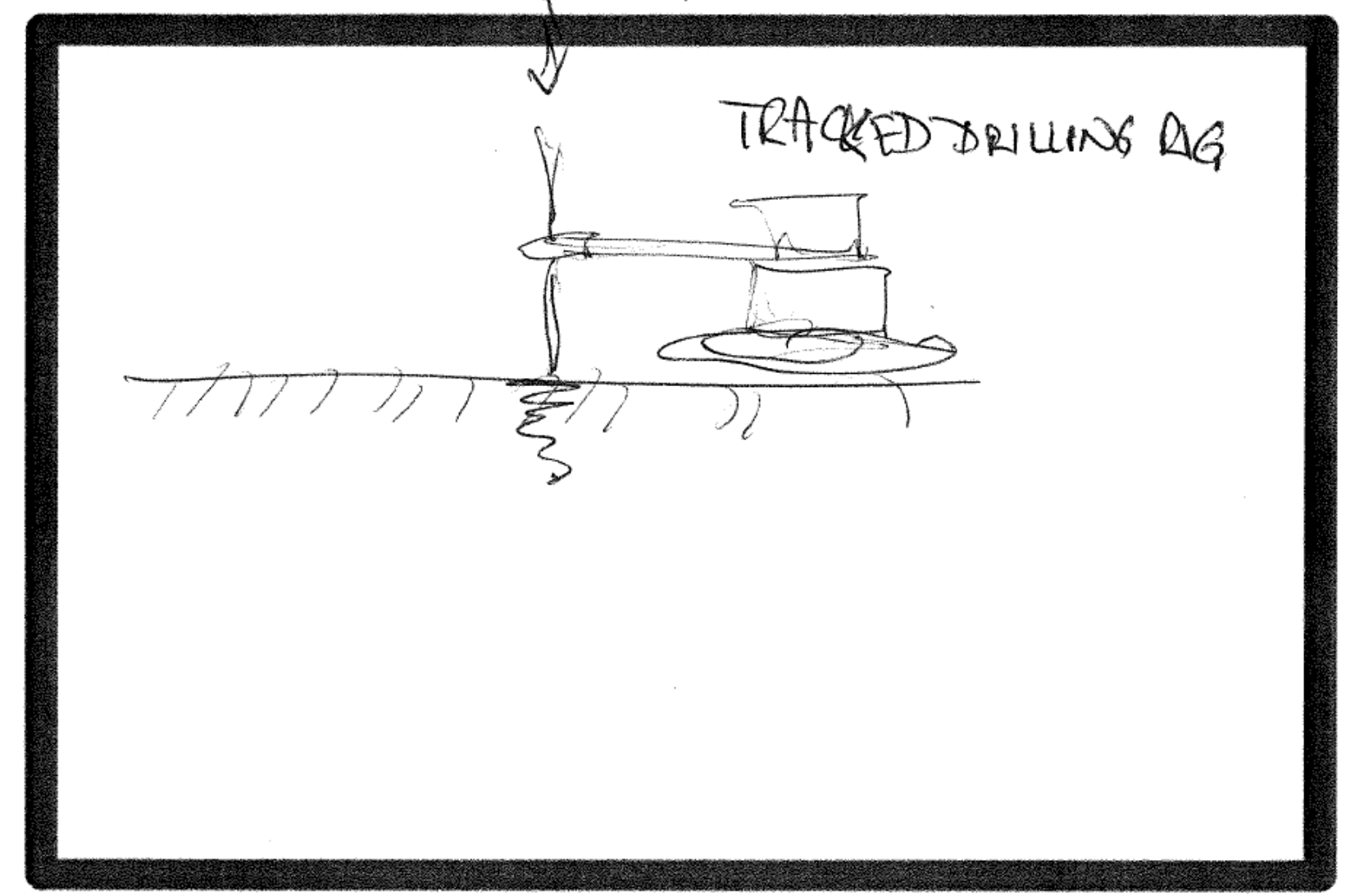




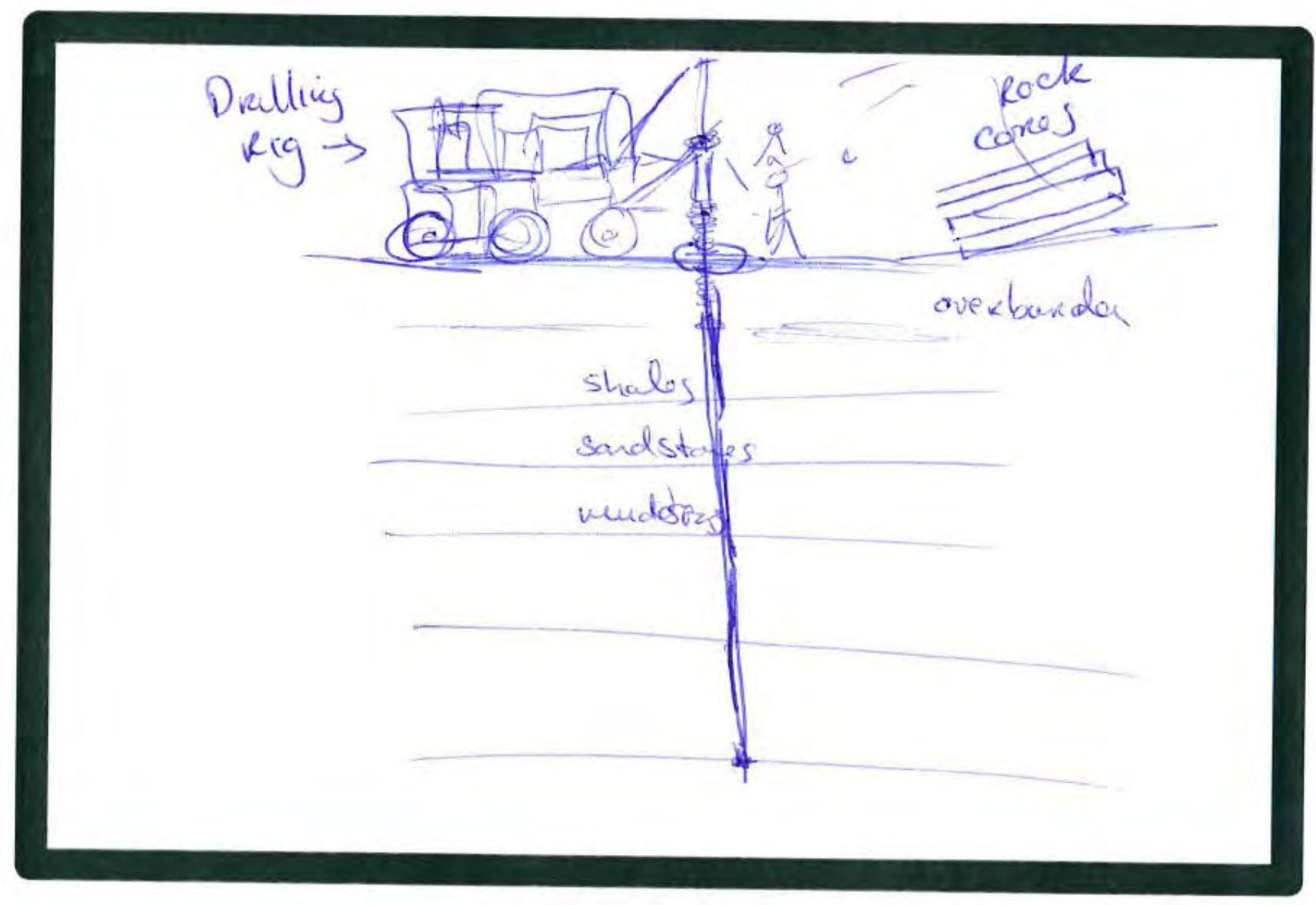




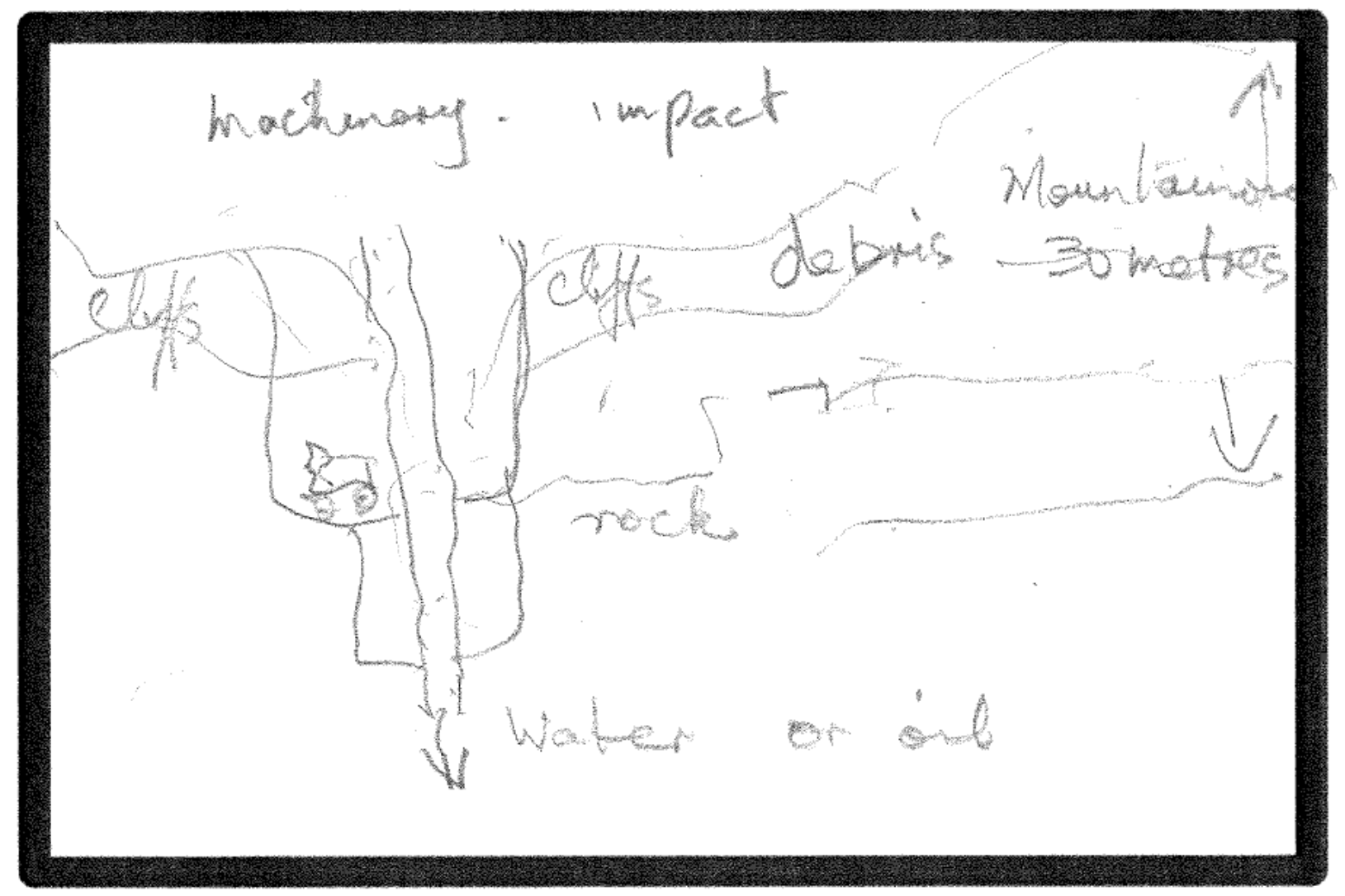




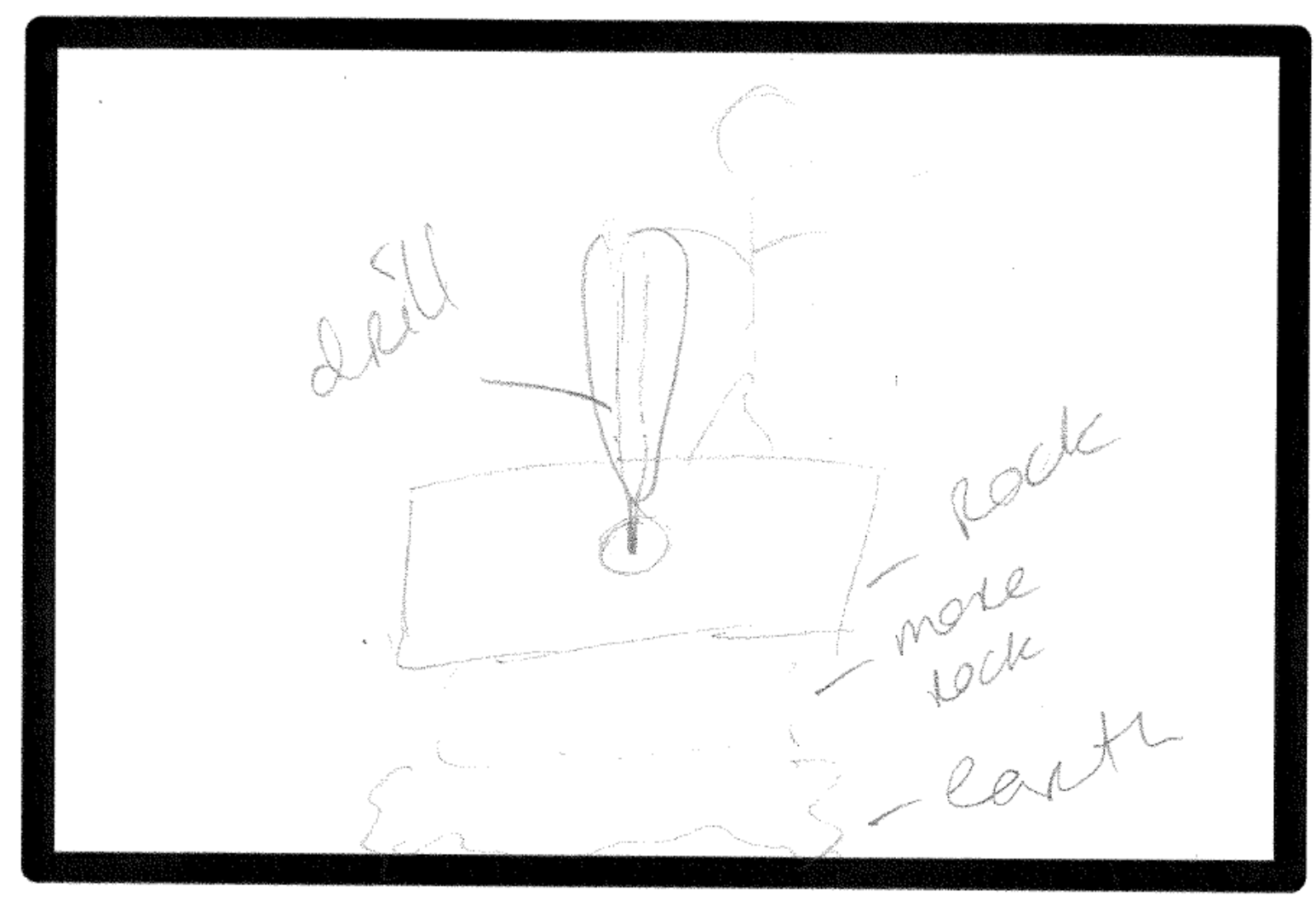




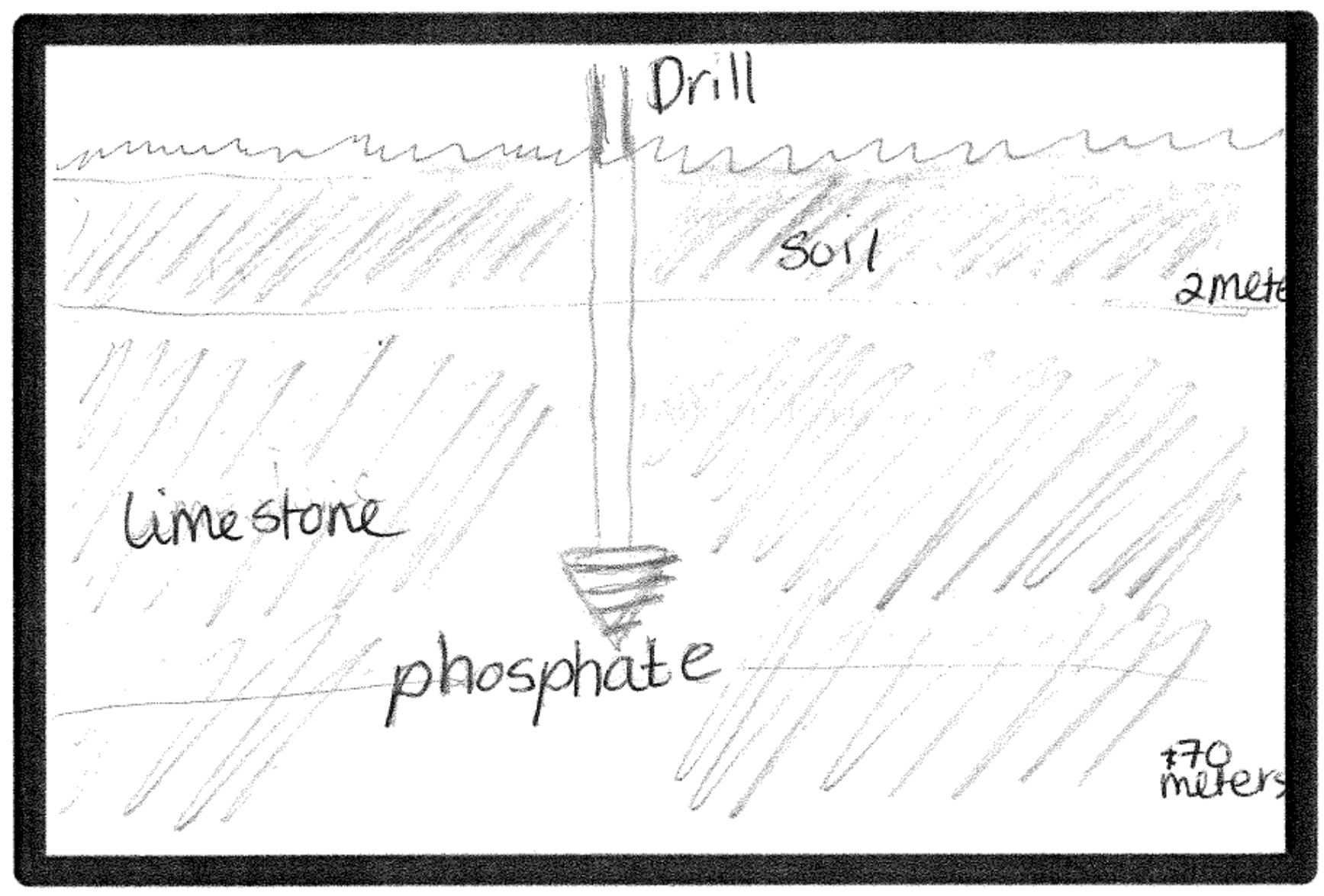


PLEASE STAY INSIDE THE BOX!

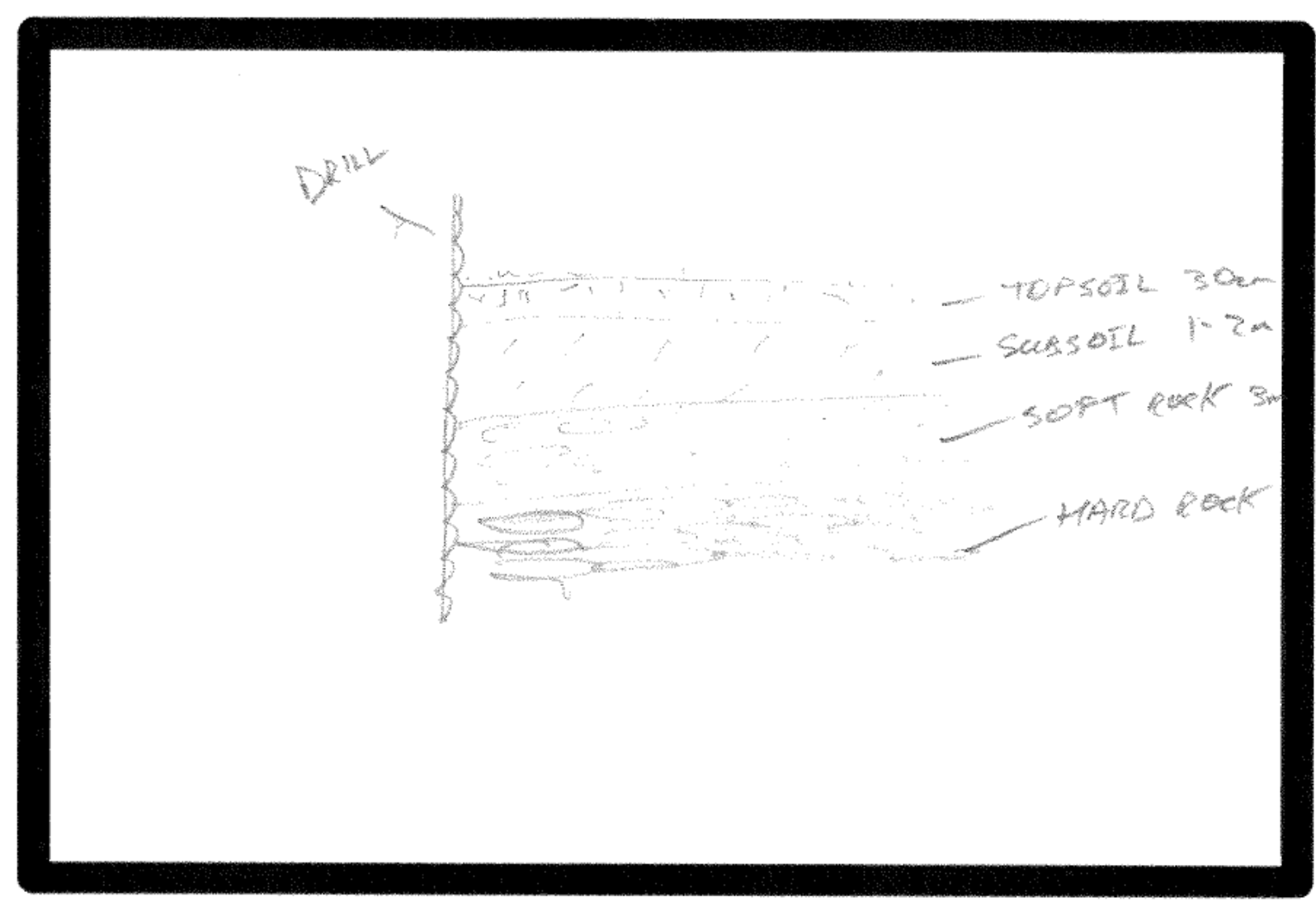




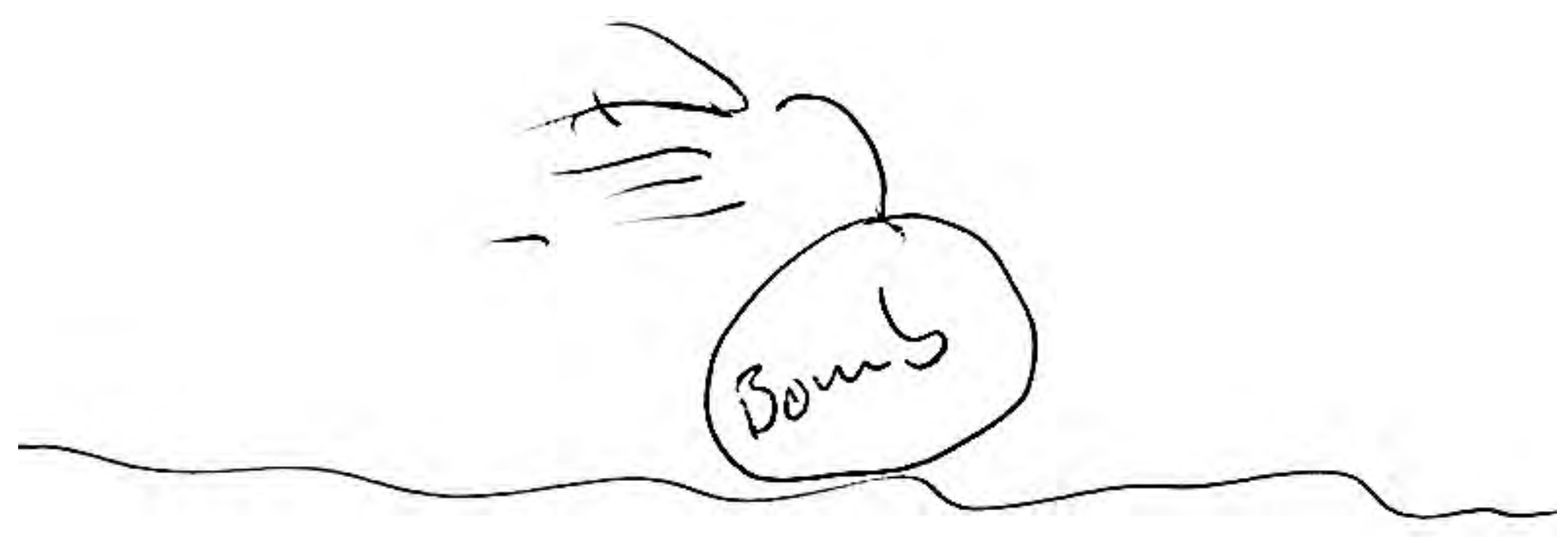

Non-expert 


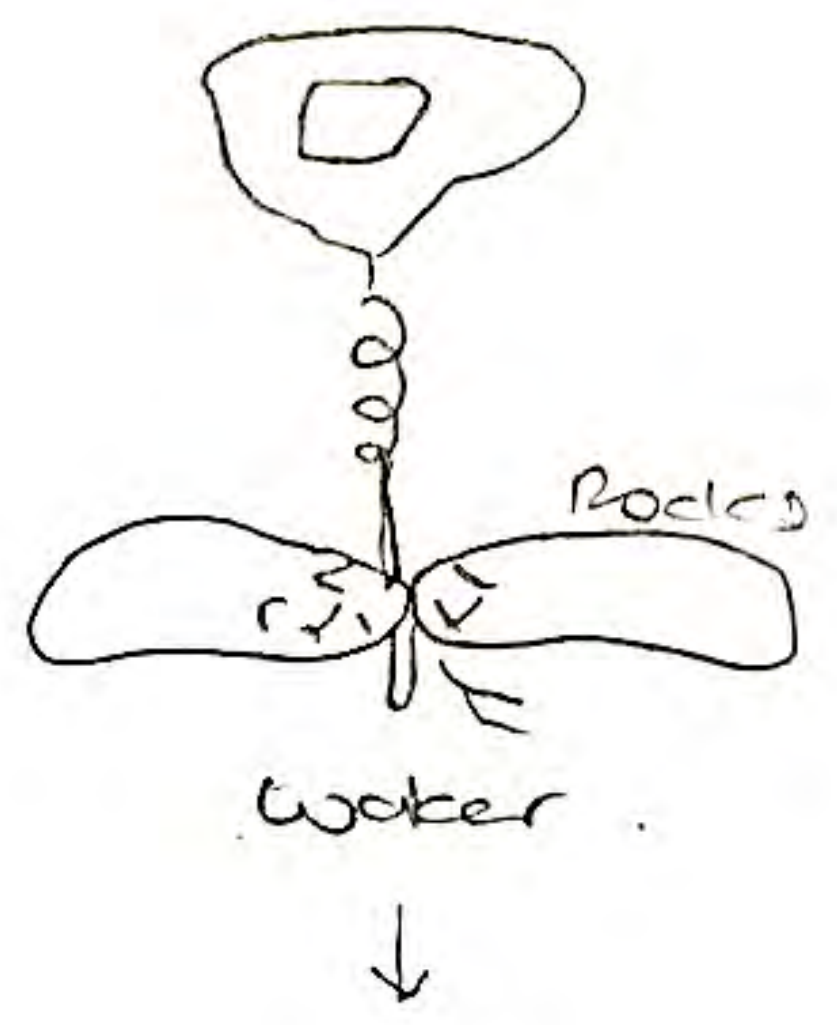

Non-expert 


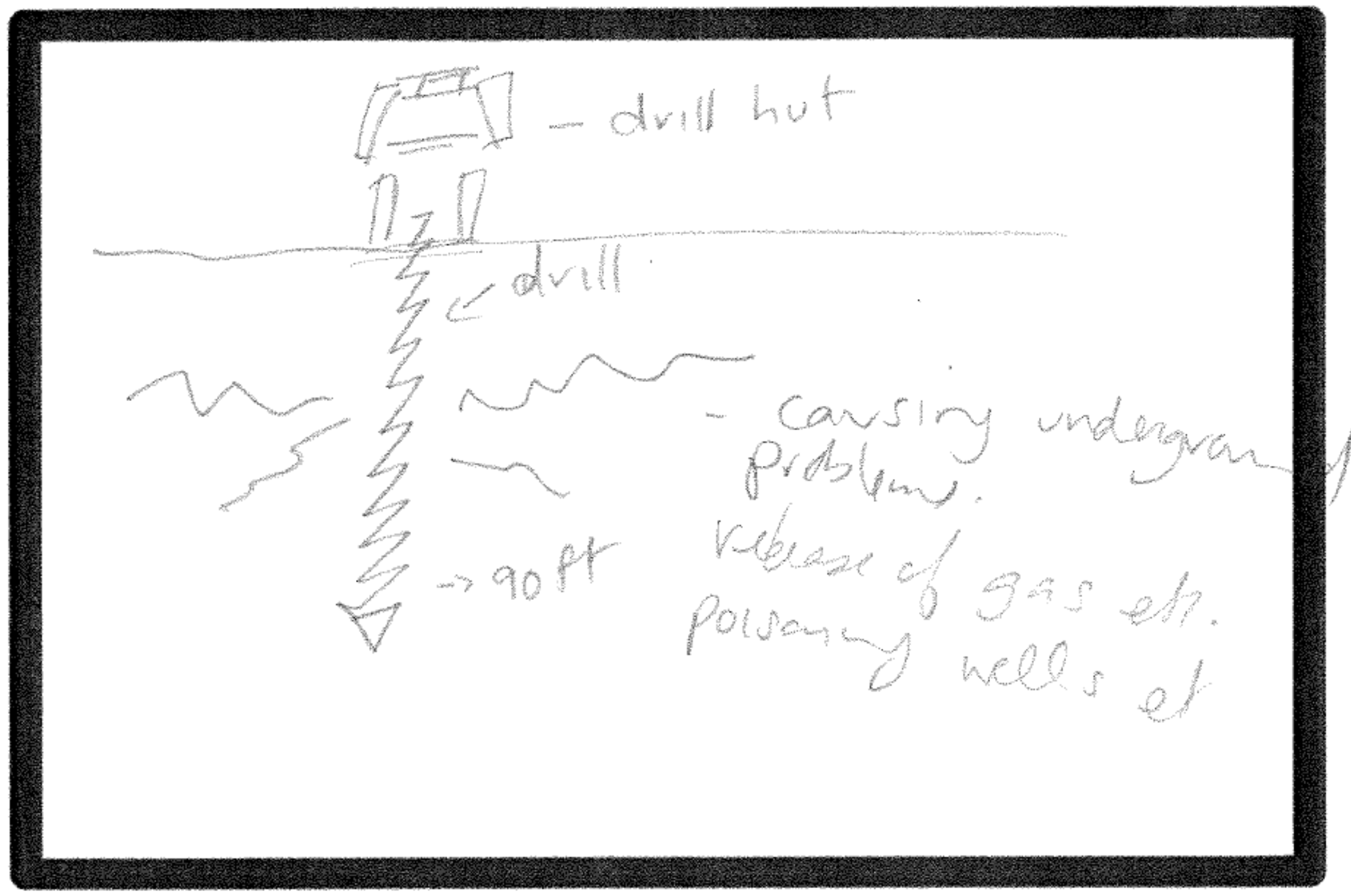


PLEASE STAY INSIDE THE BOX!

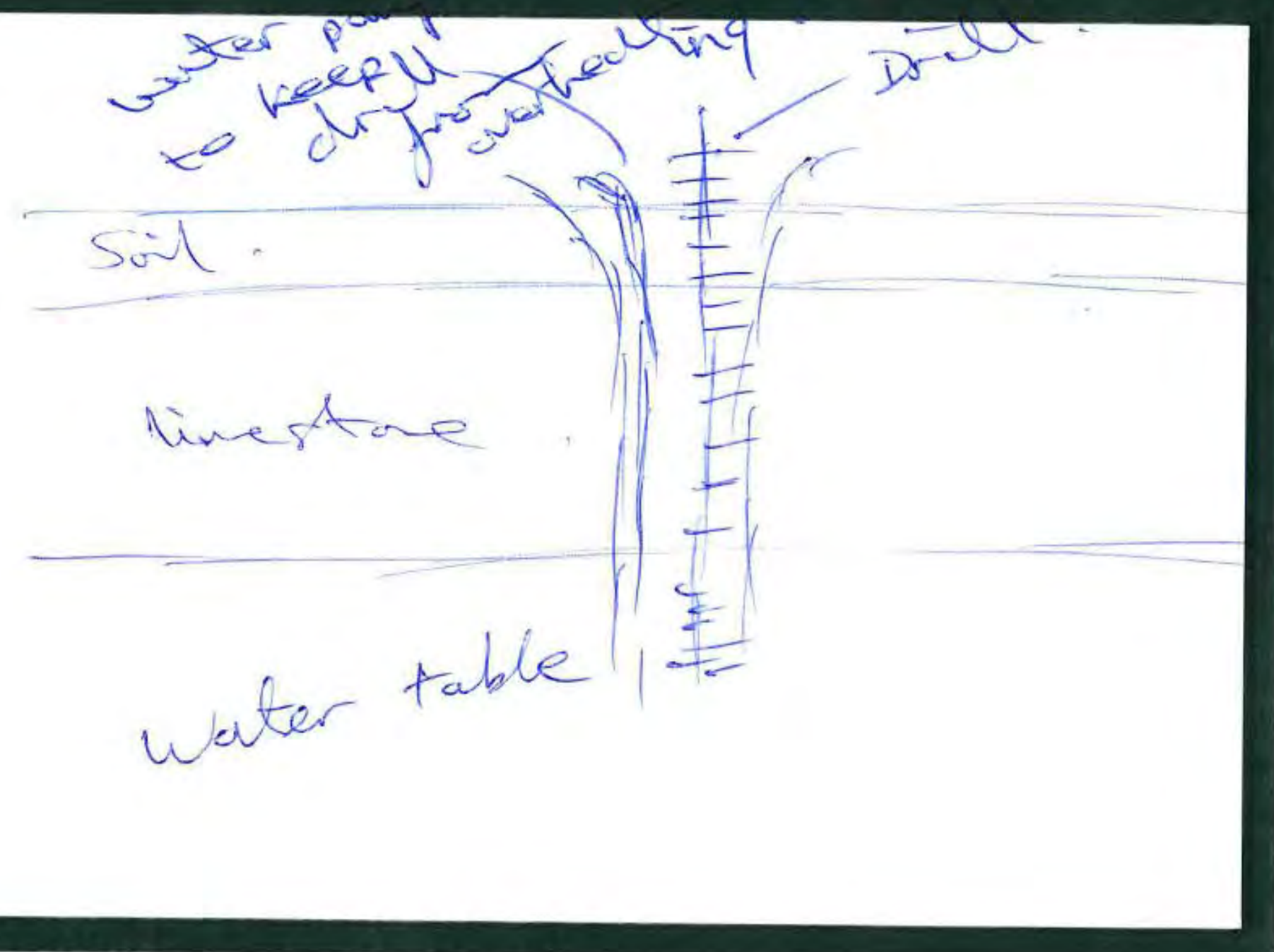


PLEASE STAY INSIDE THE BOX!

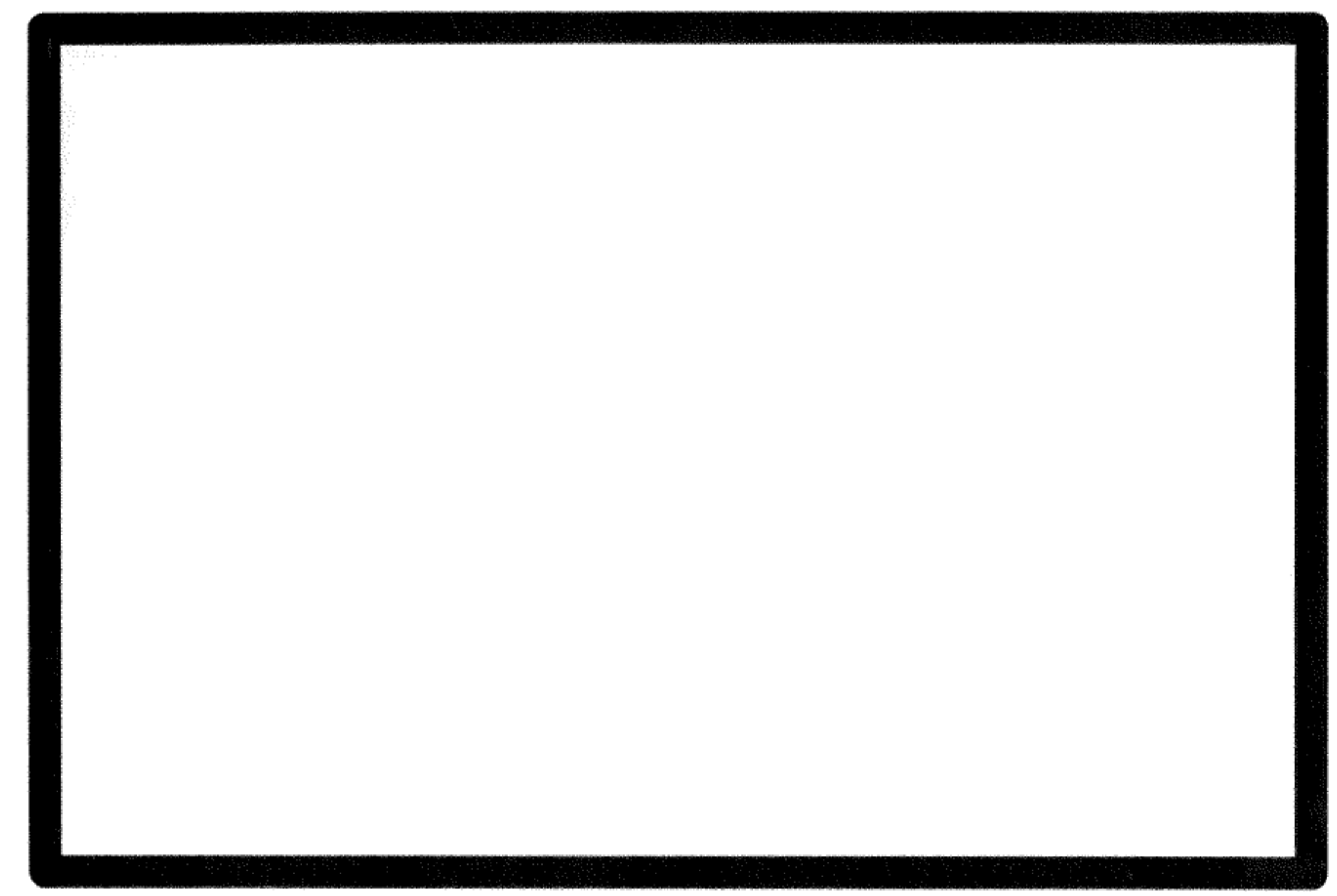


PLEASE STAY INSIDE THE BOX!

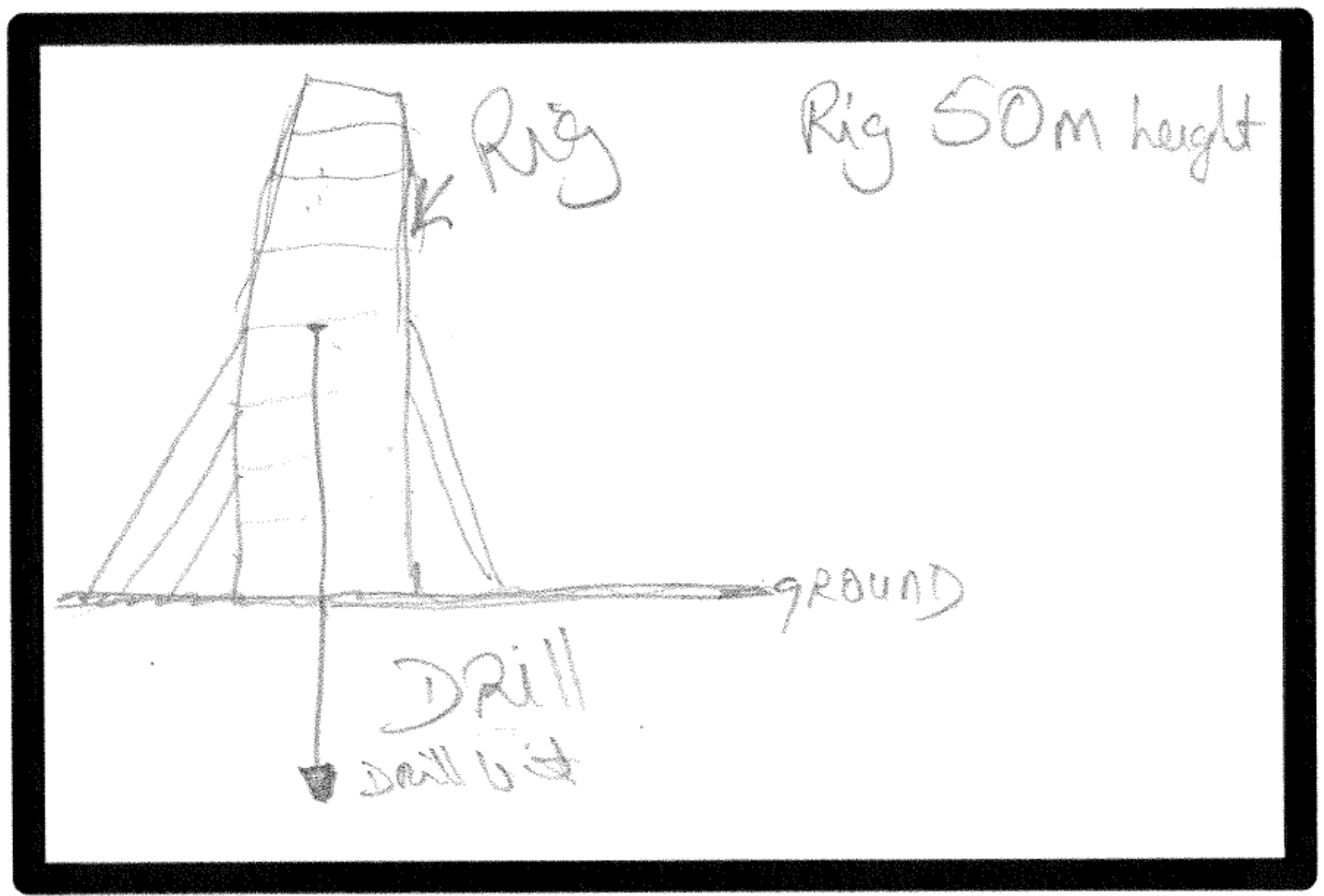




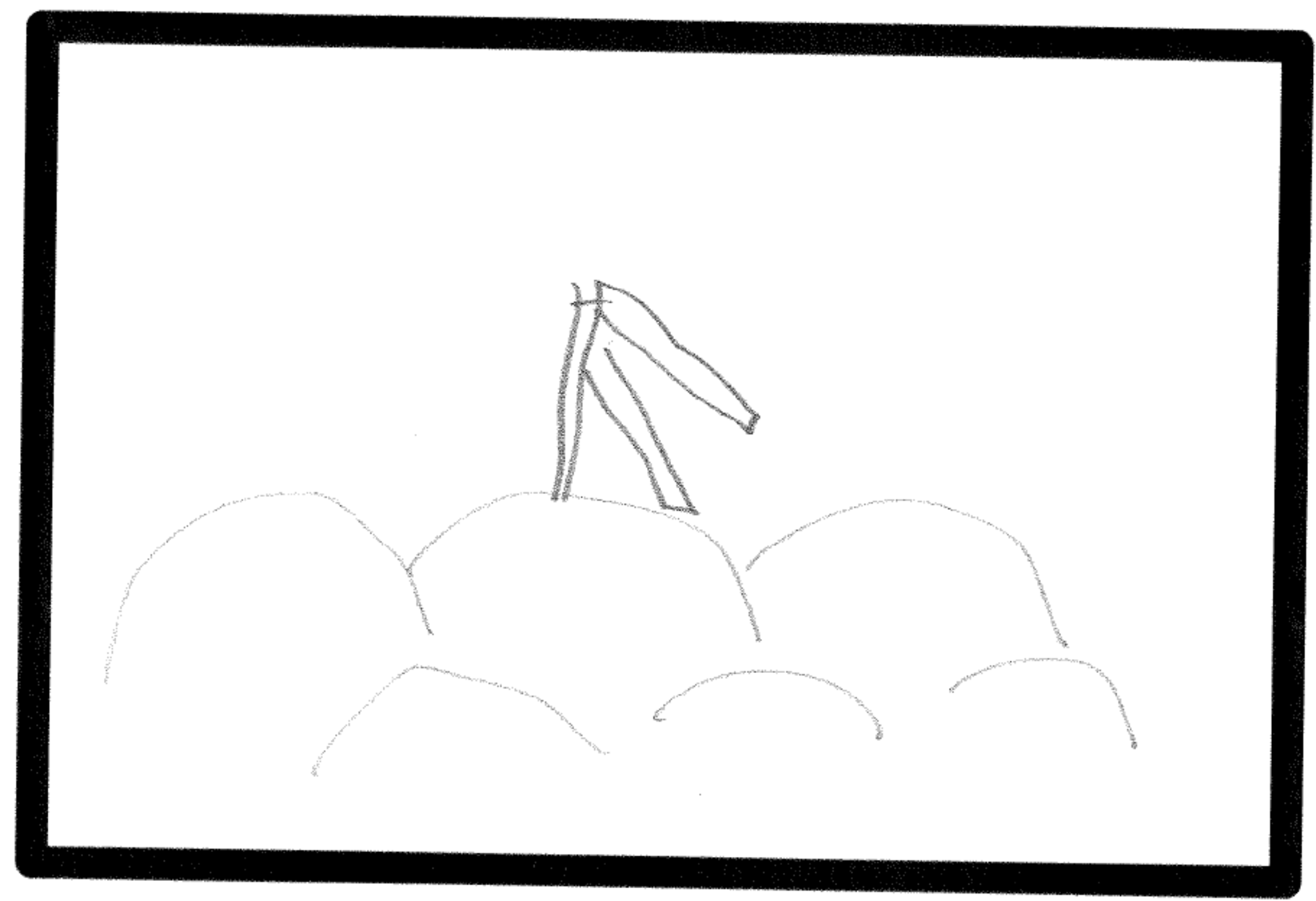

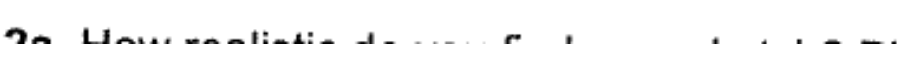




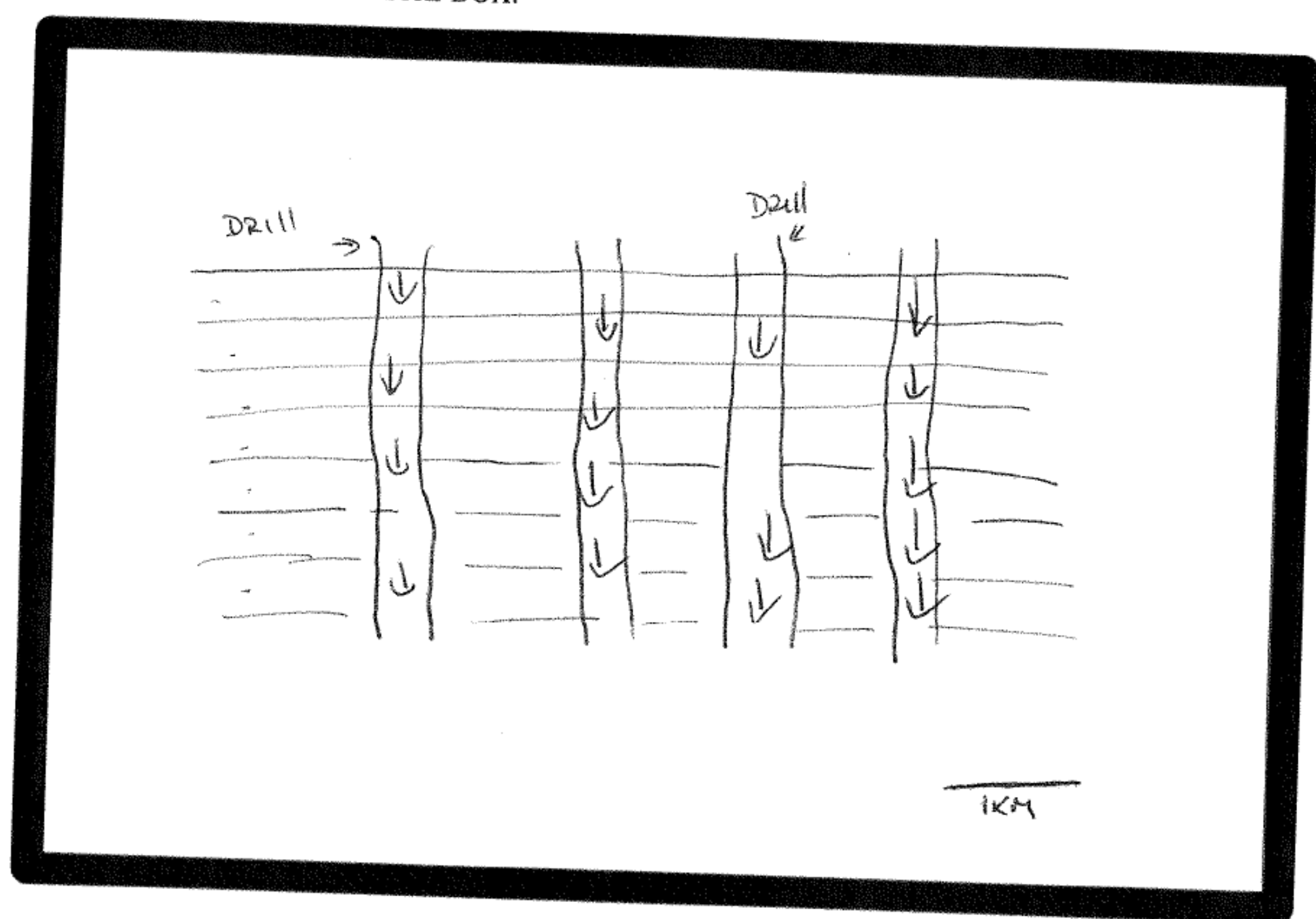

3a. How realistic dn voı find unur olentahn ni 
PLEASE STAY INSIDE THE BOX!

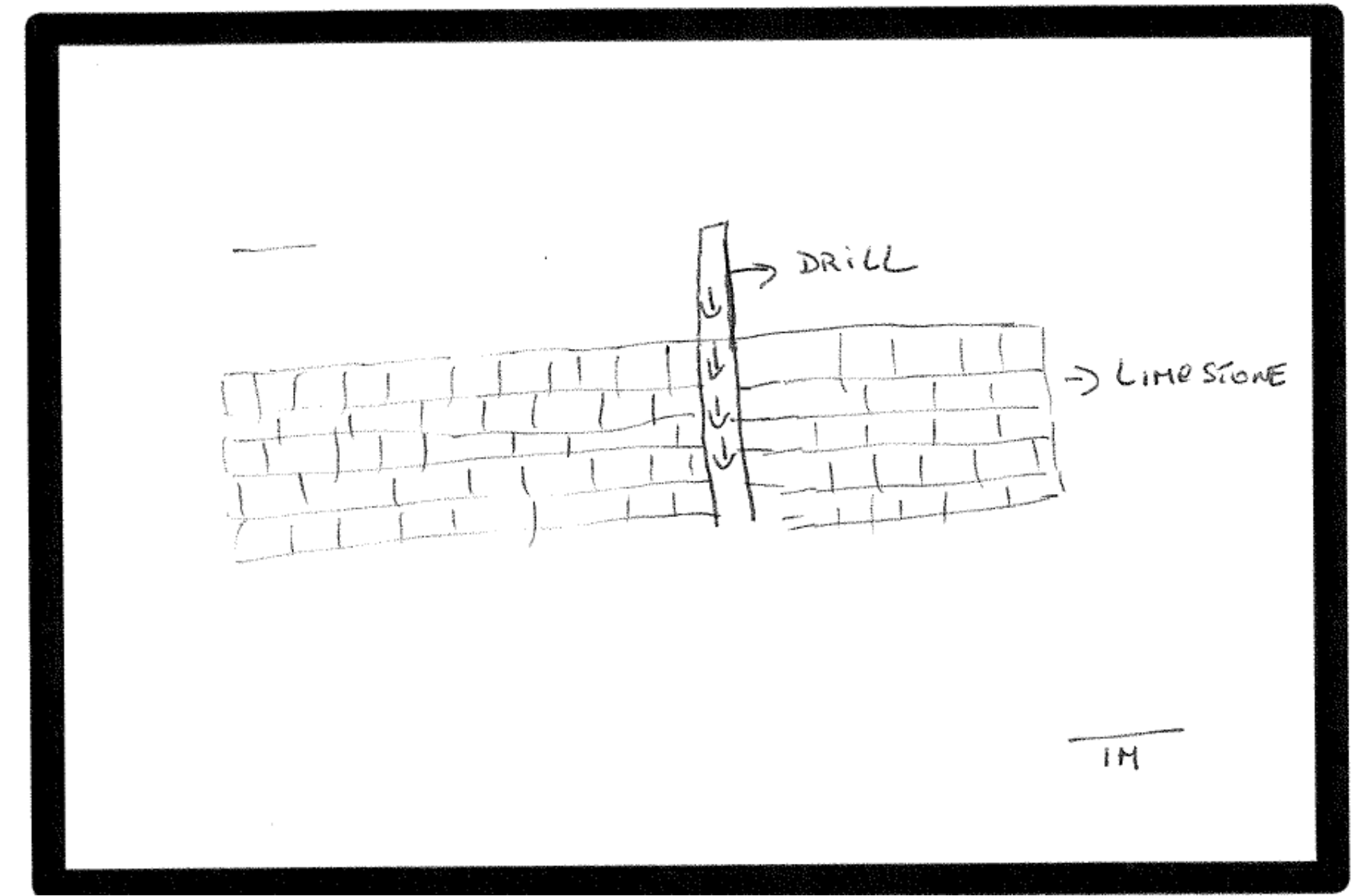




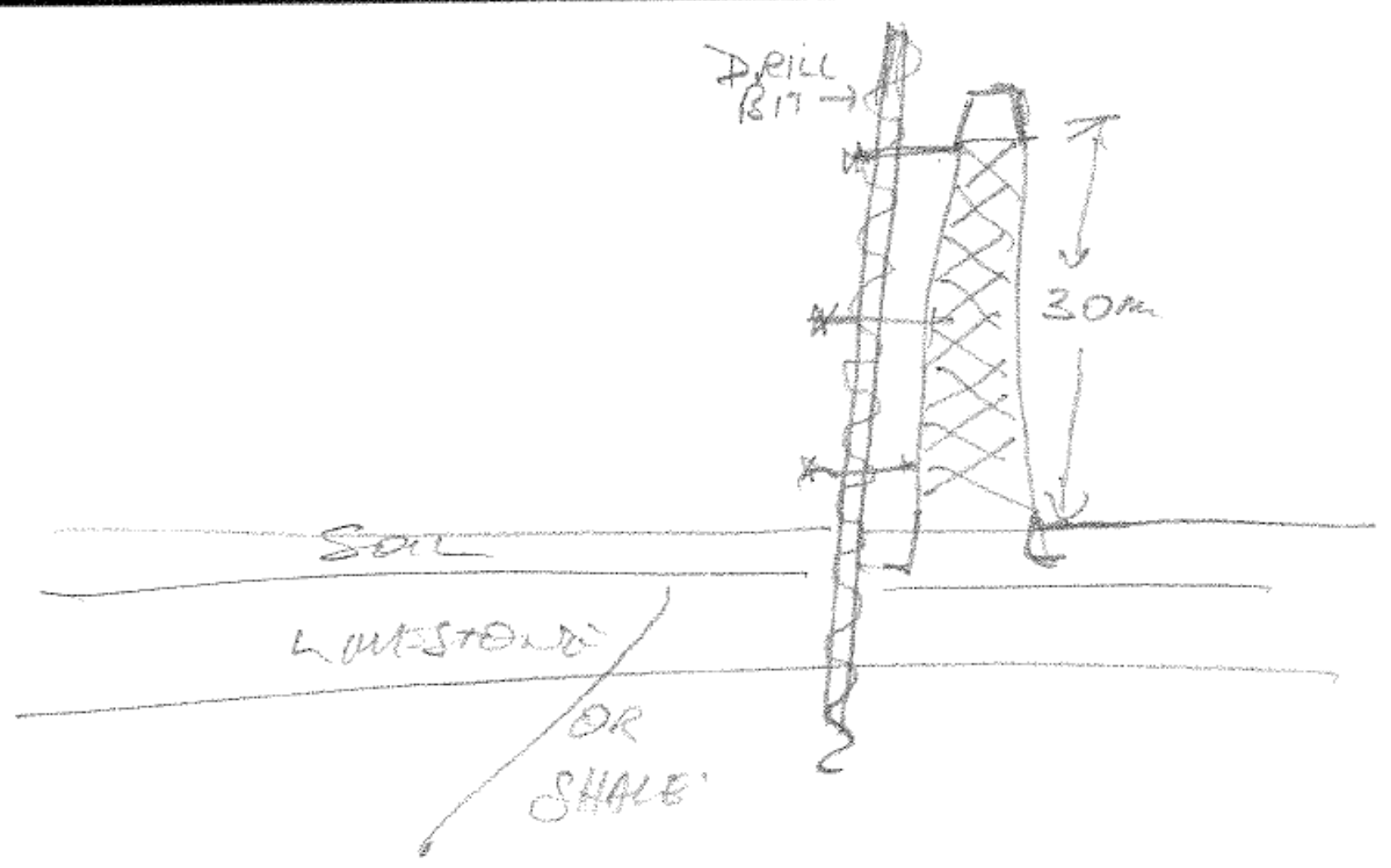

Non-expert 


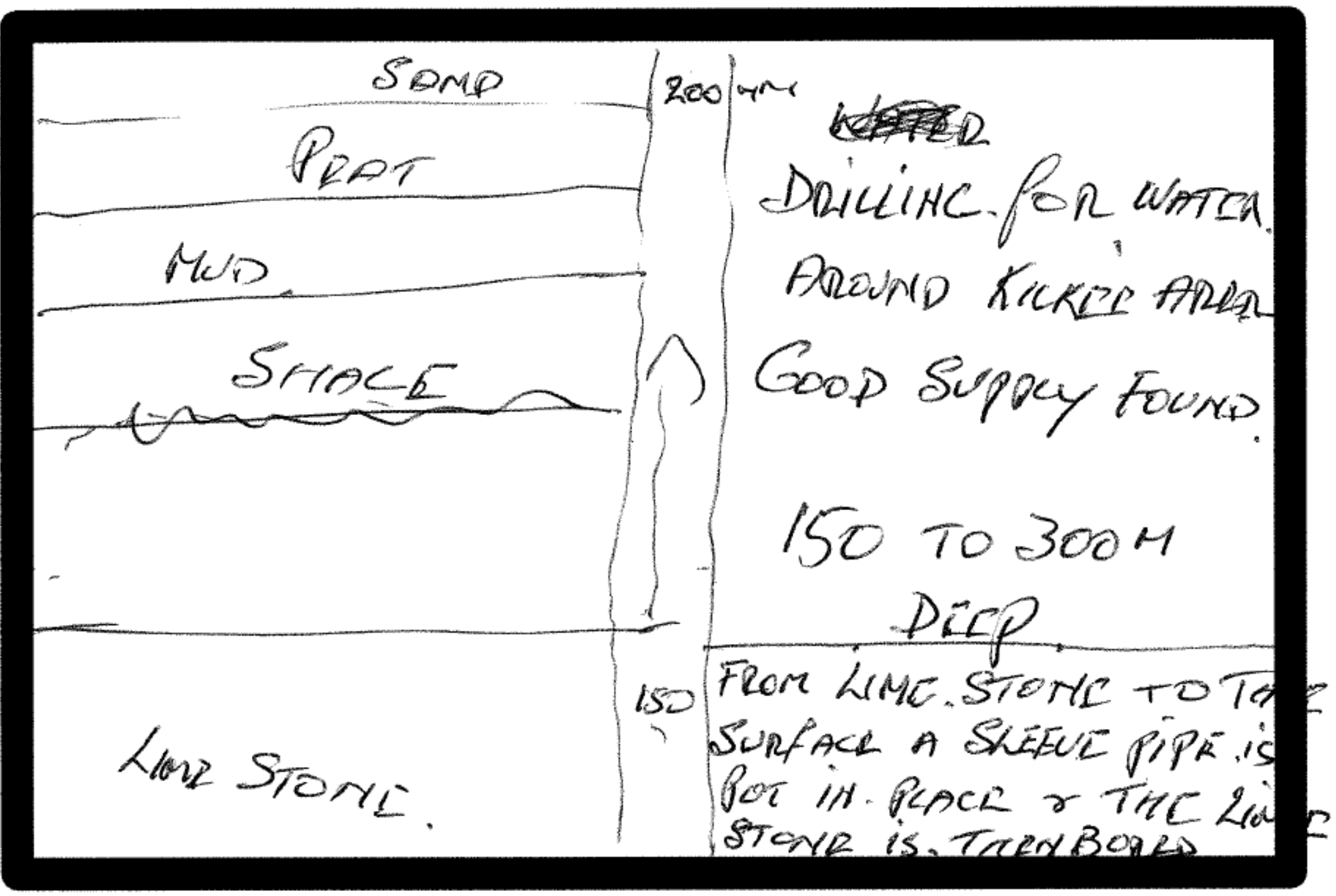


PLEASE STAY INSIDE THE BOX!

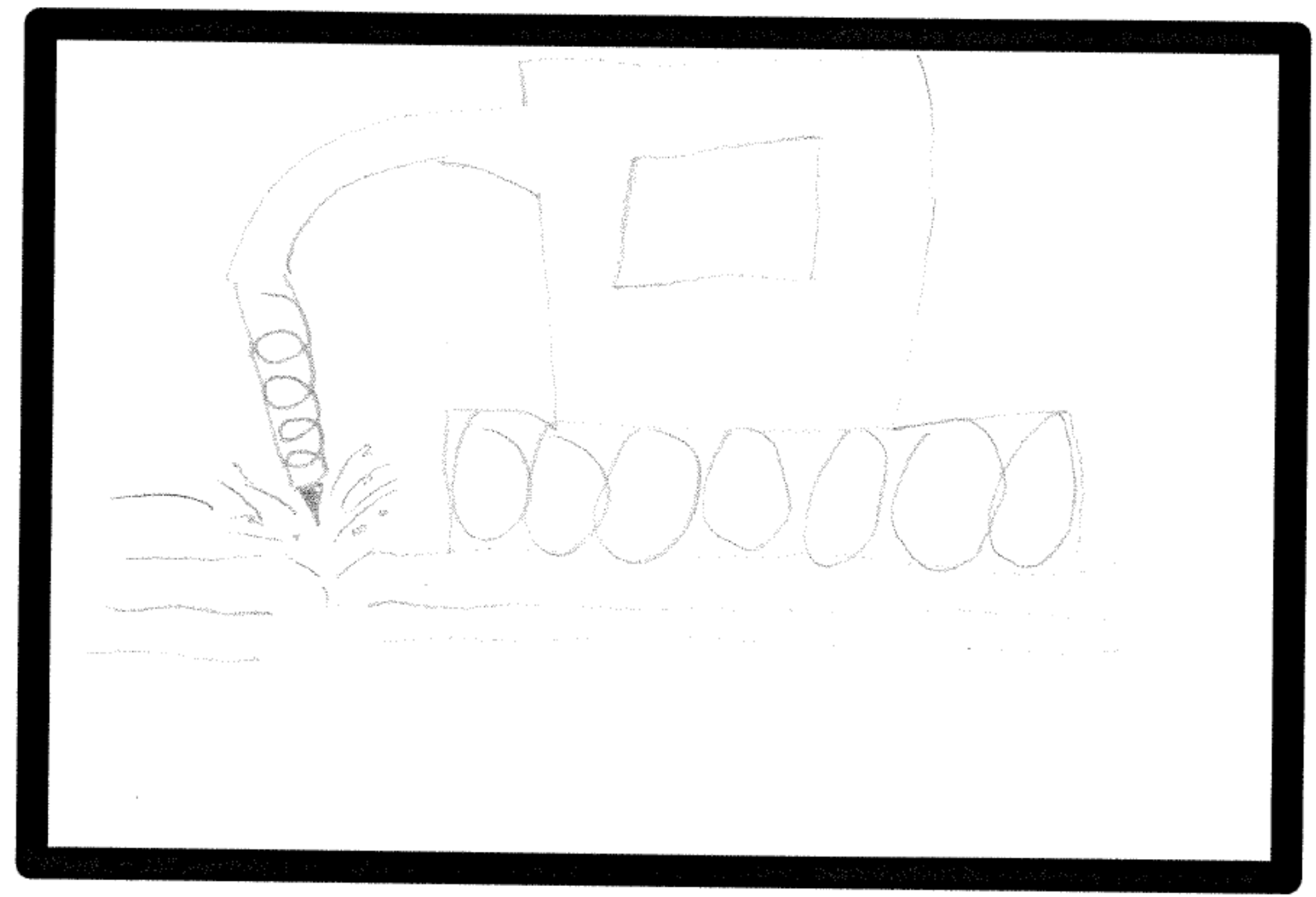


PLEASE STAY INSIDE THE BOX!

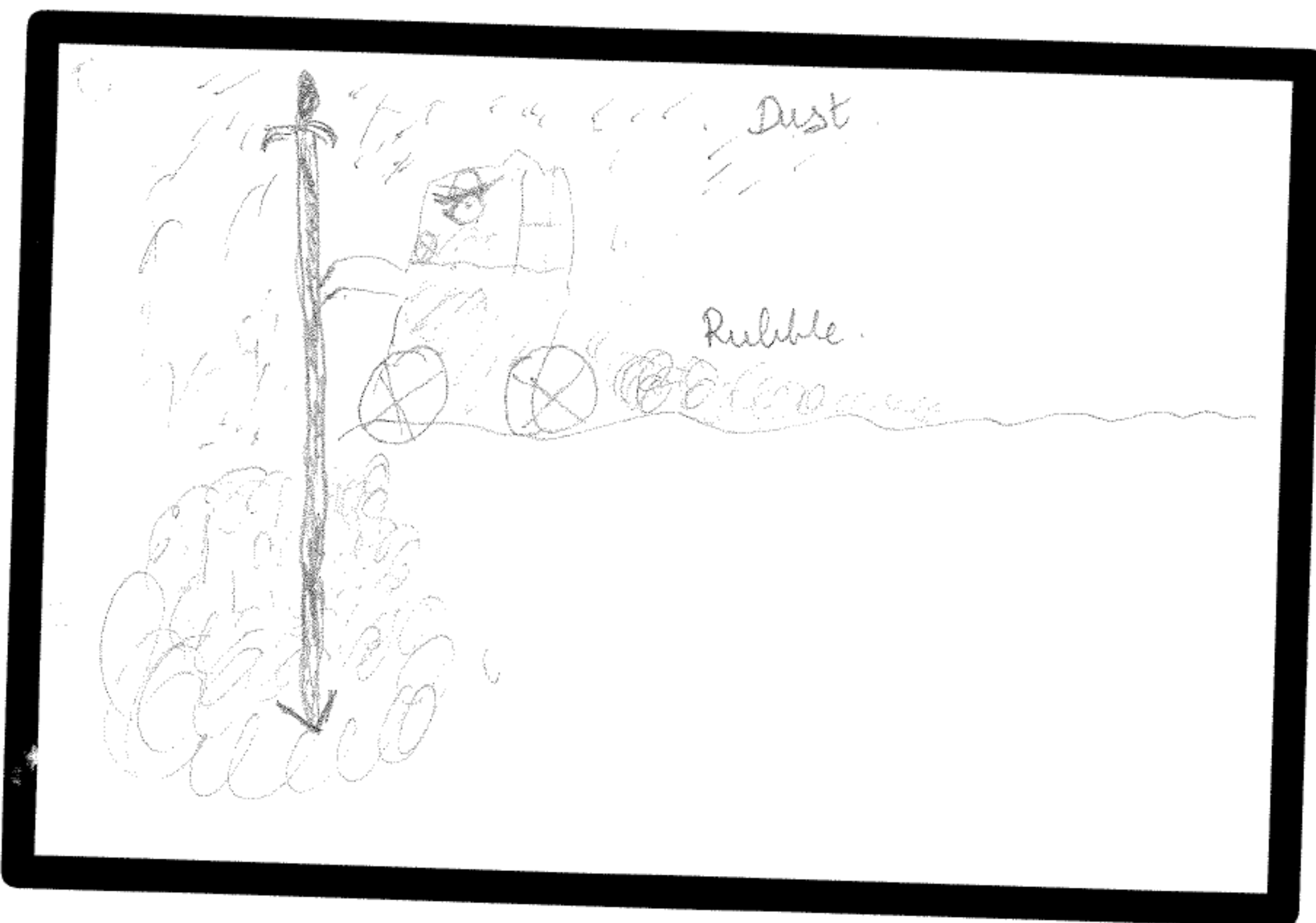

2a. How realistic do vou find vour ckateh? Dlnma _..-.t _. 
PLEASE STAY INSIDE THE BOX!

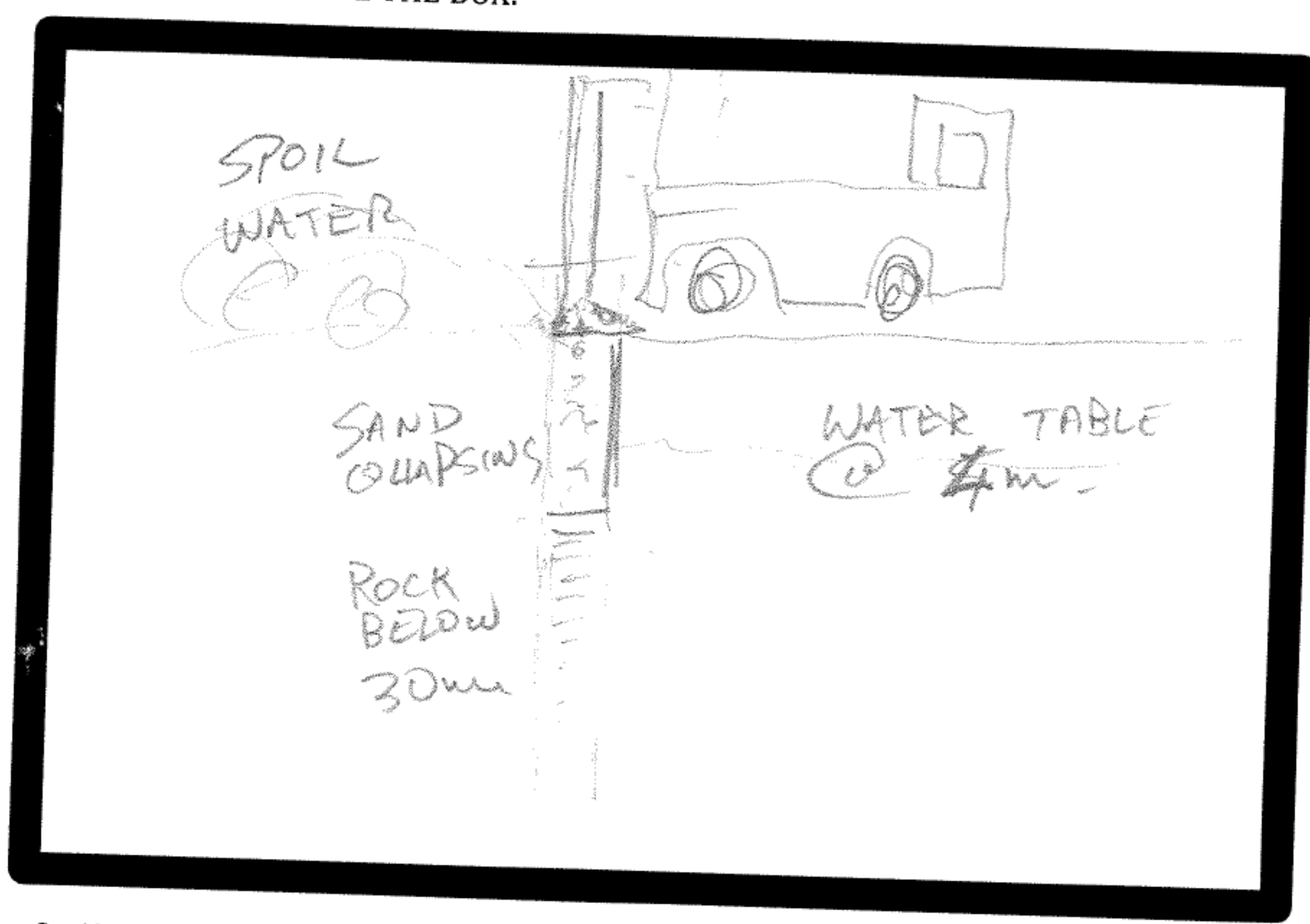

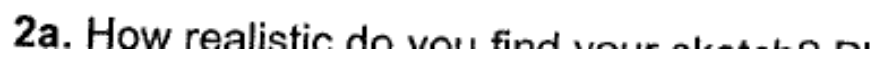


PLEASE STAY INSIDE THE BOX!

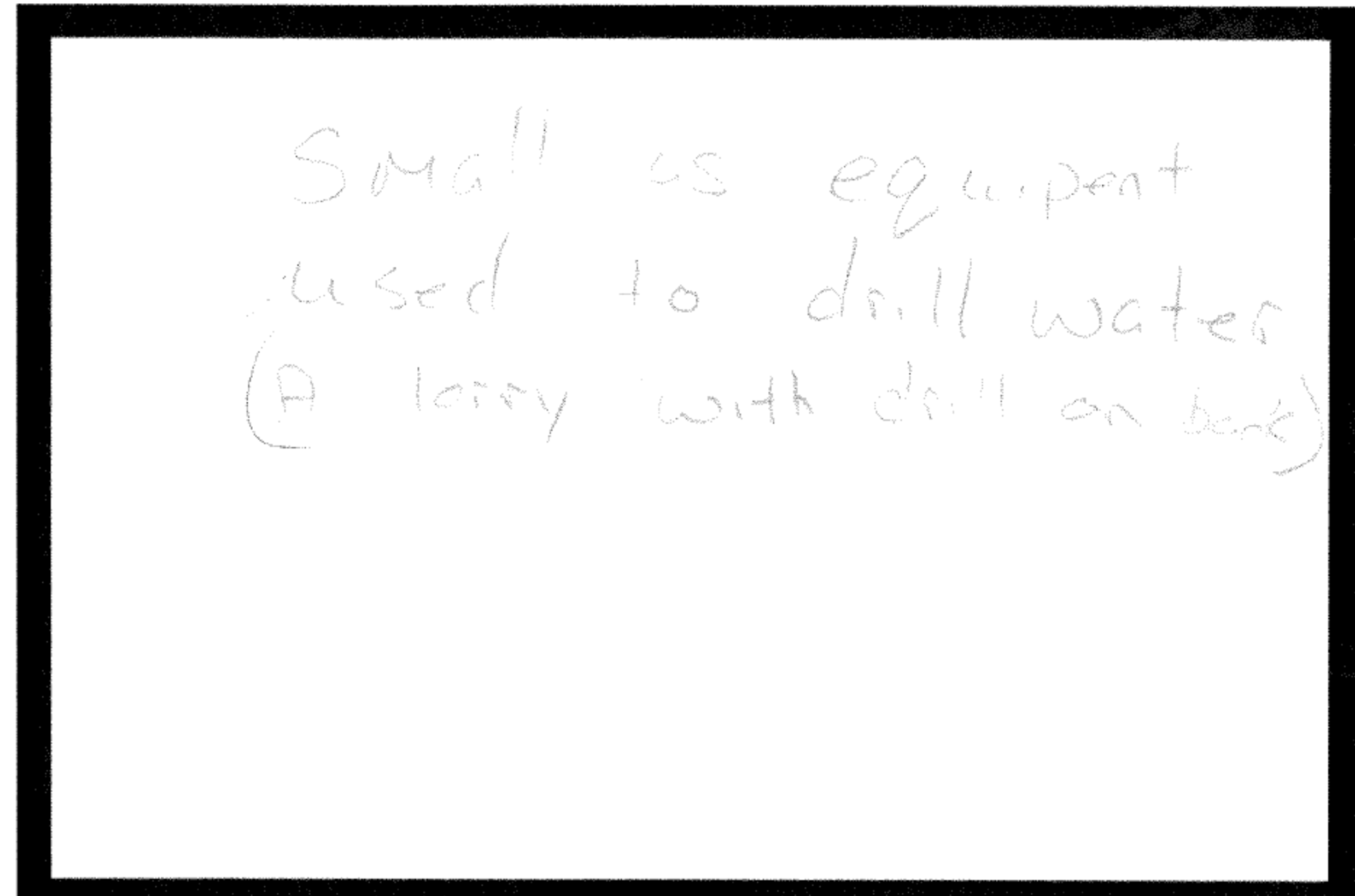


PLEASE STAY INSIDE THE BOX!

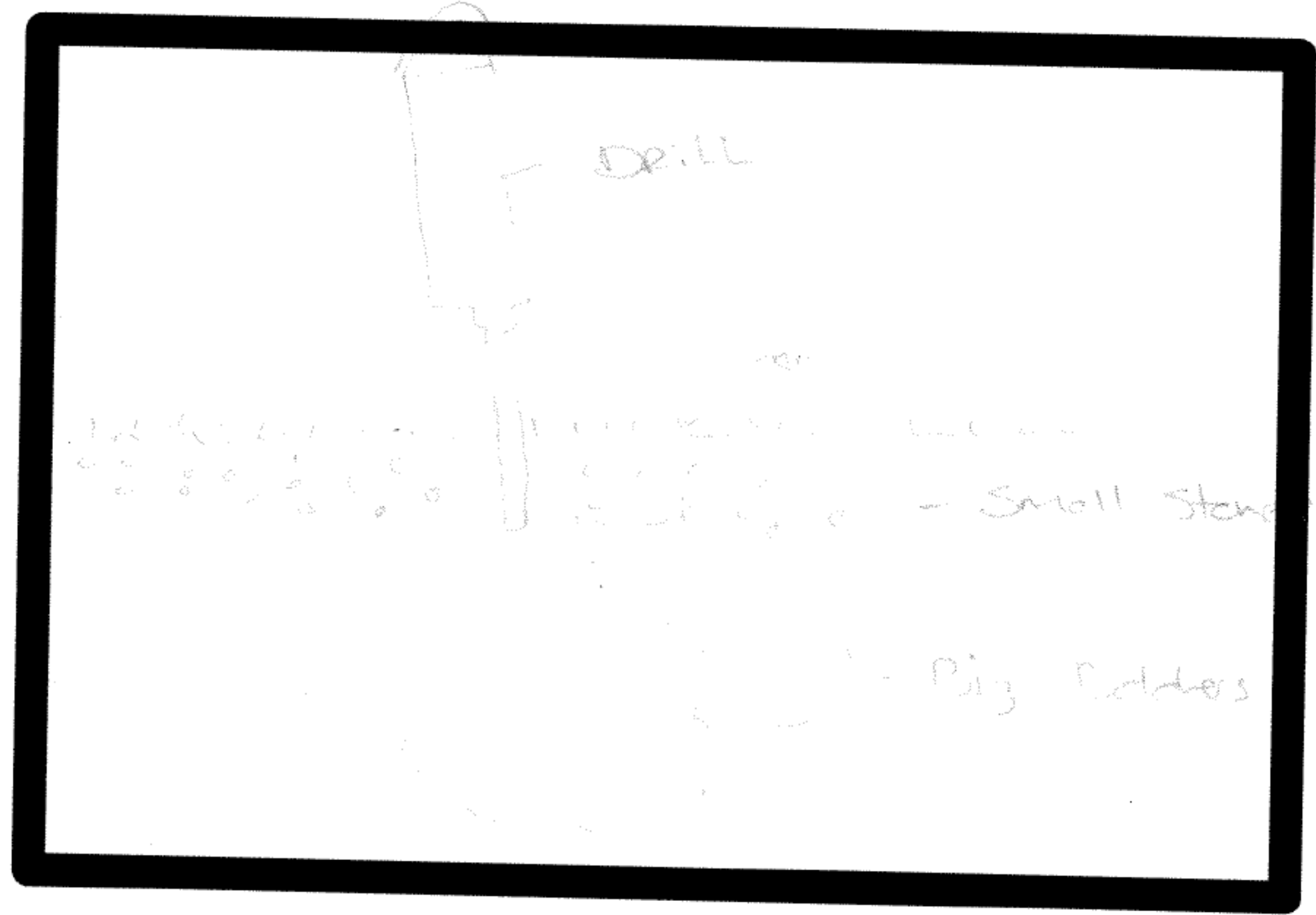

2a. How realistic do you find your sketch? Please rirrle the numbar that mam al $\ldots . .1 . .$. 


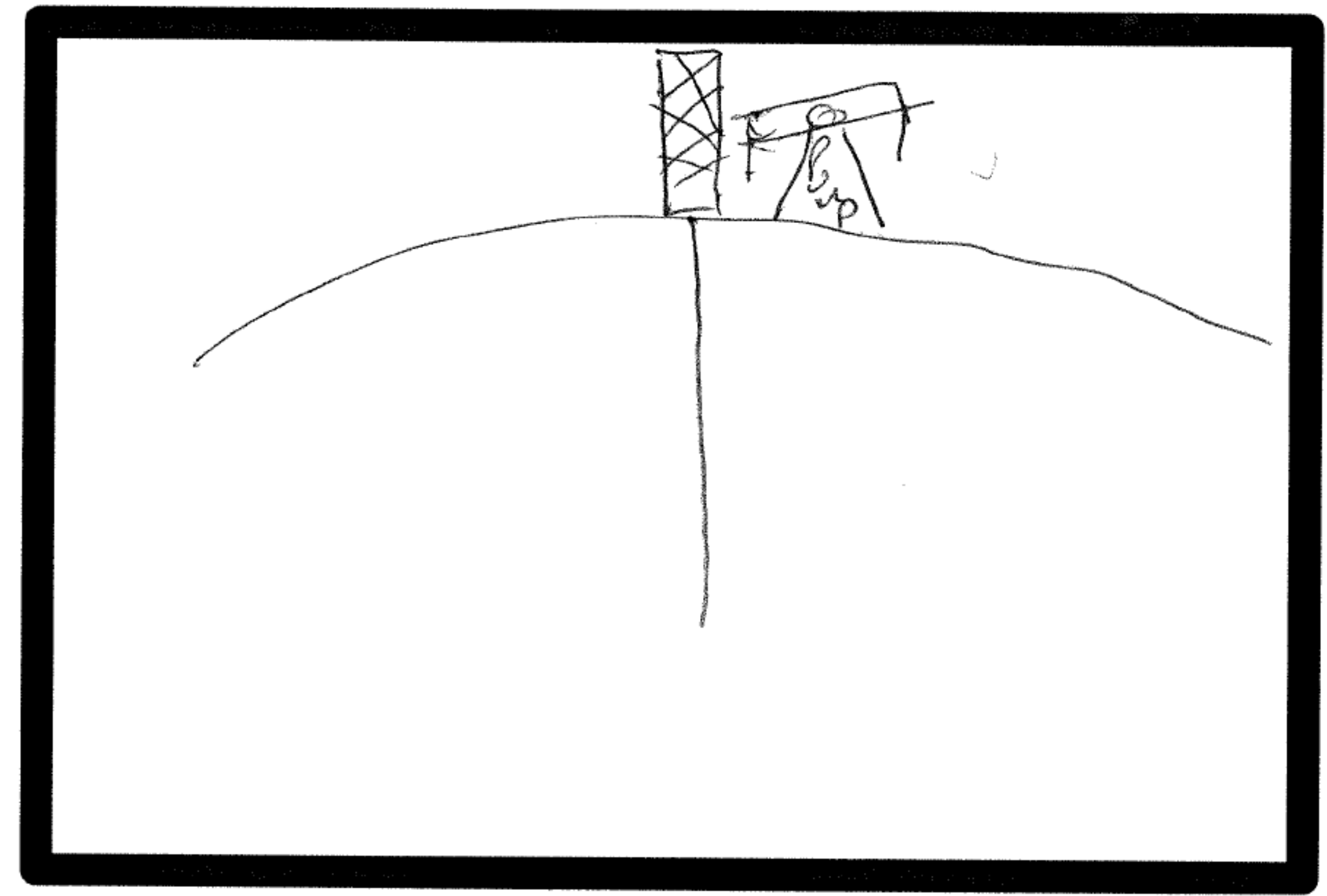


PLEASE STAY INSIDE THE BOX!

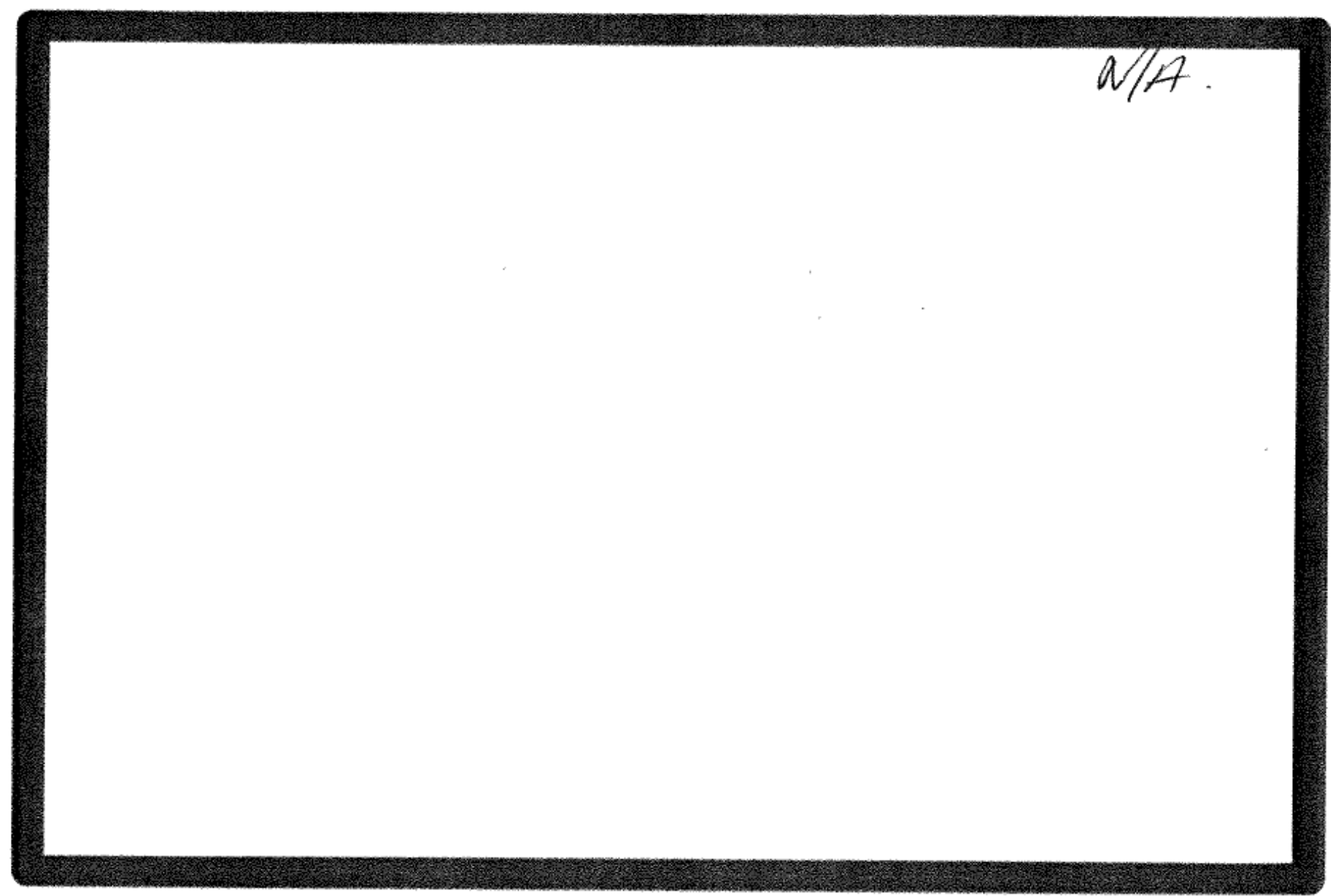

2a. How realistic do vou find vour sketch? Please circle the number that mnre clncelv renresents vont ir 
PLEASE STAY INSIDE THE BOX!

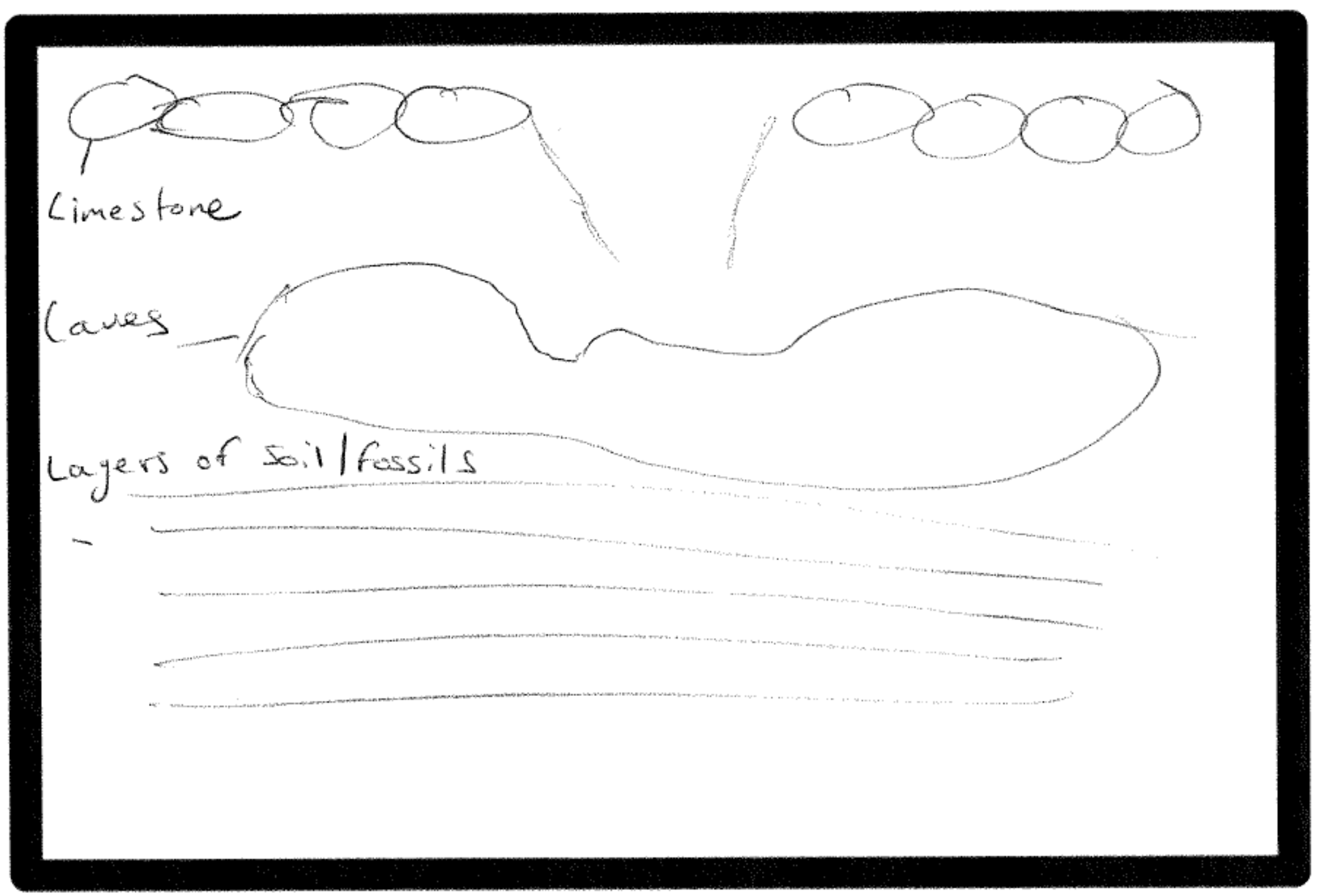




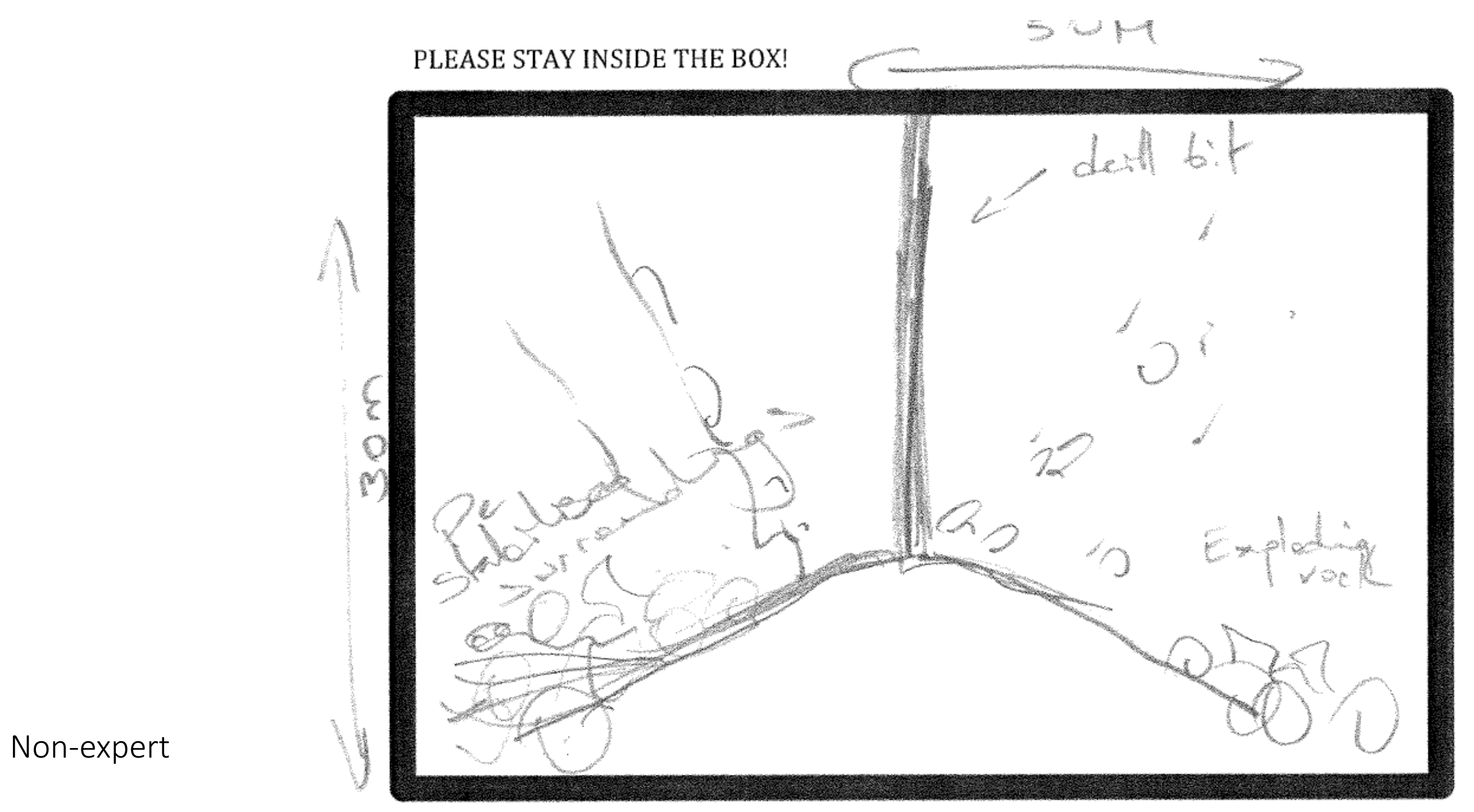




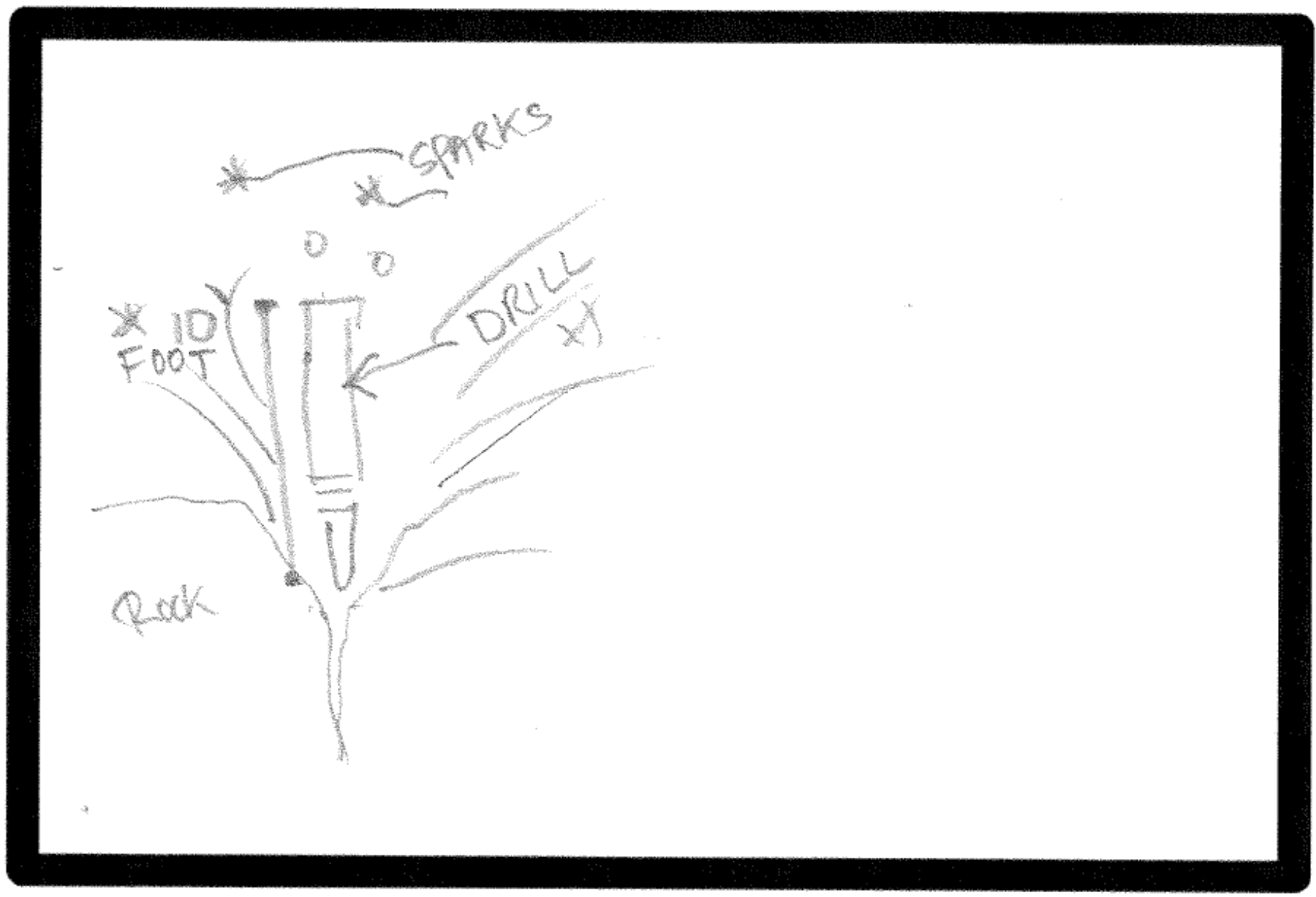


Non-expert 
PLEASE STAY INSIDE THE BOX!

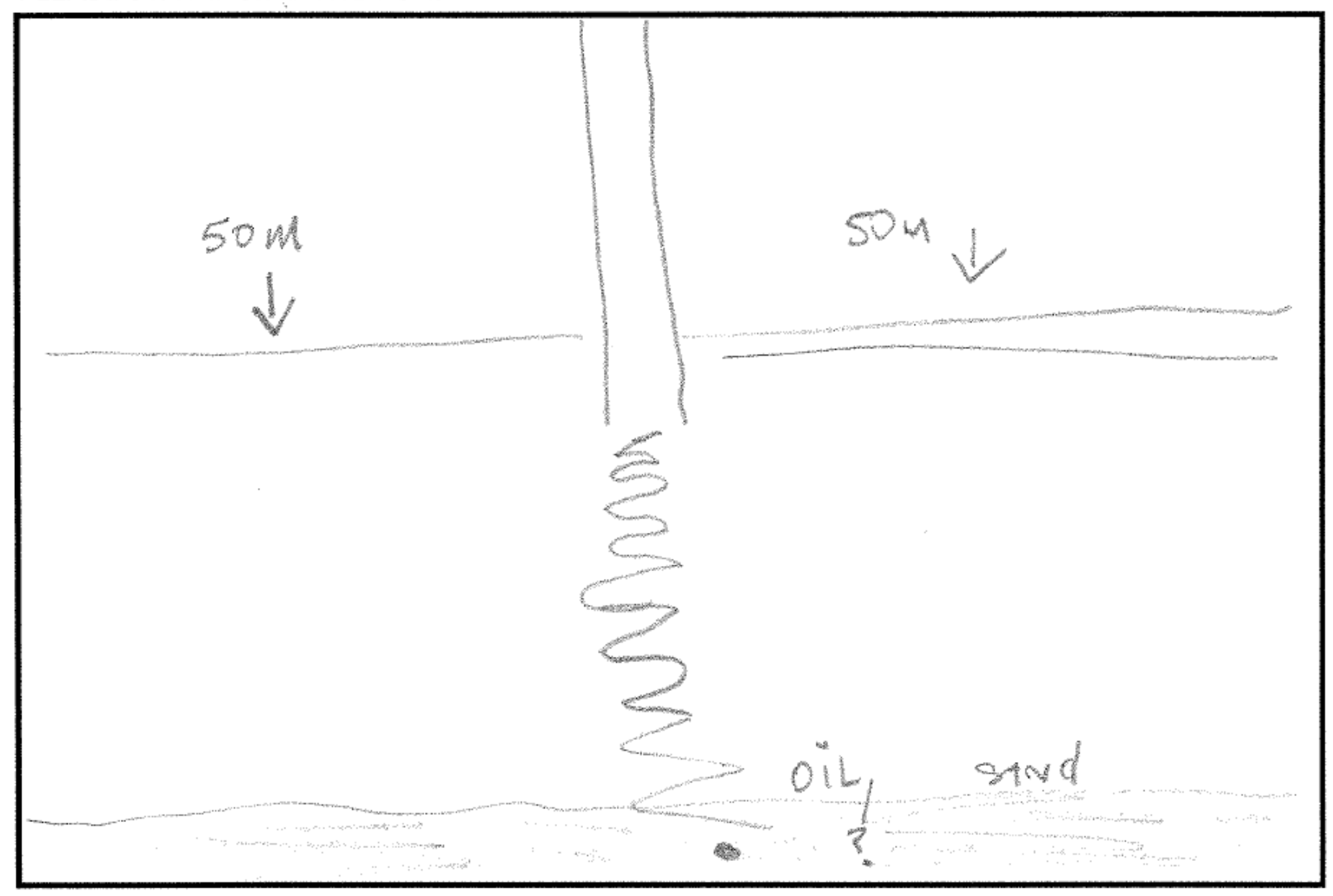

Non-expert 


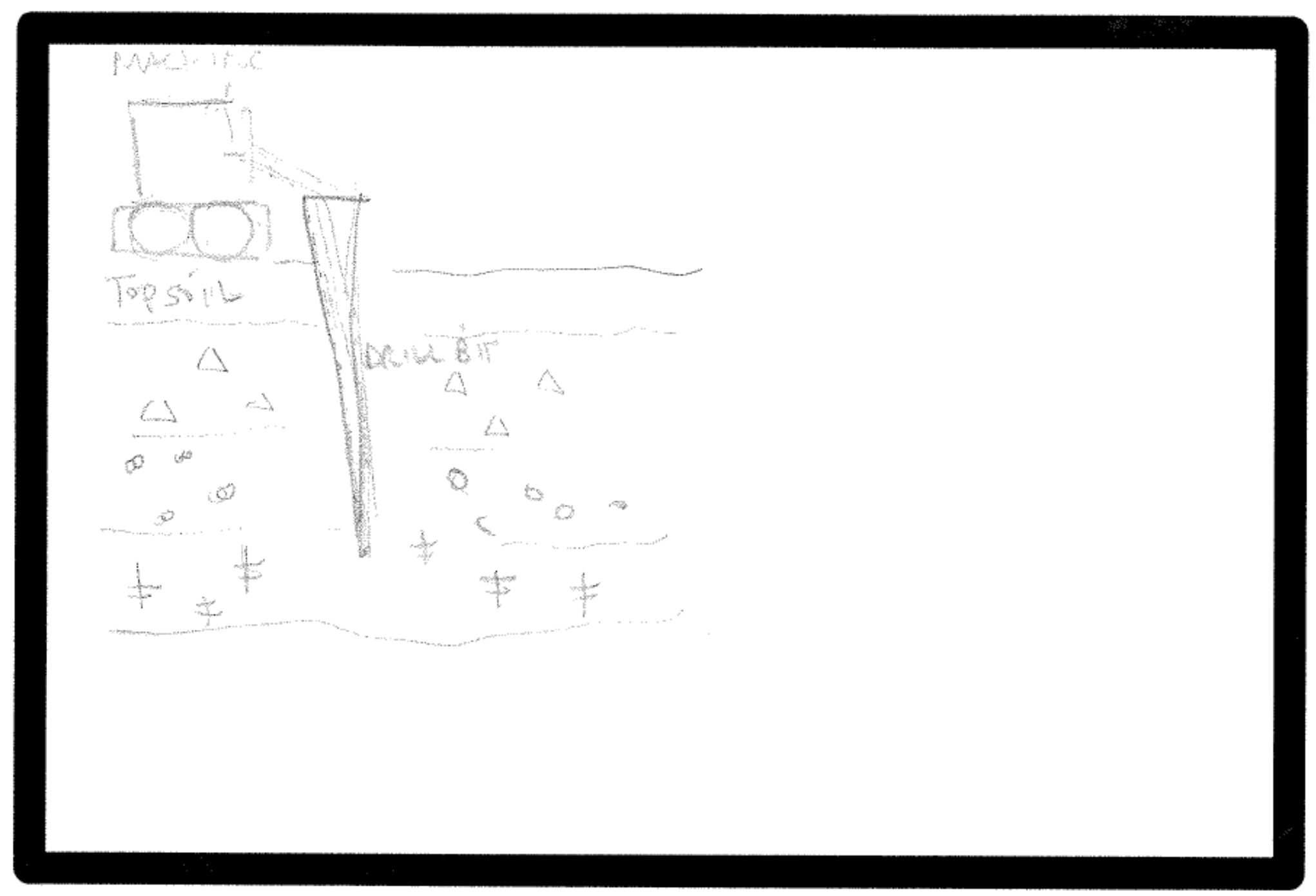


Rock, Clay, Boil

$3.5 \mathrm{M}$

Rock Clay

6.M

Rock

$30 \mathrm{~m}$

Rock Stone Granite mixed with or aesidueson Oil

Non-expert 
- Imagine that a mining or quarrying company Mining/quarrying has come to County Clare. Please sketch what the quarrying or mining activity would look like 


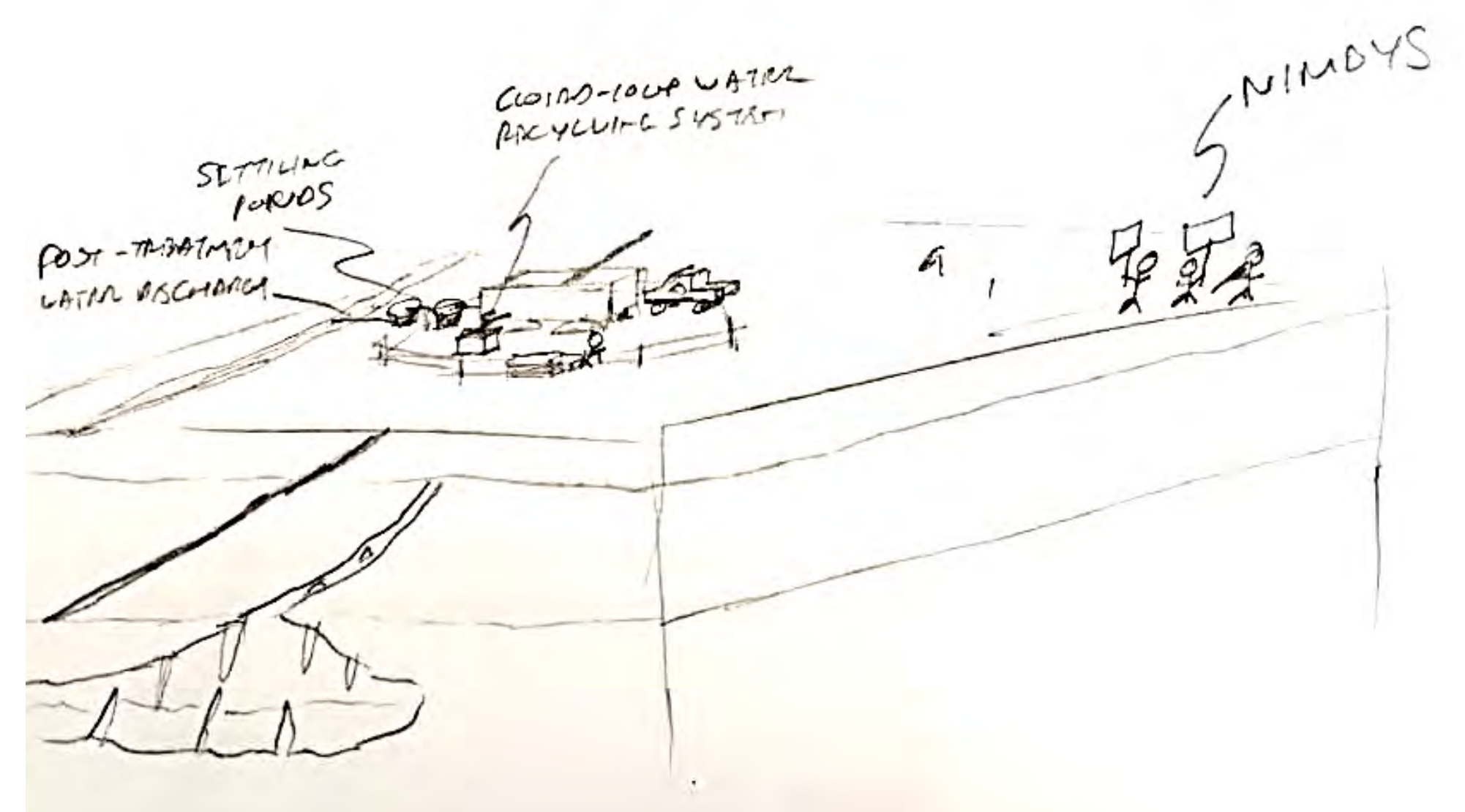

Expert 


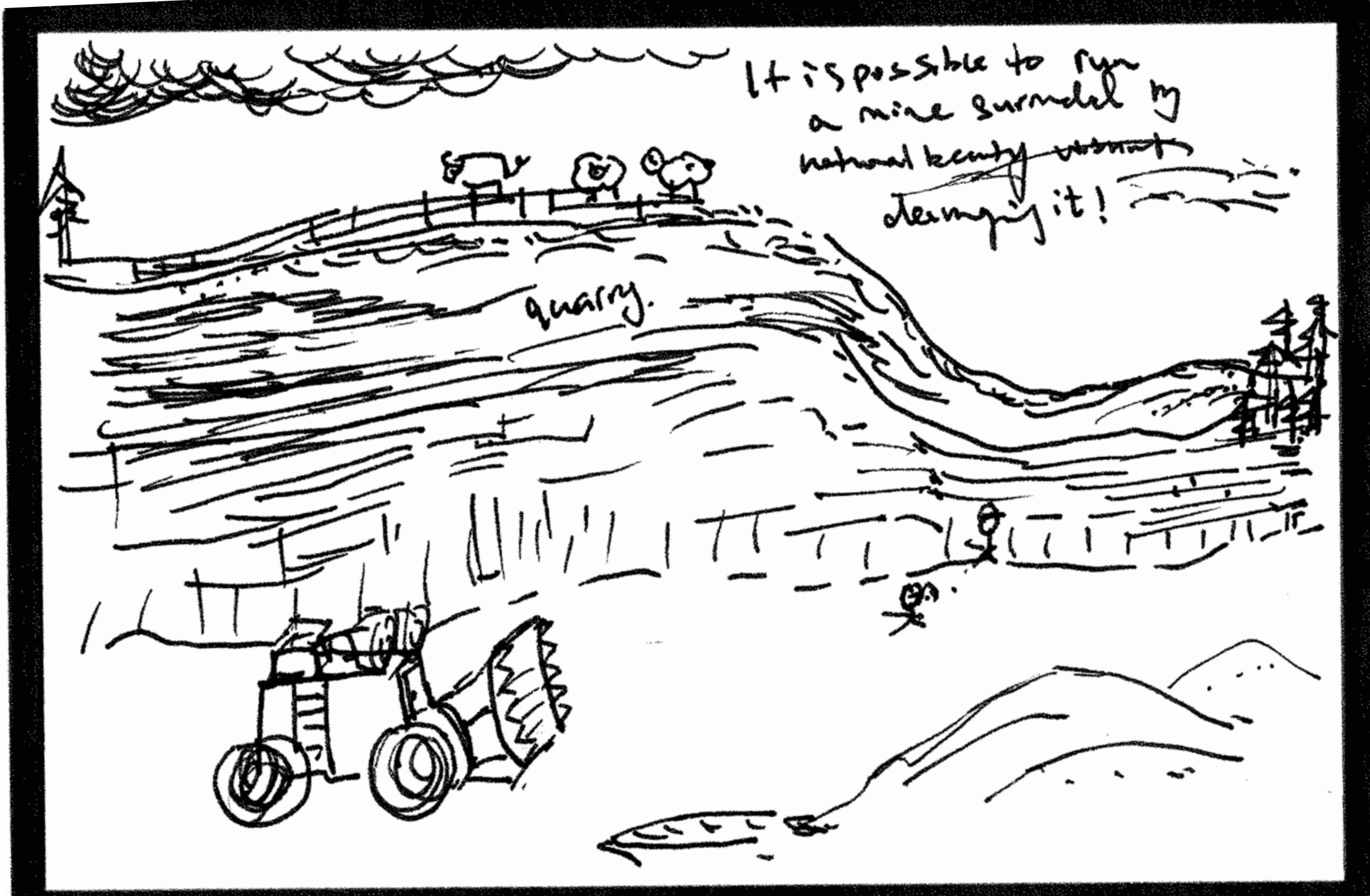




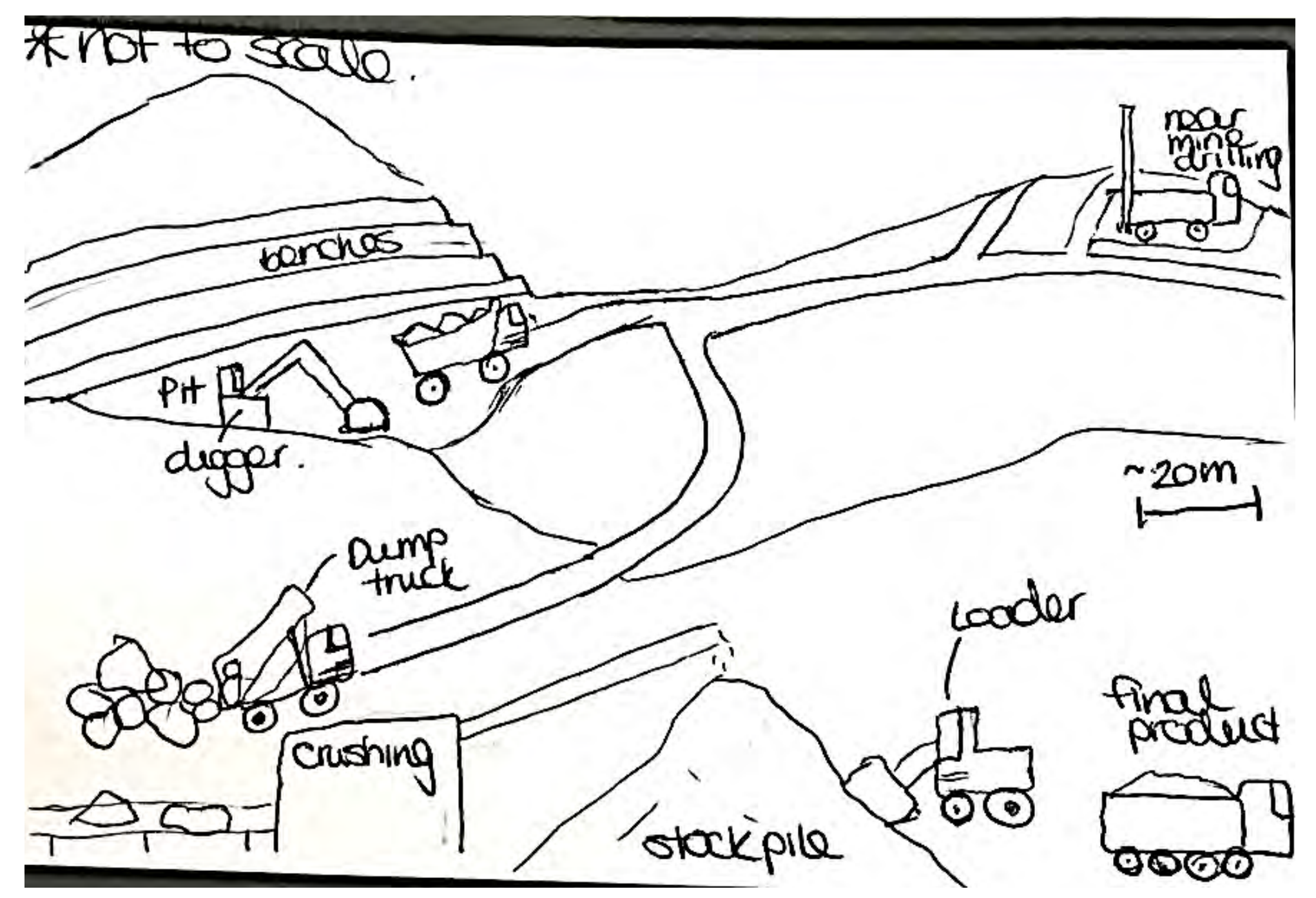




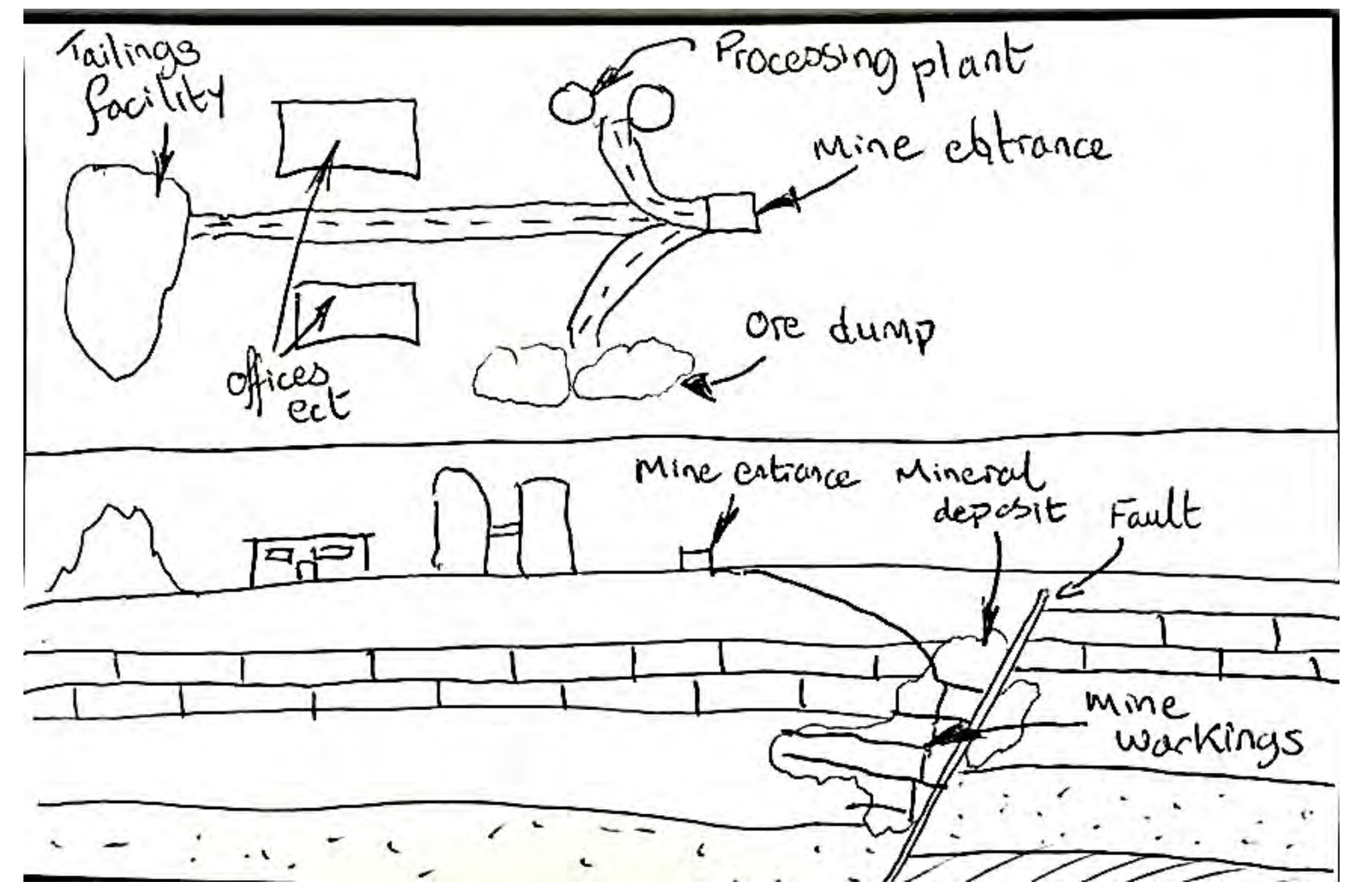

Expert 


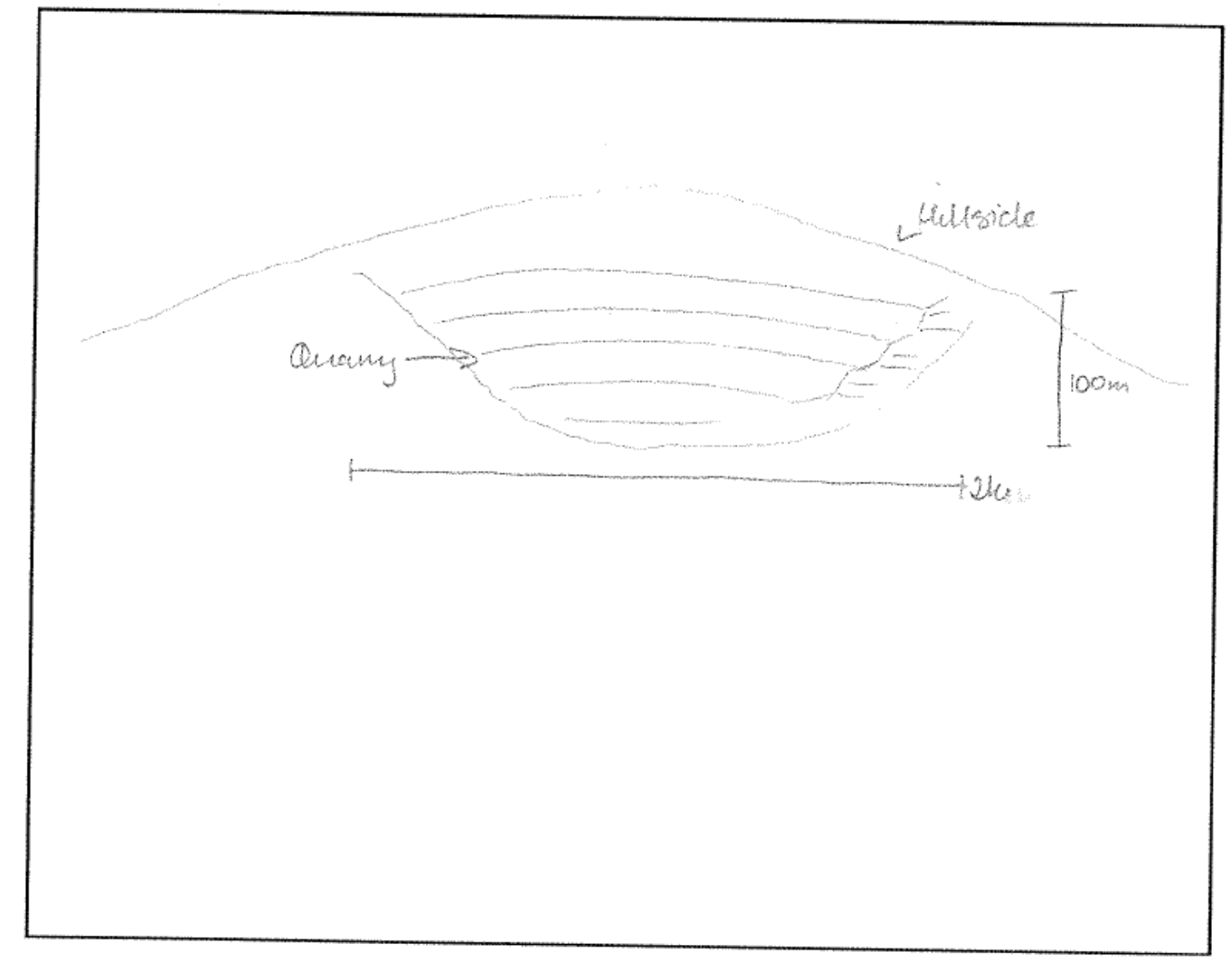




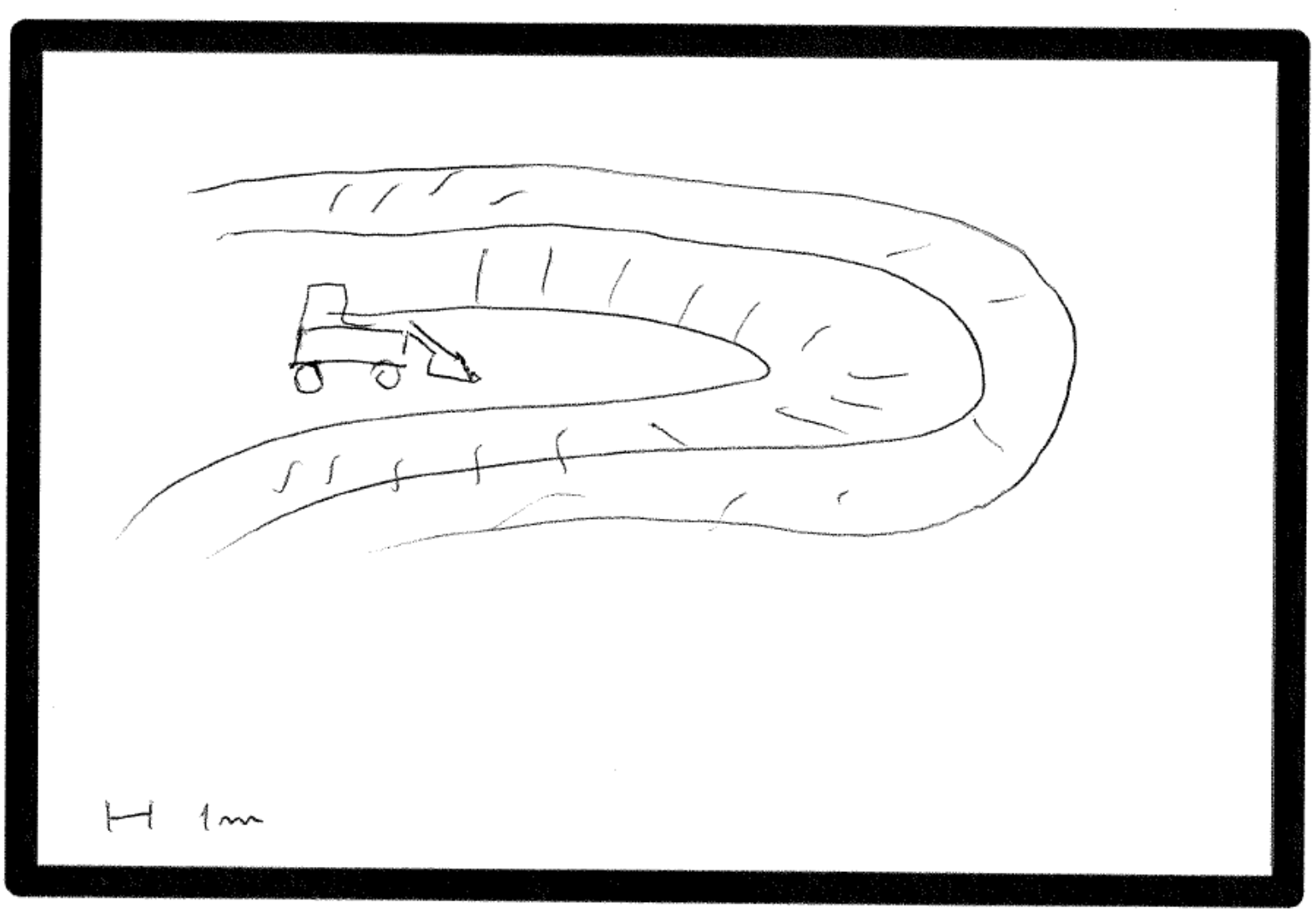




\section{PLEASE STAY INSIDE THE BOX!}

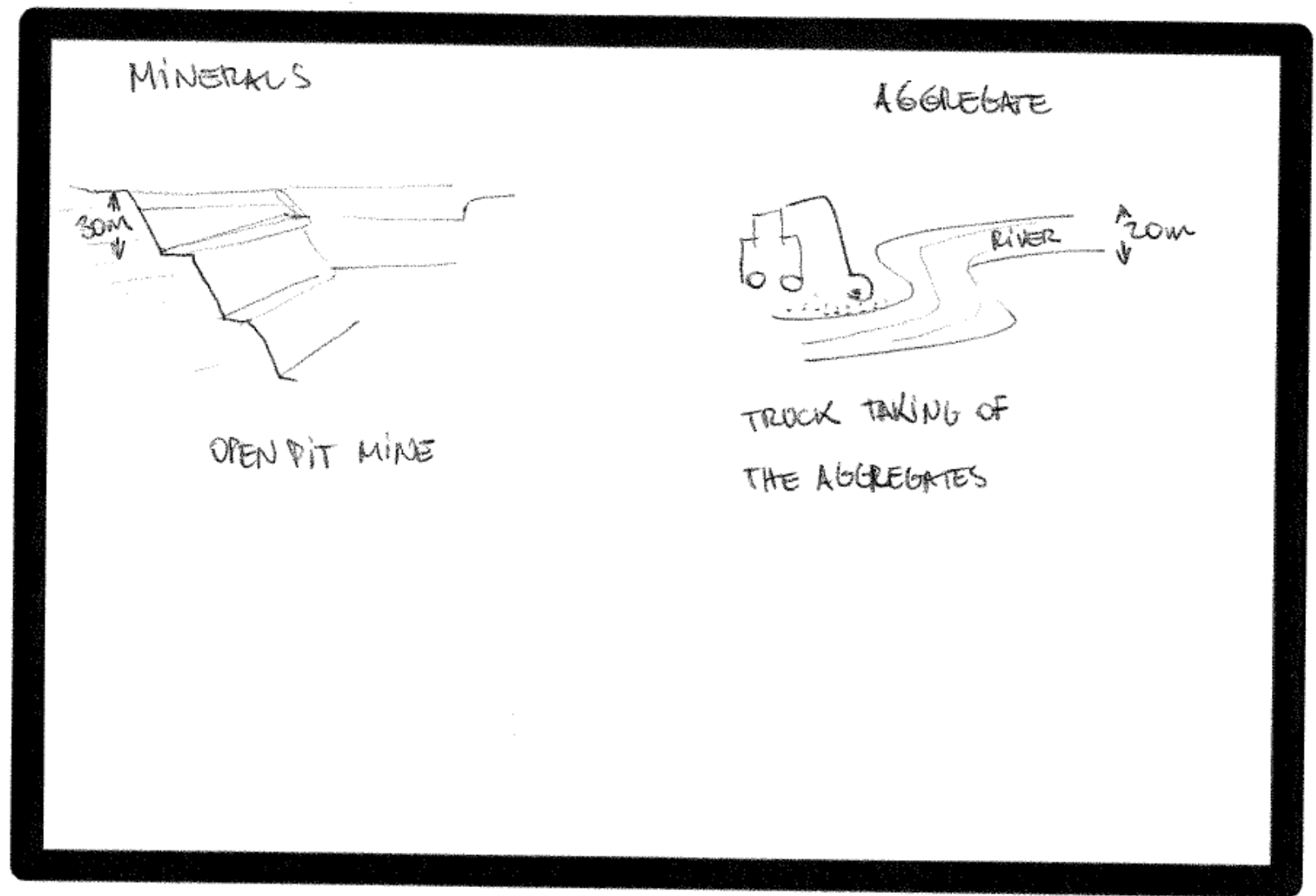




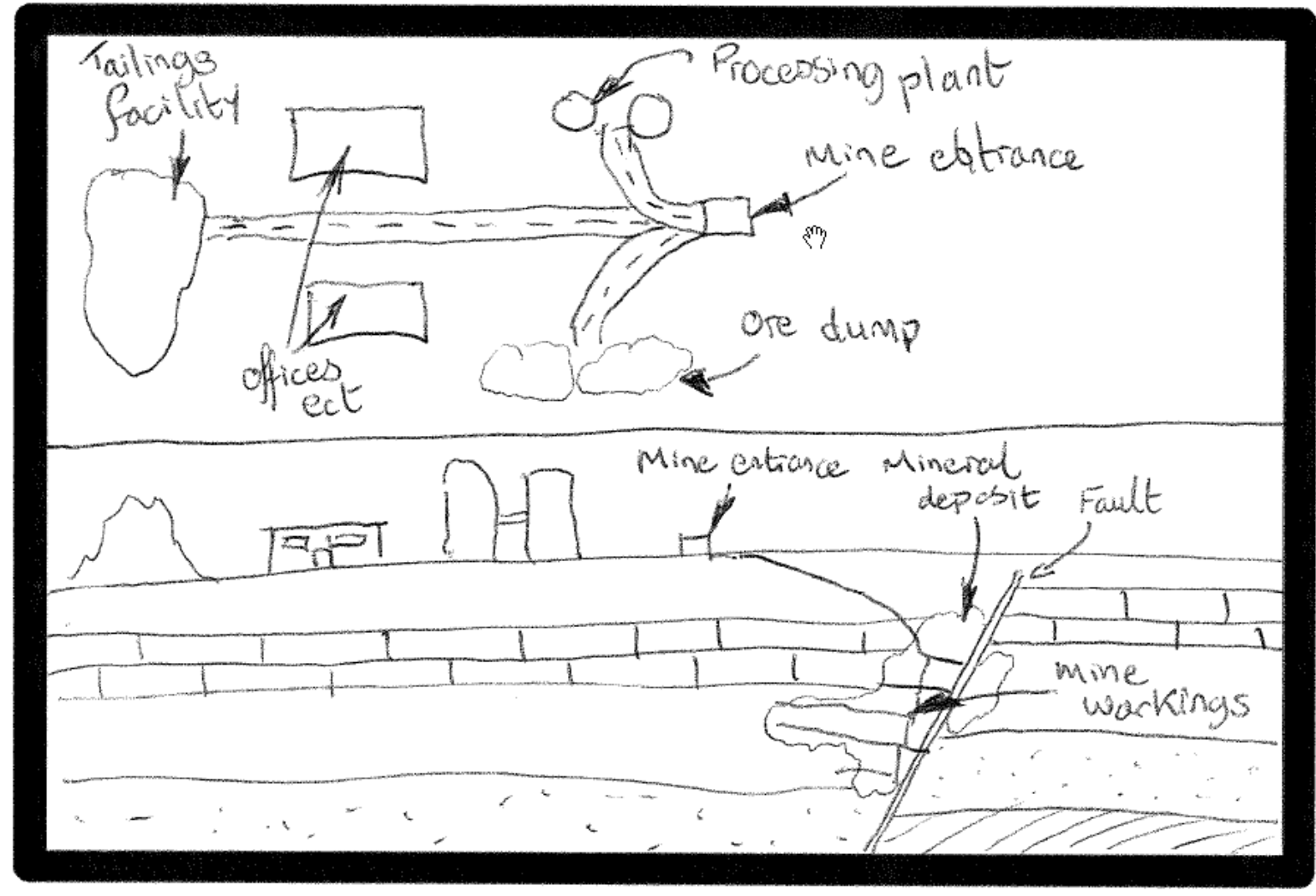


PLEASE STAY INSIDE THE BOX!

\section{Expert}

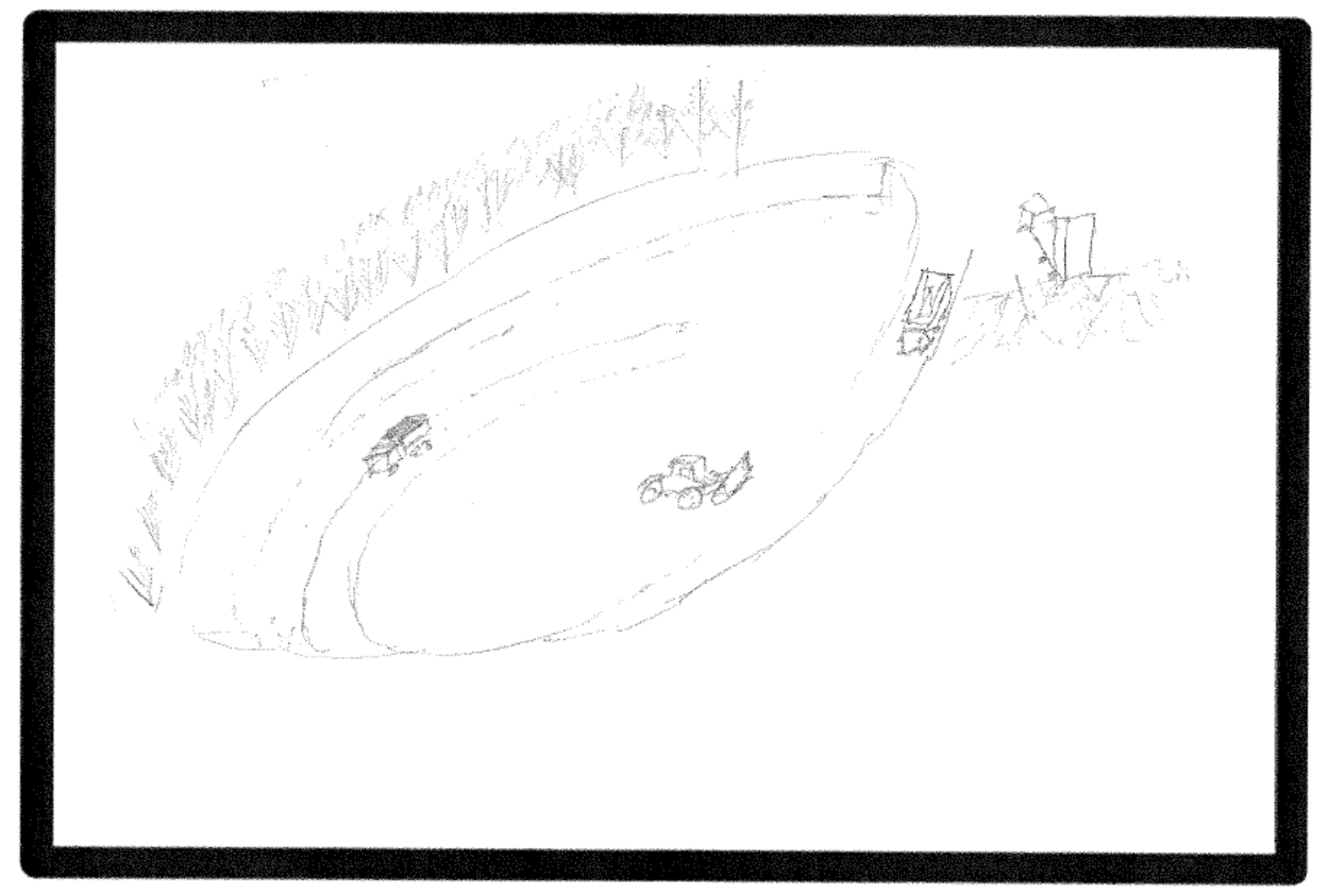




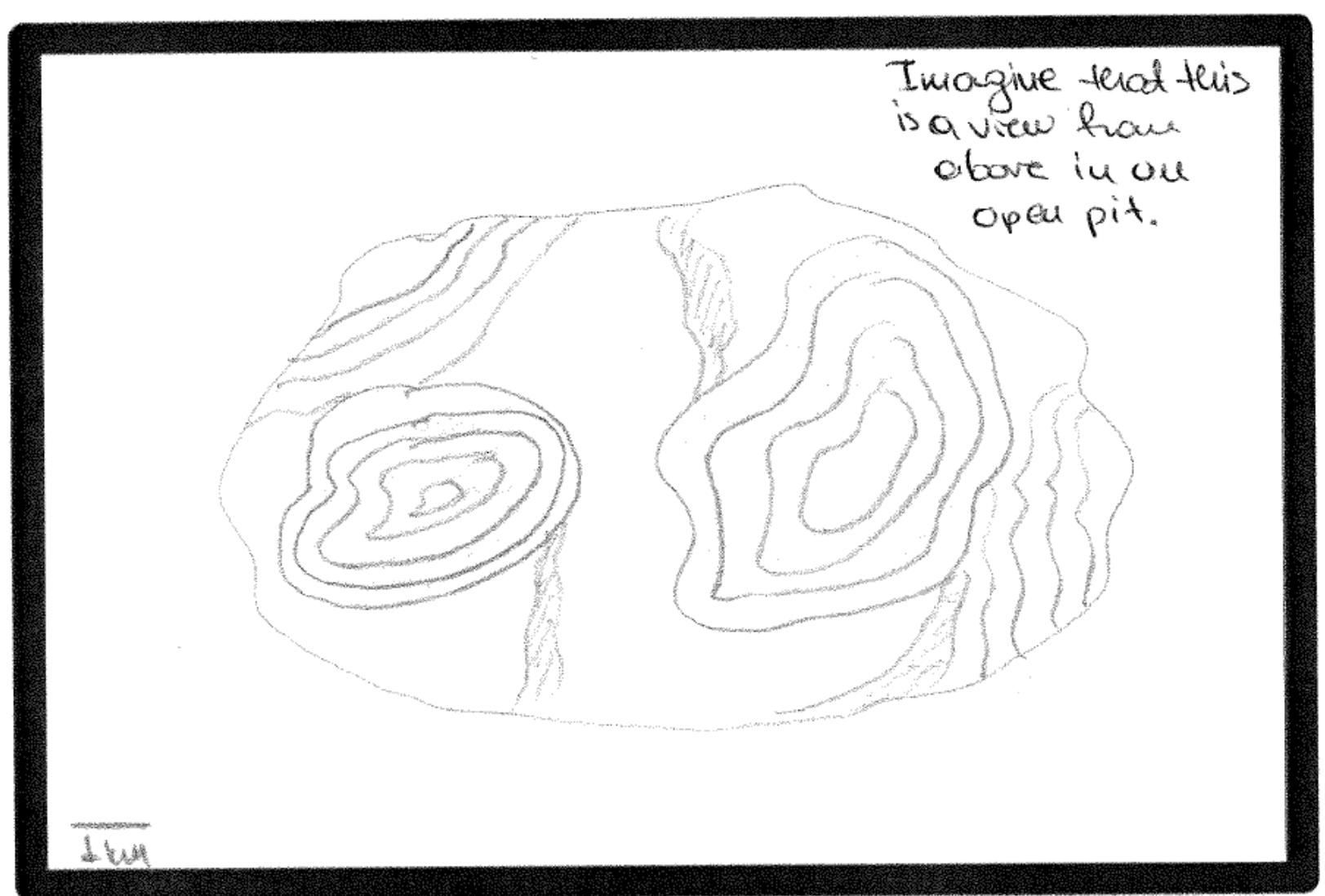


PLEASE STAY INSIDE THE BOX!

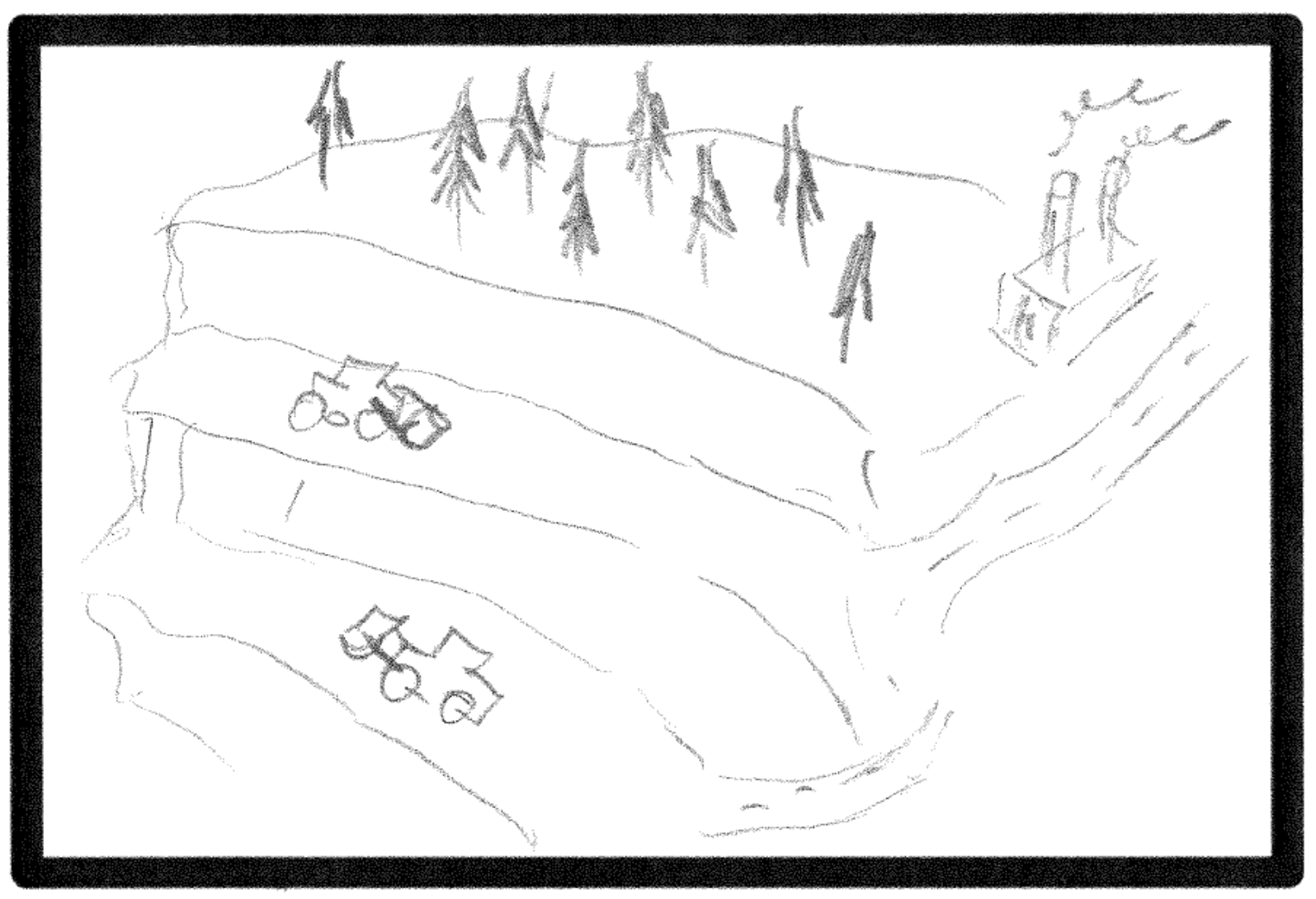


PLEASE STAY INSIDE THE BOX!

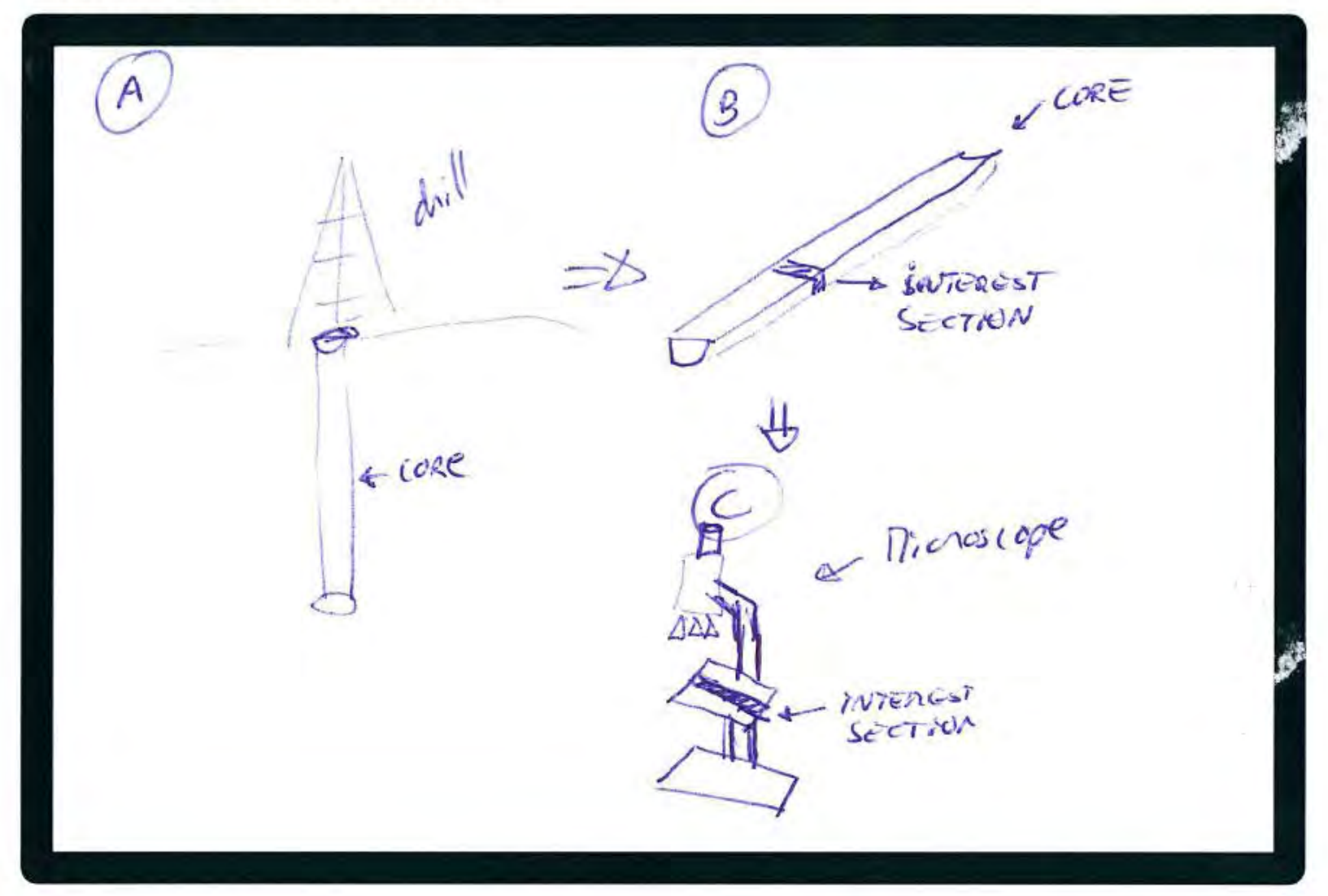




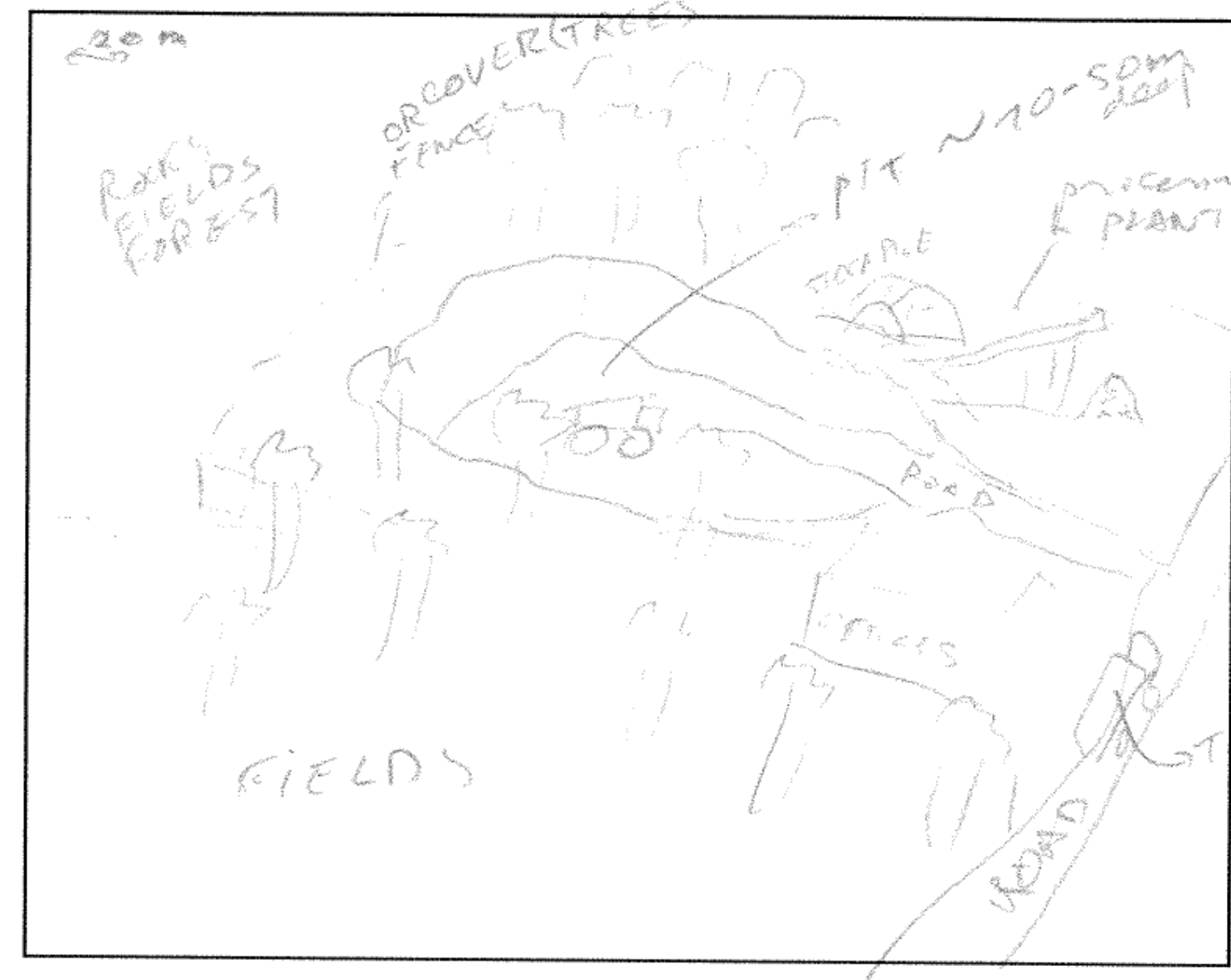




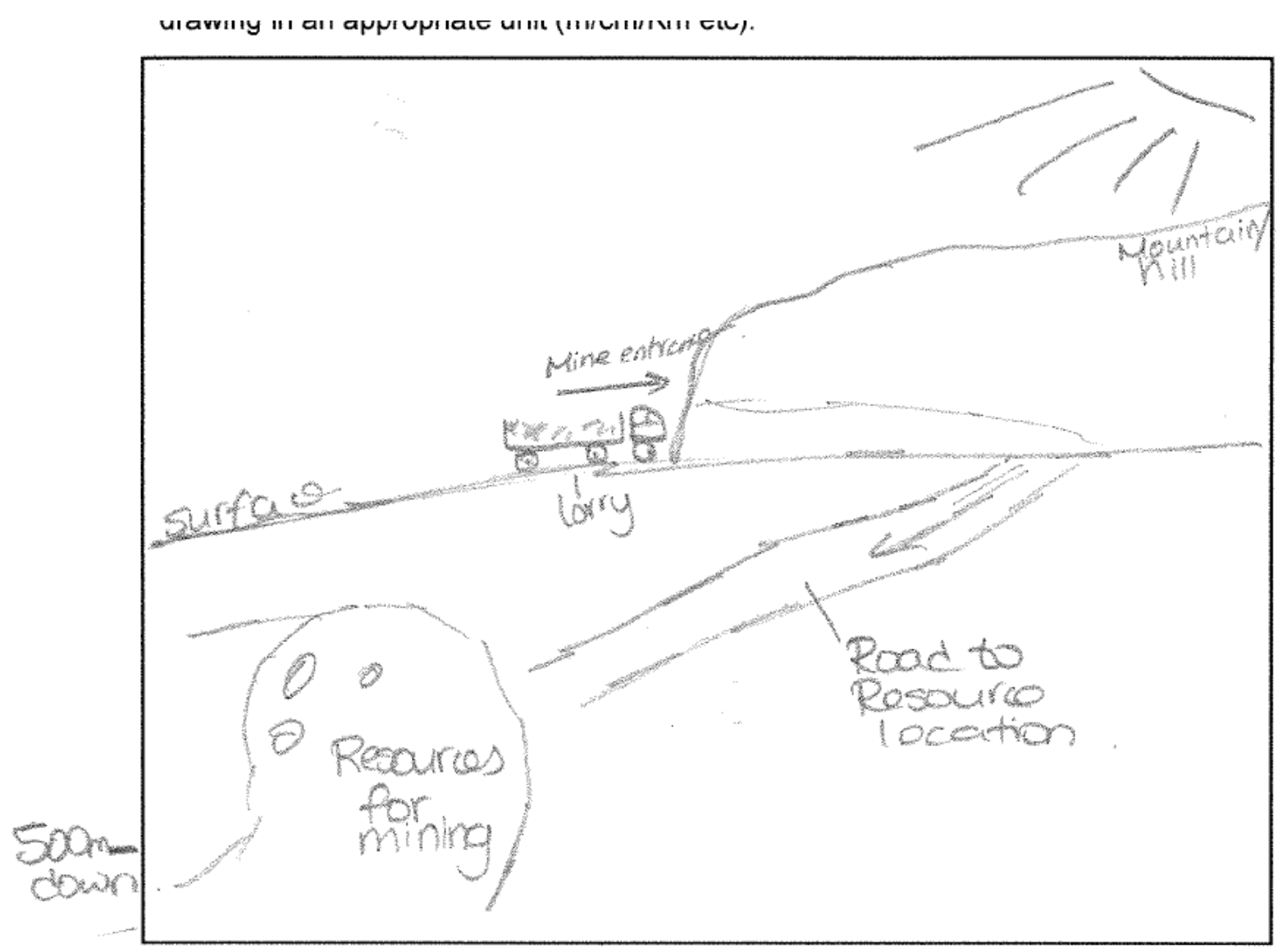

Expert 


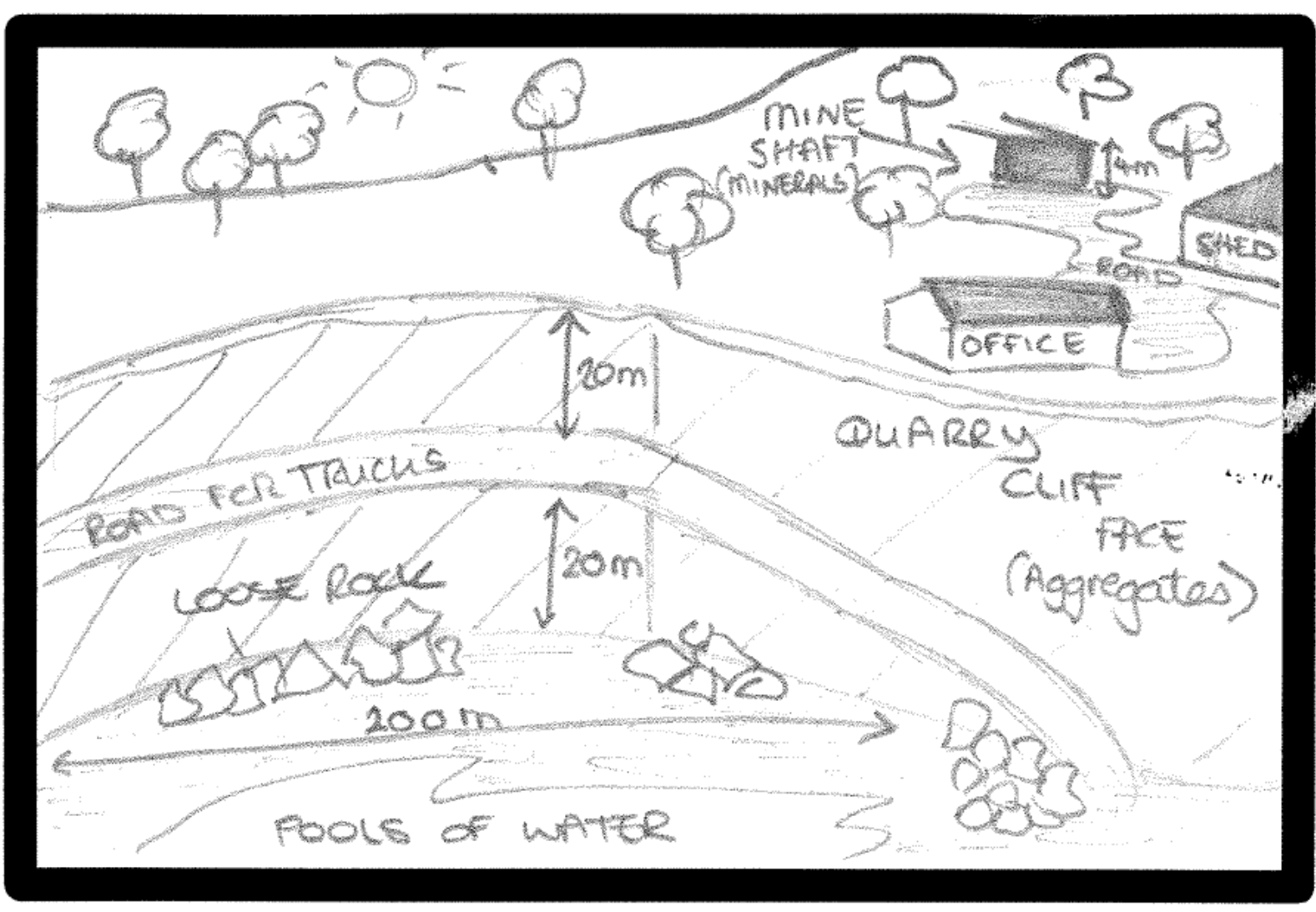


PLEASE STAY INSIDE THE BOX!

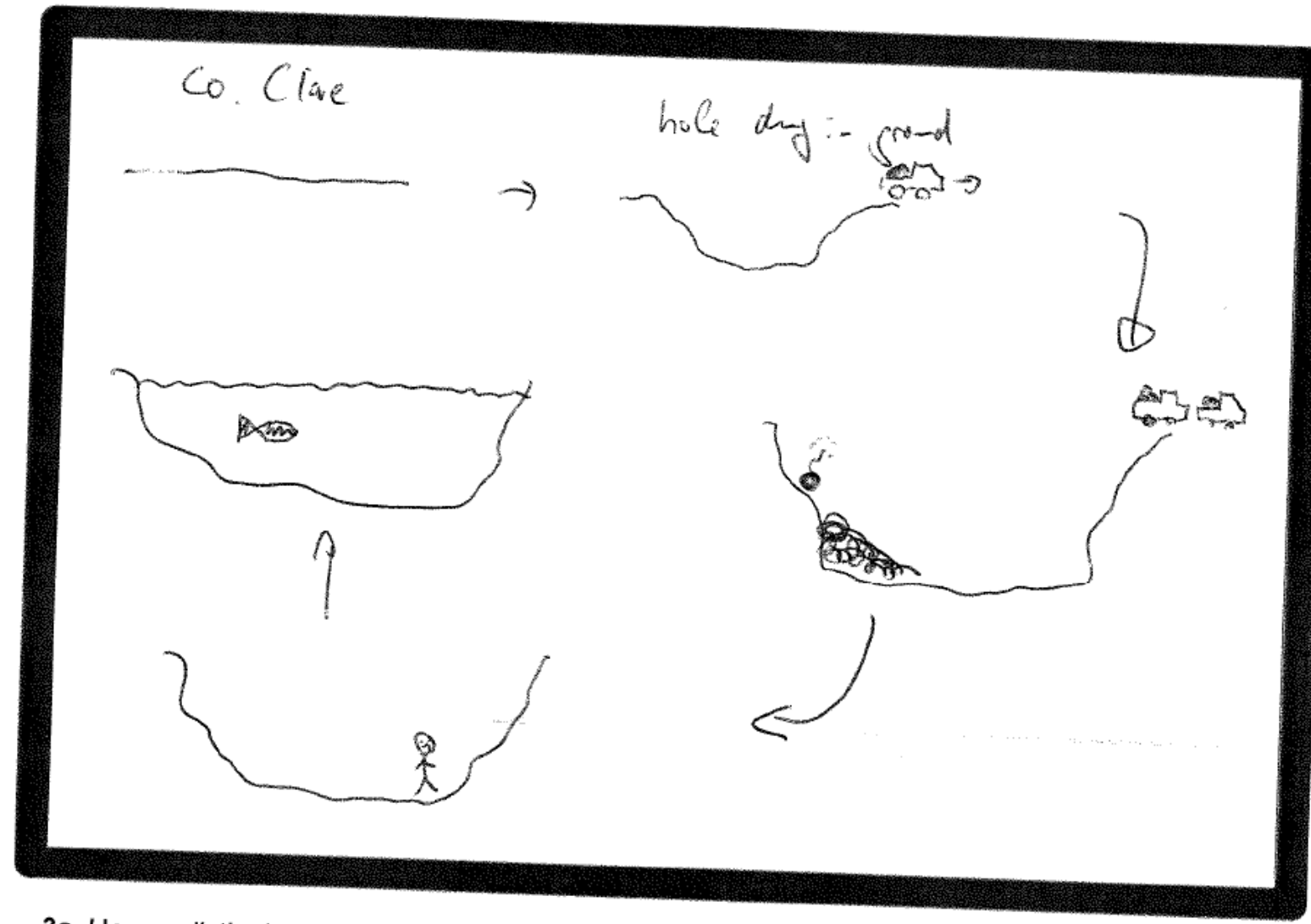




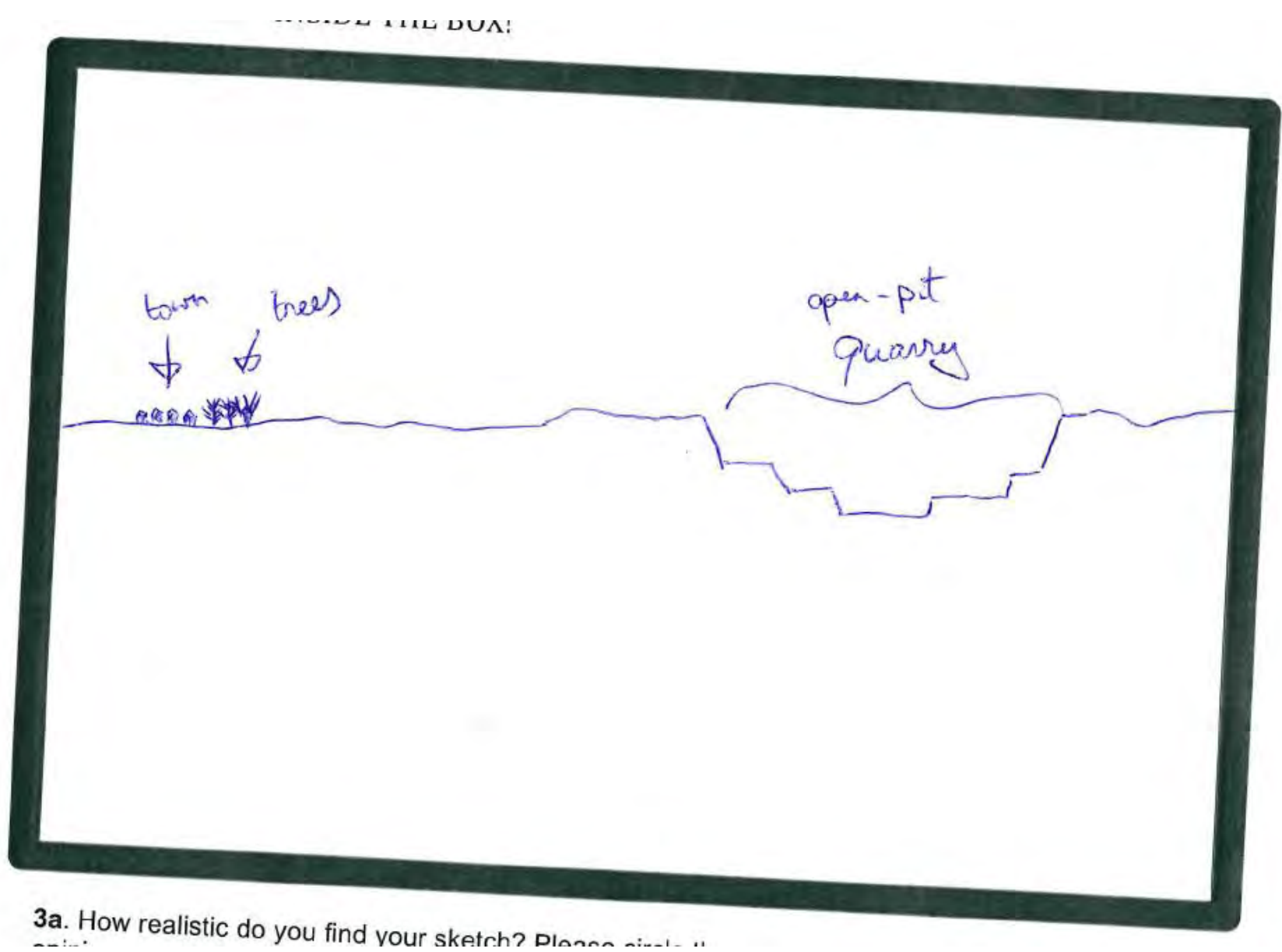




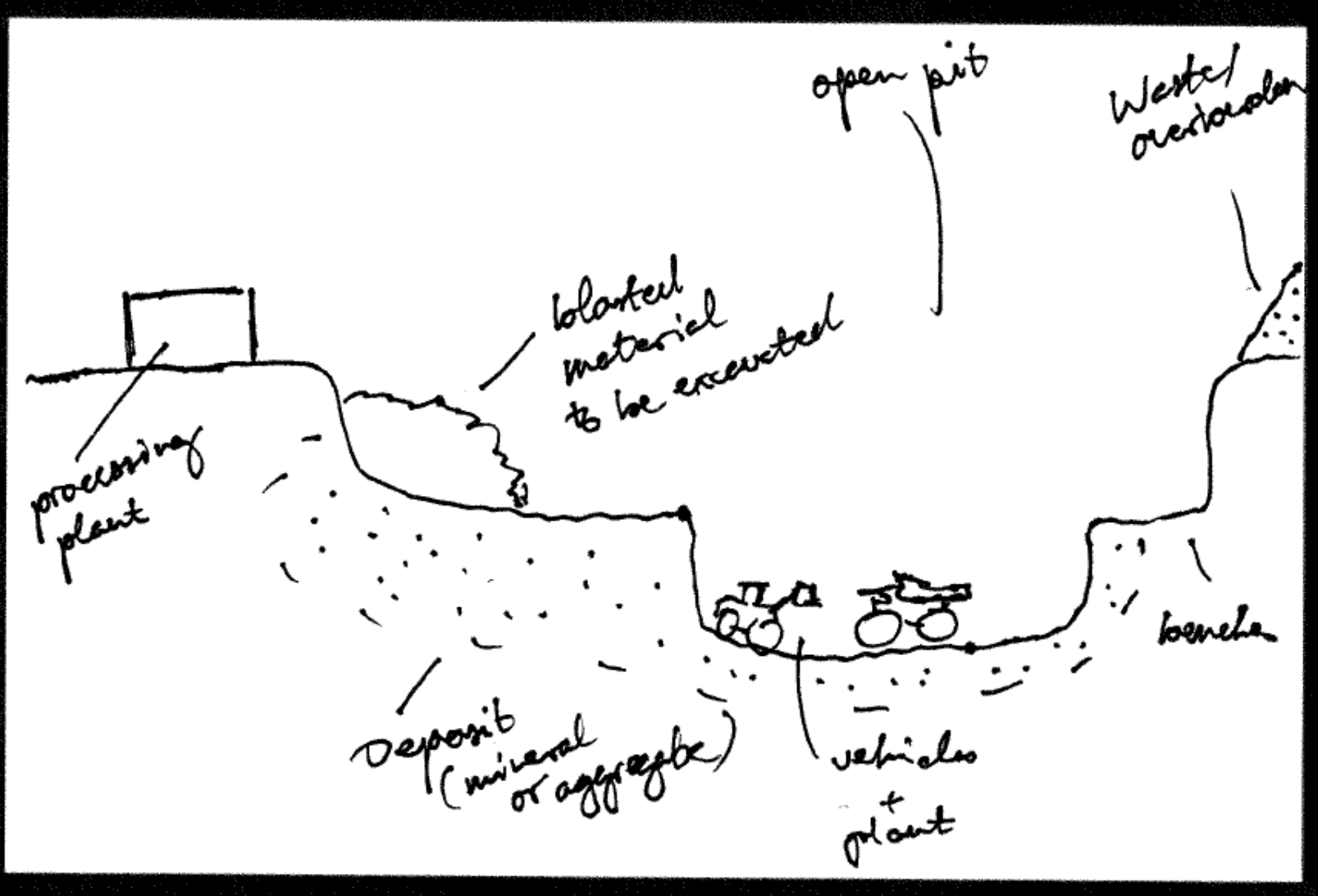




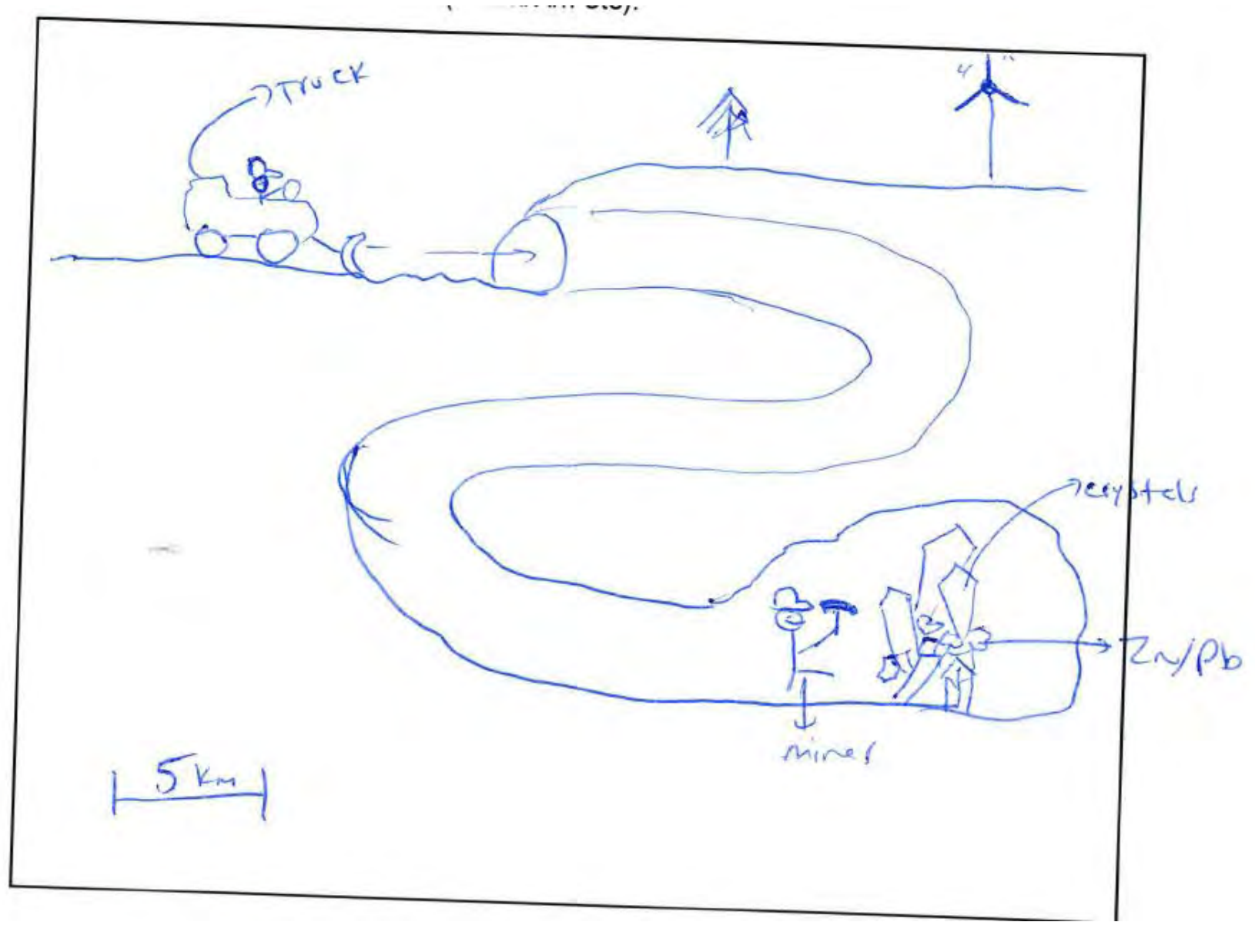




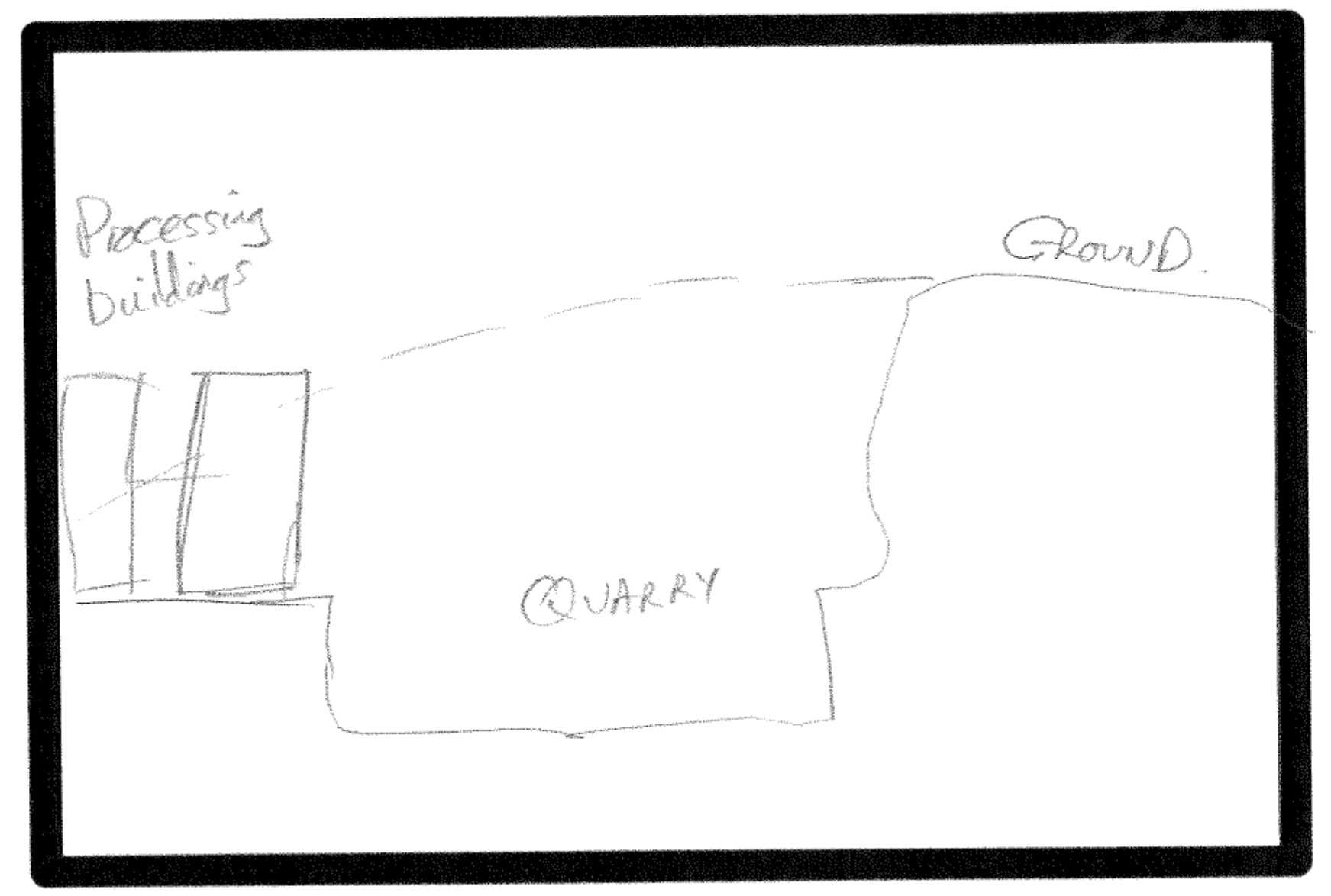




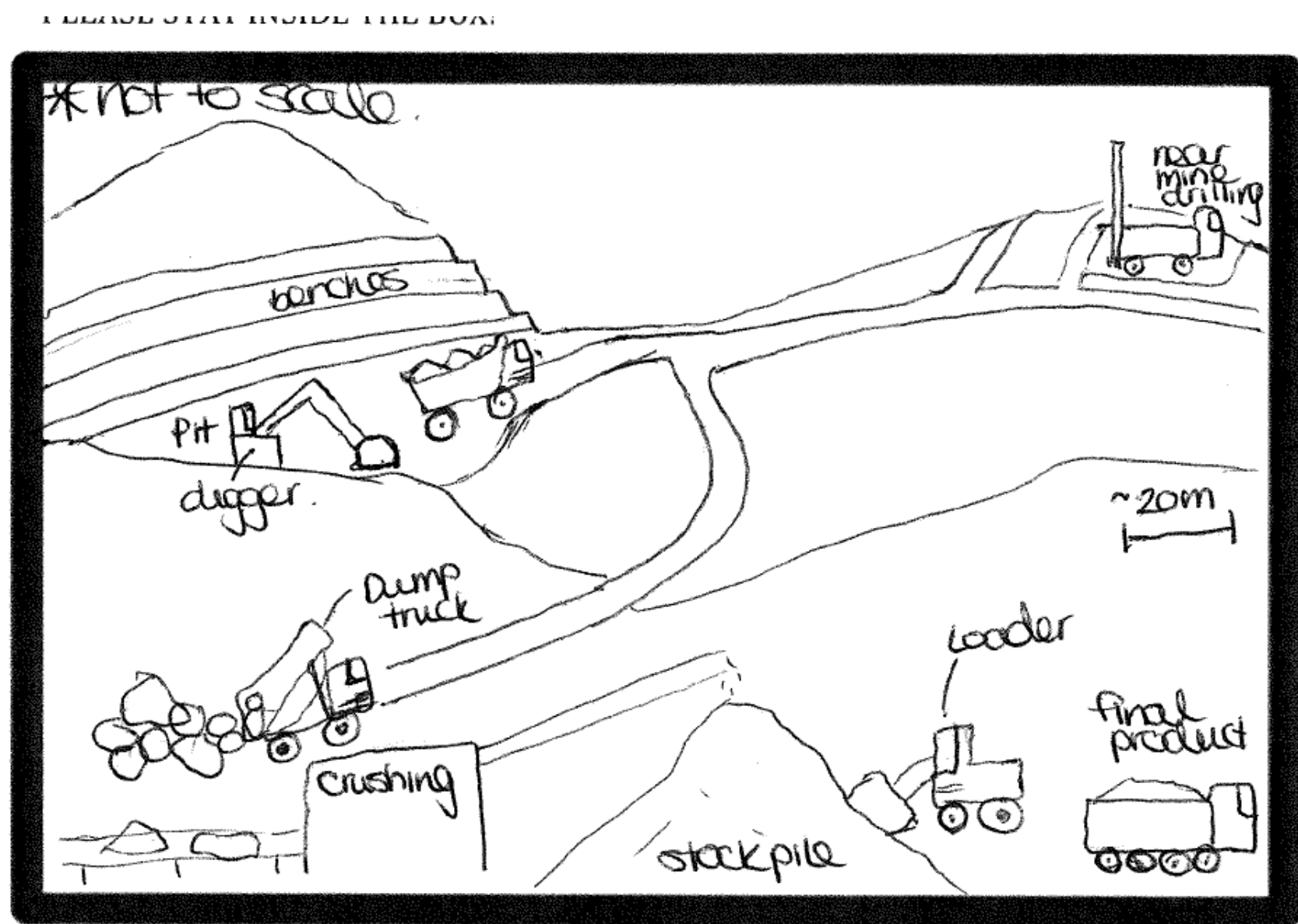




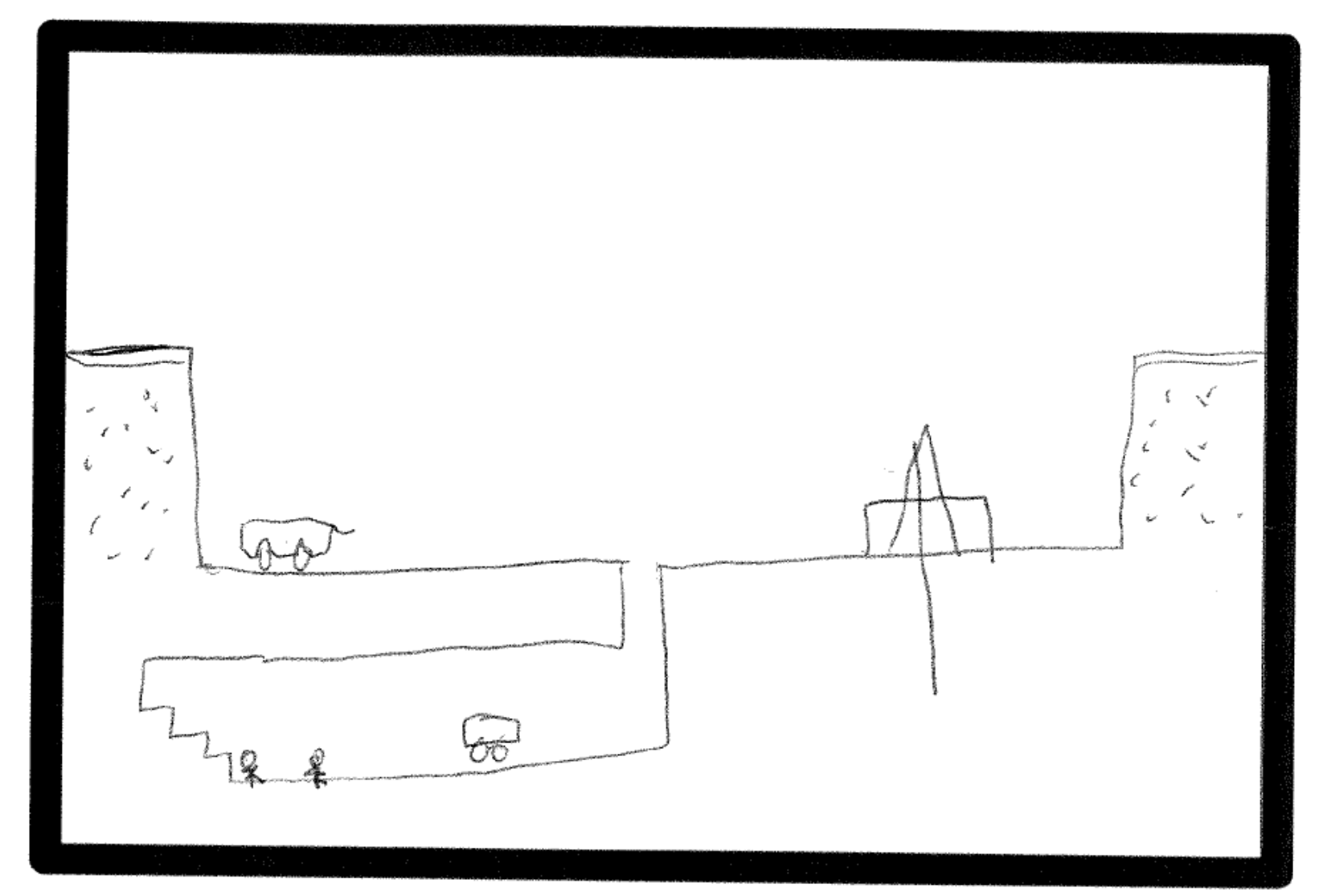




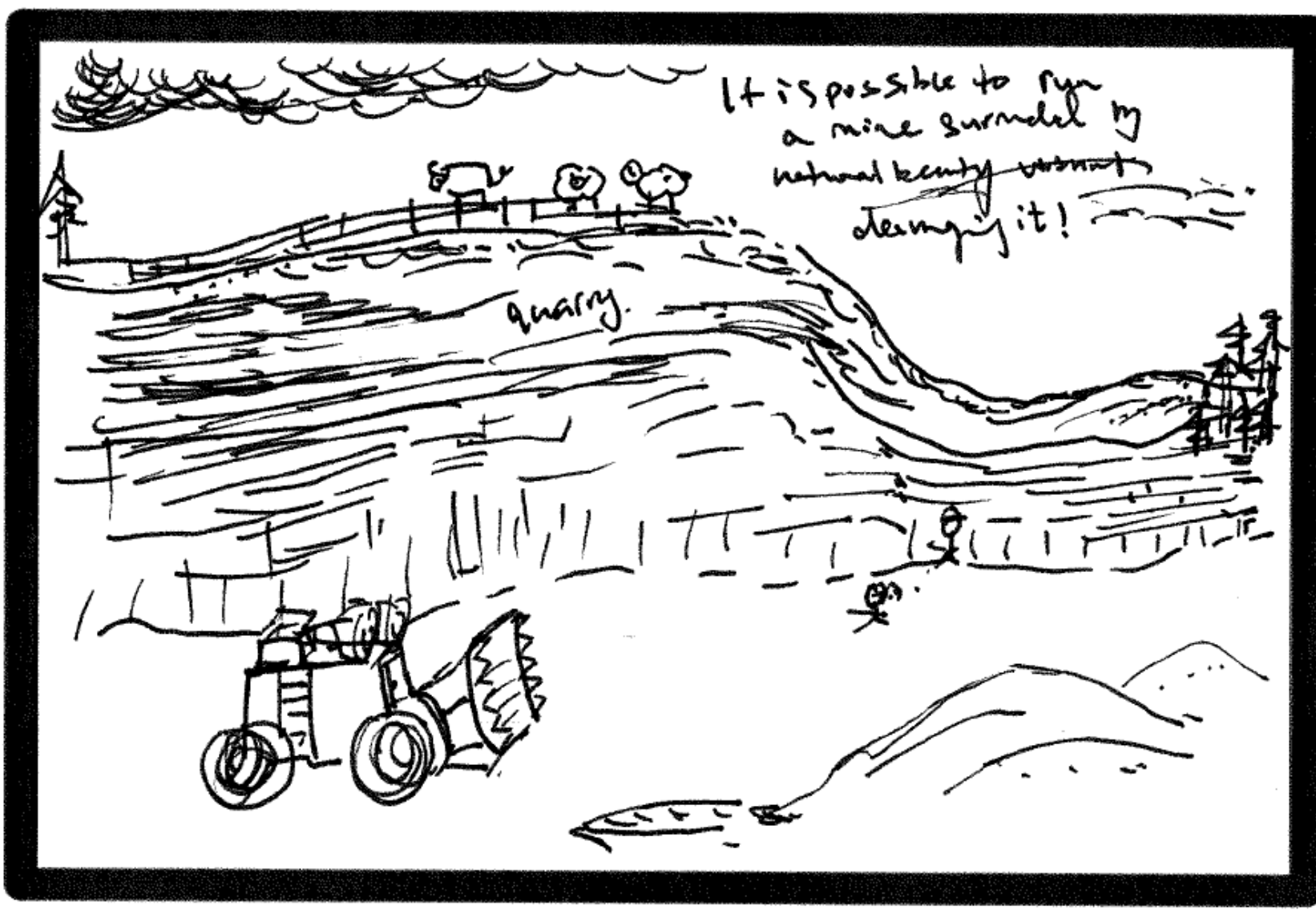


PLEASE STAY INSIDE THE BOX!

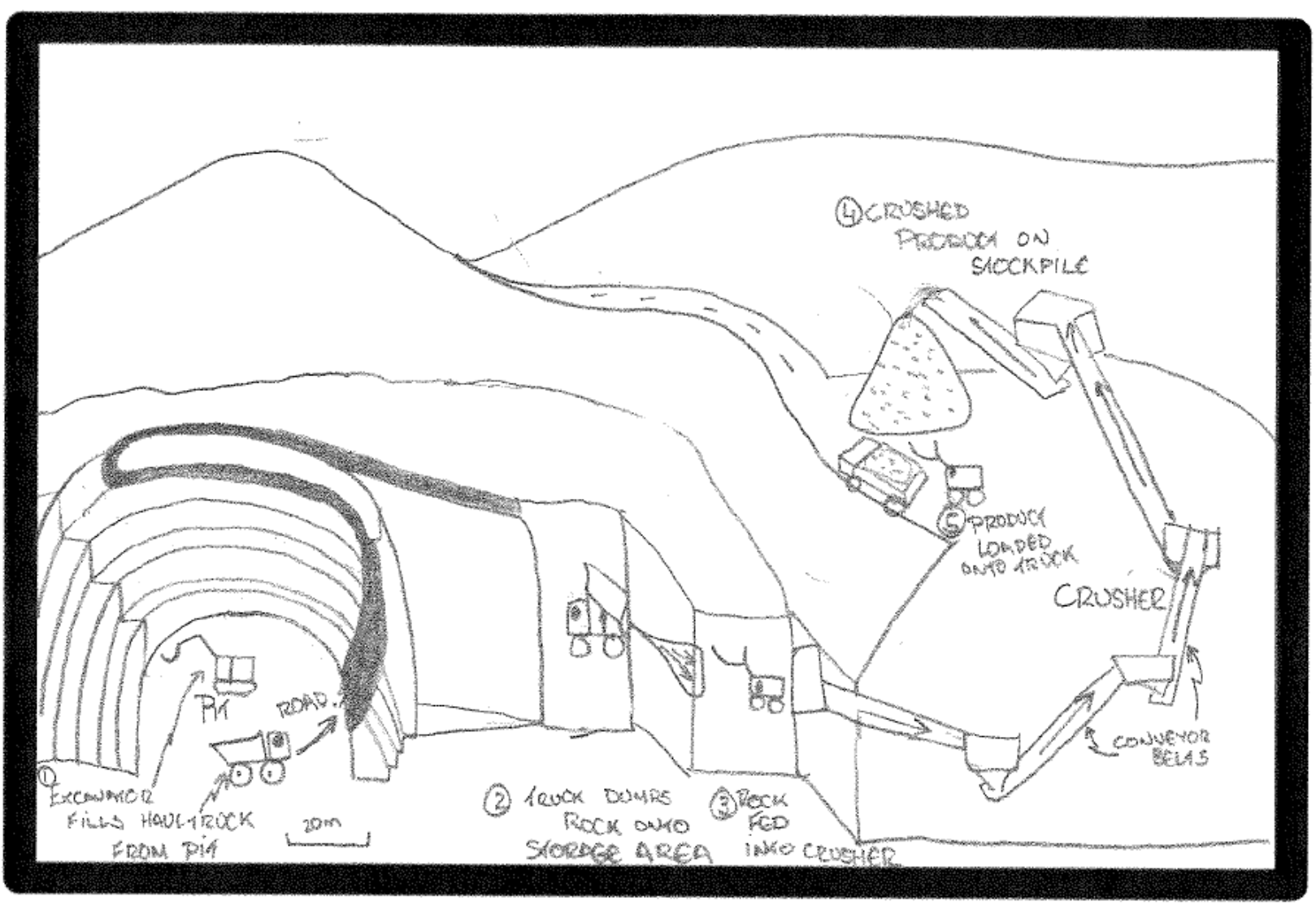




\section{PLEASE STAY INSIDE THE BOX!}

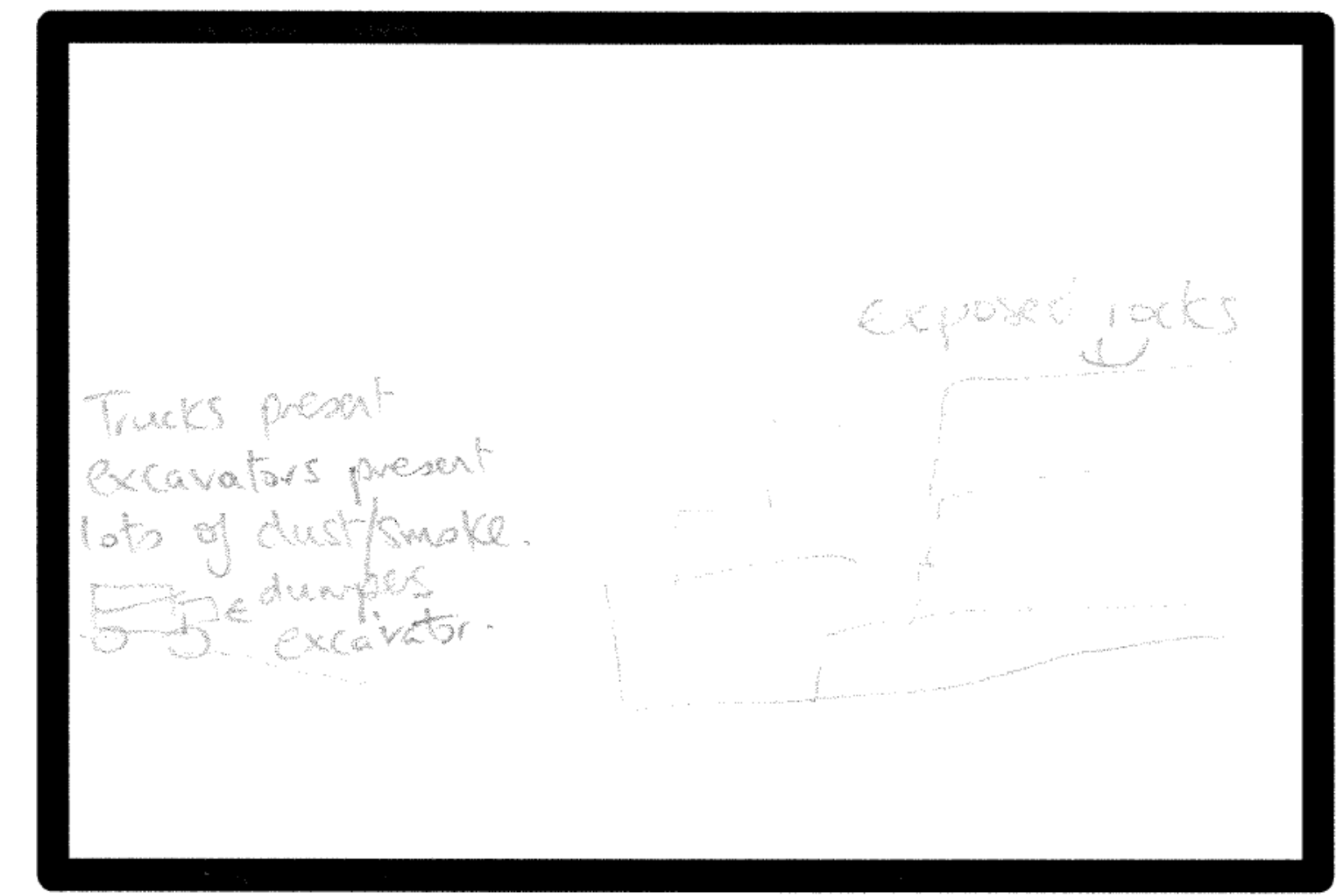




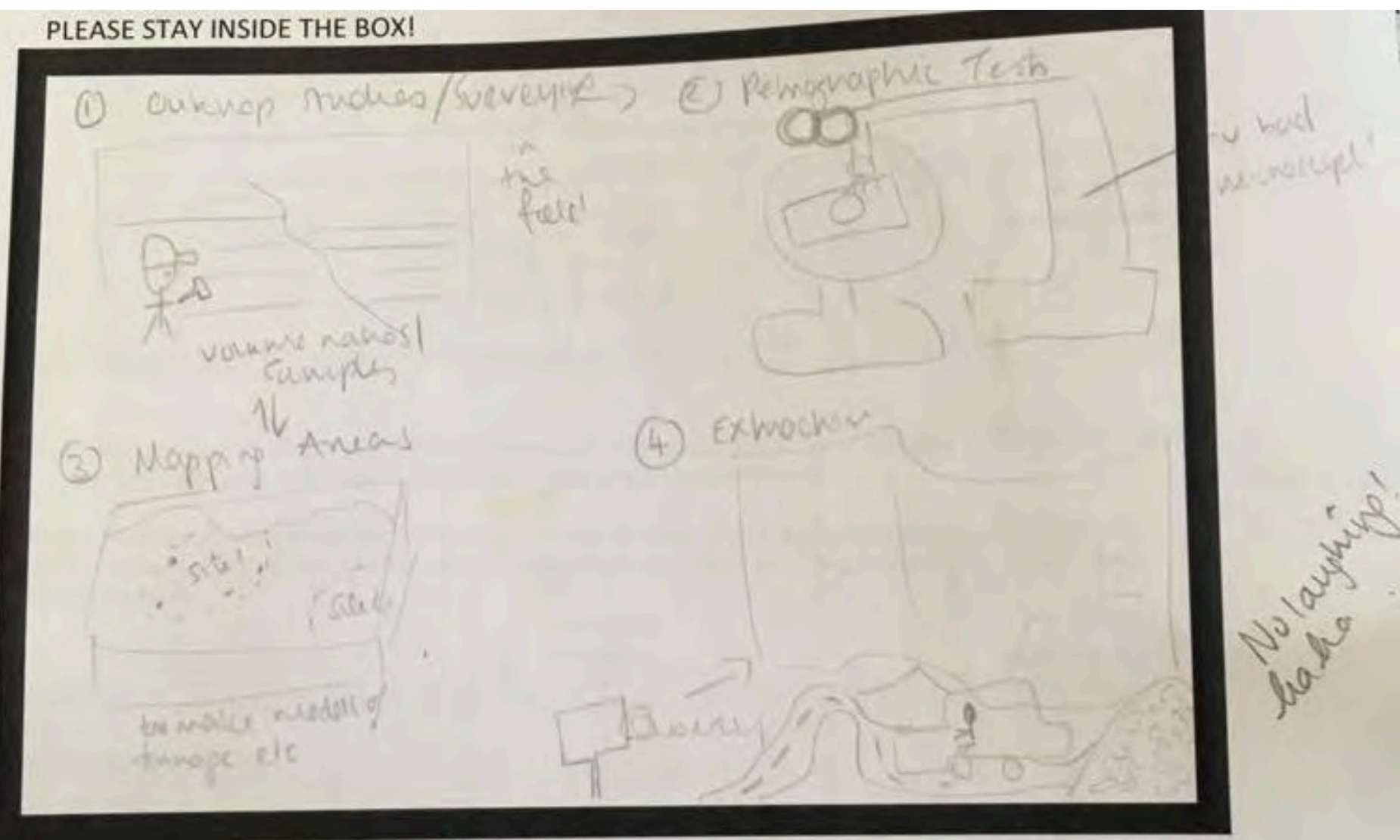


PLEASE STAY INSIDE THE BOXITROL in SE NA-

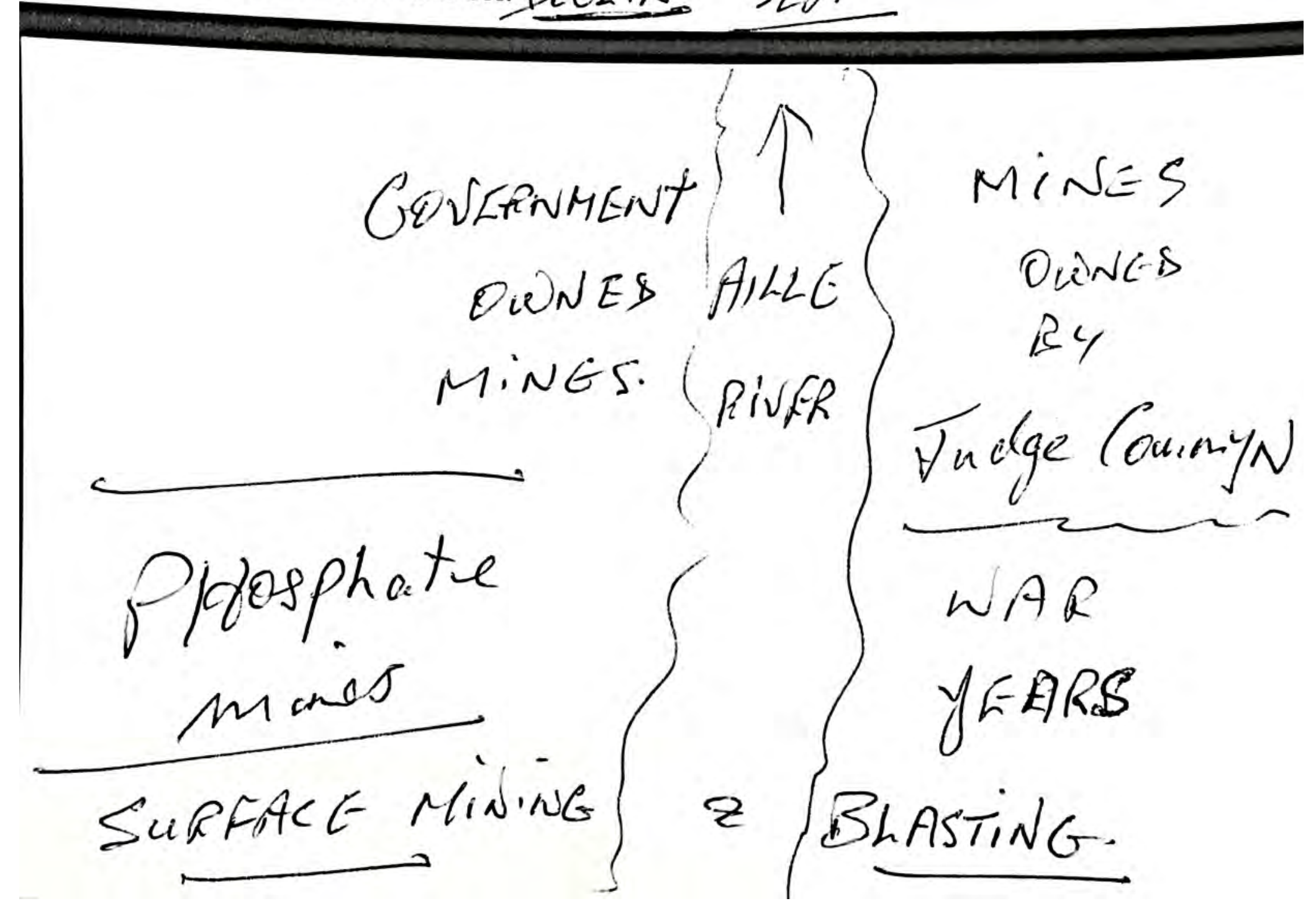




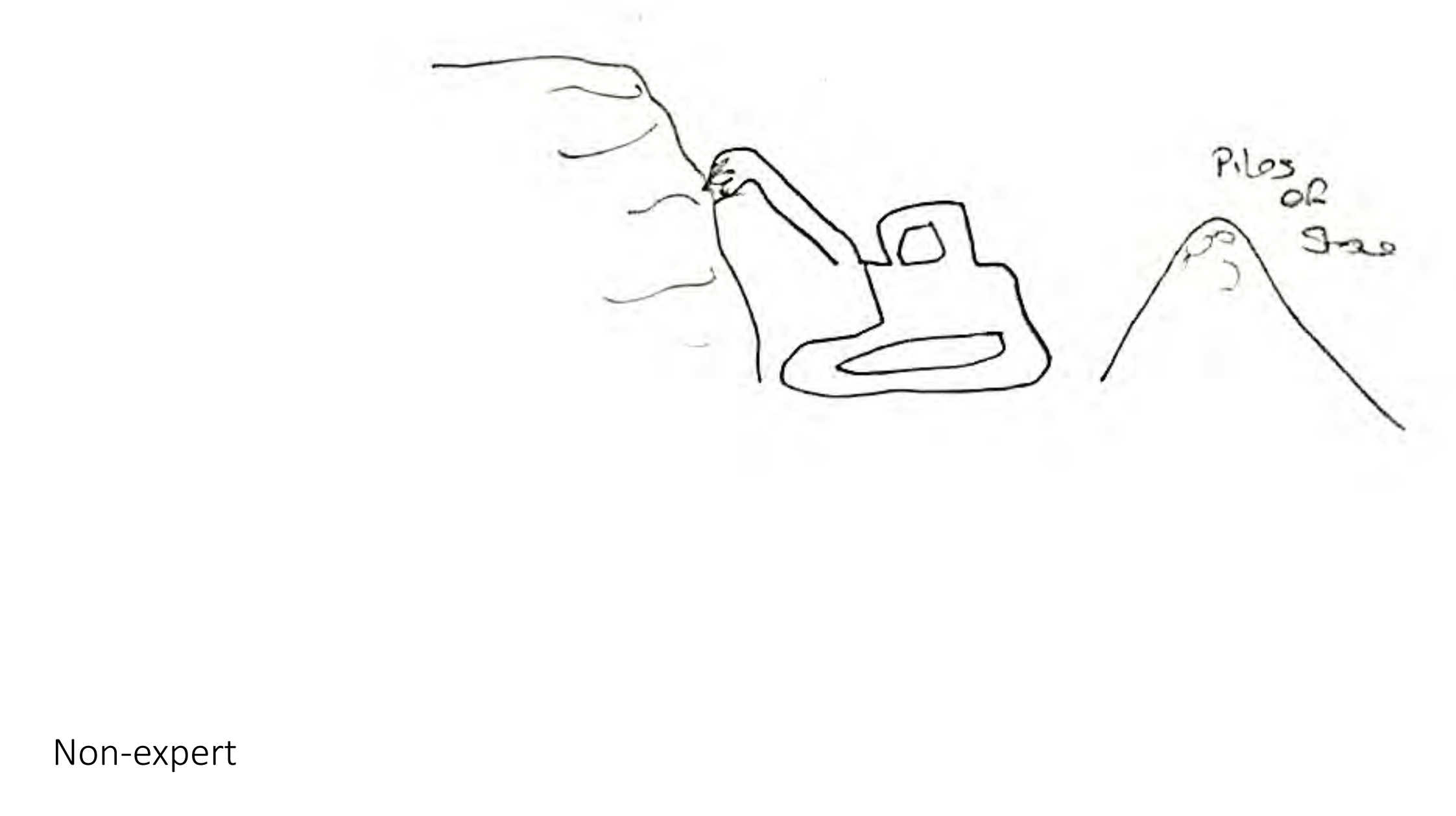


<smiles>CCOC1CCCCC1</smiles>

Non-expe 


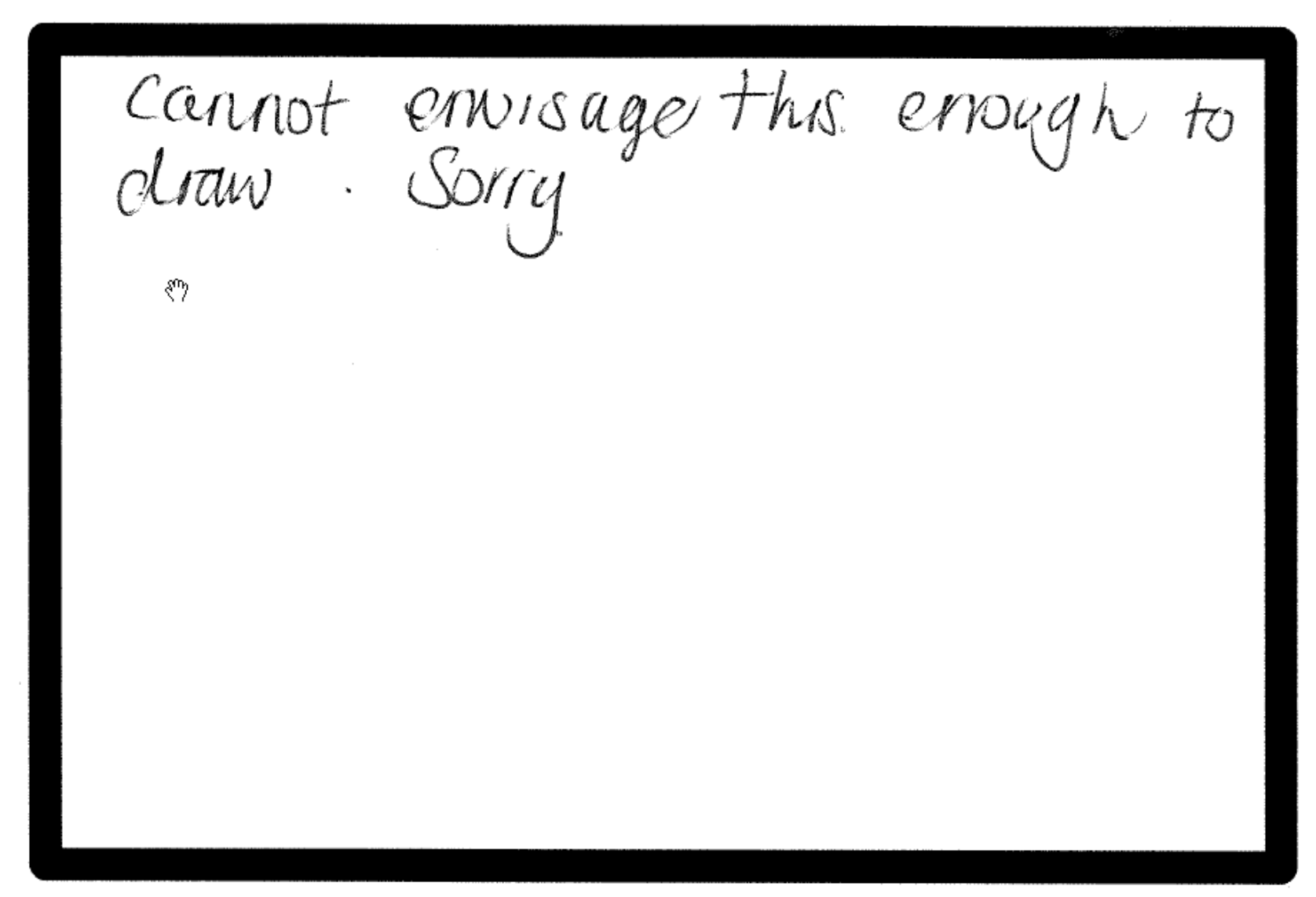


PLEASE STAY INSIDE THE BOX!

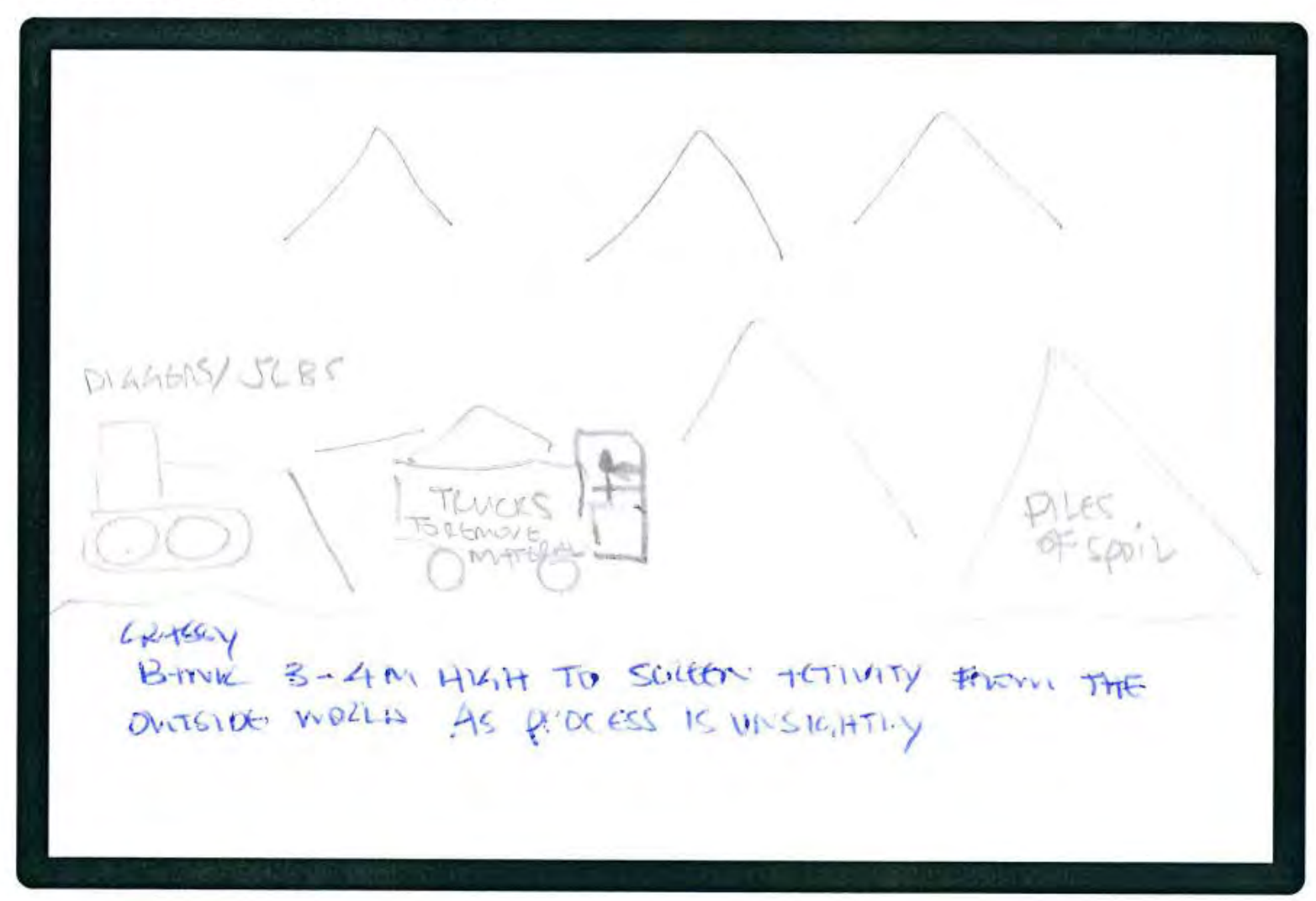


PLEASE STAY INSIDE THE BOX!

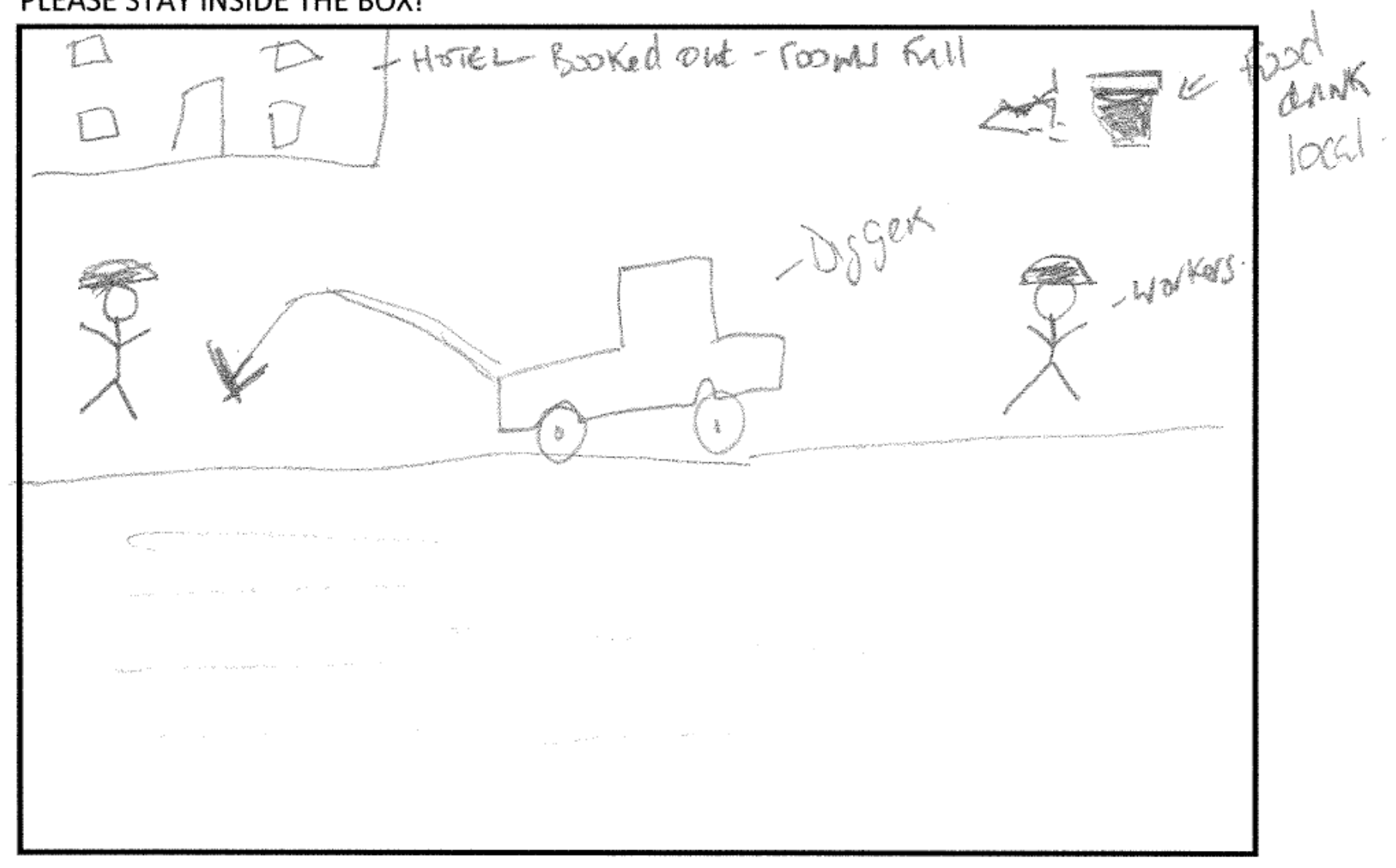

Non-expert 


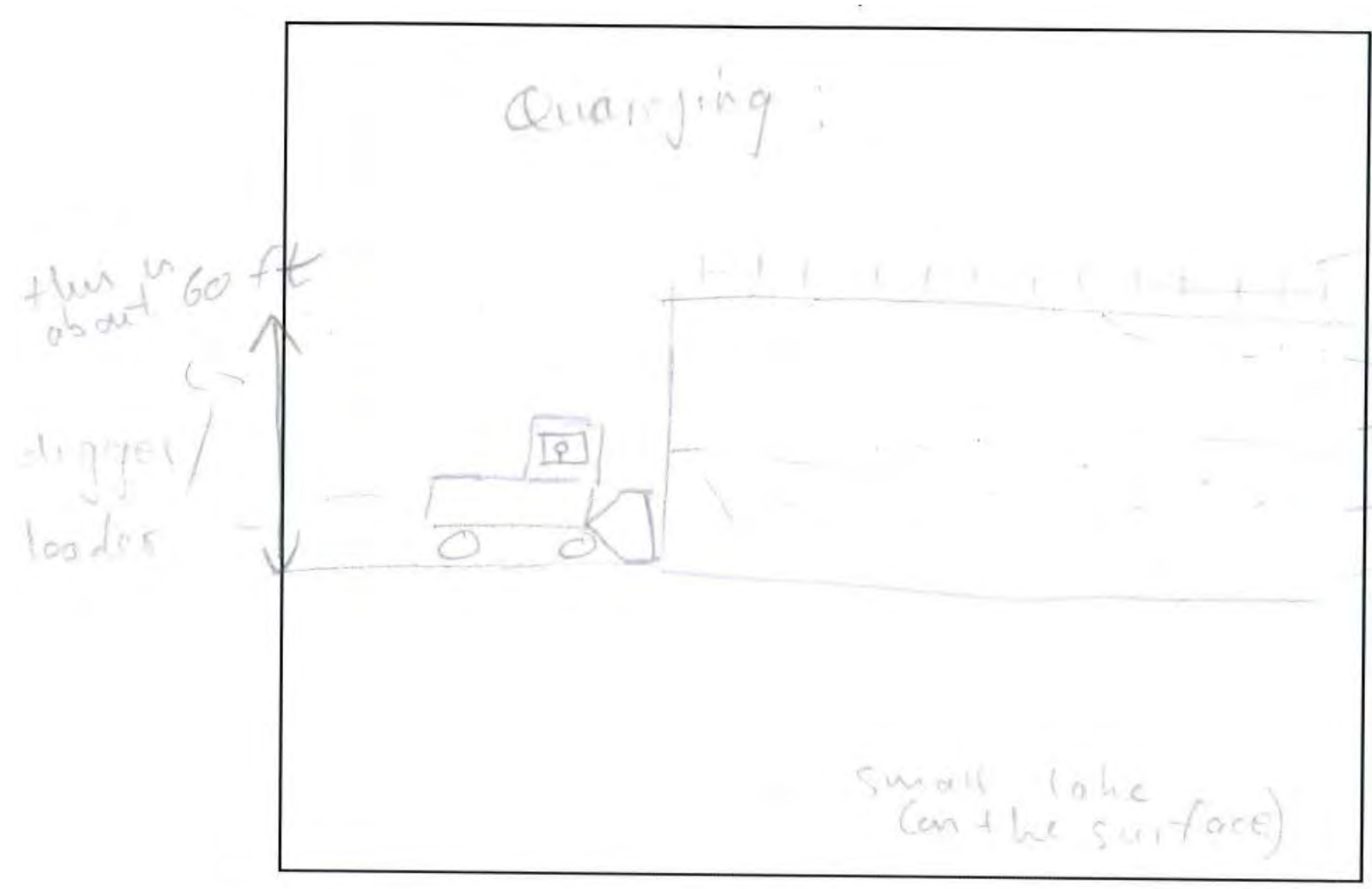

Non-expert 


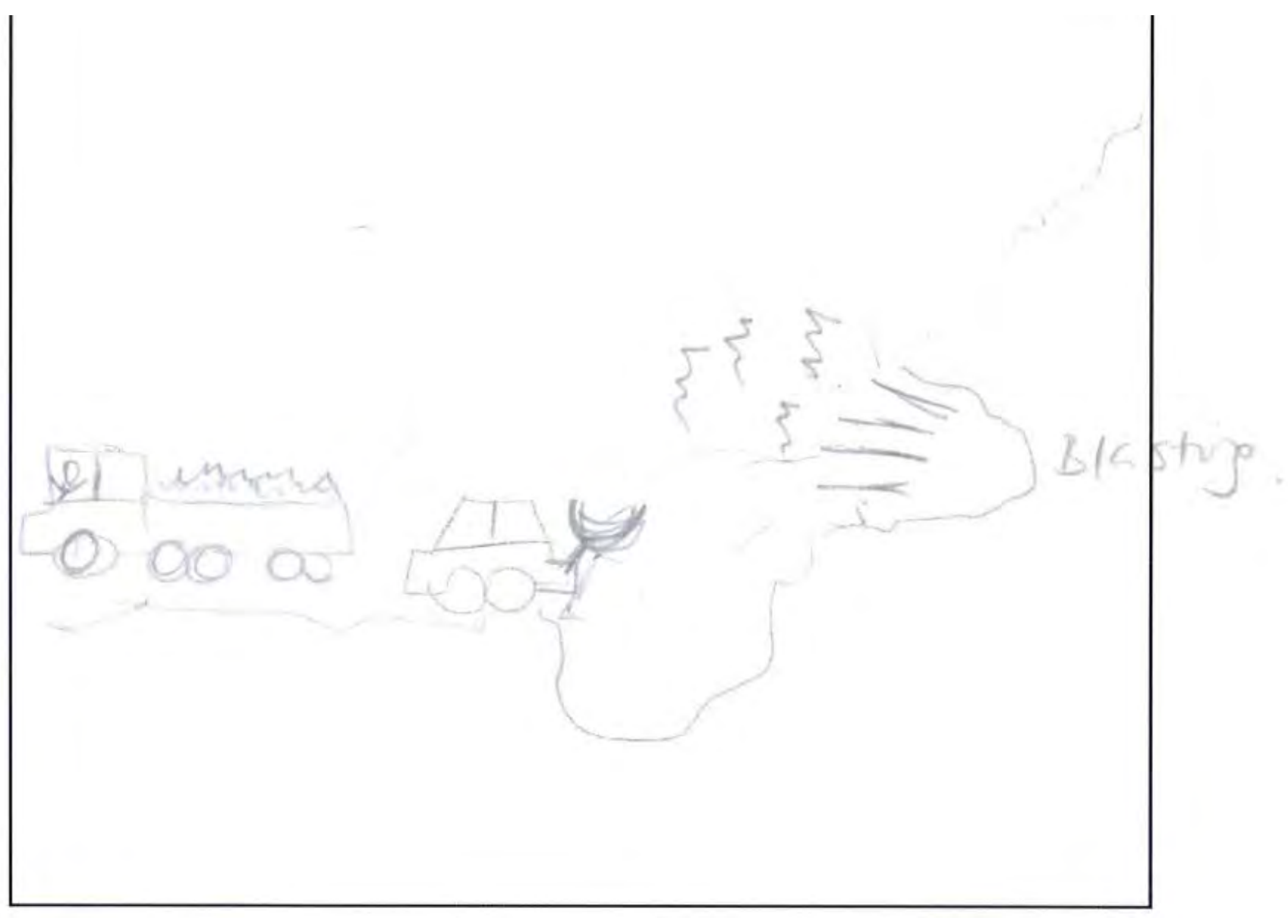

Non-expert 


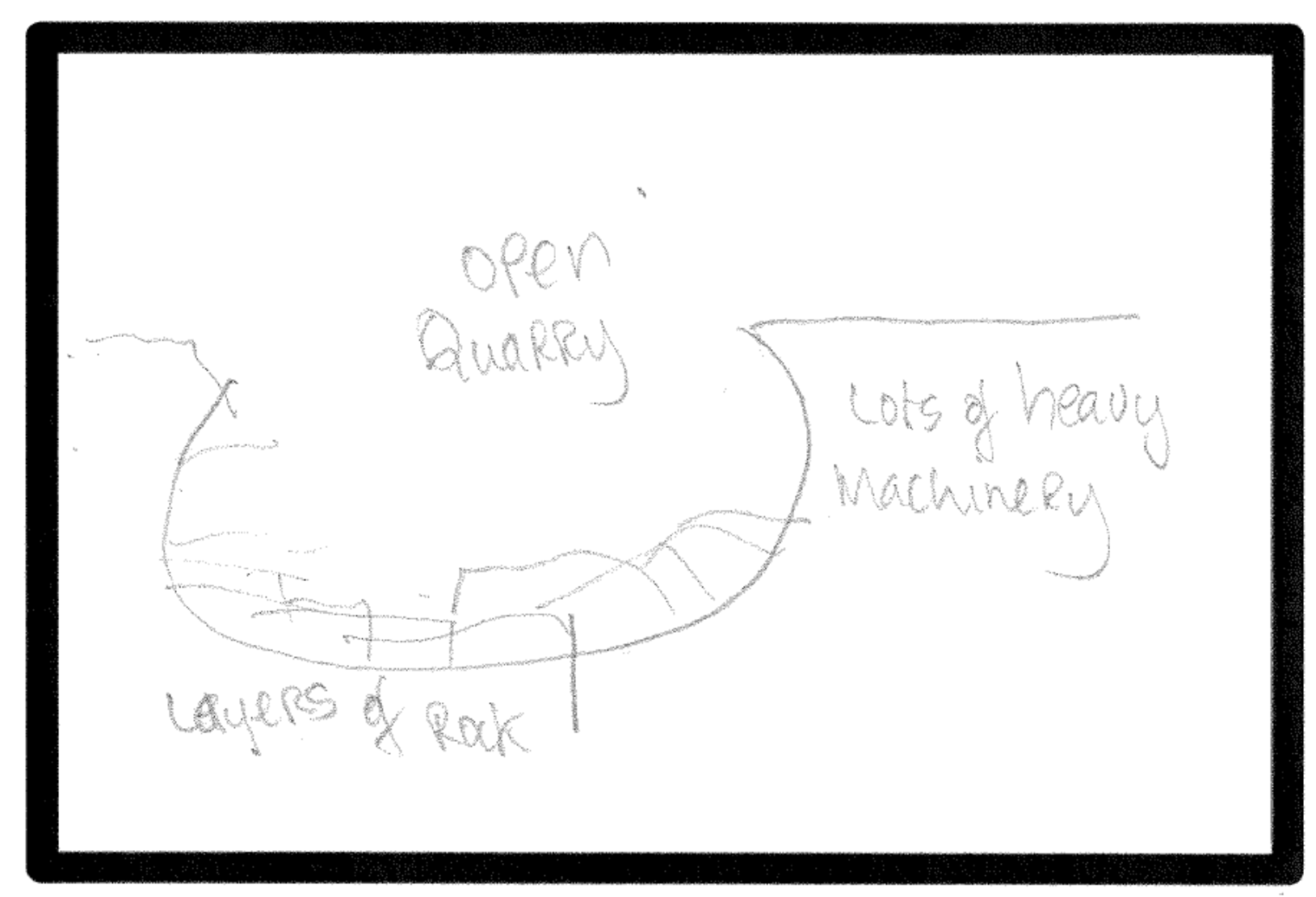




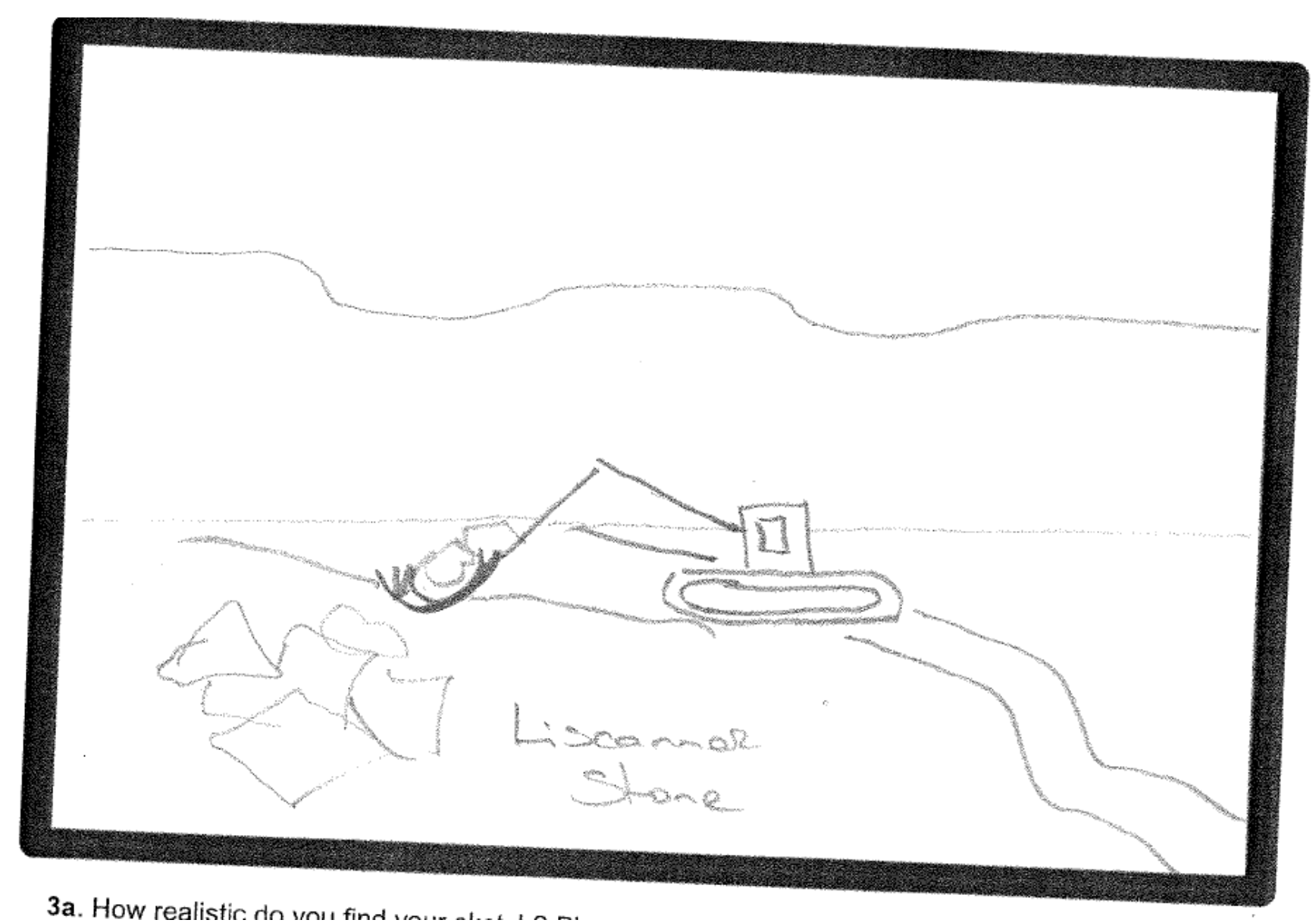




\section{PLEASE STAY INSIDE THE BOX!}

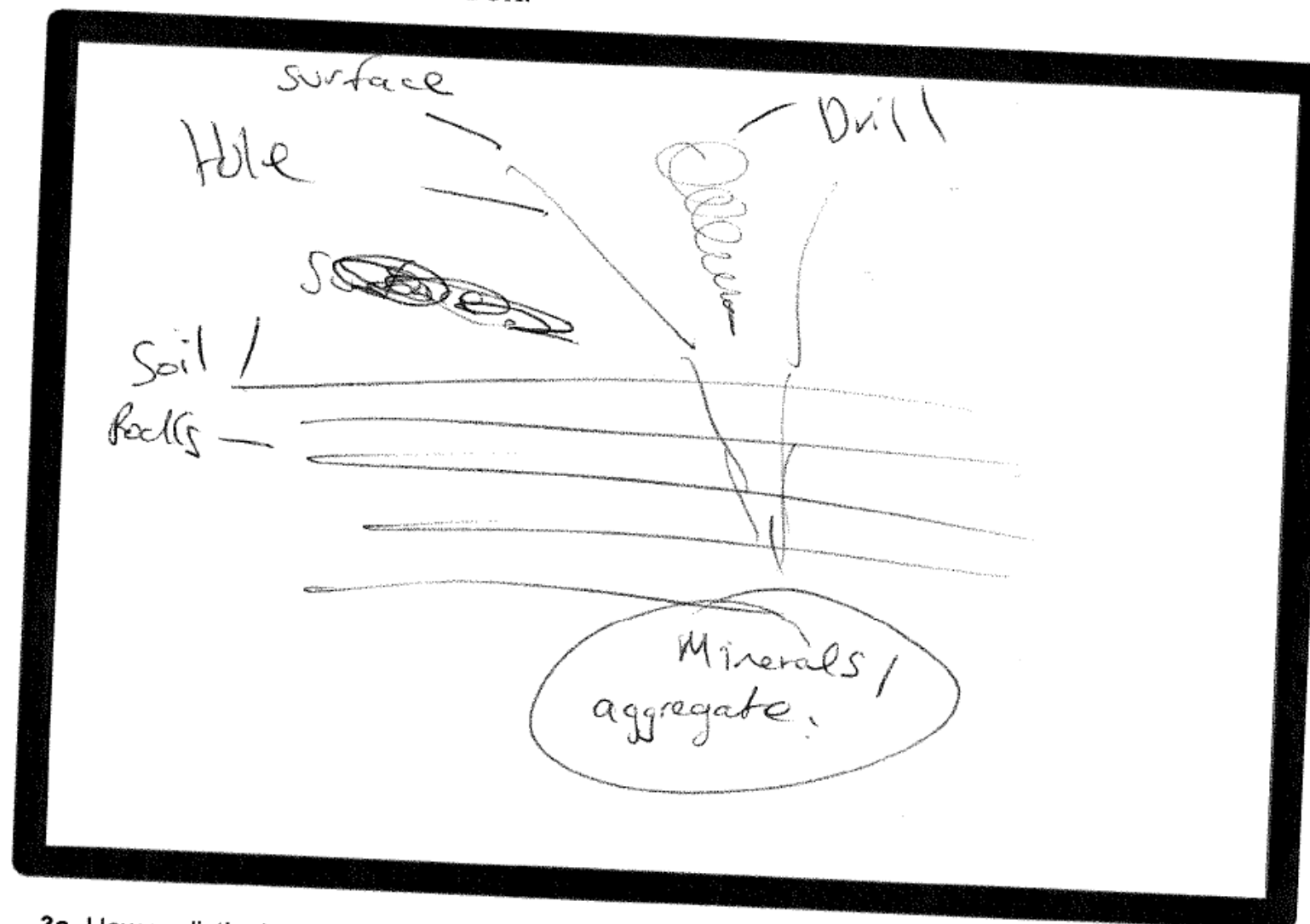


PLEASE STAY INSIDE THE BOX!

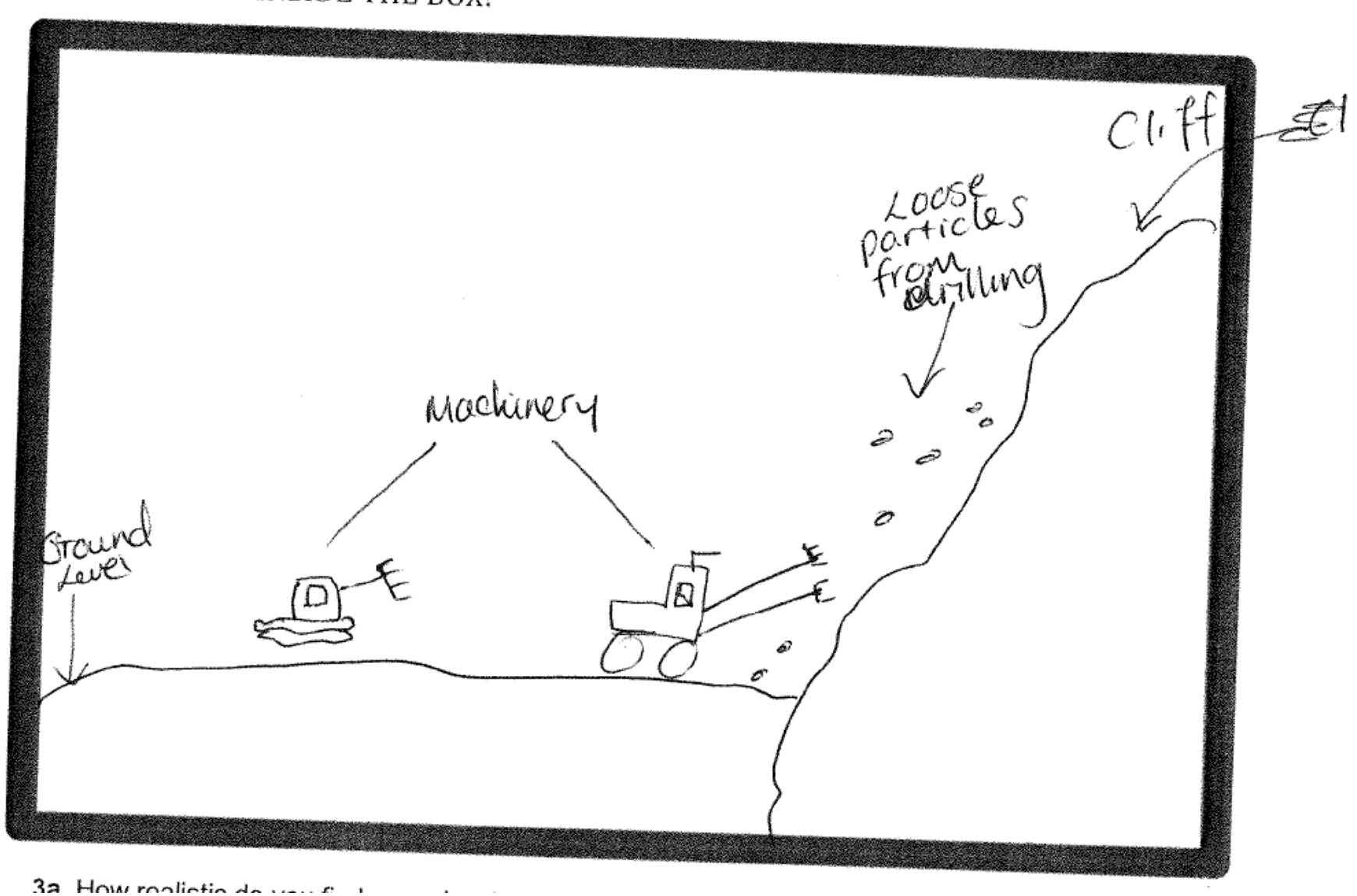


PLEASE STAY INSIDE THE BOX!

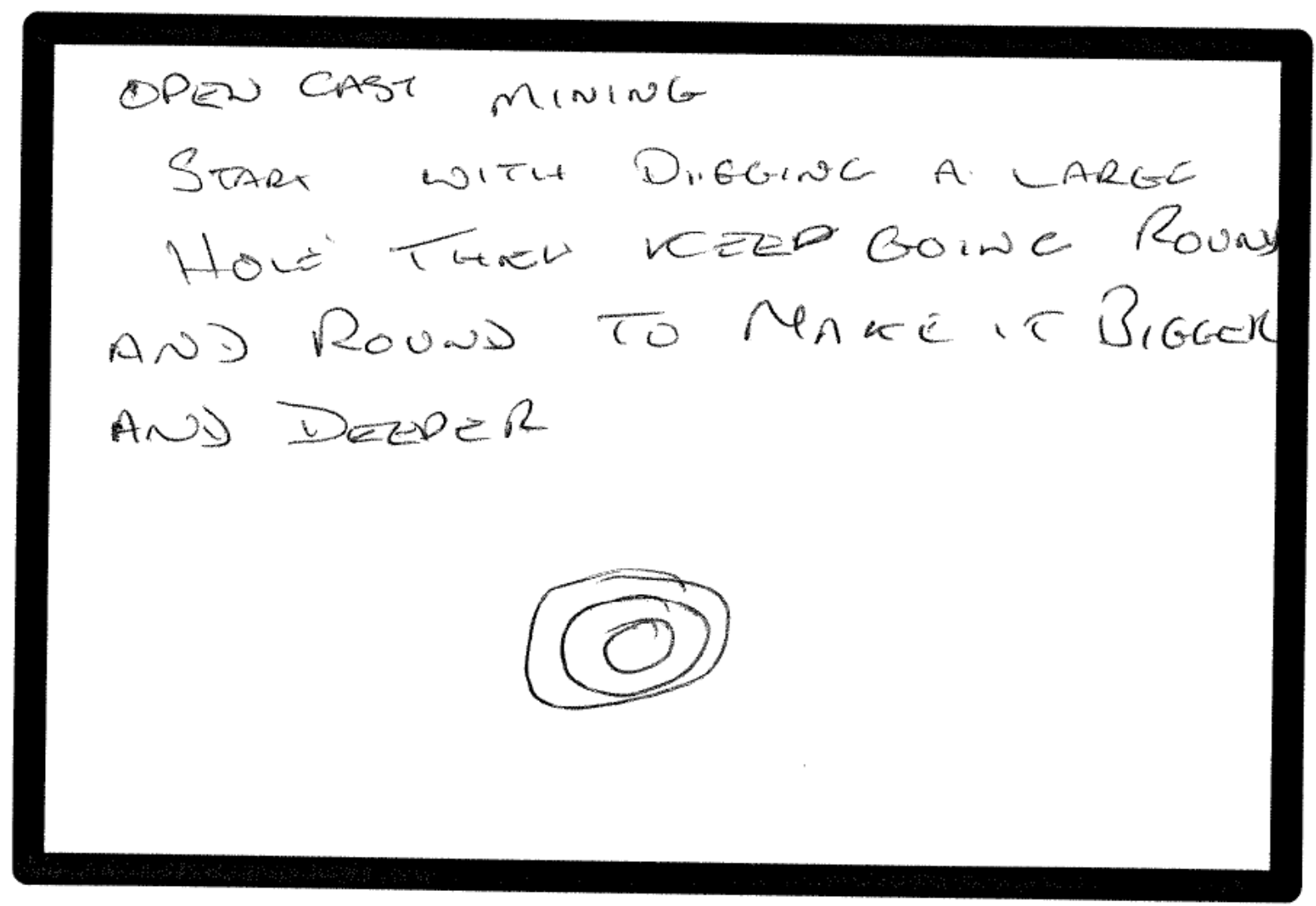


PLEASE STAY INSIDE THE BOX!

3a. How realictir do unu find t.e 
PLEASE STAY INSIDE THE BOX!

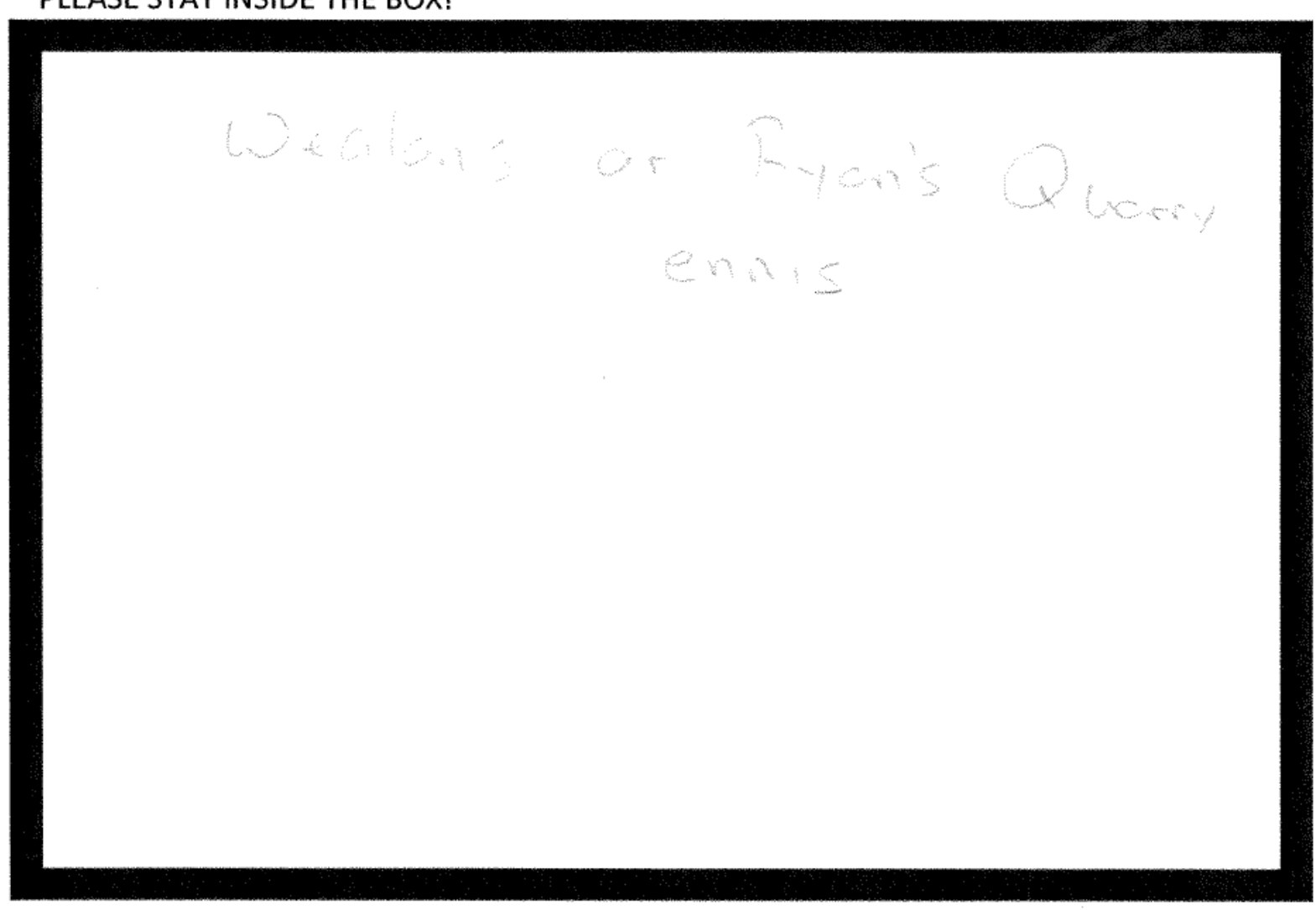

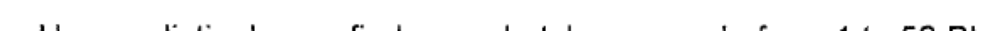

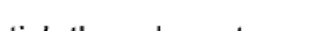




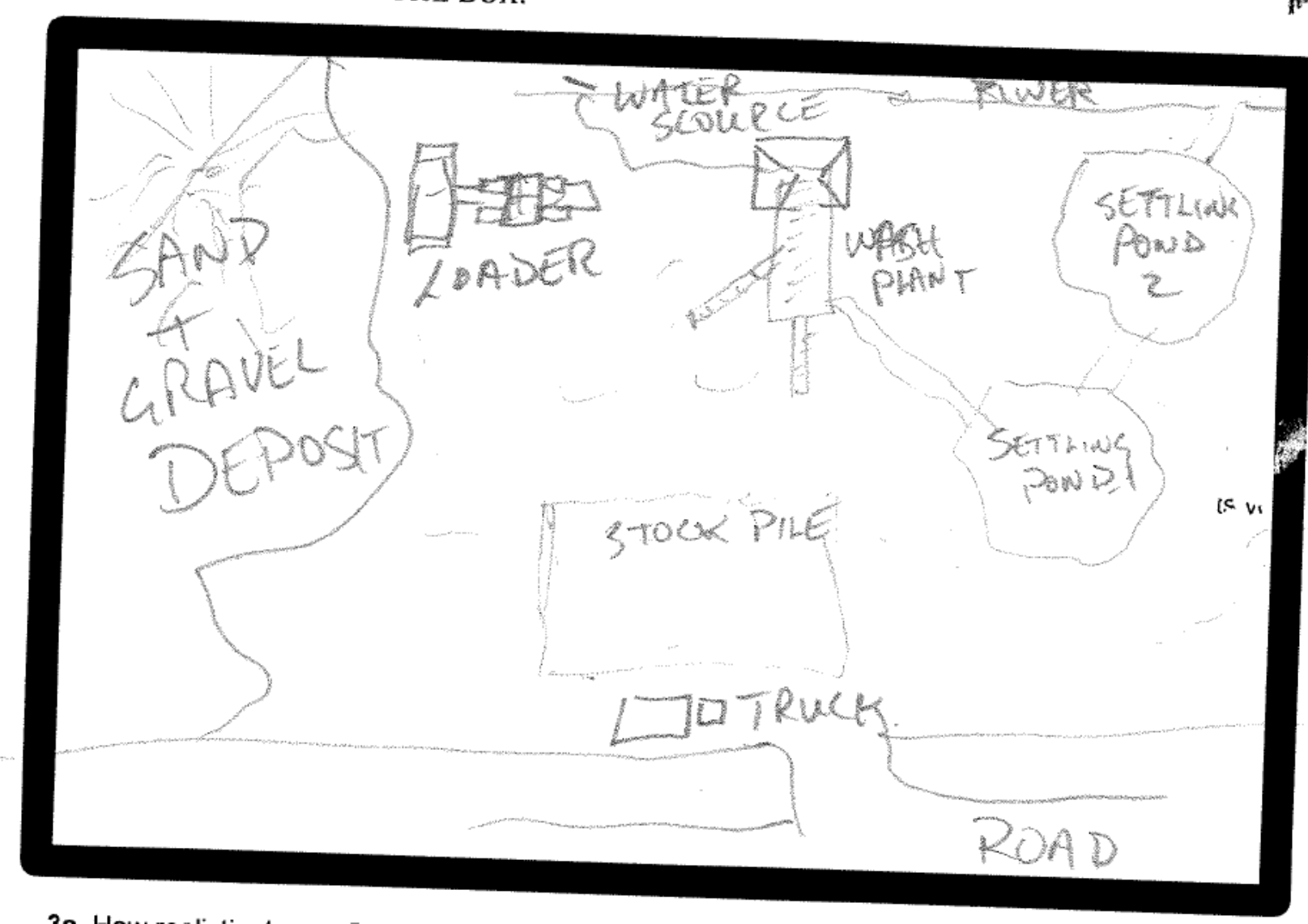




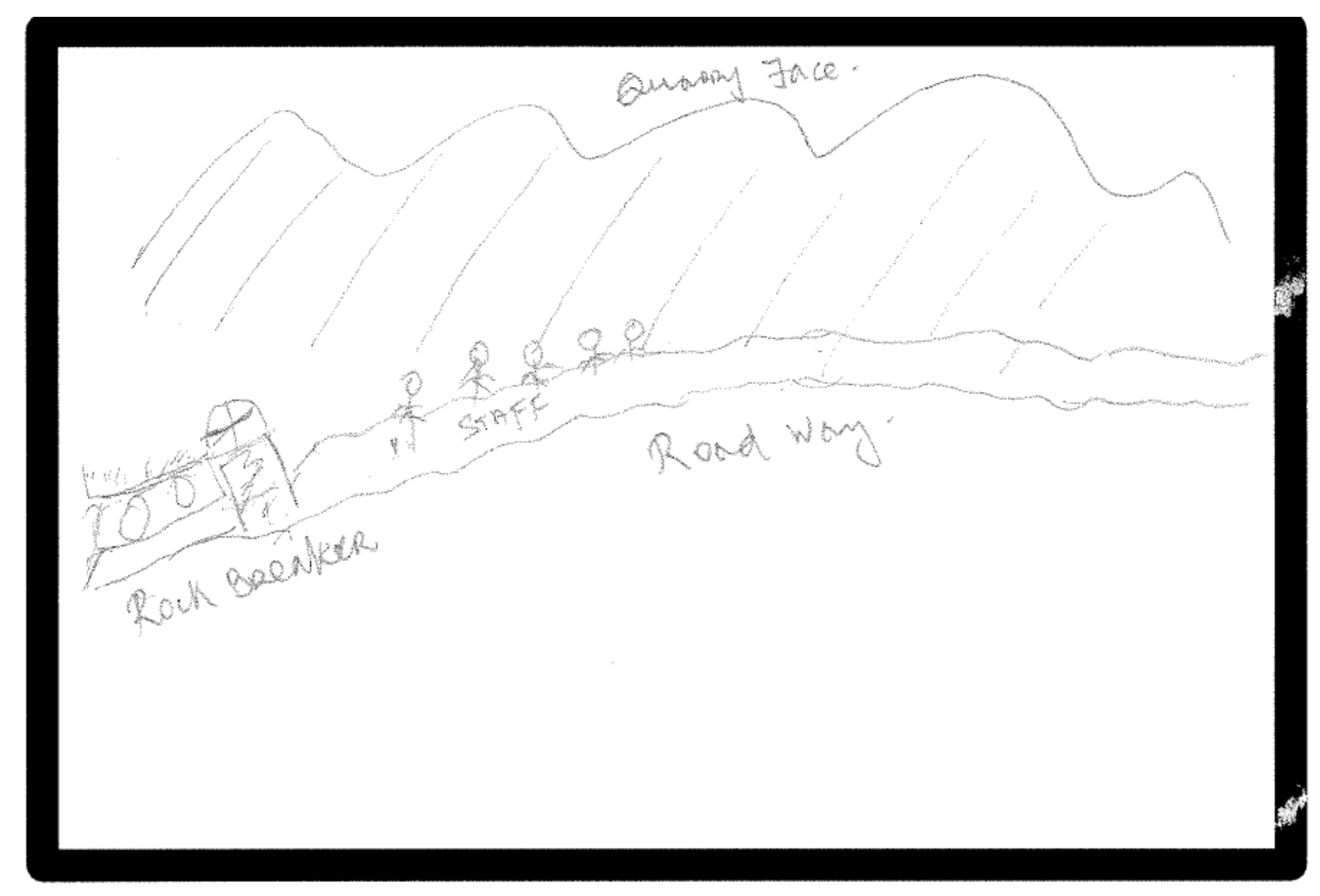




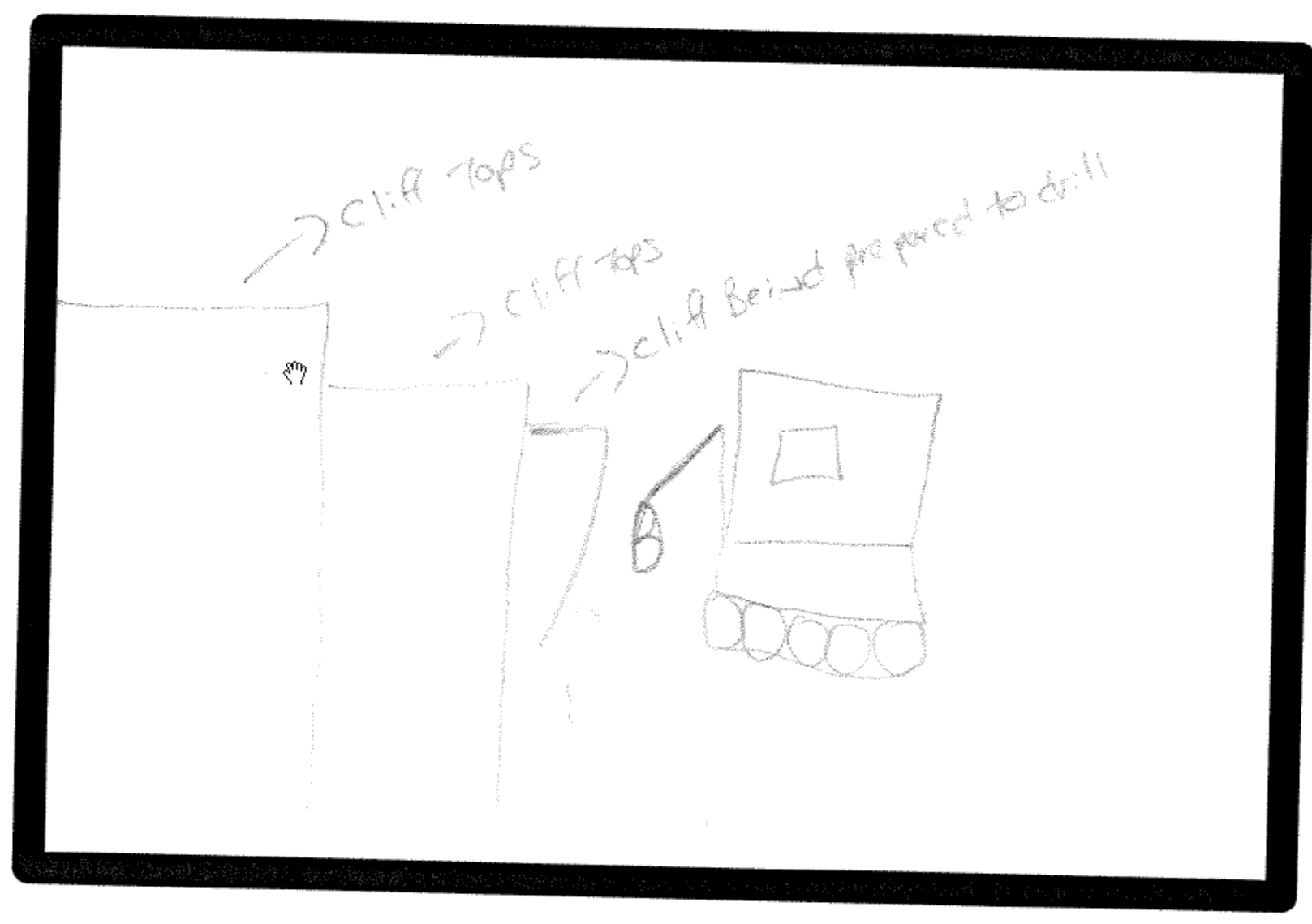




$$
\nabla
$$


PLEASE STAY INSIDE THE BOX!

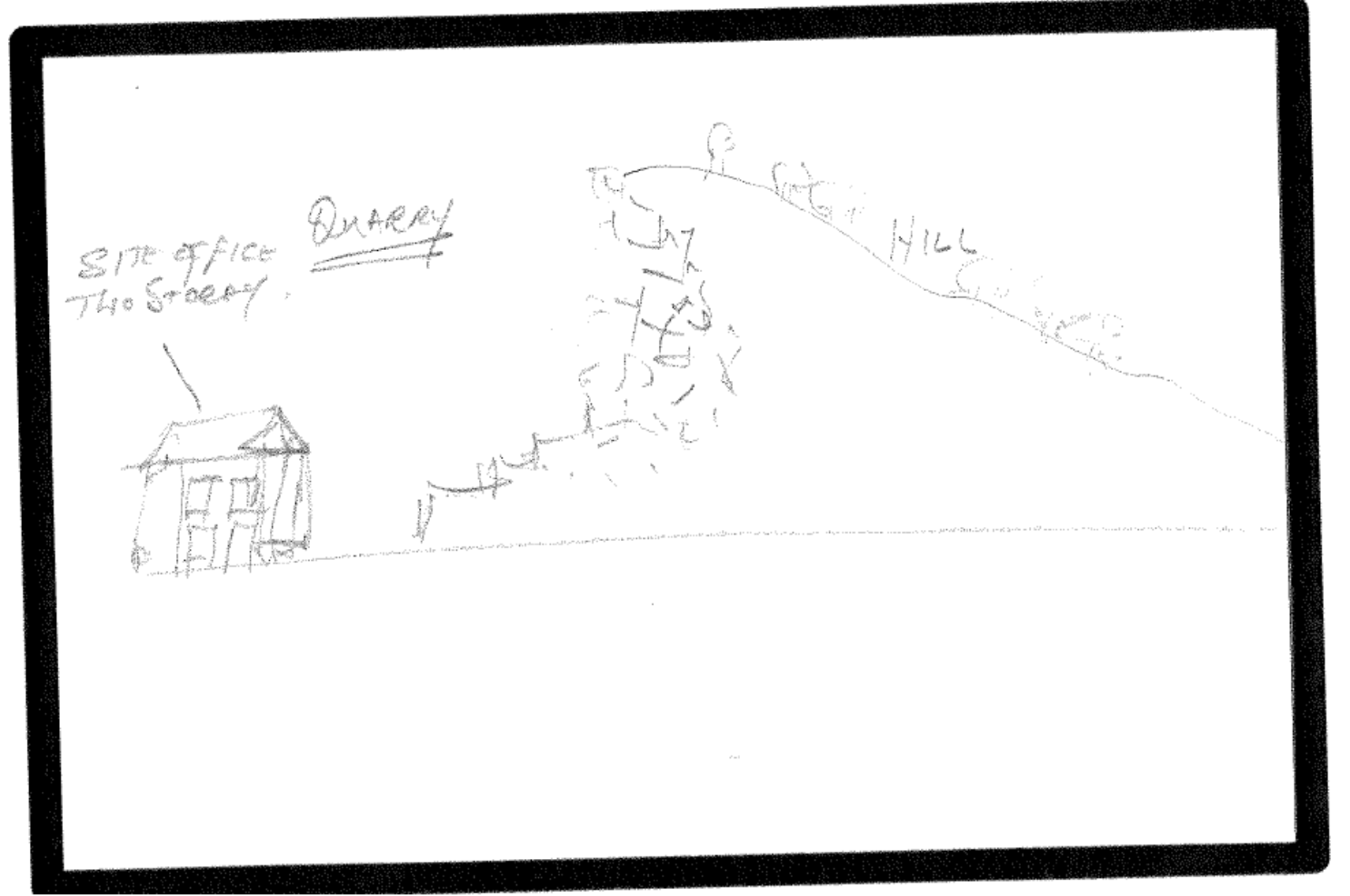


PLEASE STAY INSIDE THE BOX!

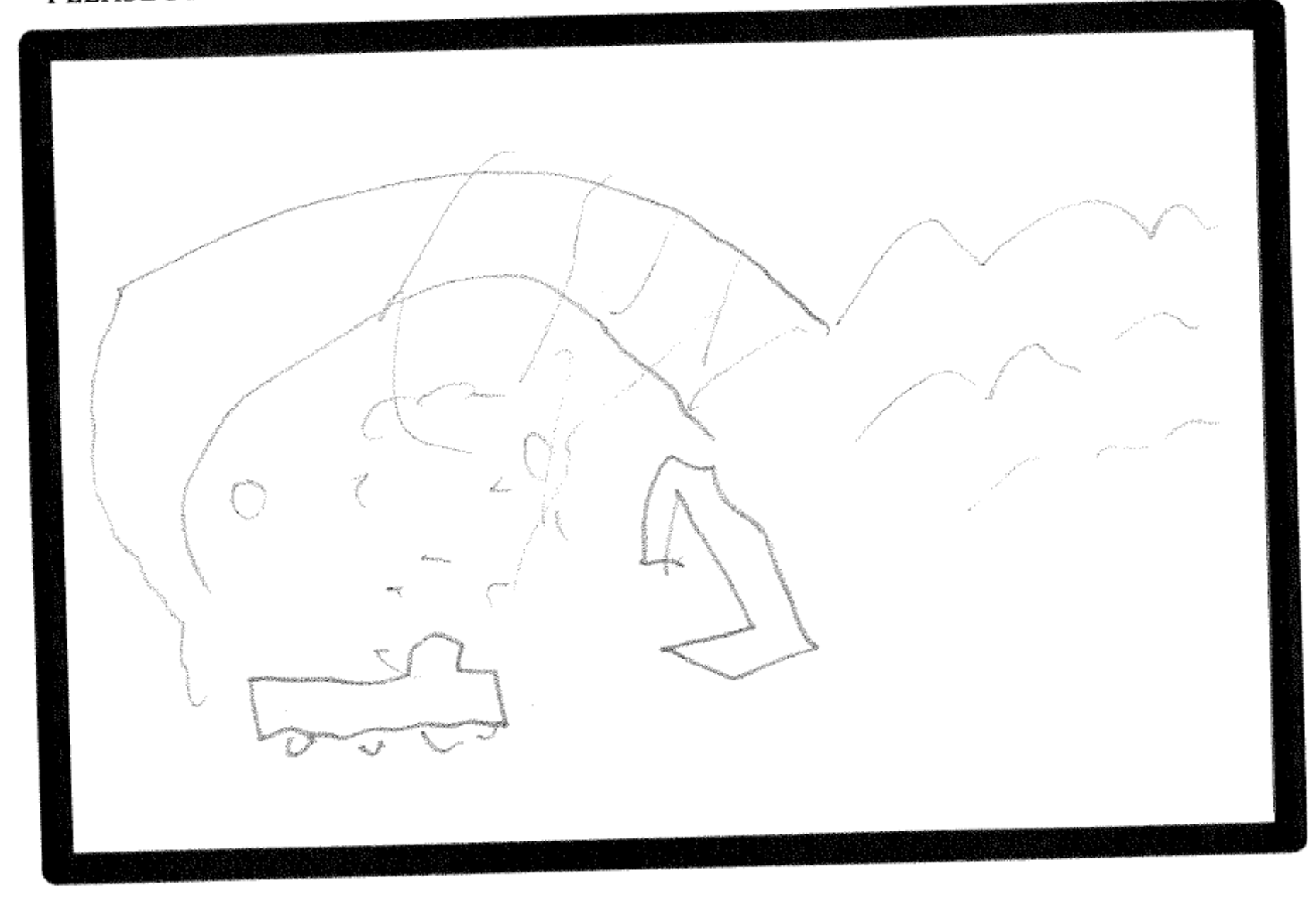




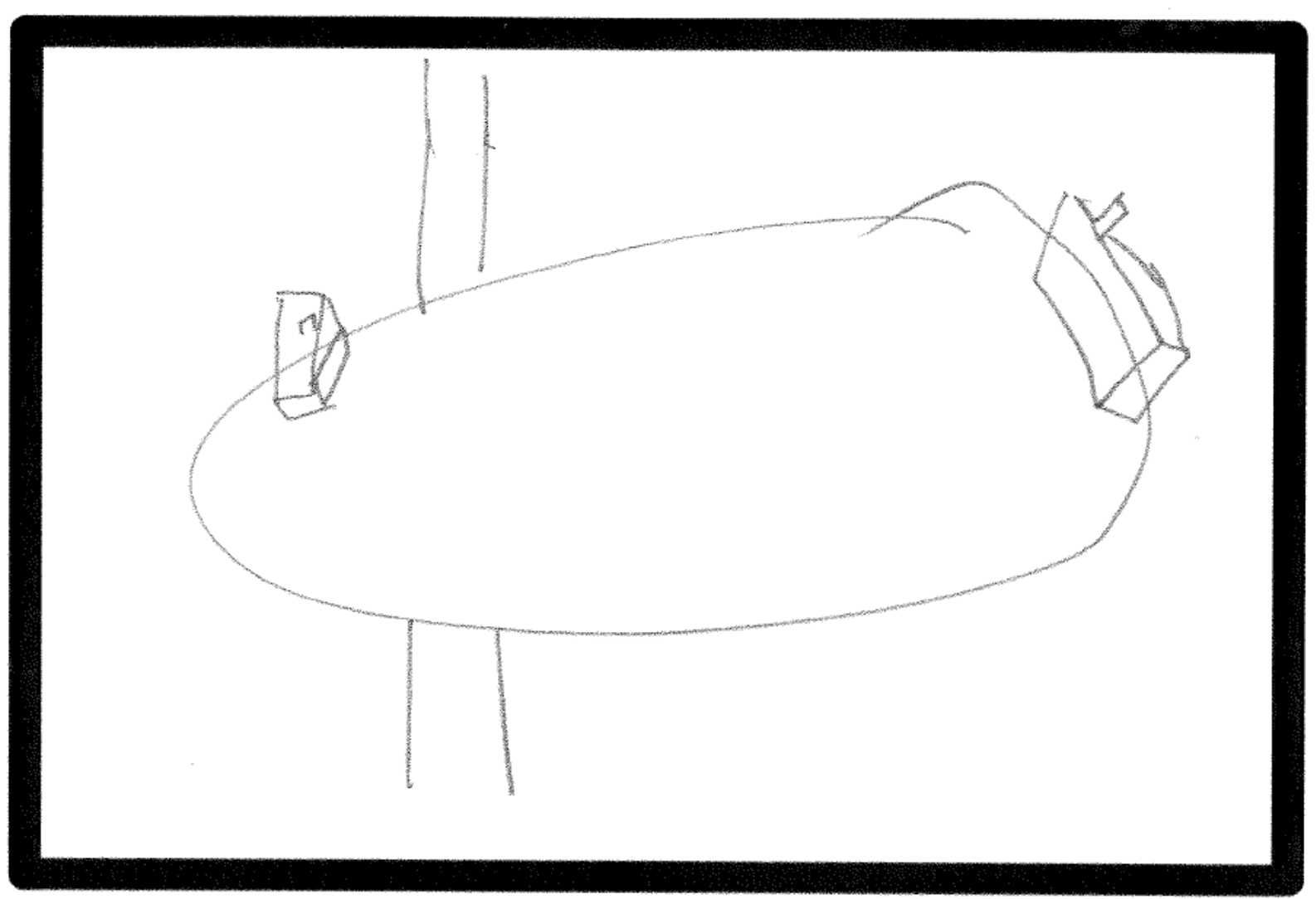


PLEASE STAY INSIDE THE BOX! 
PLEASE STAY INSIDE THE BOX! 
PLEASE STAY INSIDE THE BOX!

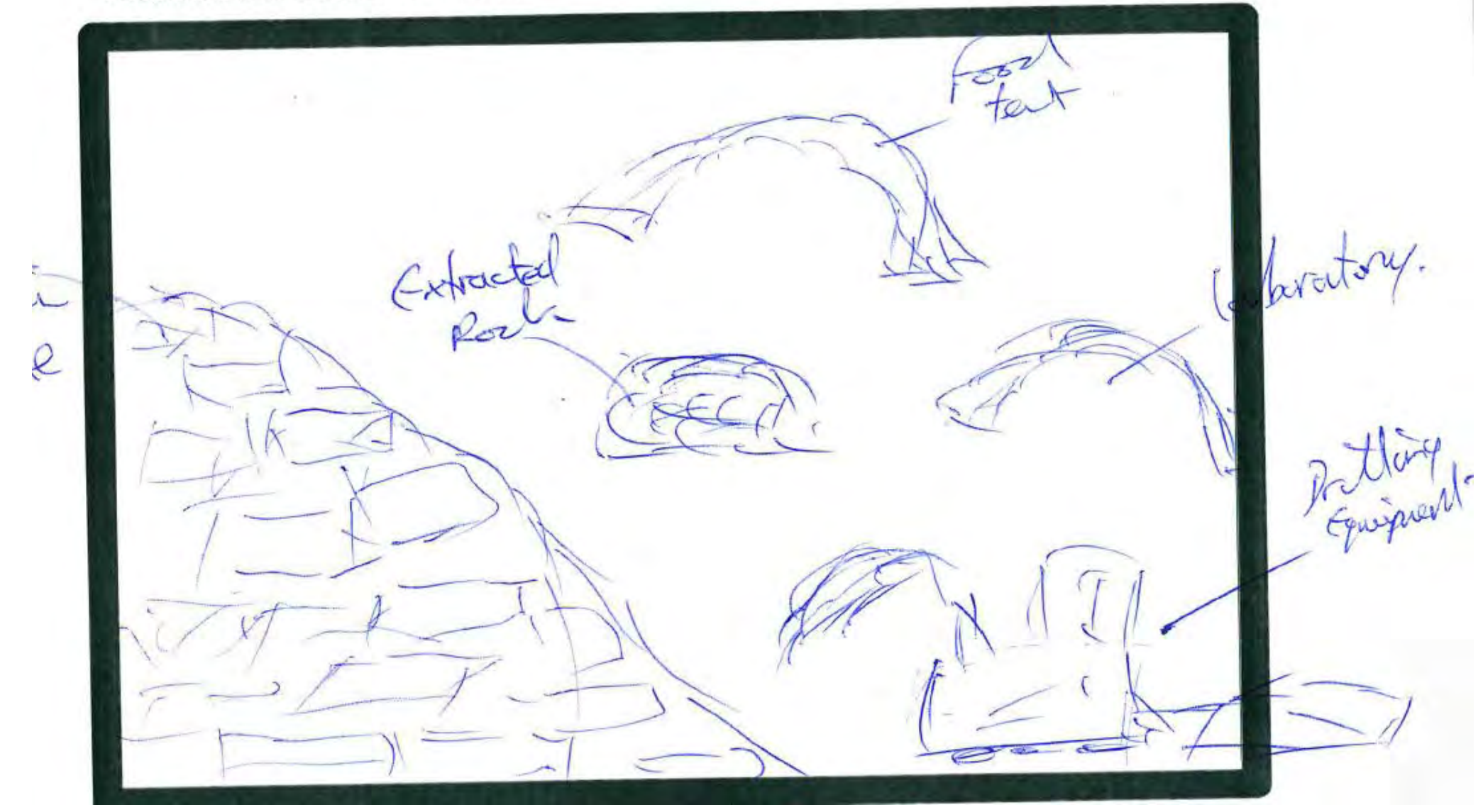


PLEASE STAY INSIDE THE BOX! P P l U t c

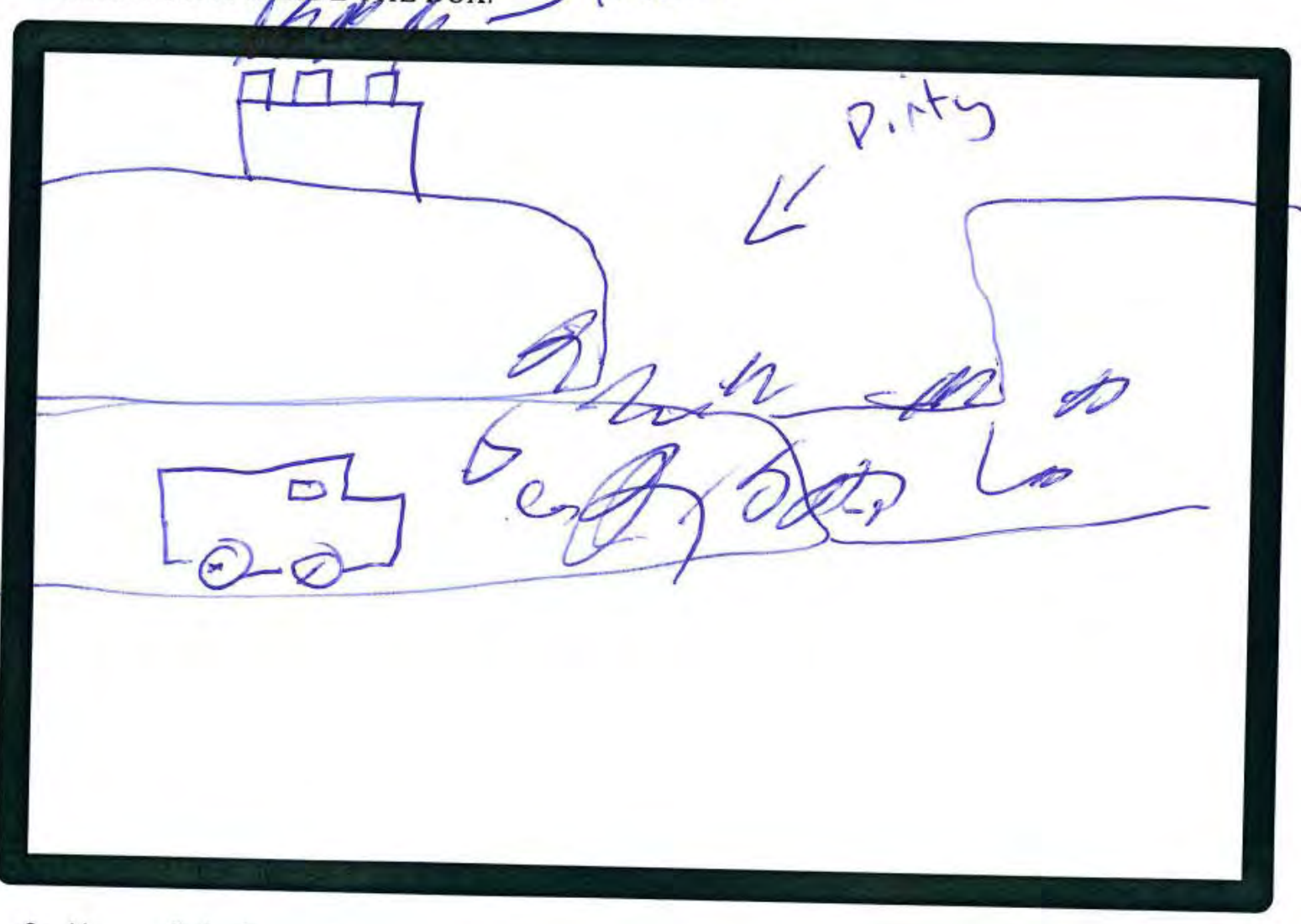


PLEASE STAY INSIDE THE BOX!

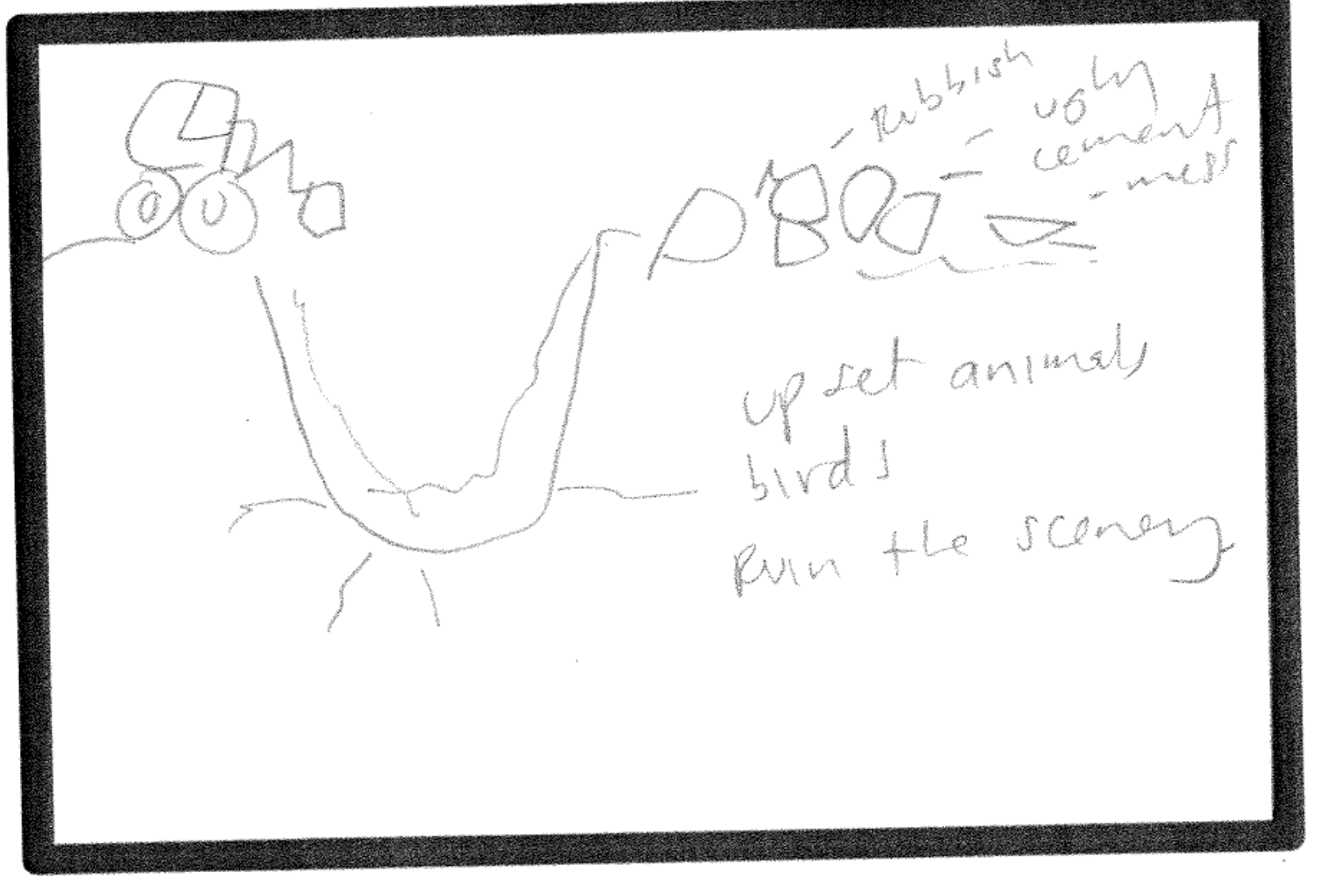




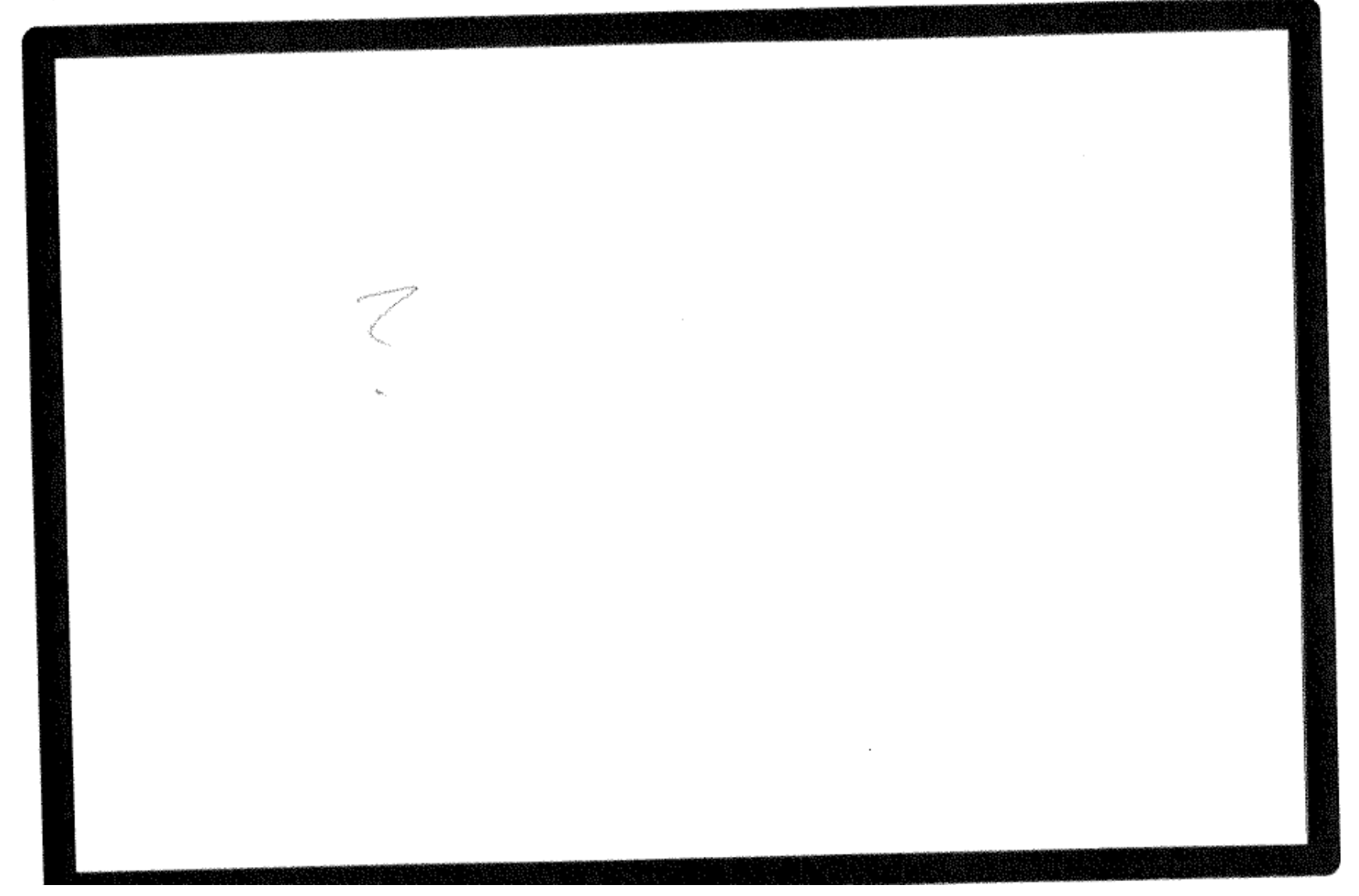




$$
\square
$$


PLEASE STAY INSIDE THE BOX!

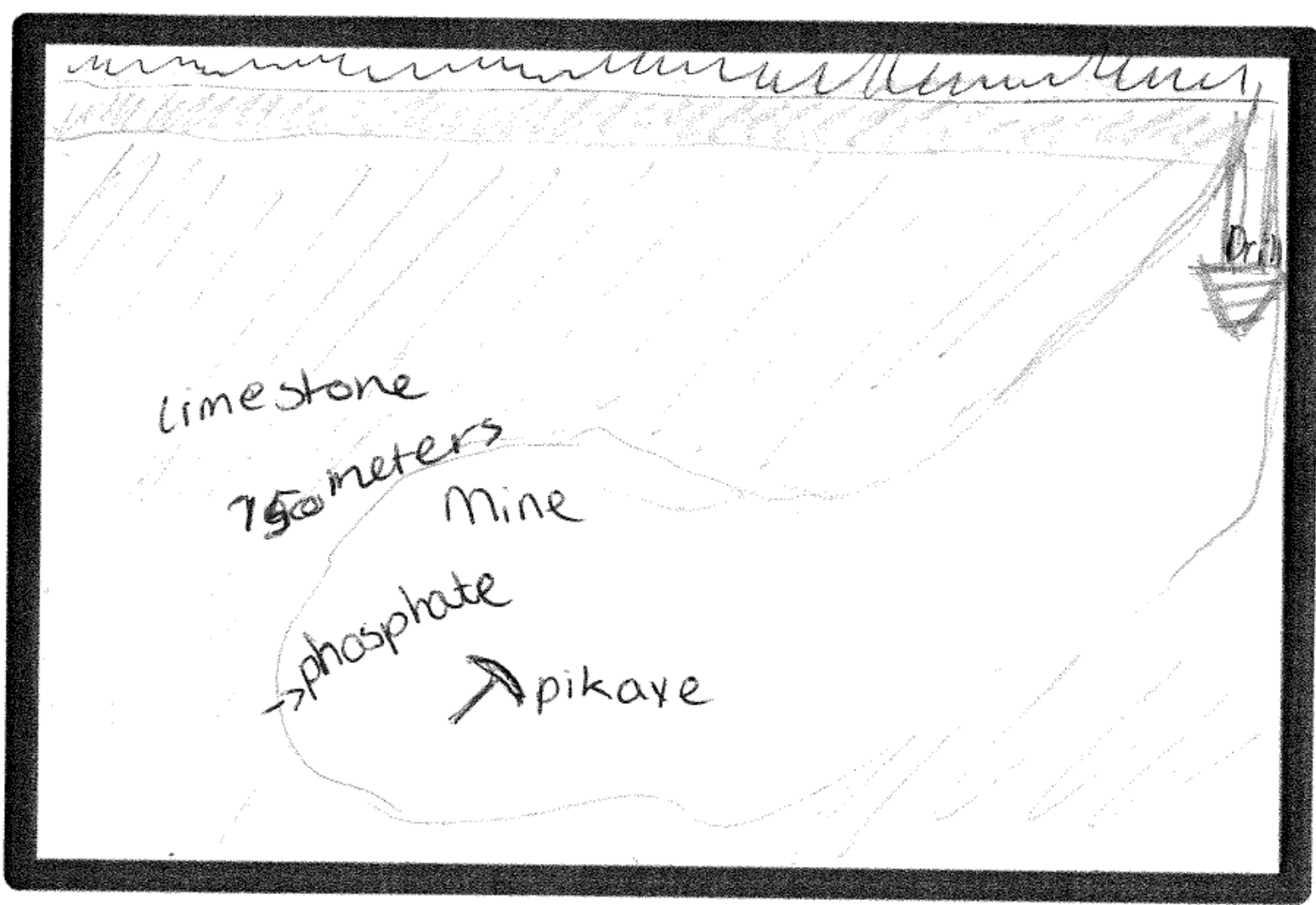




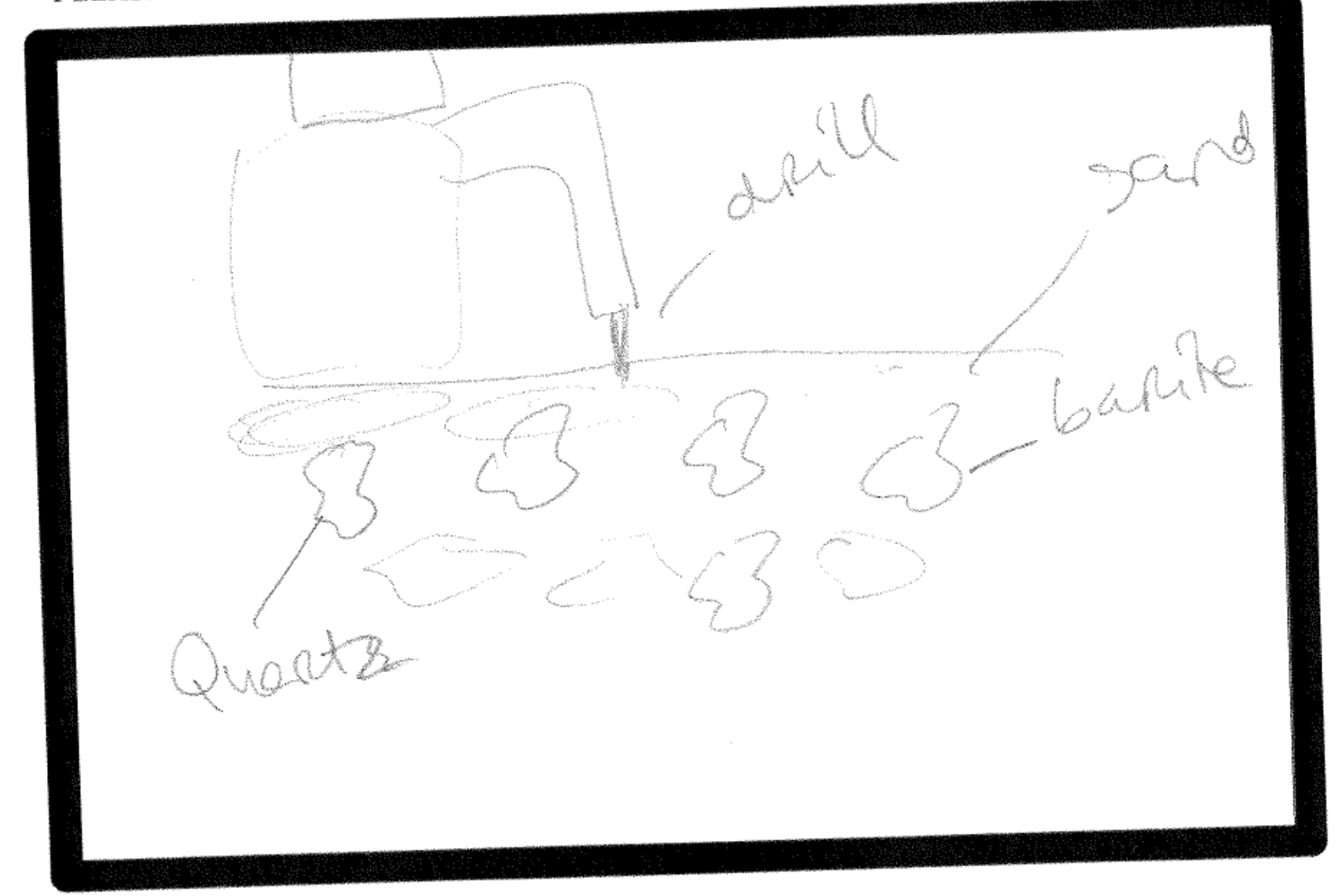


PLEASE STAY INSIDE THE BOX!

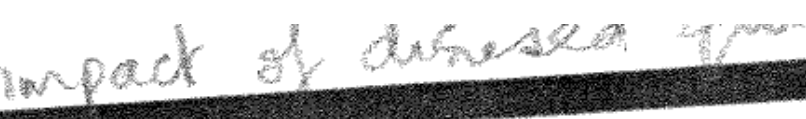

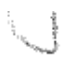

Non-expert

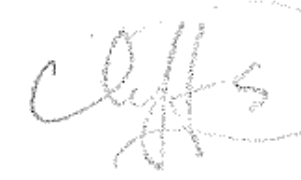

Rubble cabins mactunerg abandoned 
PLEASE STAY INSIDE THE BOX!

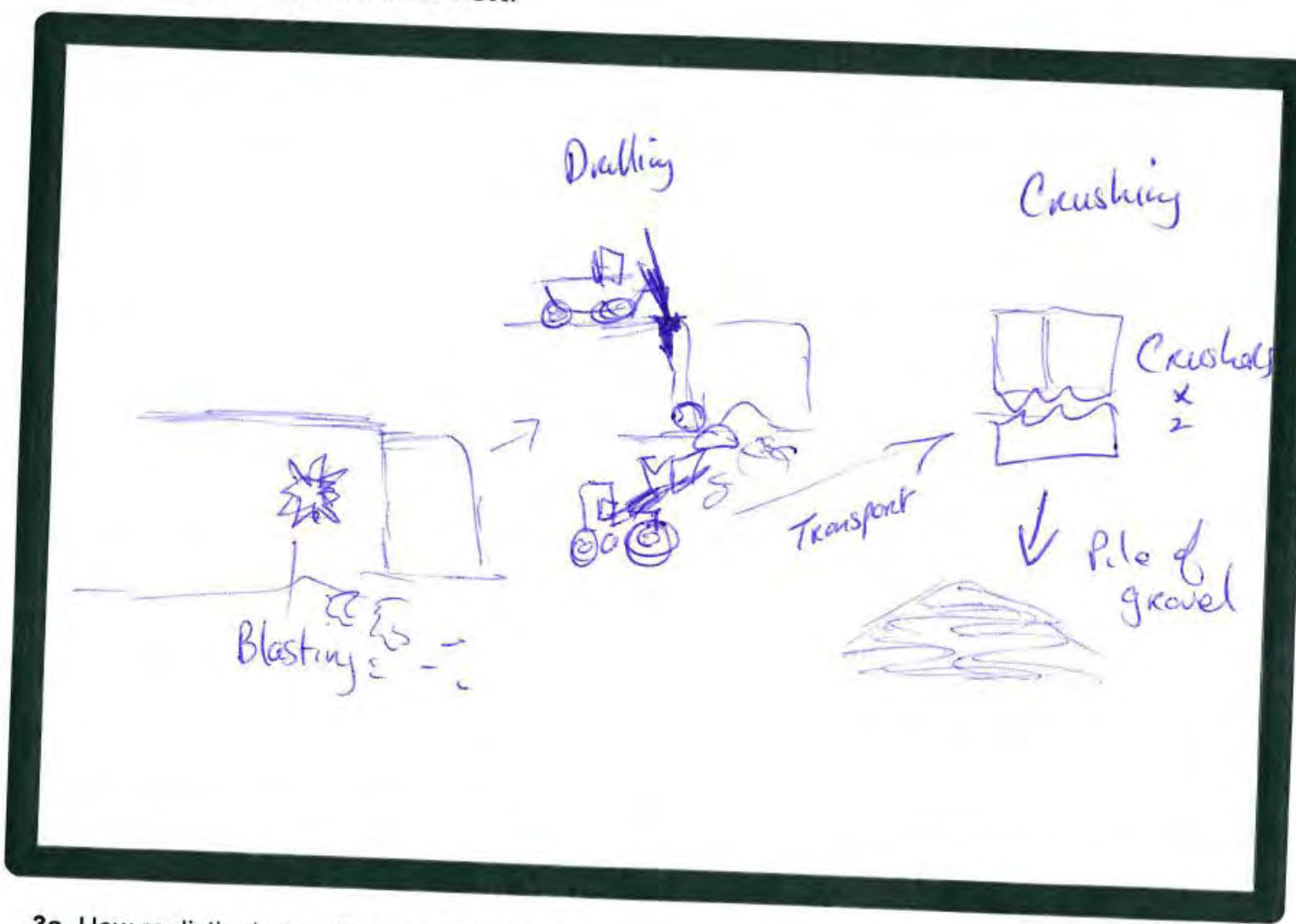




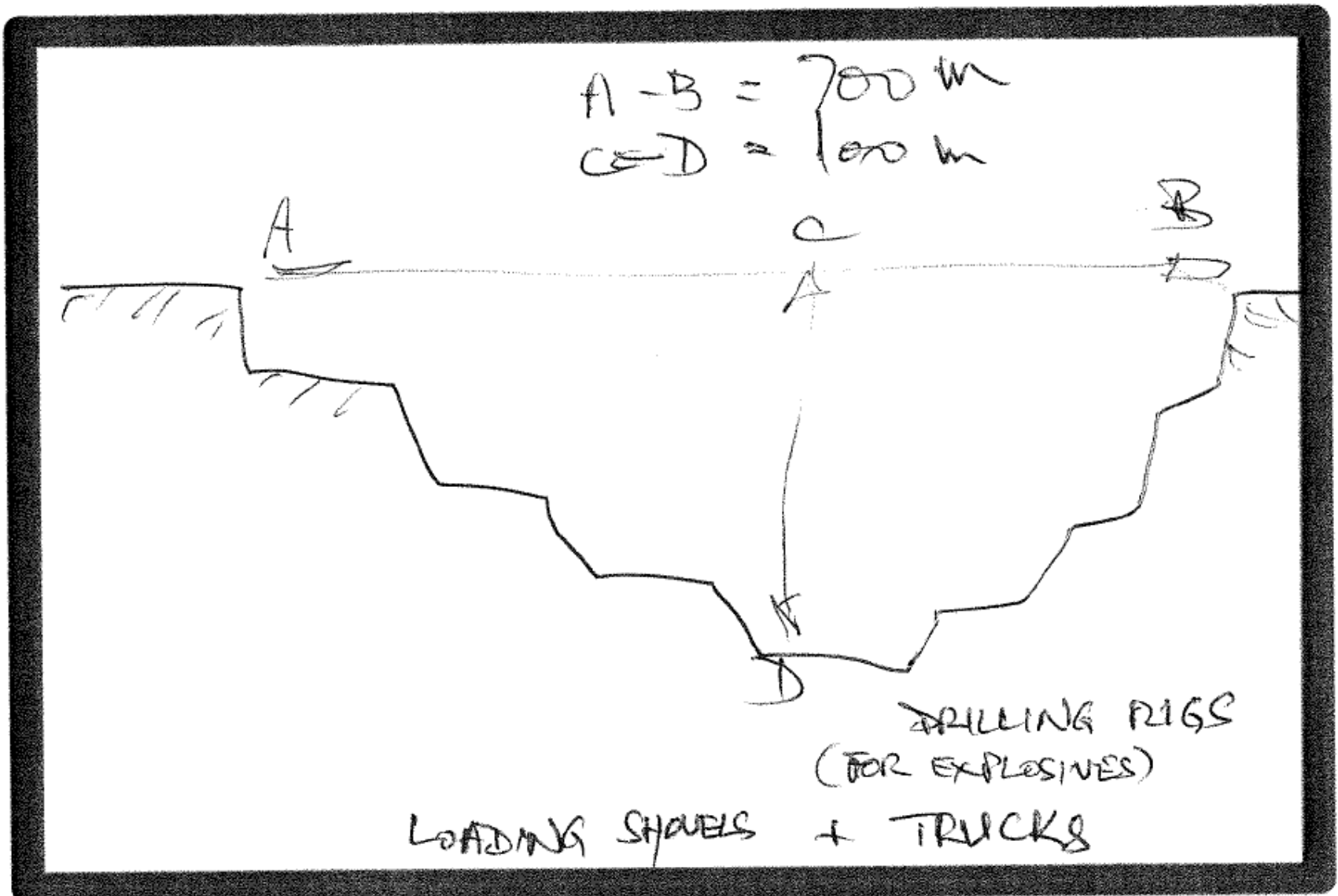


PLEASE STAY INSIDE THE BOX!

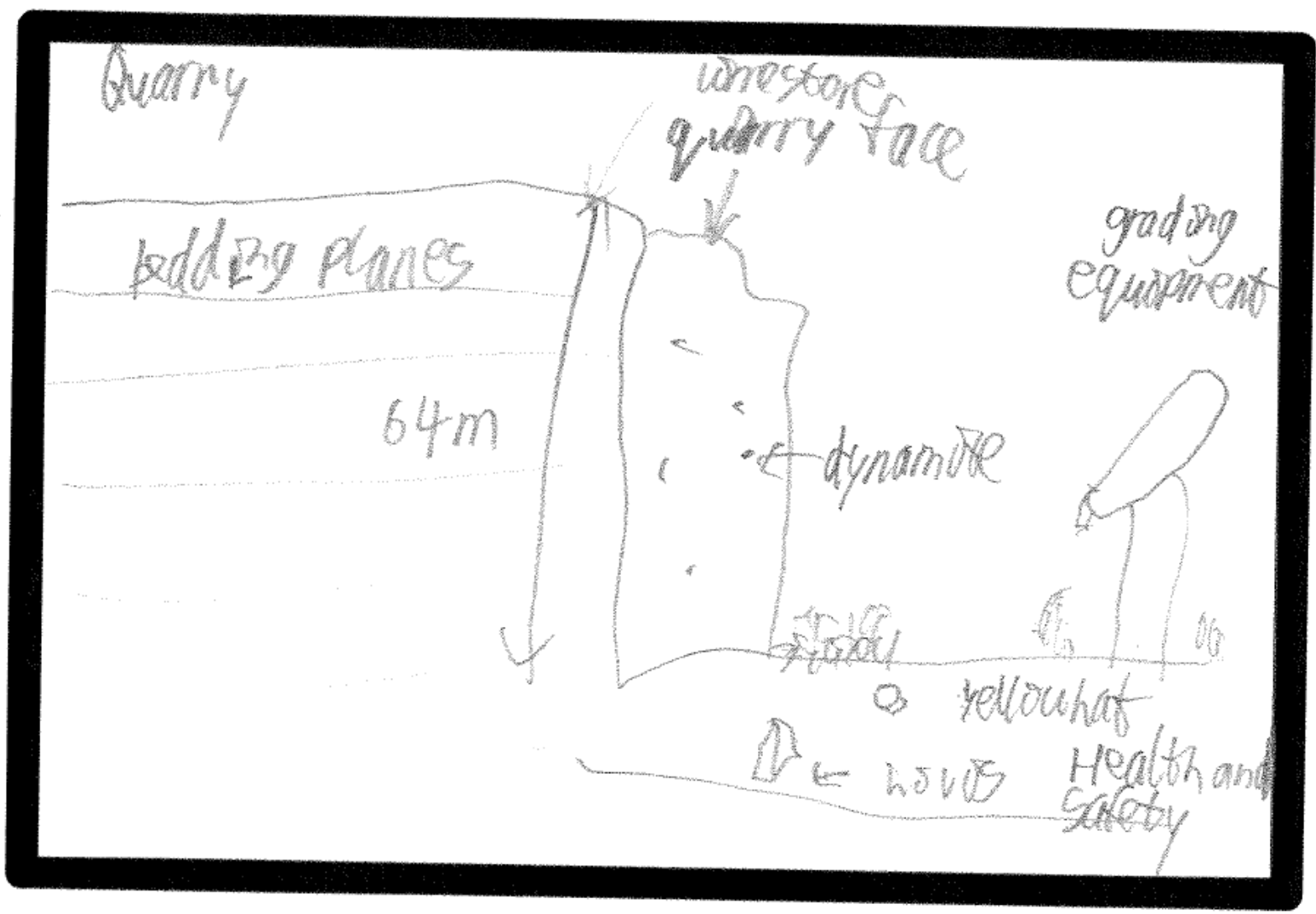


PLEAsE STAY INSIDE THE BoXIDEQL iN SE JT-

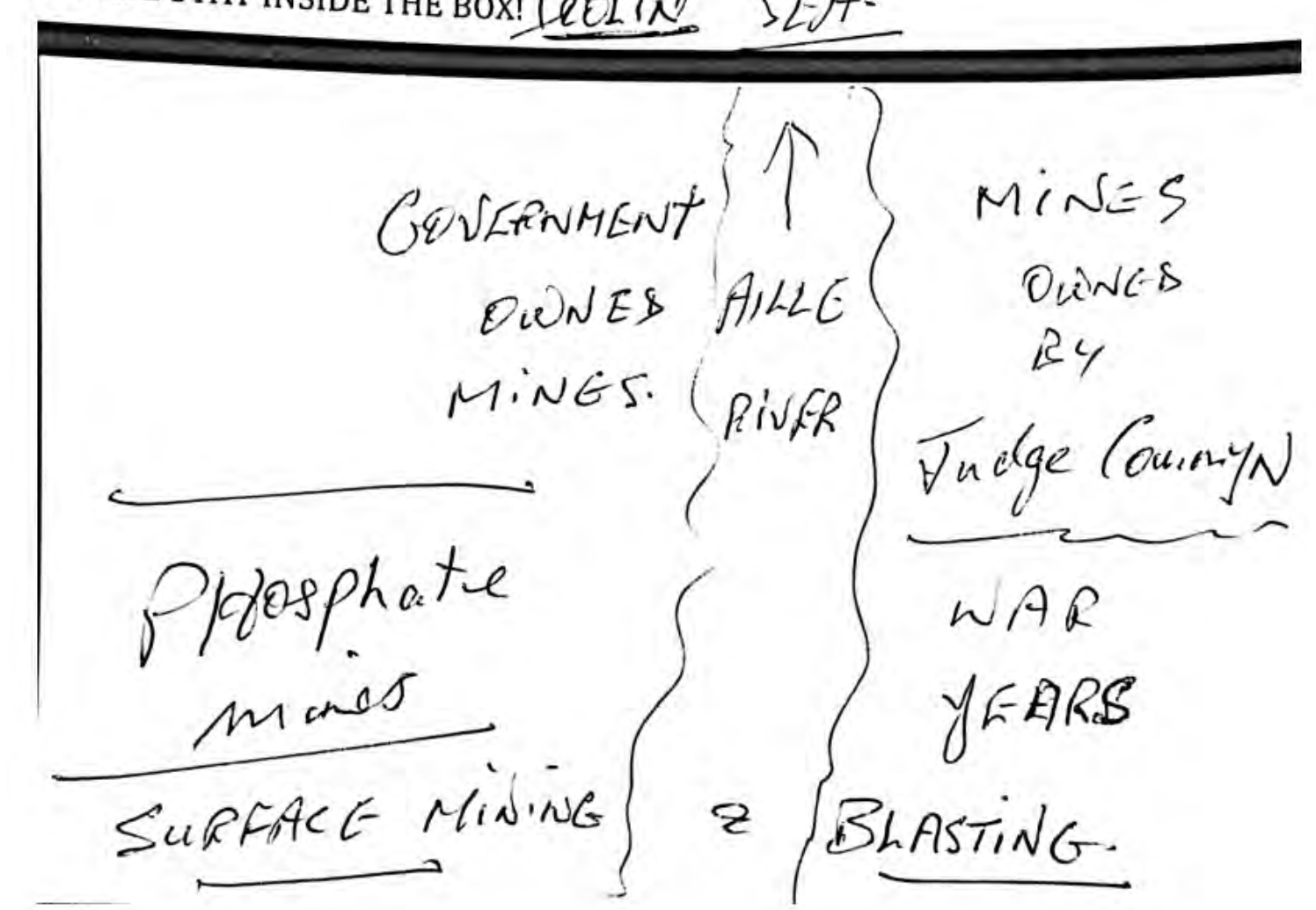

Non-expert 


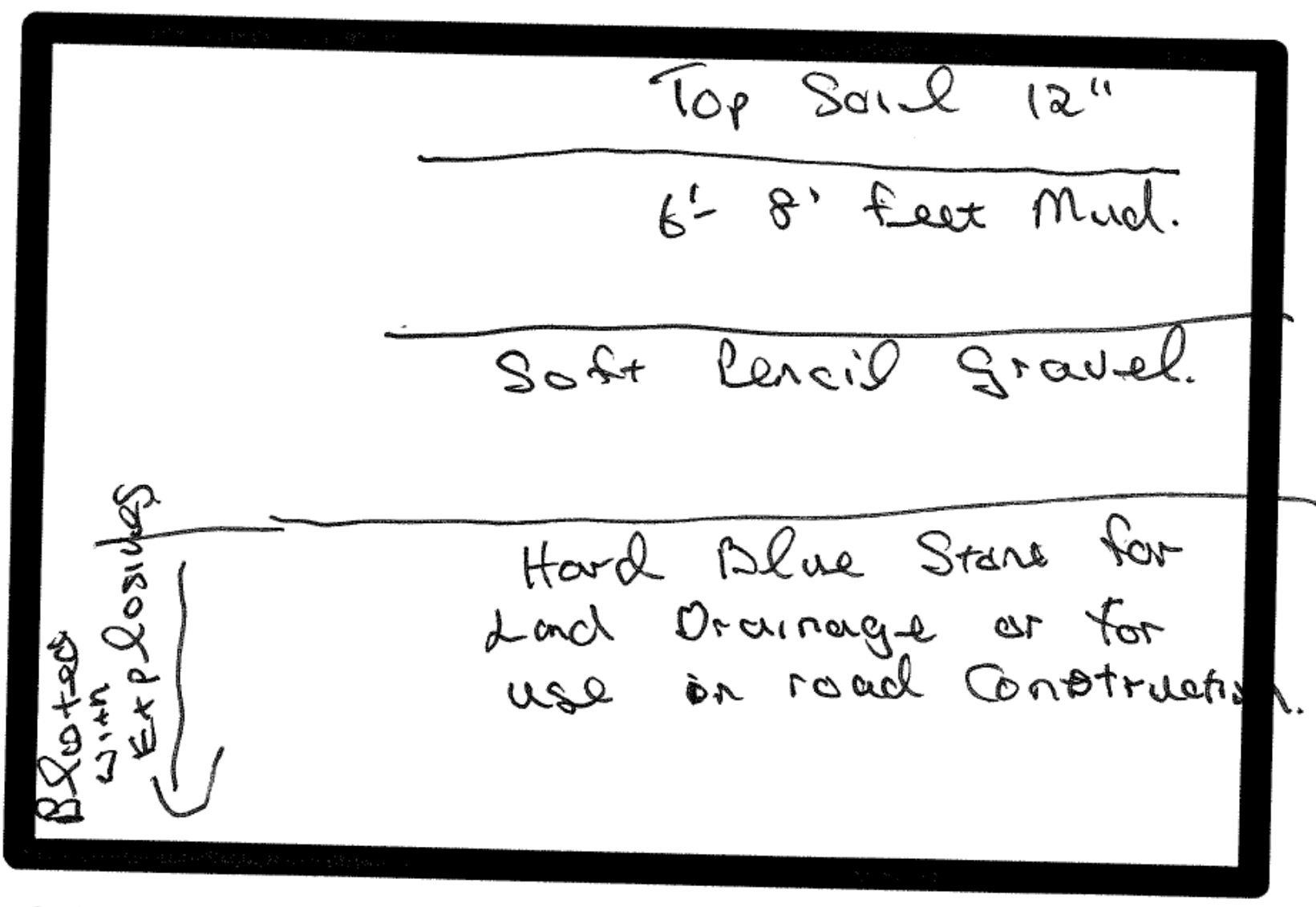




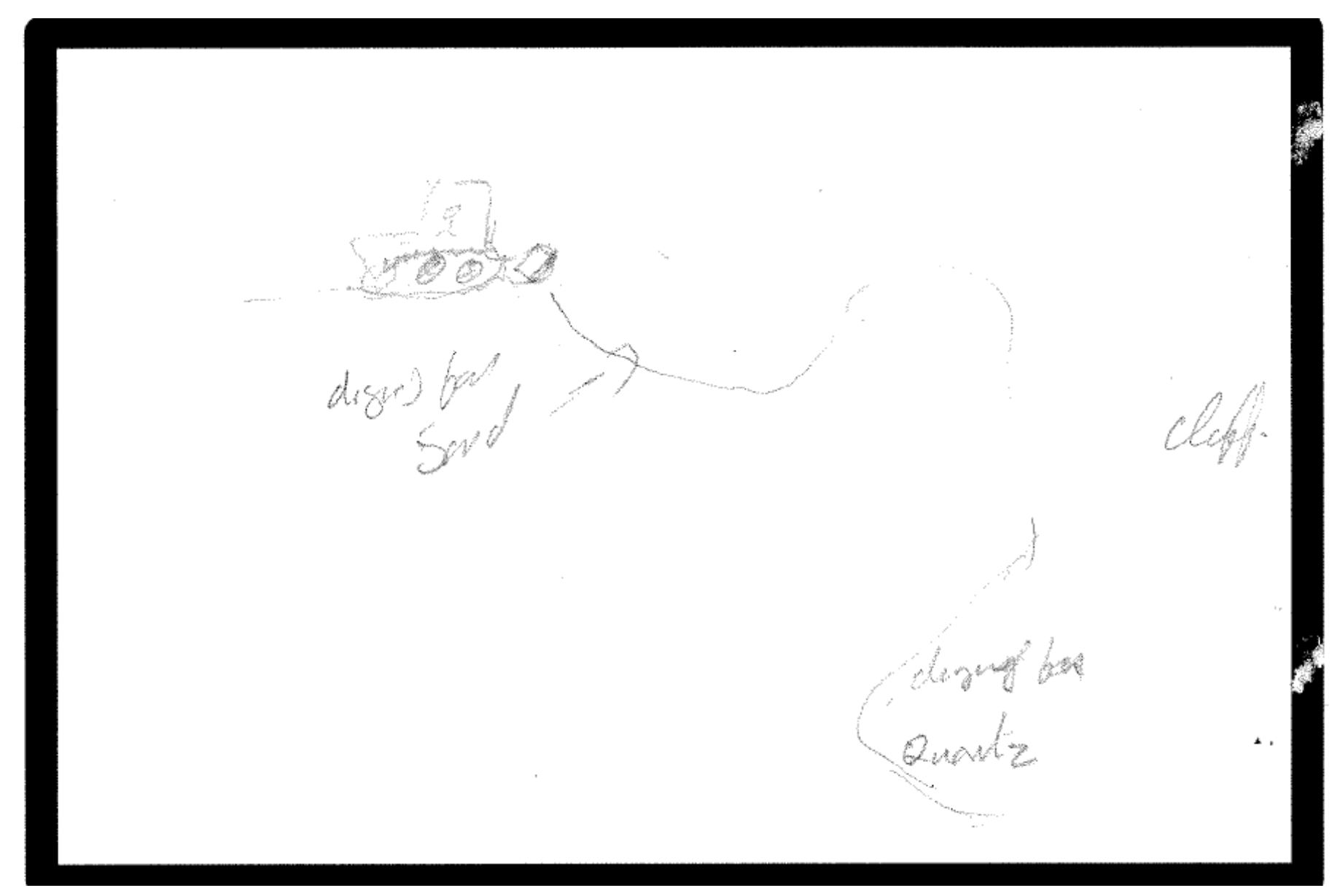




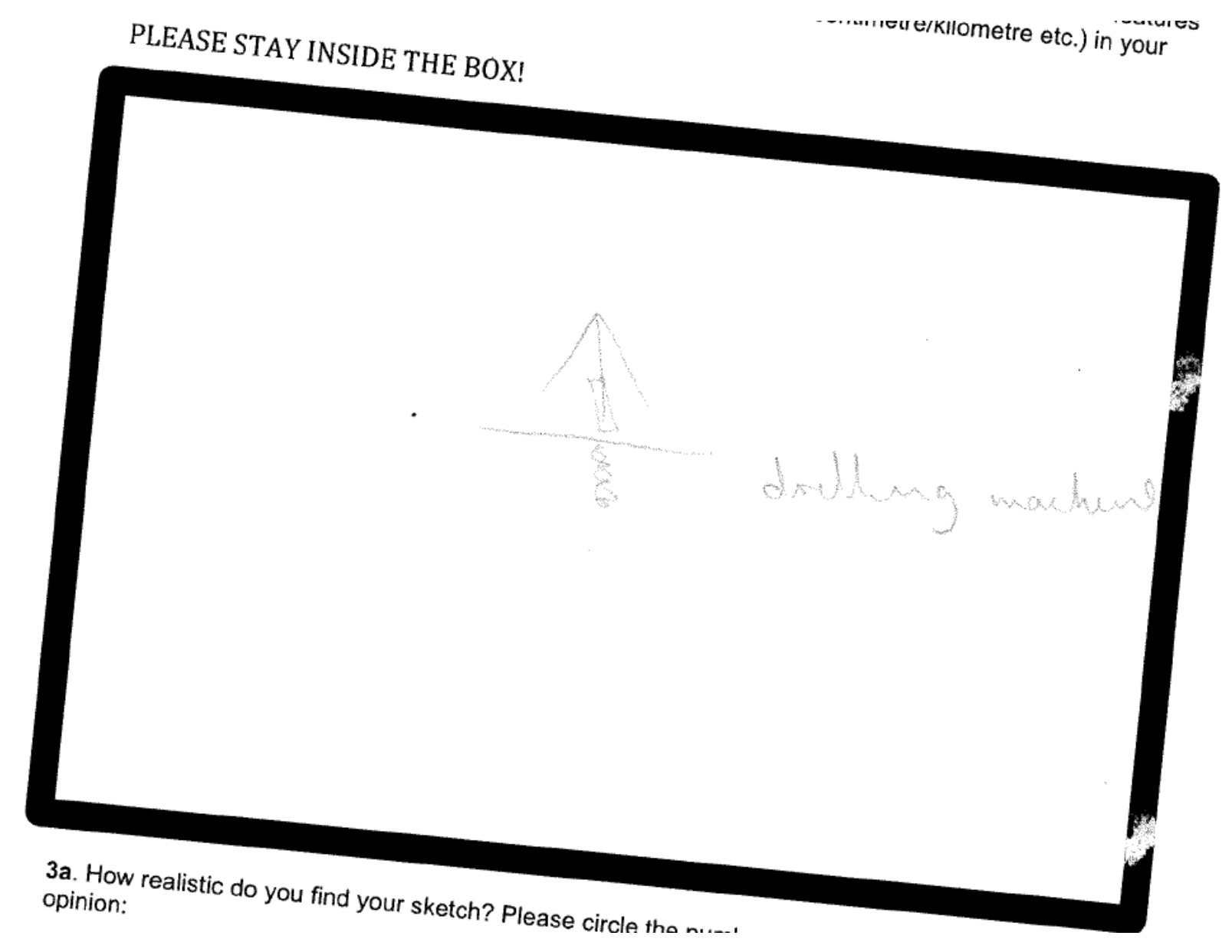




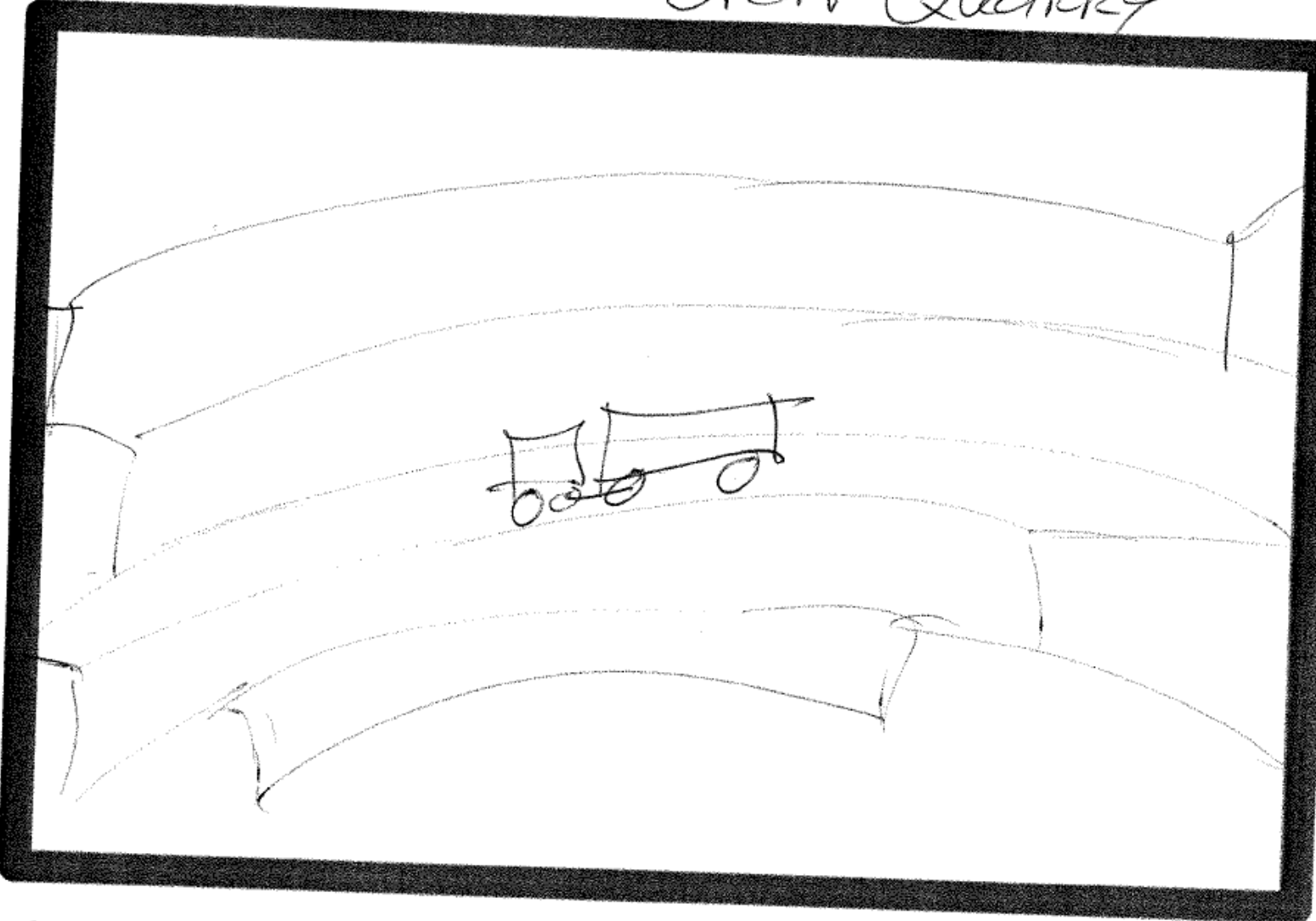




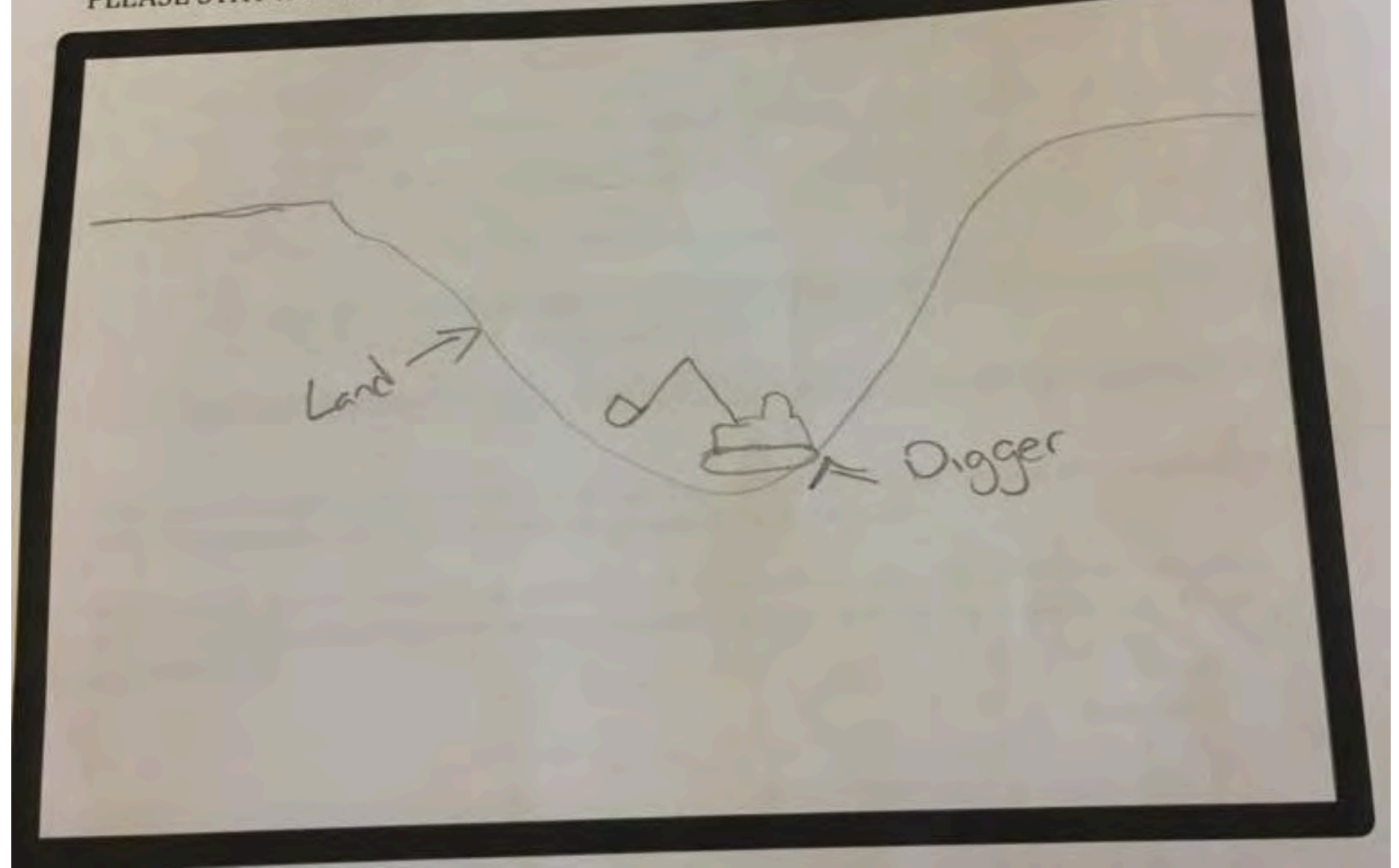

Non-expert 


\section{Flooding}

- Imagine that a field or land area in County Clare is currently flooded. Please sketch what the flooding would look like 


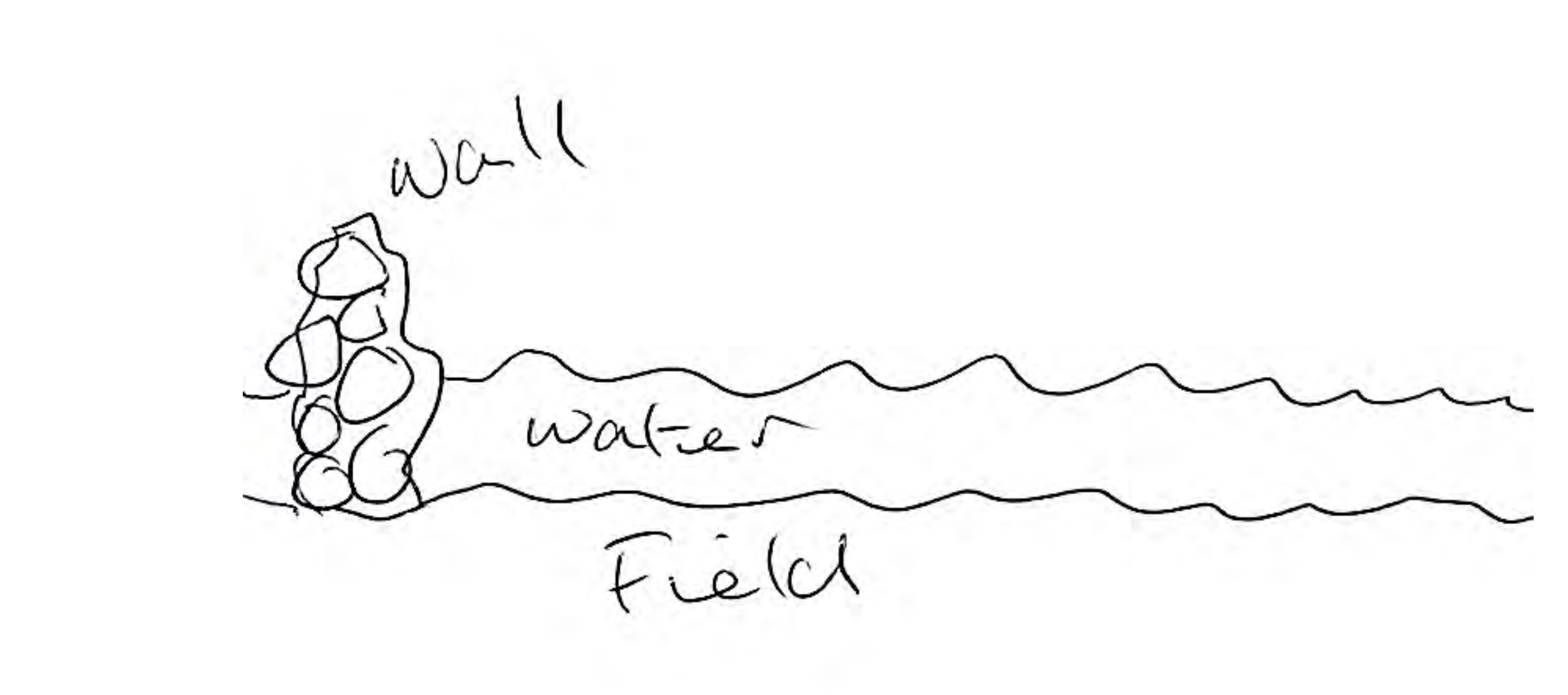




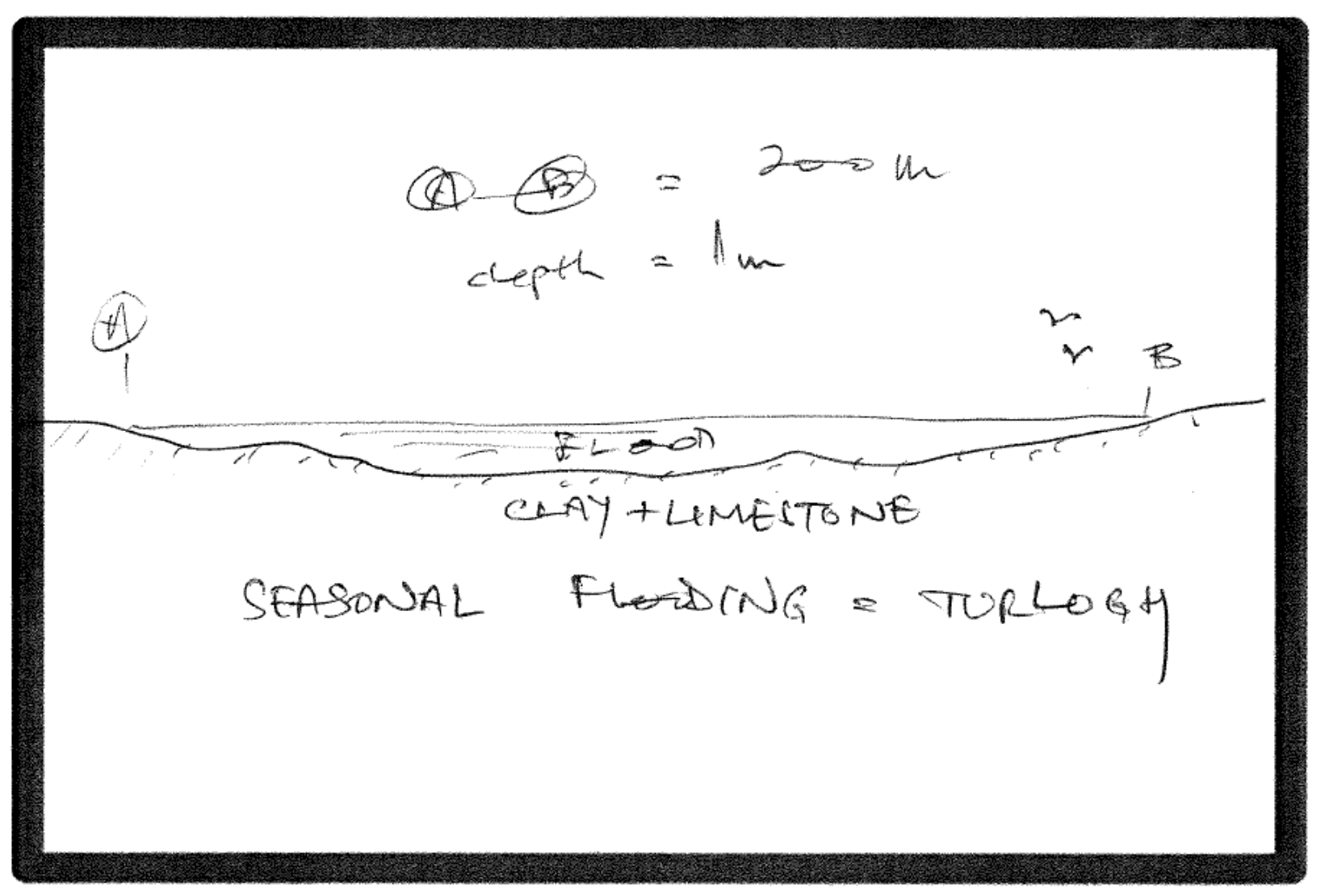


PLEASE STAY INSIDE THE BOX!

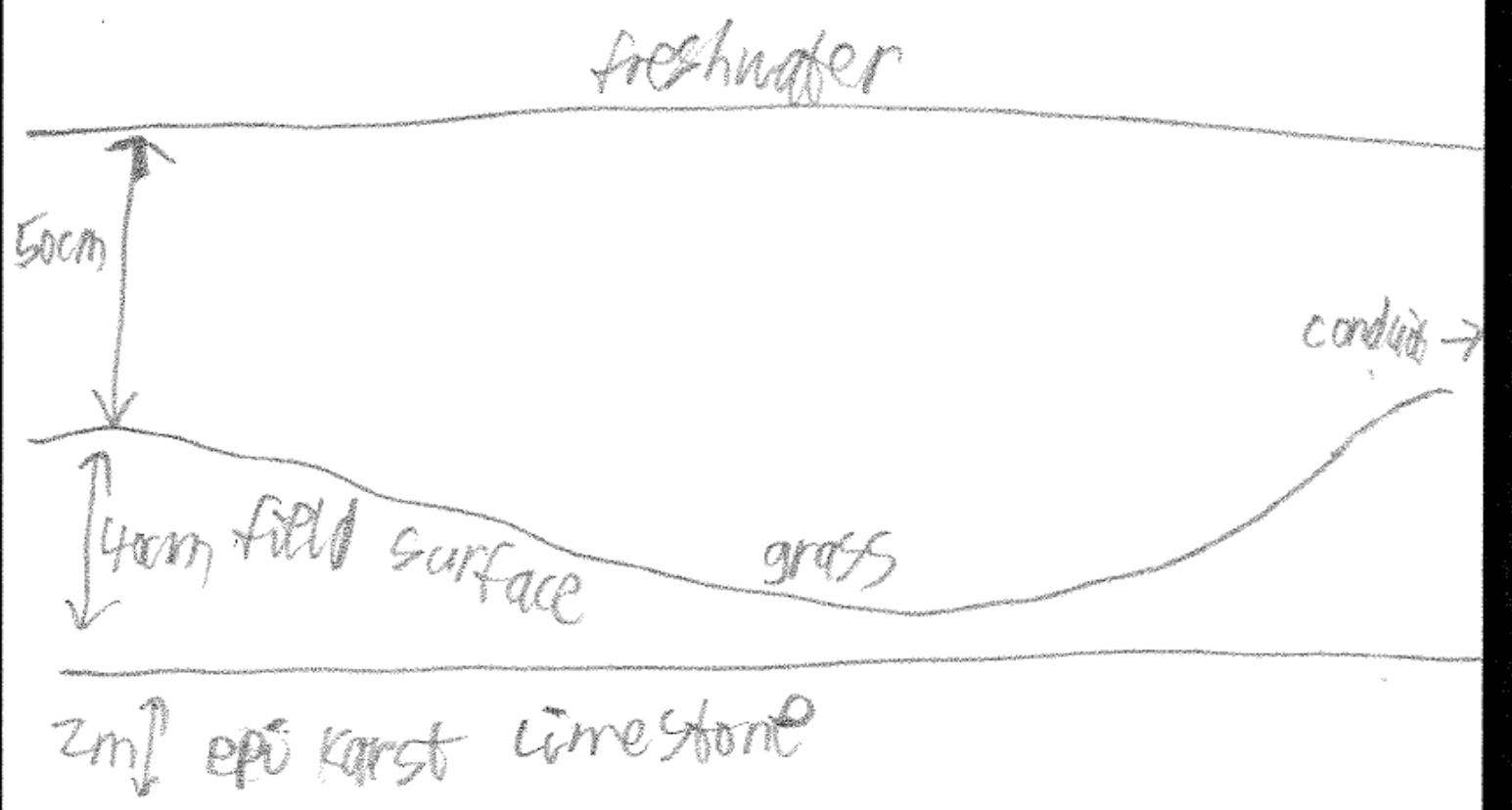

Non-expert 
PLEASE STAY INSIDE THE BOX! INALH RivER.

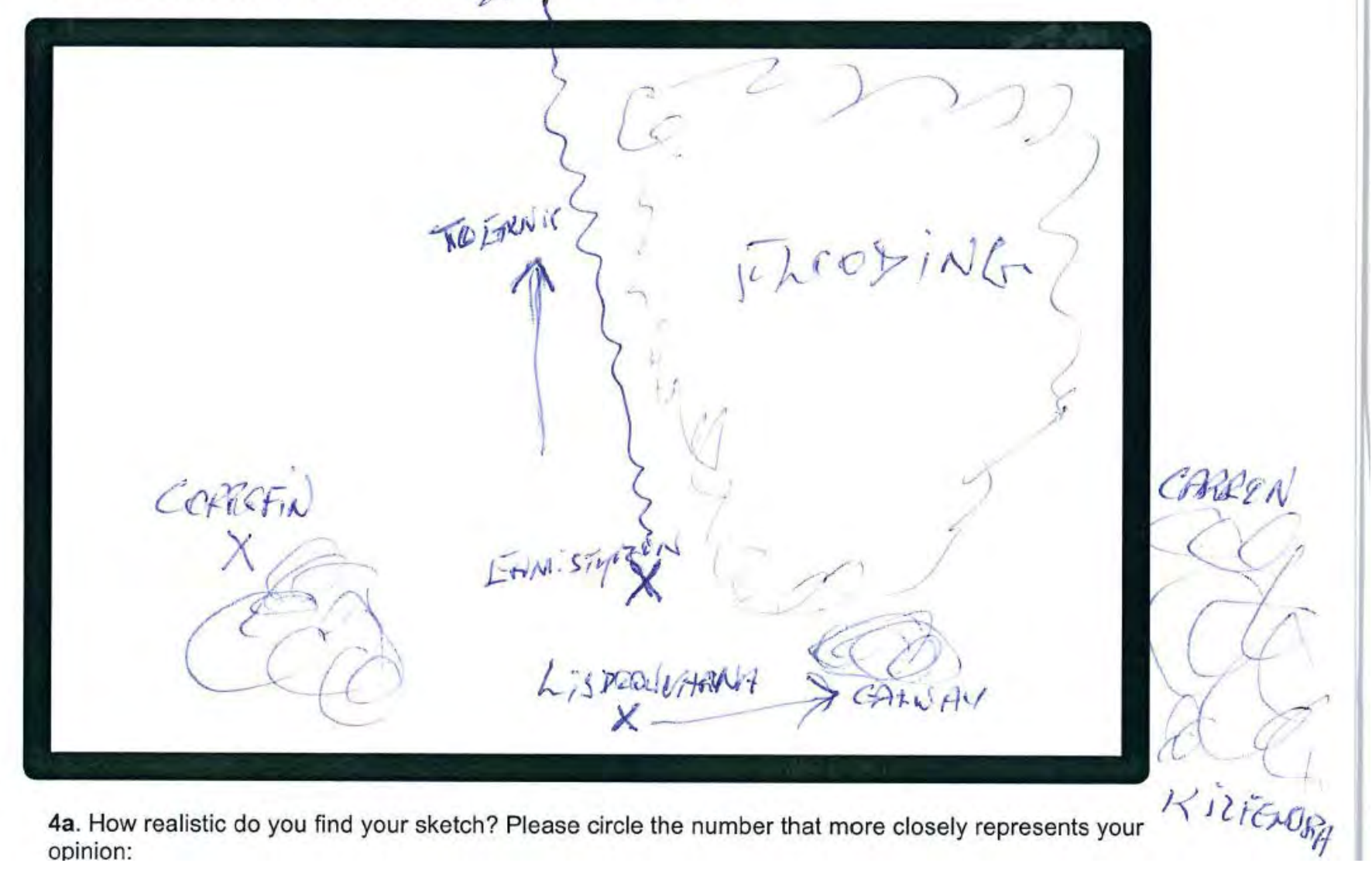
opinion: 


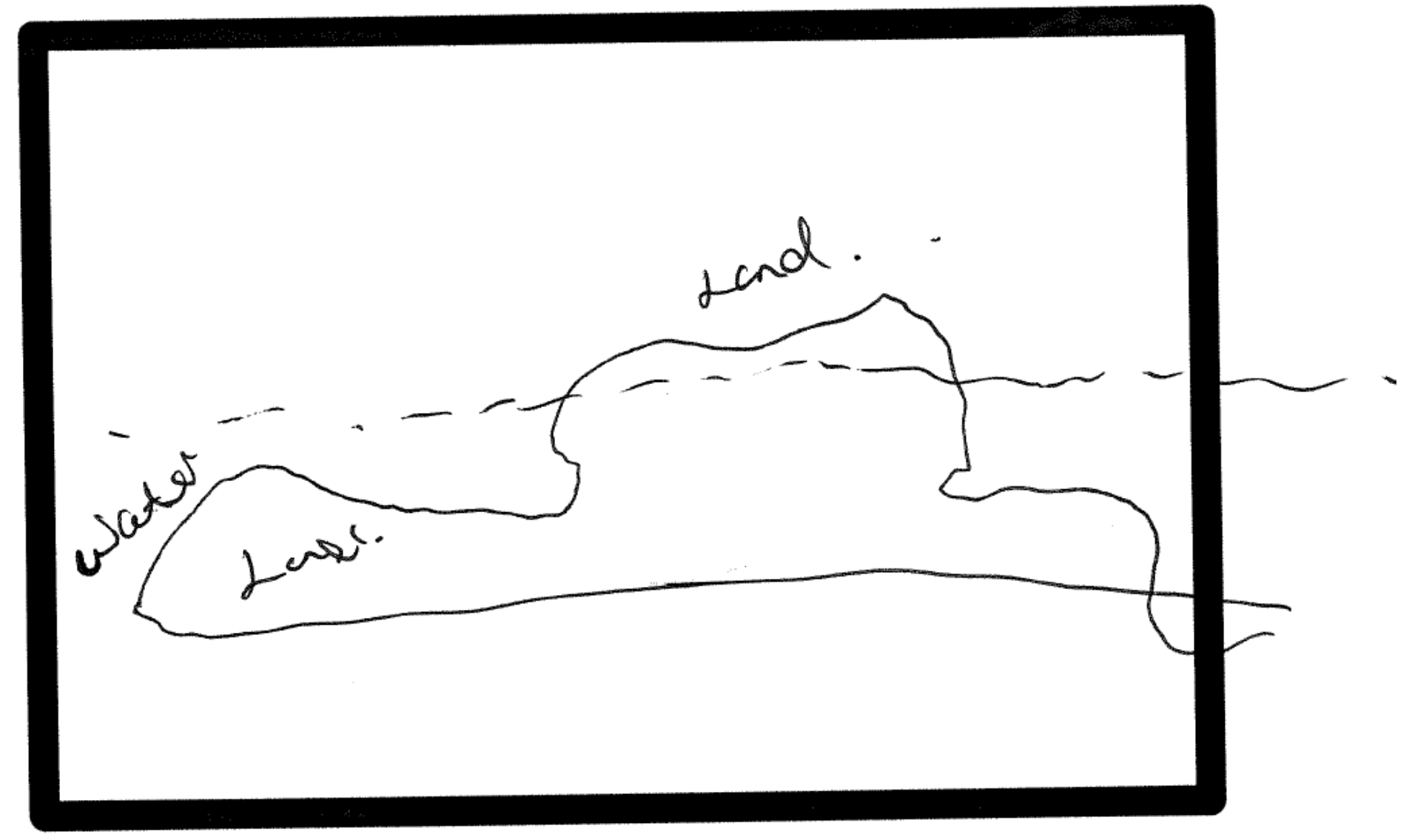


PLEASE STAY INSIDE THE BOX!

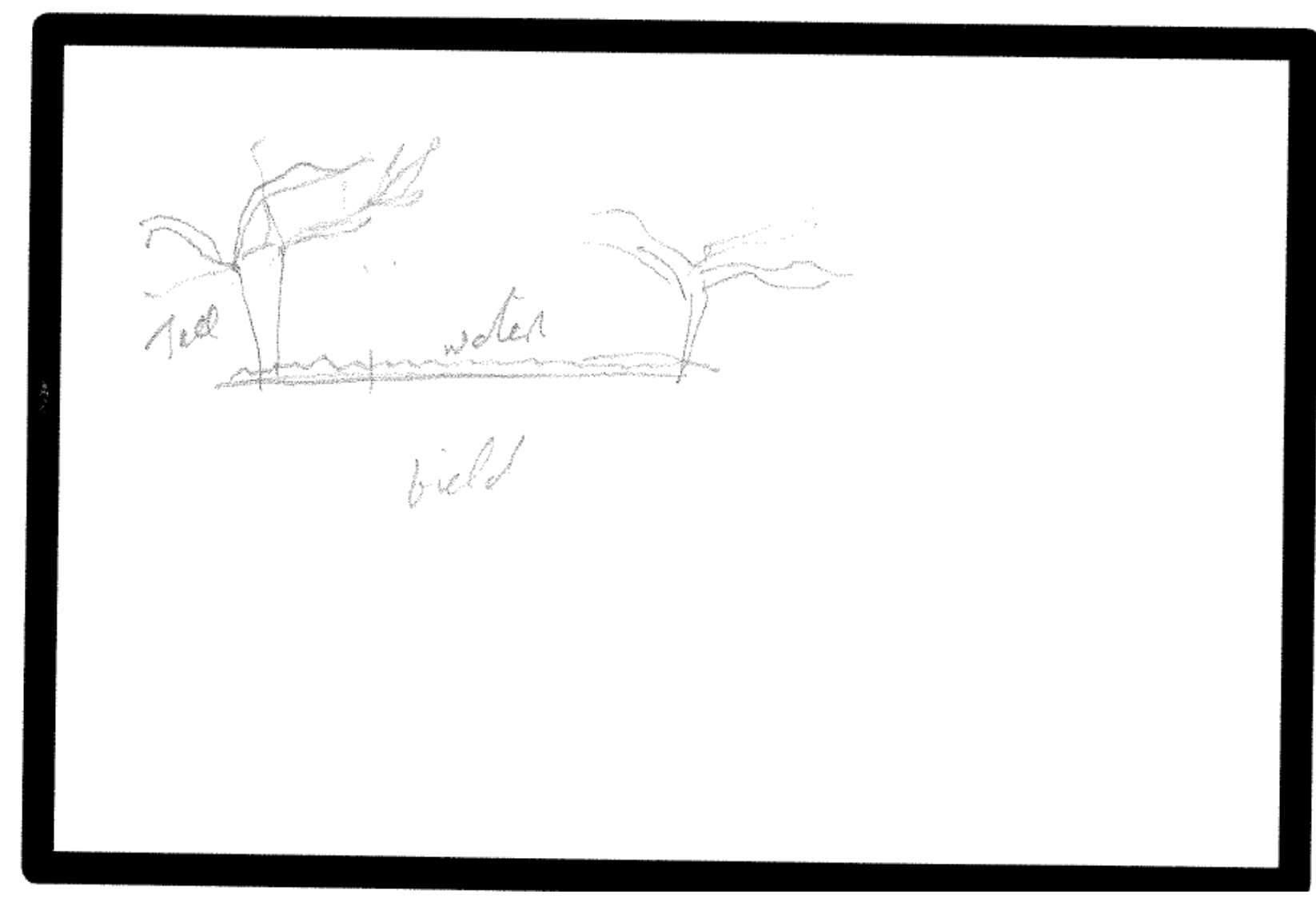




$$
\Gamma
$$




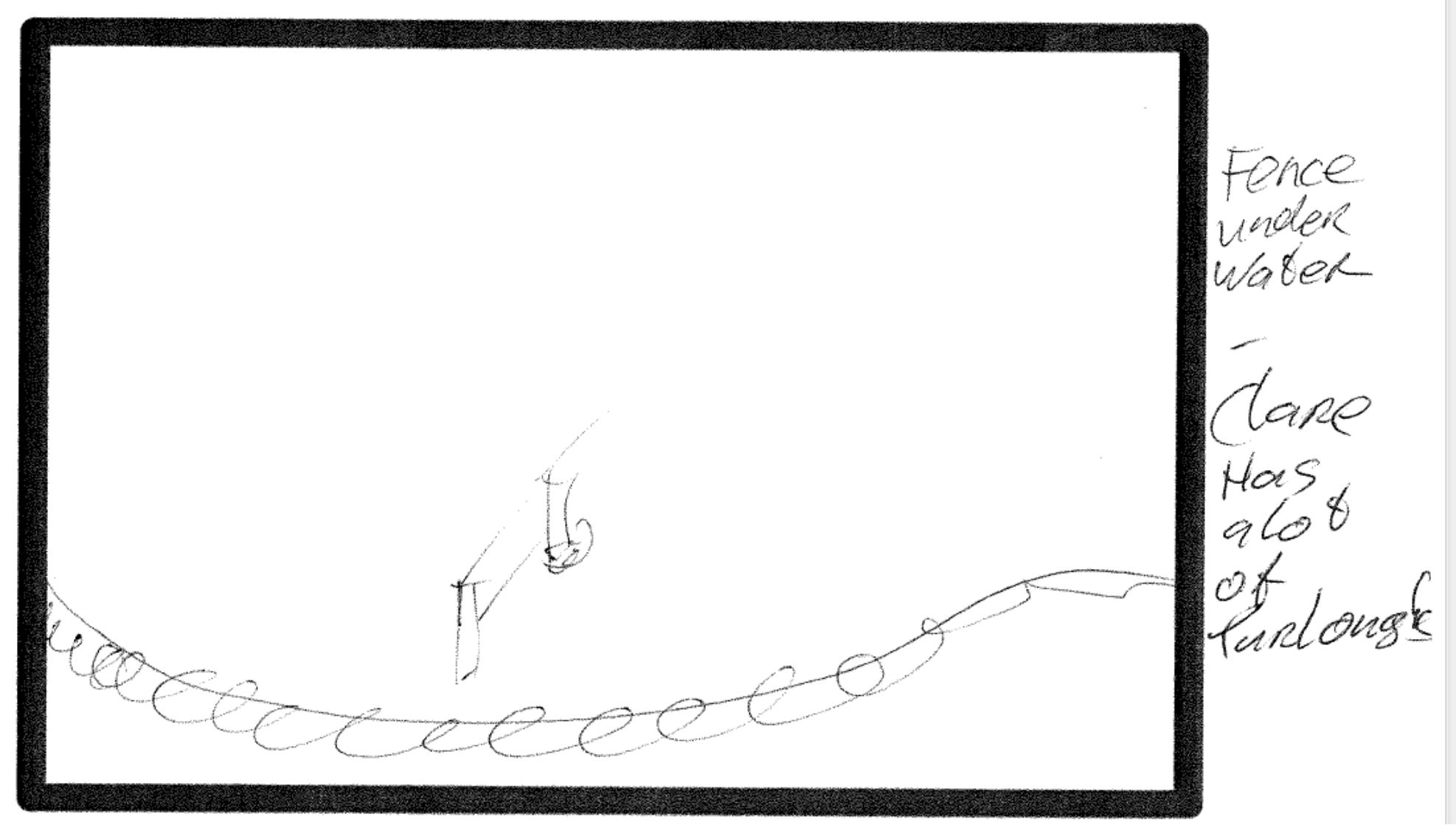


PLEASE STAY INSIDE THE BOX!

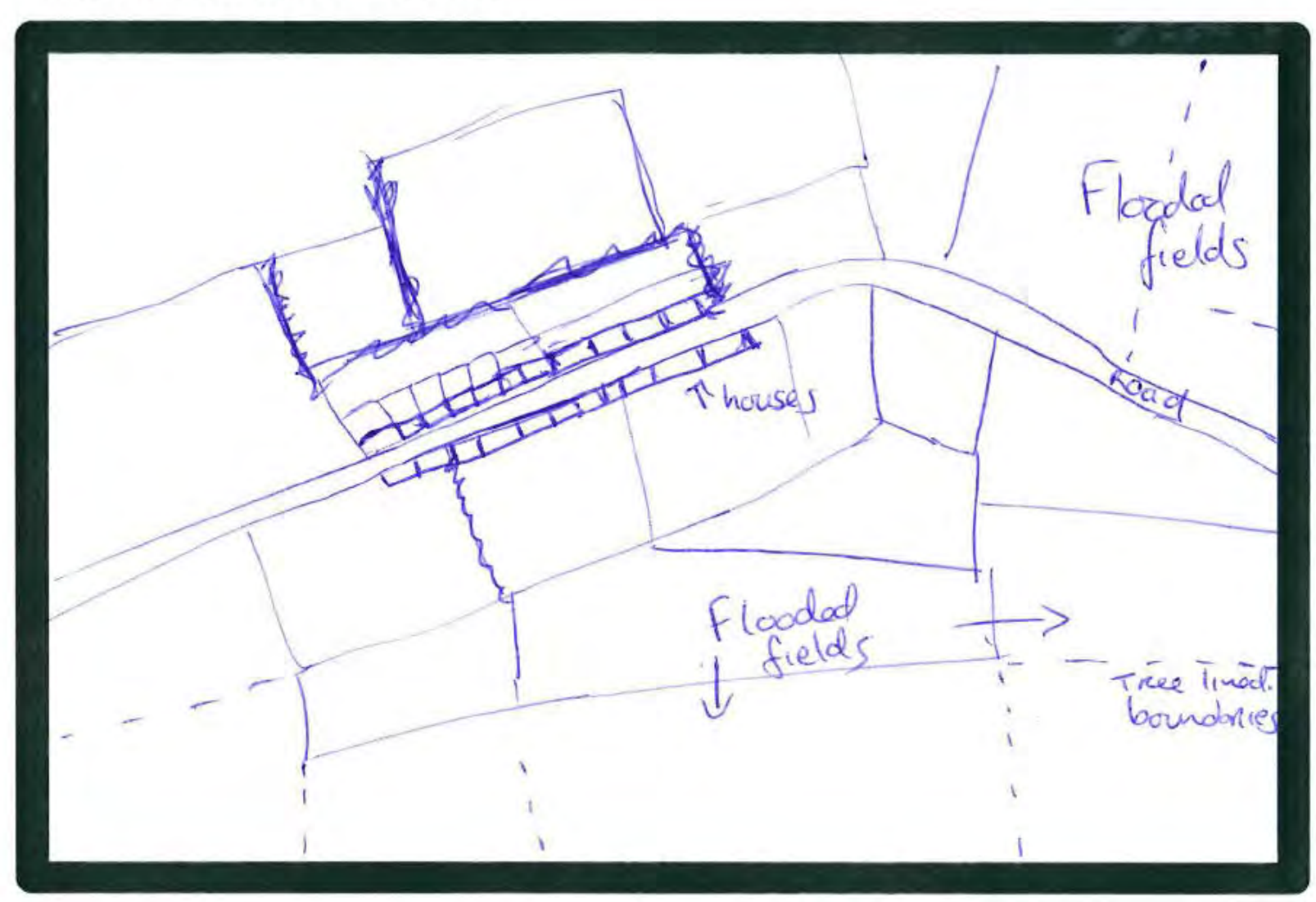


PLEASE STAY INSIDE THE BOX!

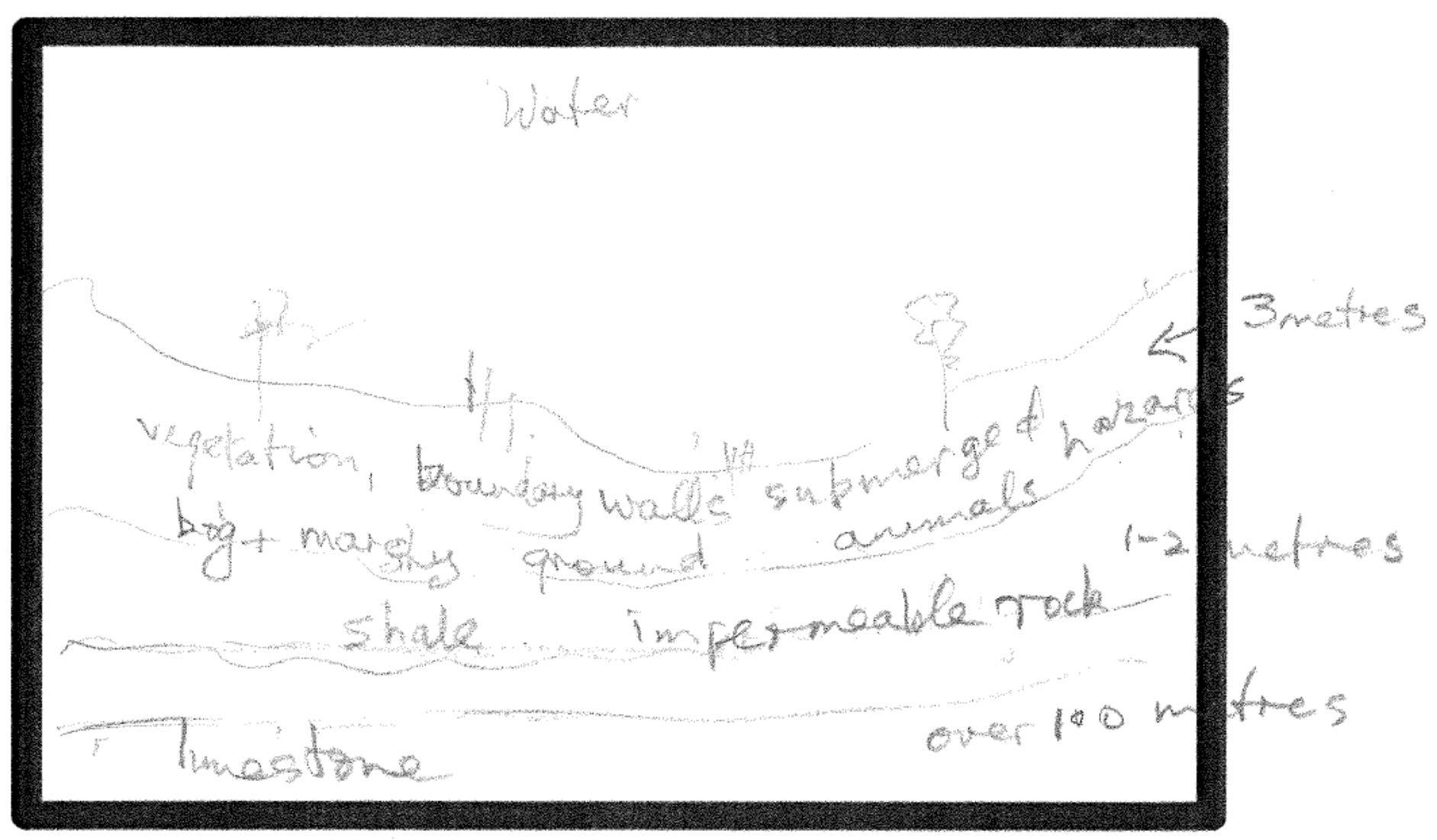




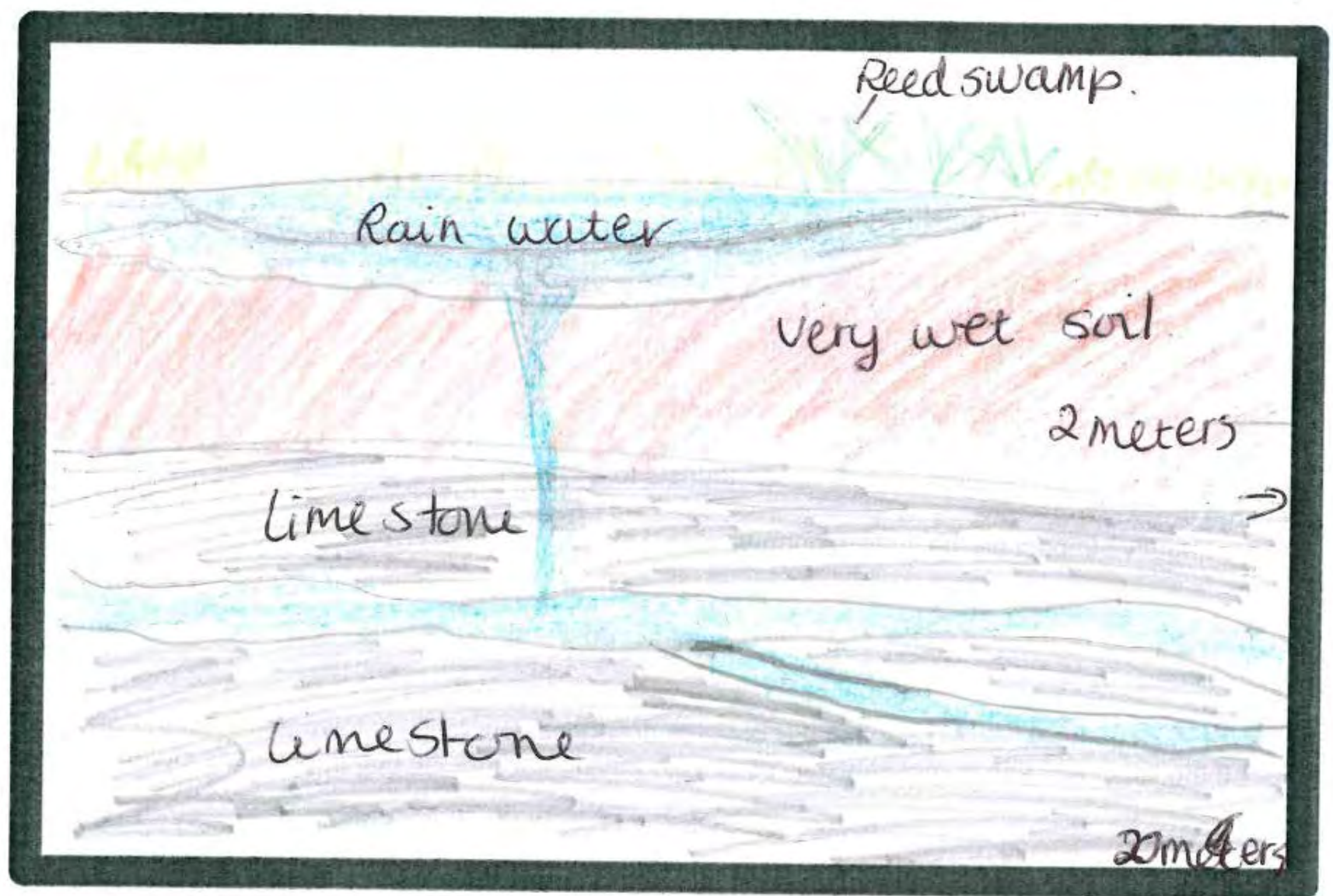




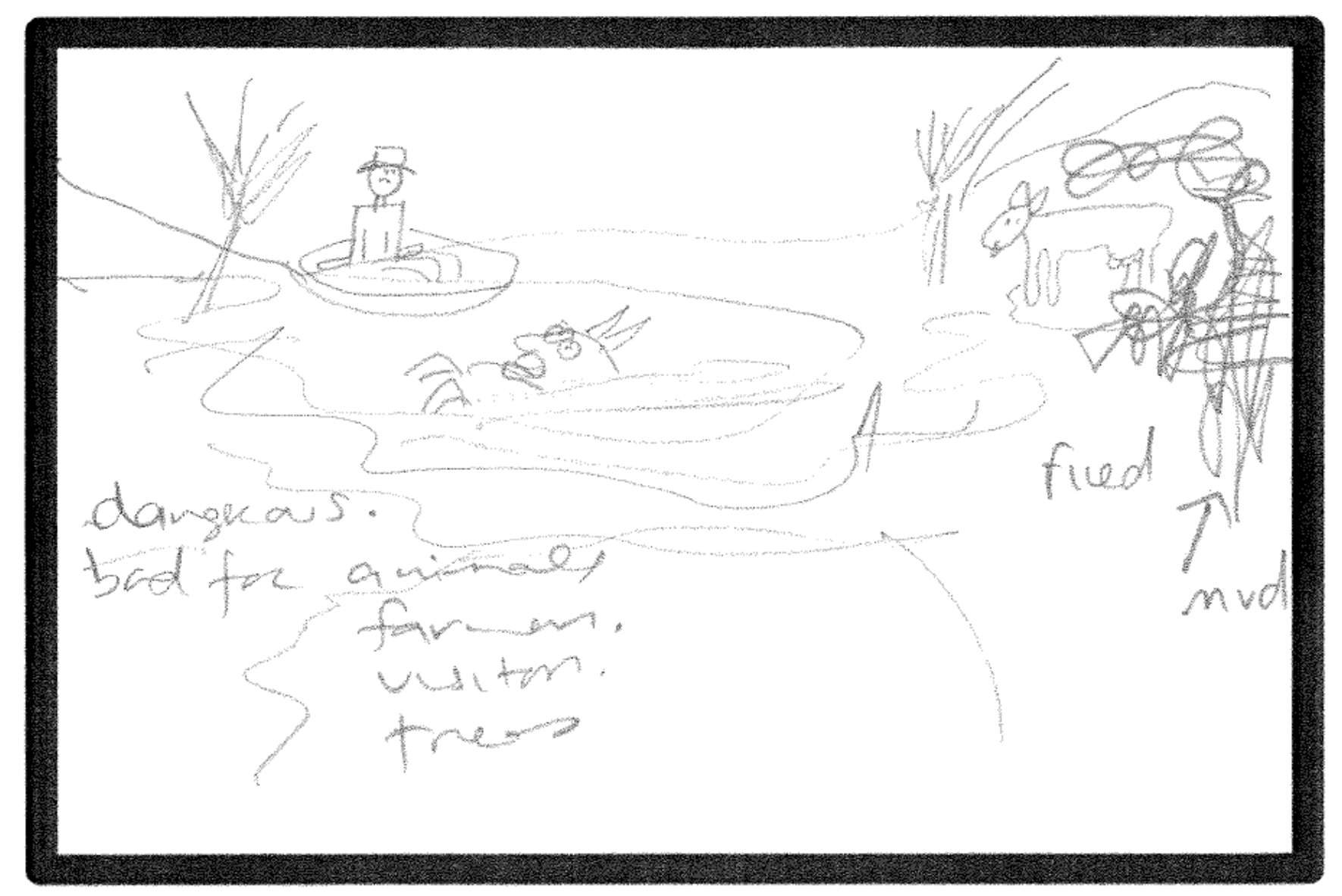


PLEASE STAY INSIDE THE BOX!

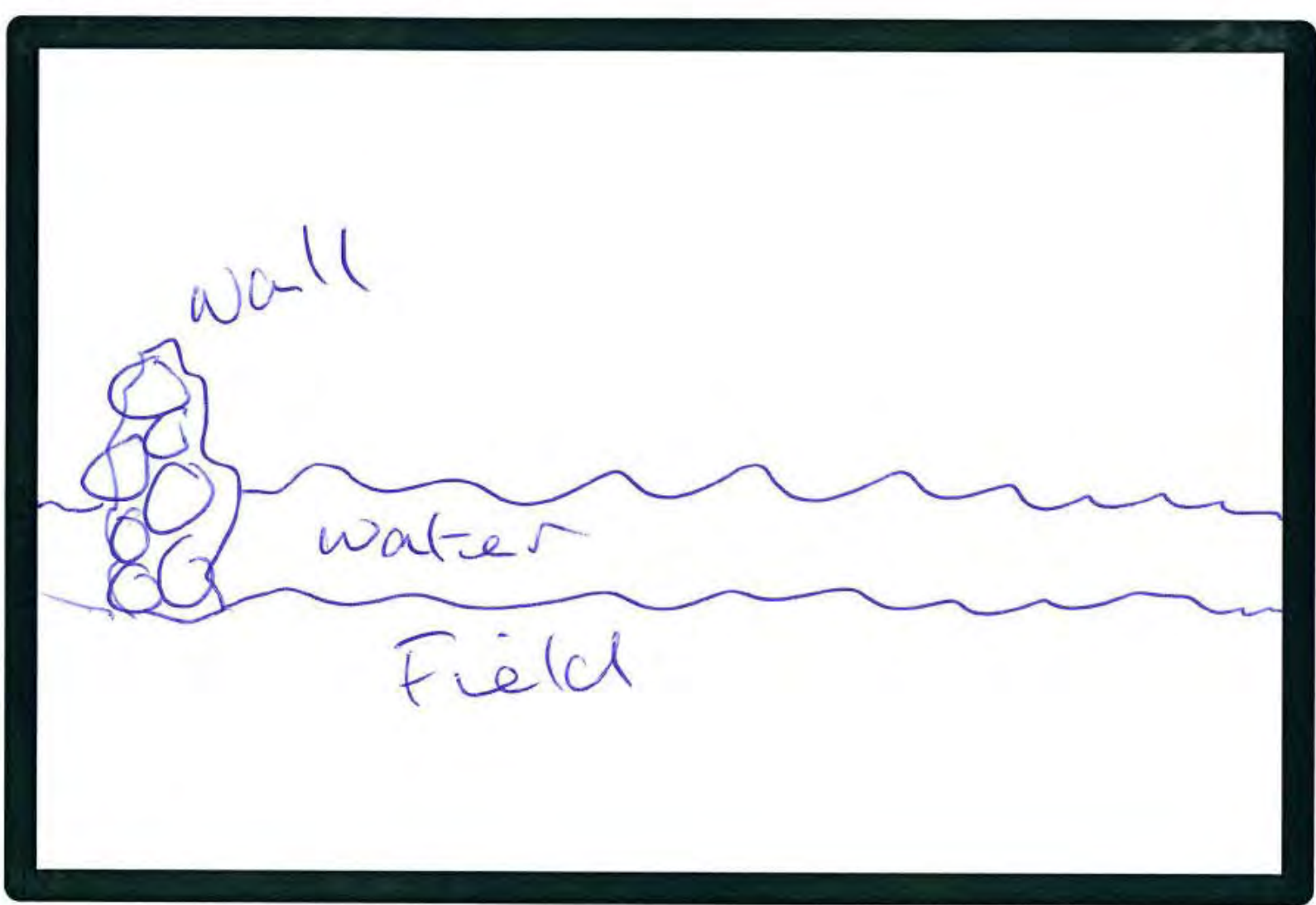

Non-expert 
PLEASE STAY INSIDE THE BOX!

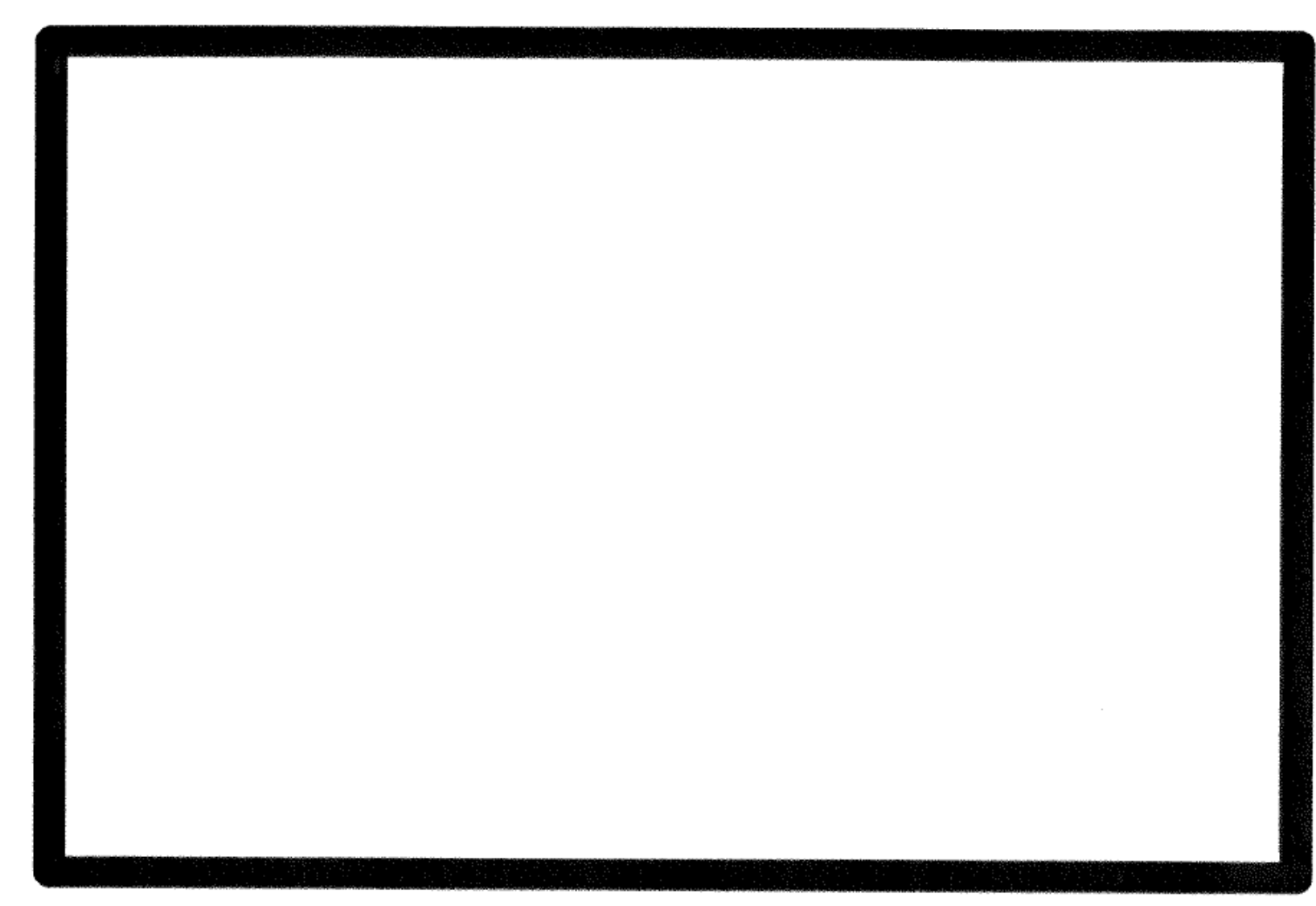




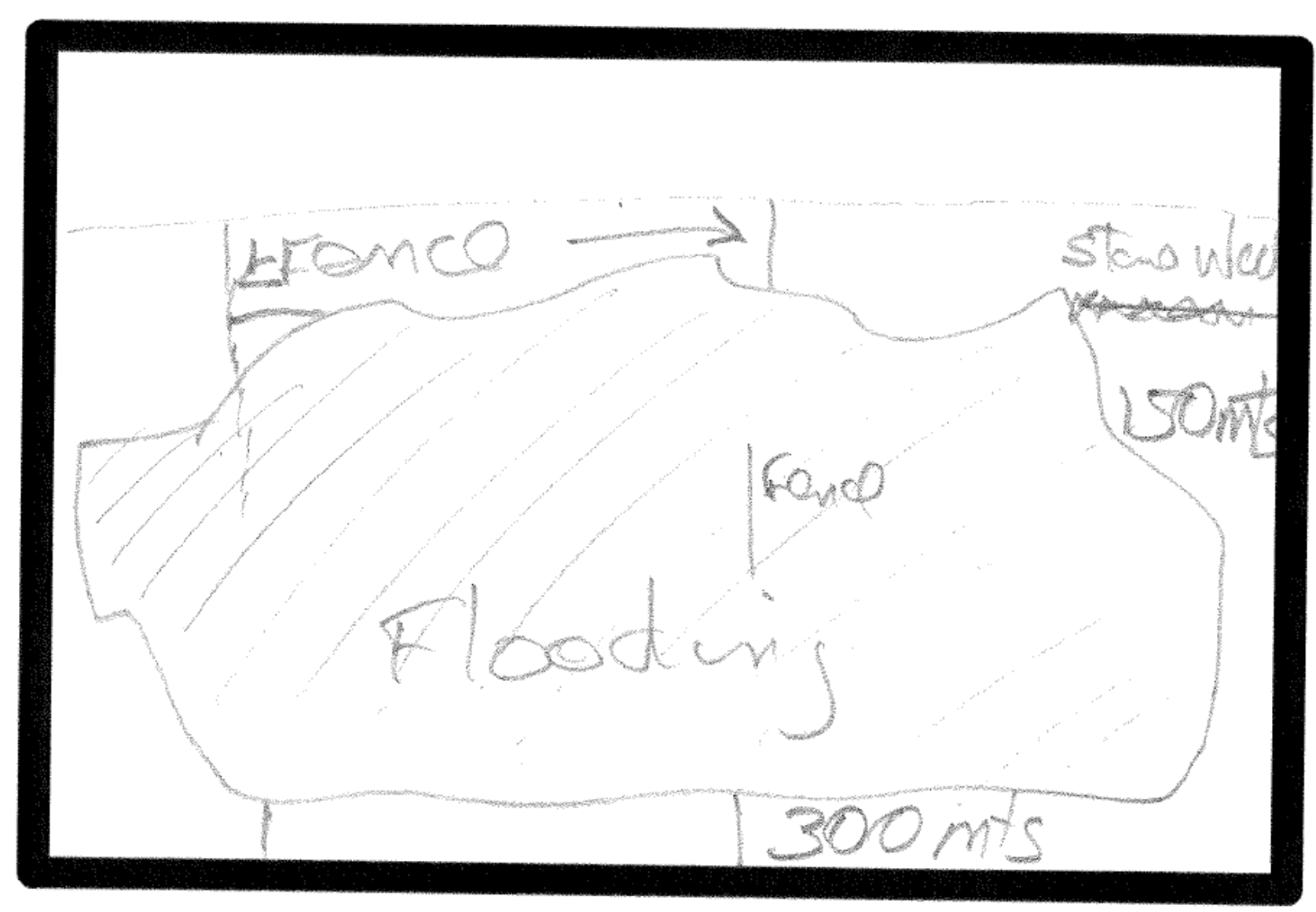




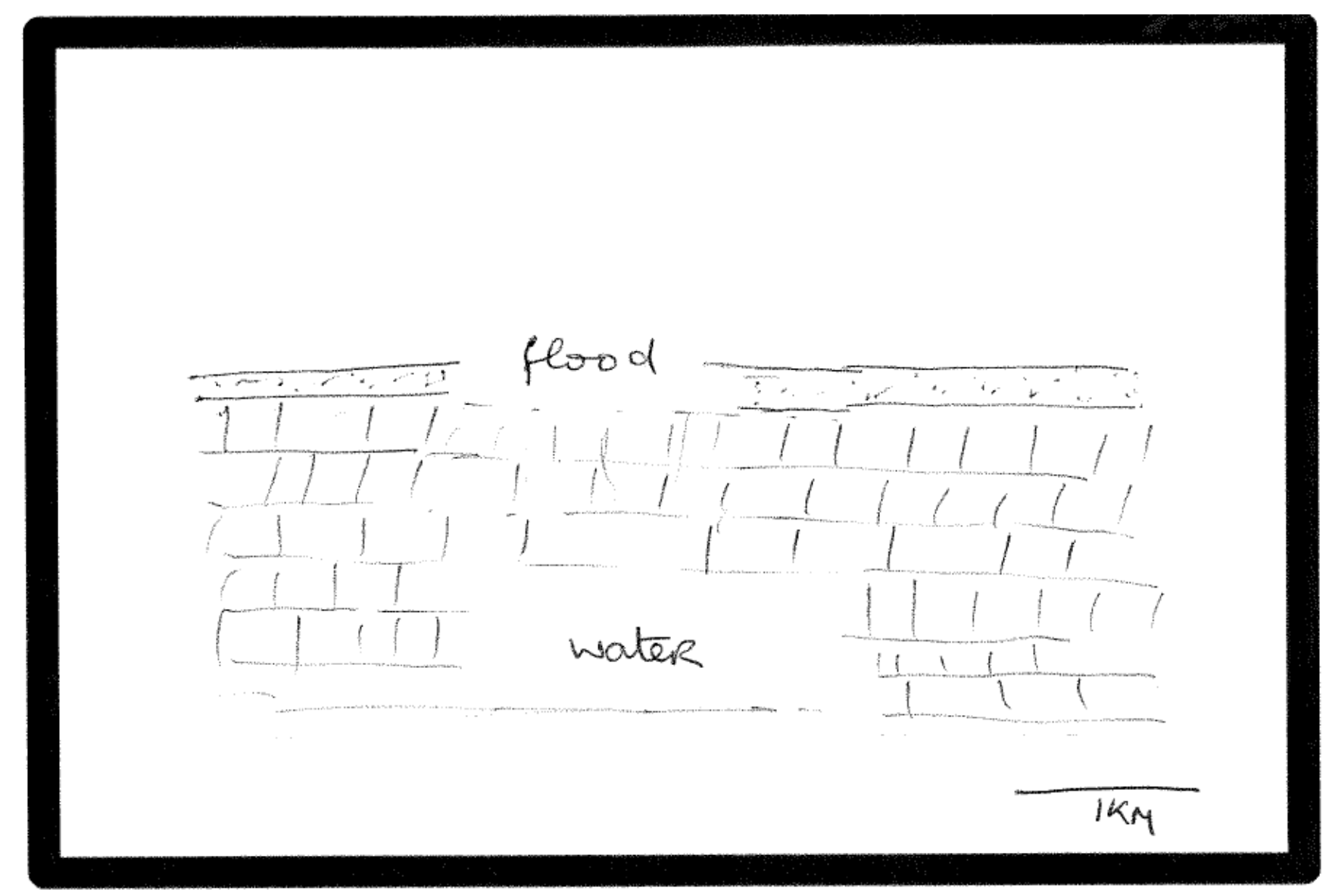




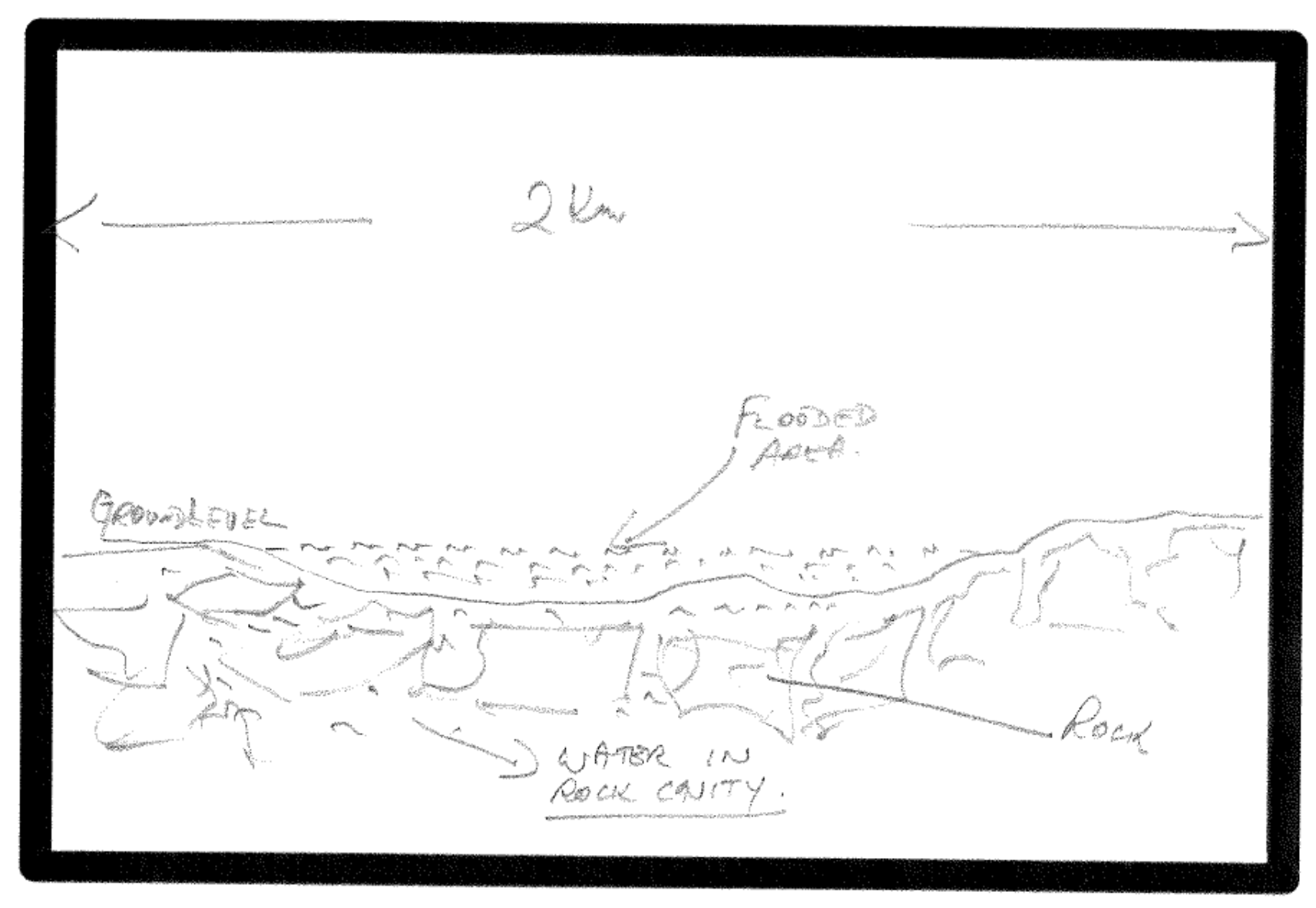


PLEASE STAY INSIDE THE BOX!

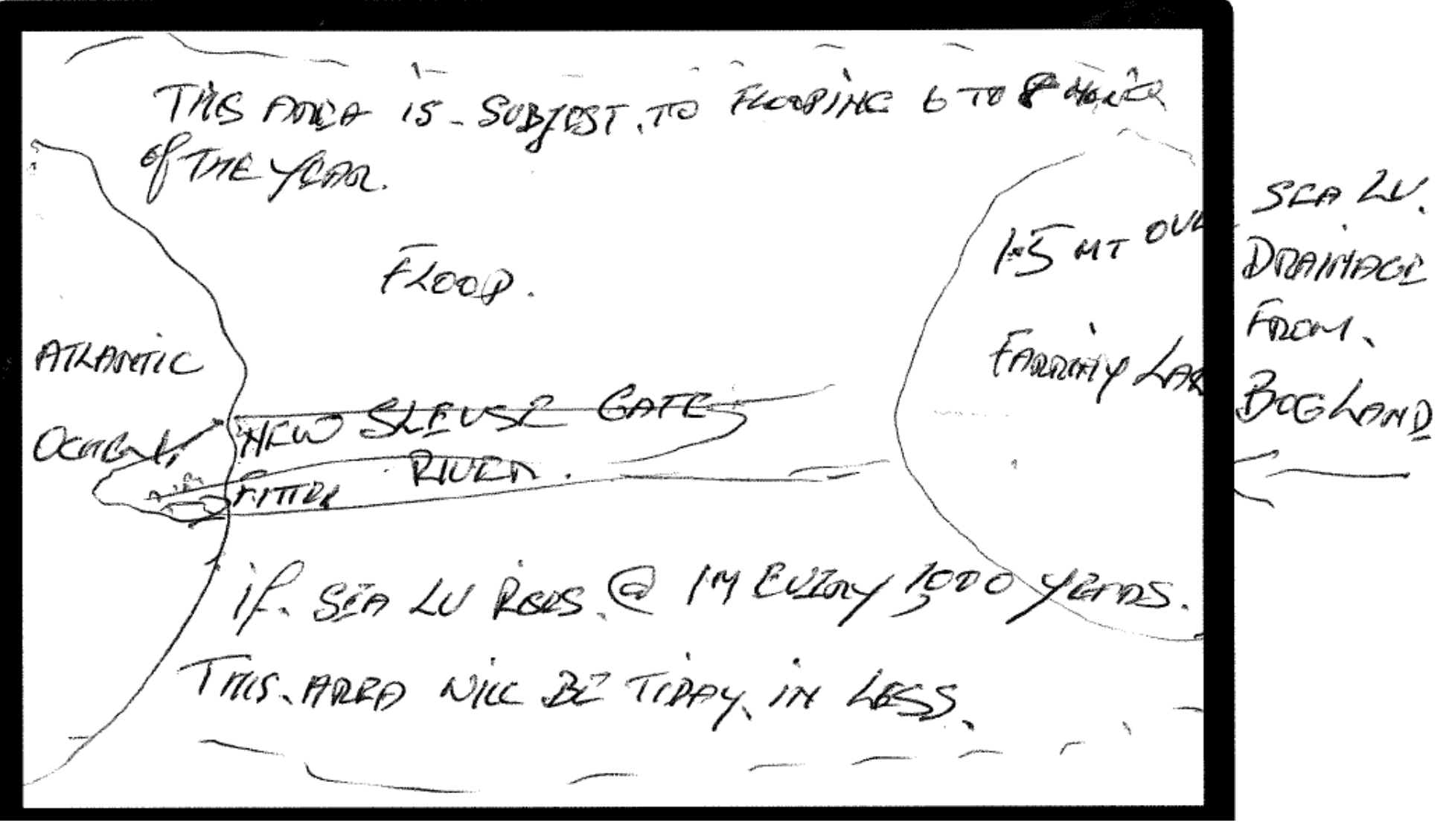




$$
\square
$$


PLEASE STAY INSIDE THE BOX!

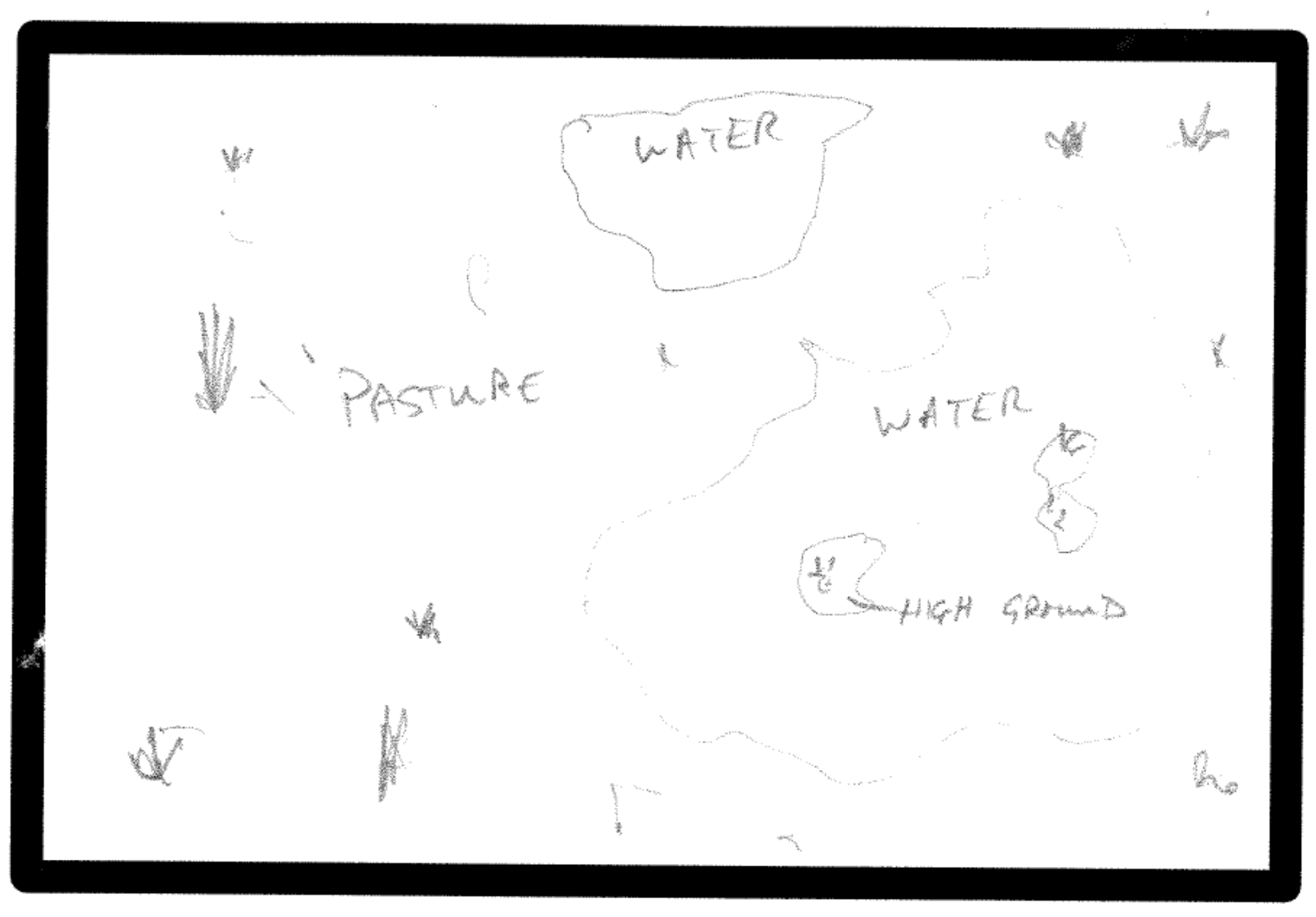


TLEMJE DIAI INSIVE ITE DUN:

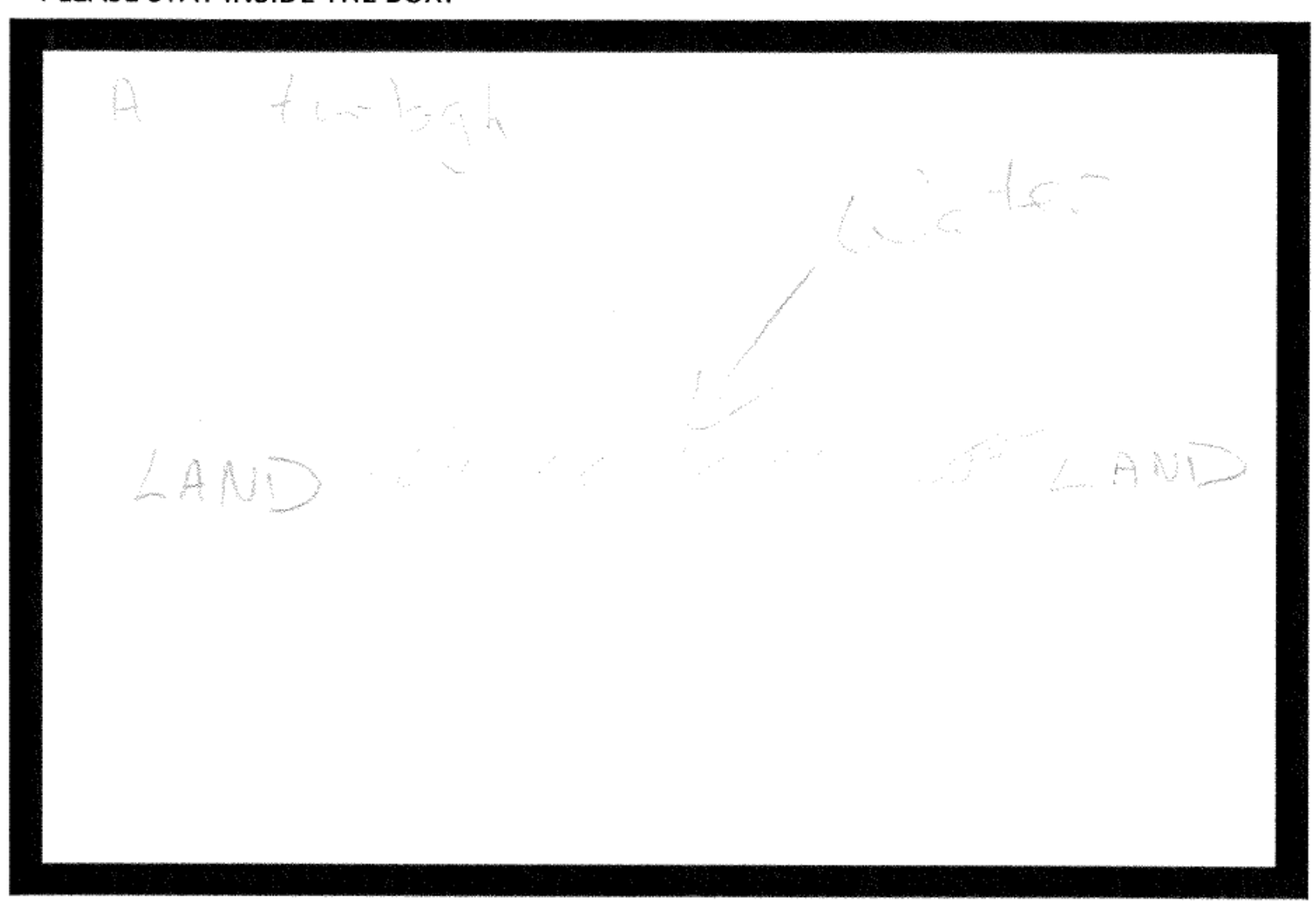




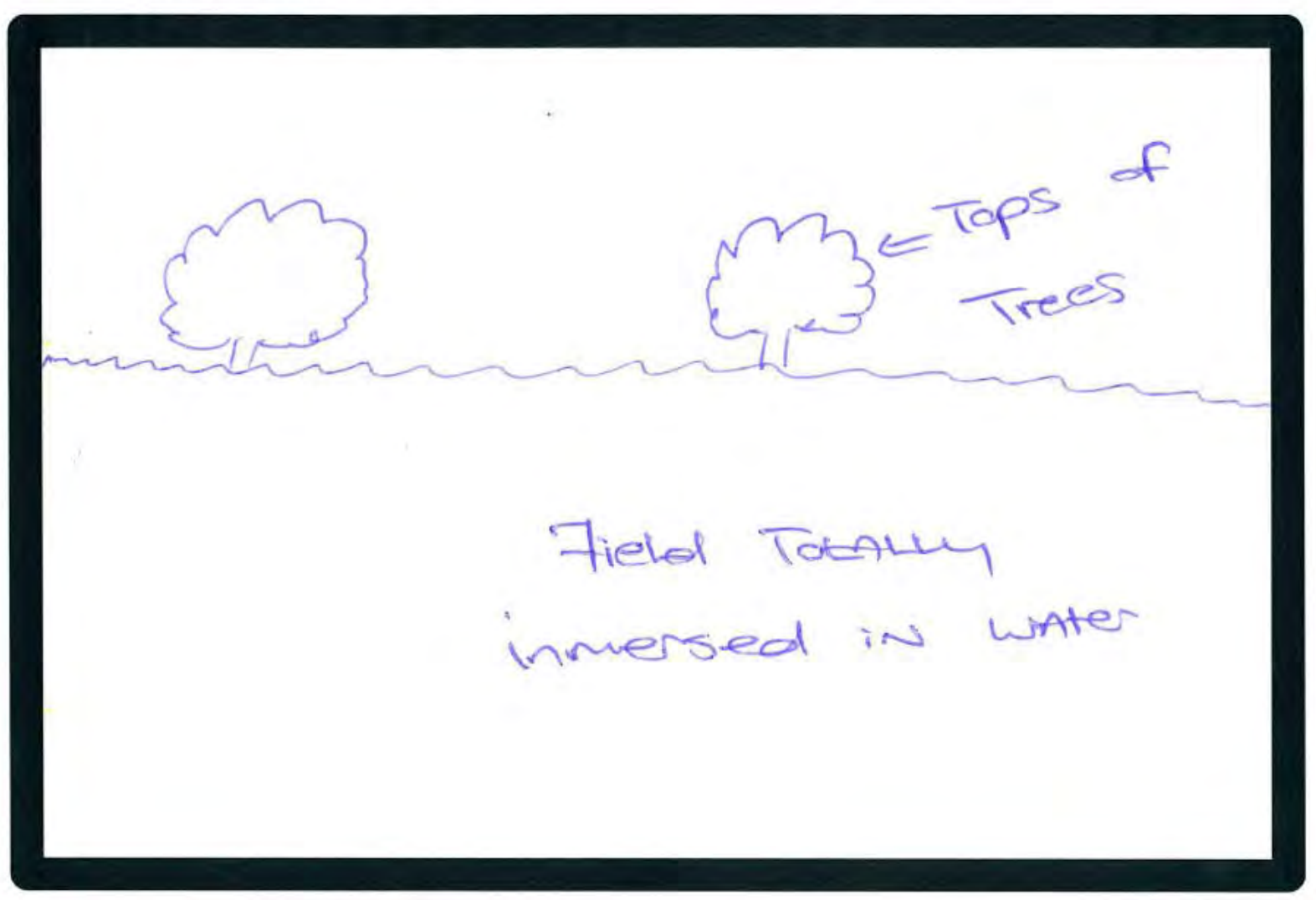




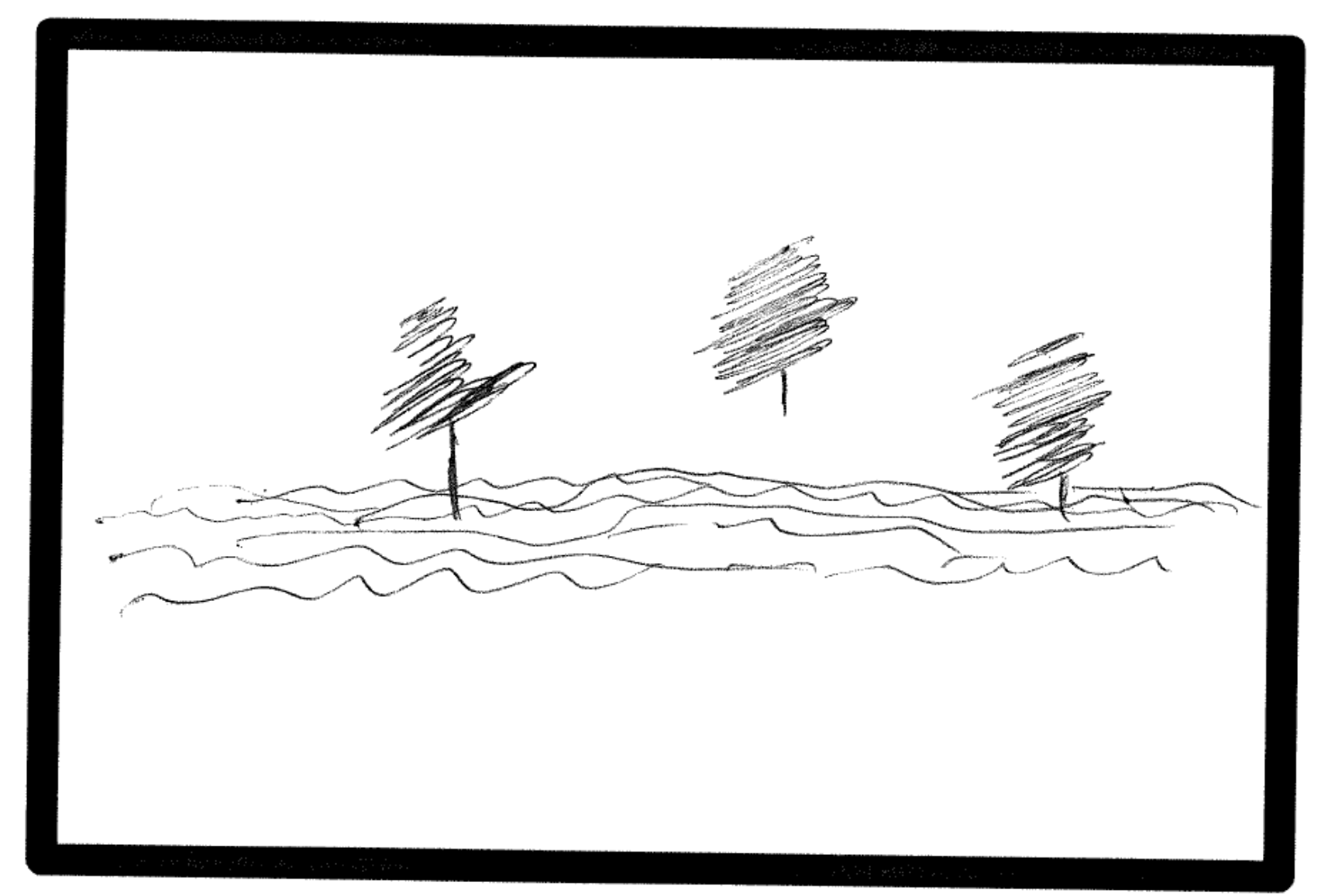




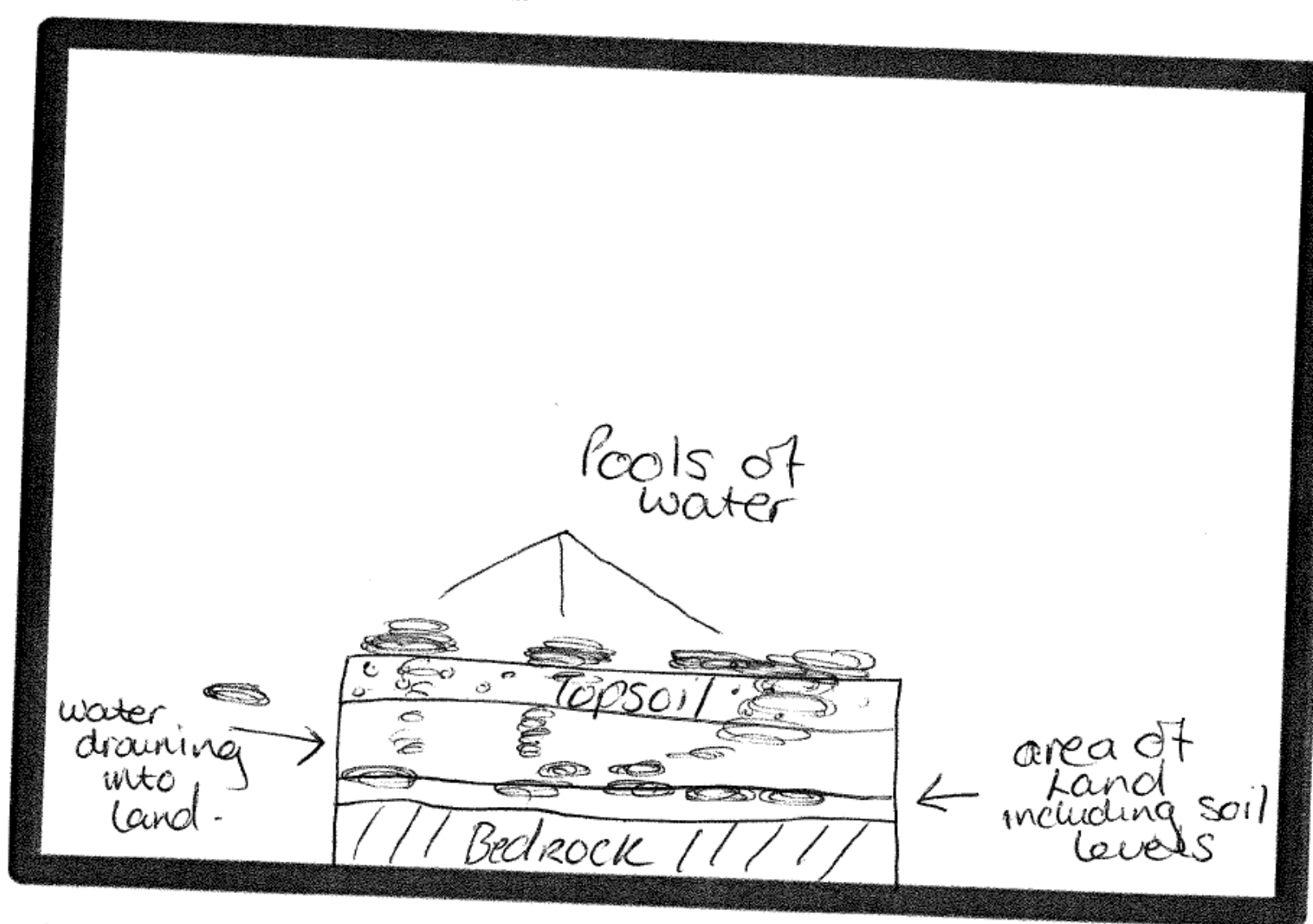


PLEASE STAY INSIDE THE BOX!

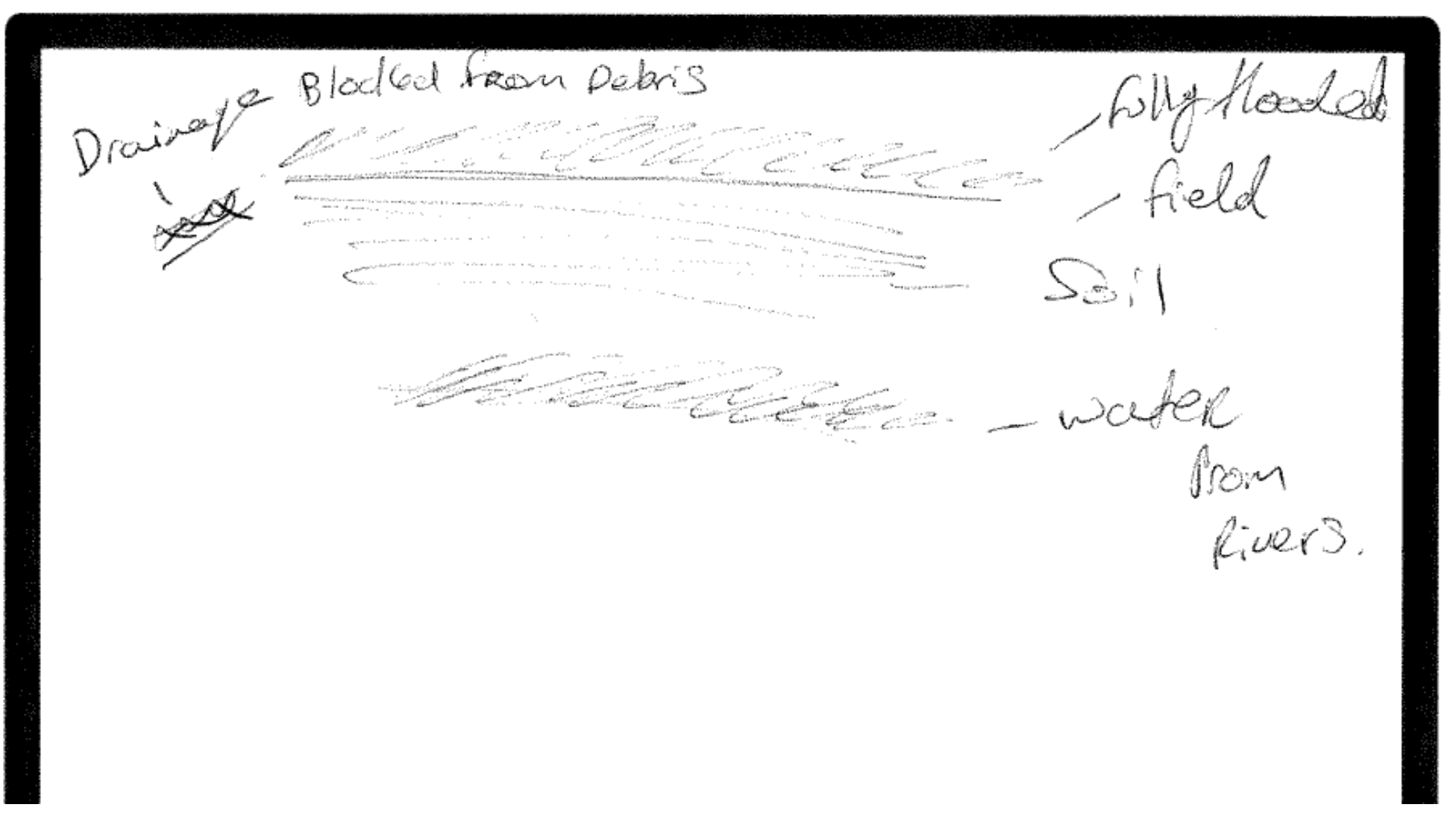


PLEASE STAY INSIDE THE BOX!

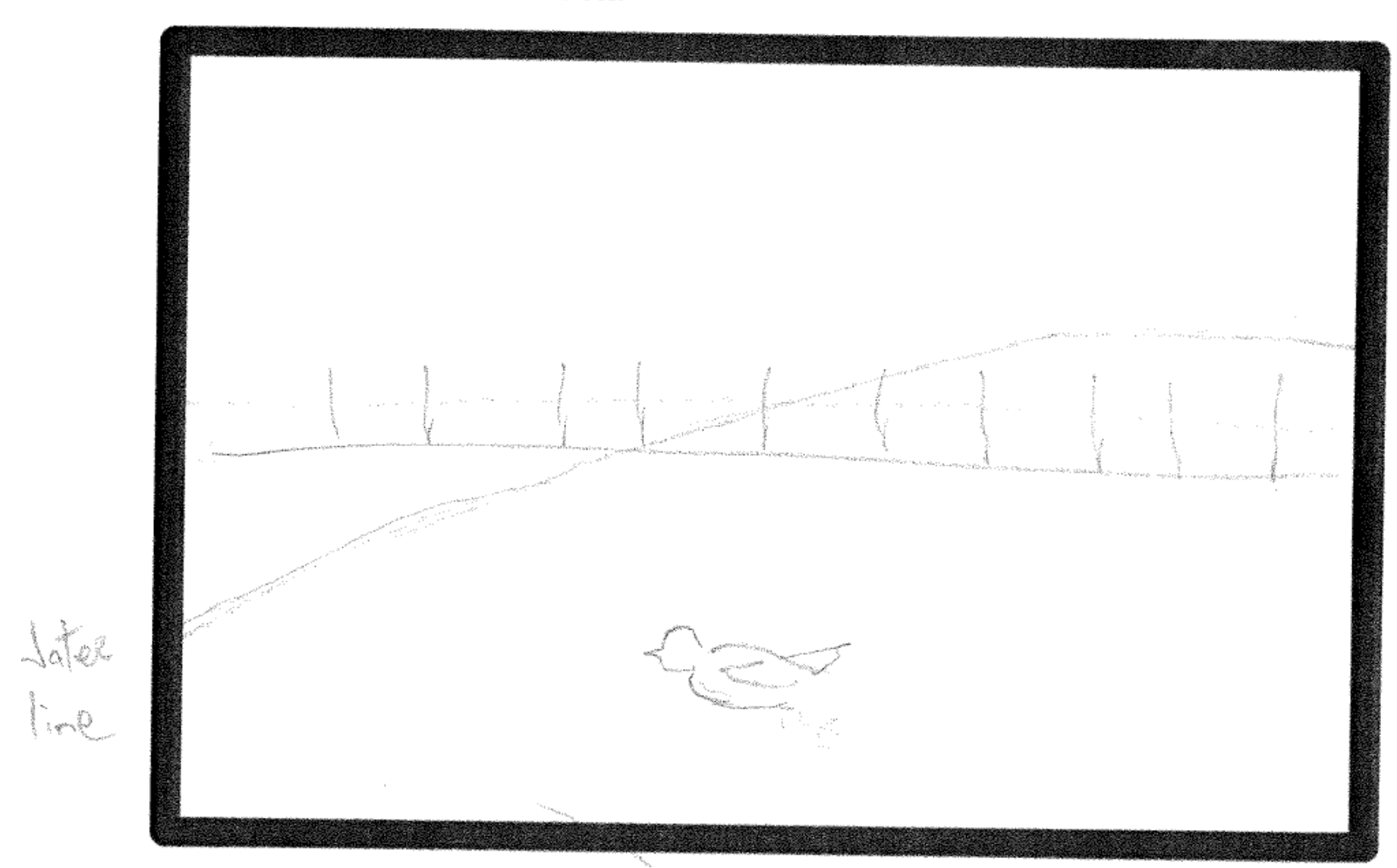




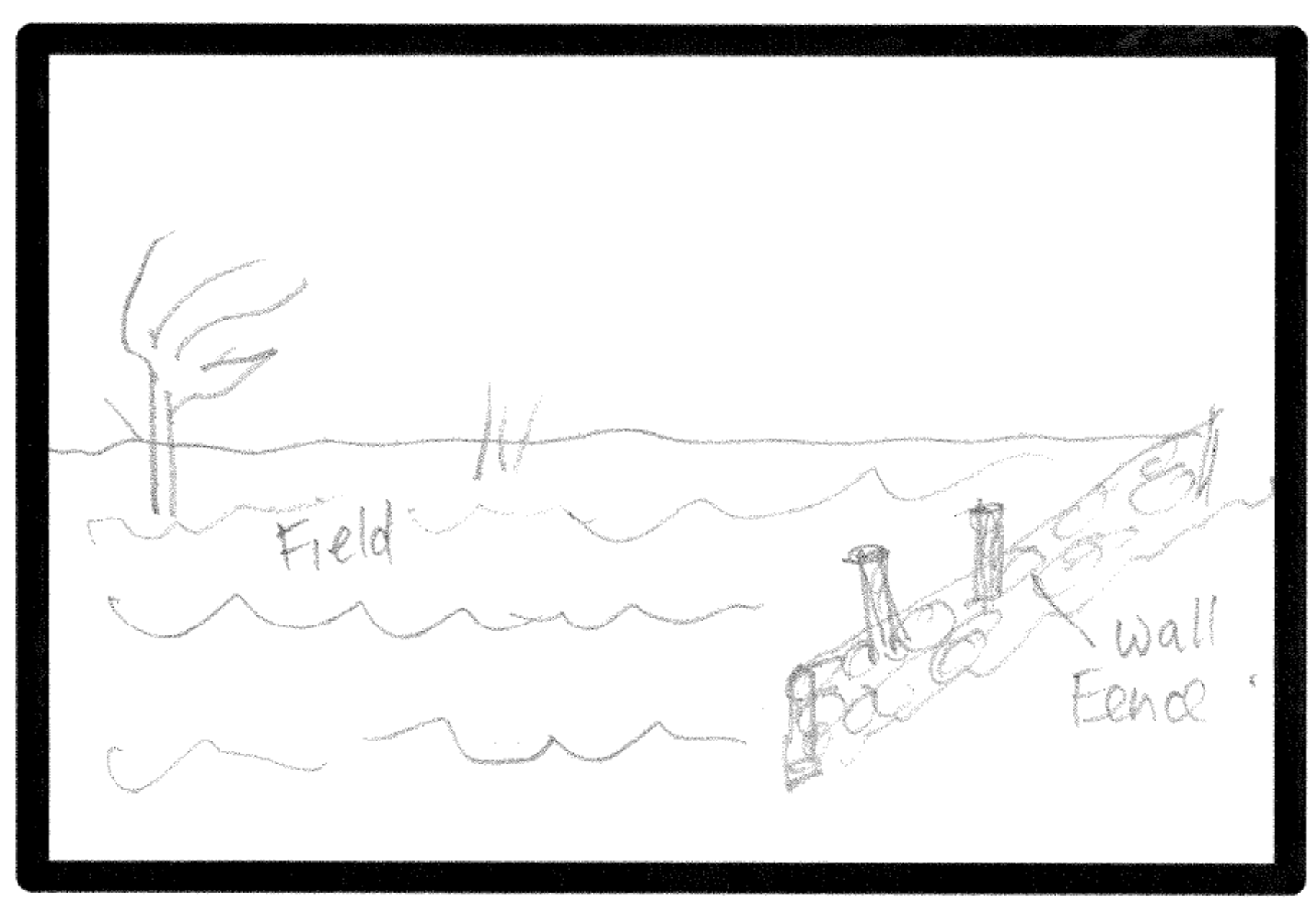




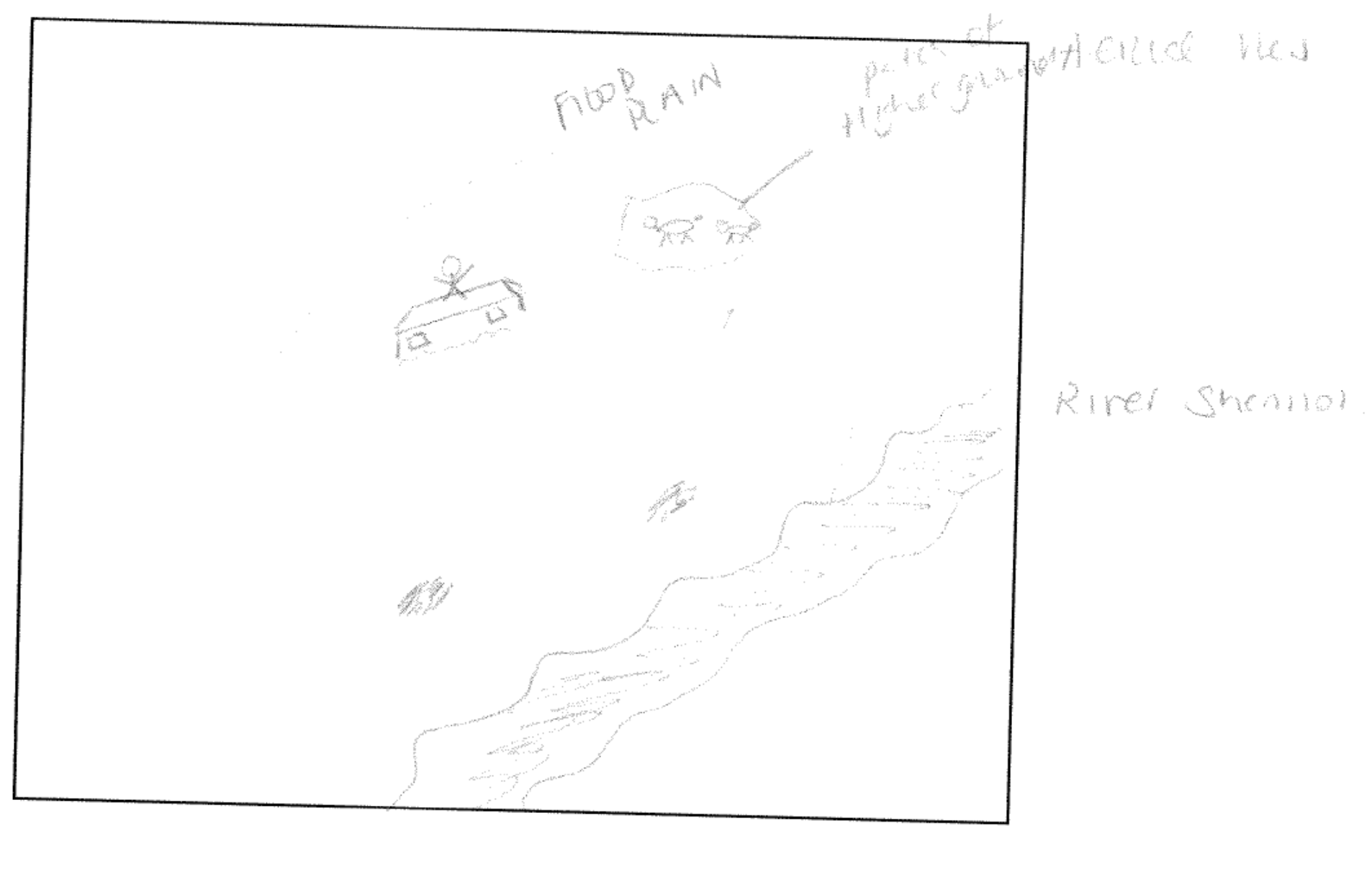




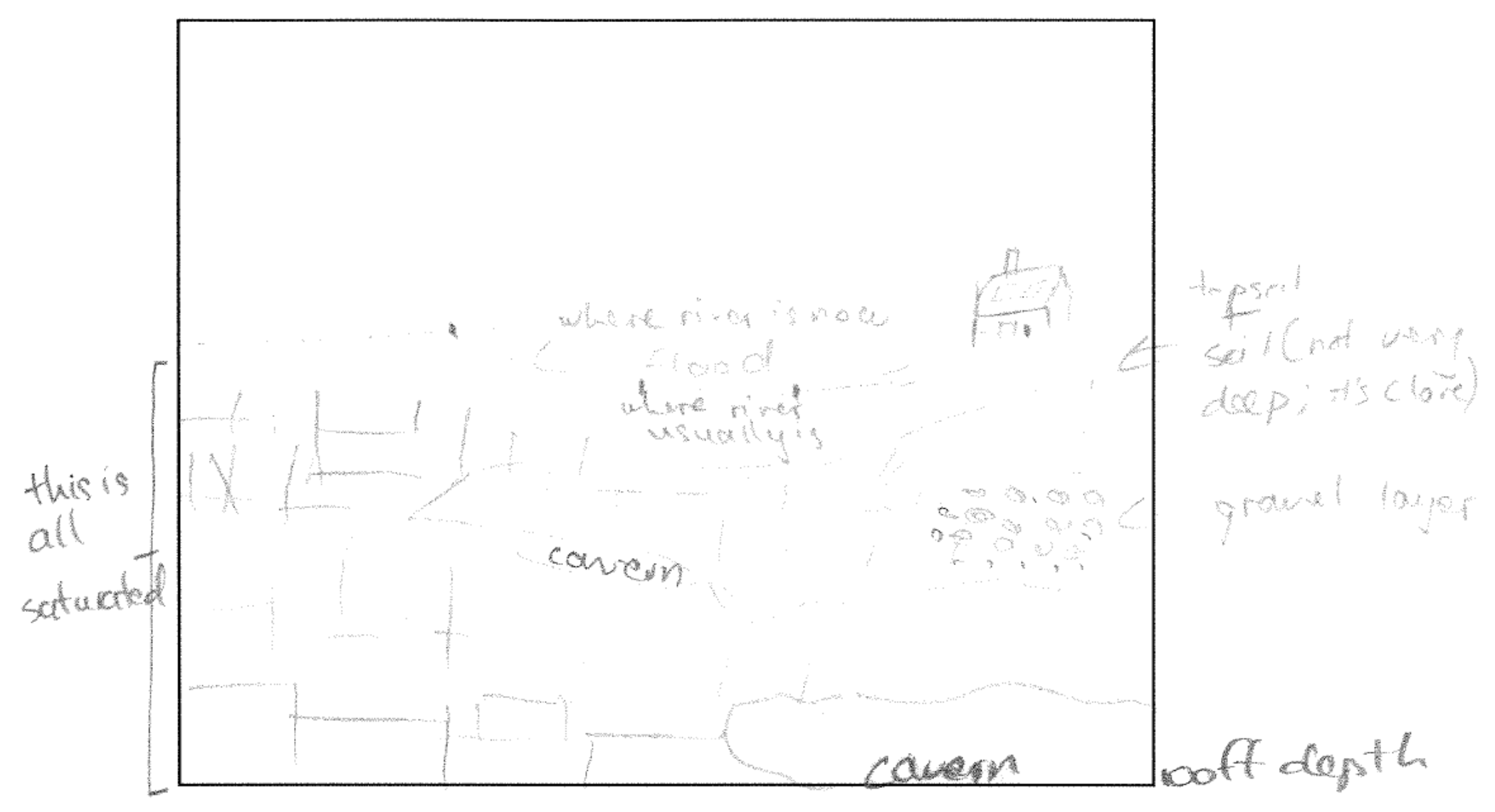

Non-expert 
PLEASE STAY INSIDE THE BOX

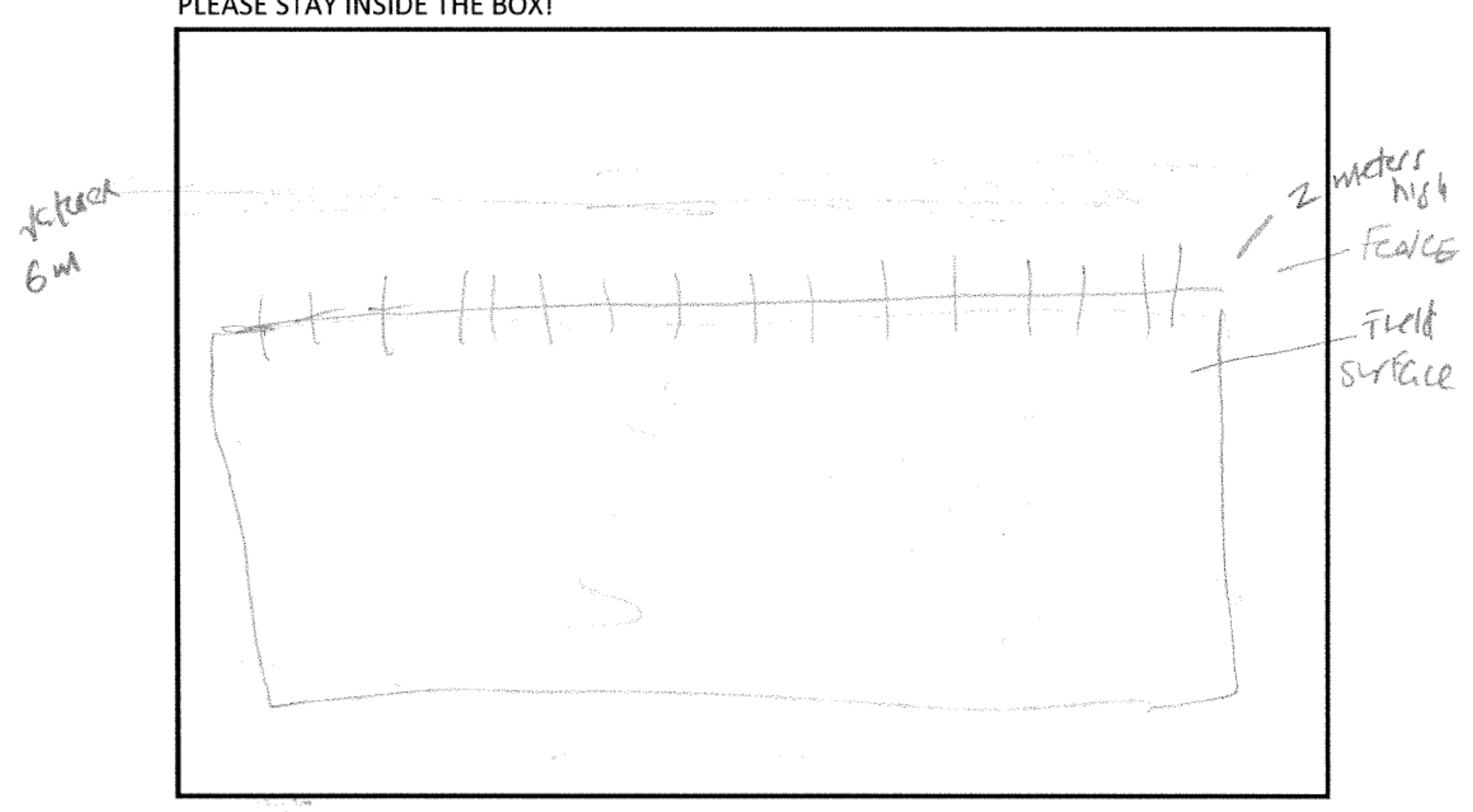


PLEASE STAY INSIDE THE BOX!

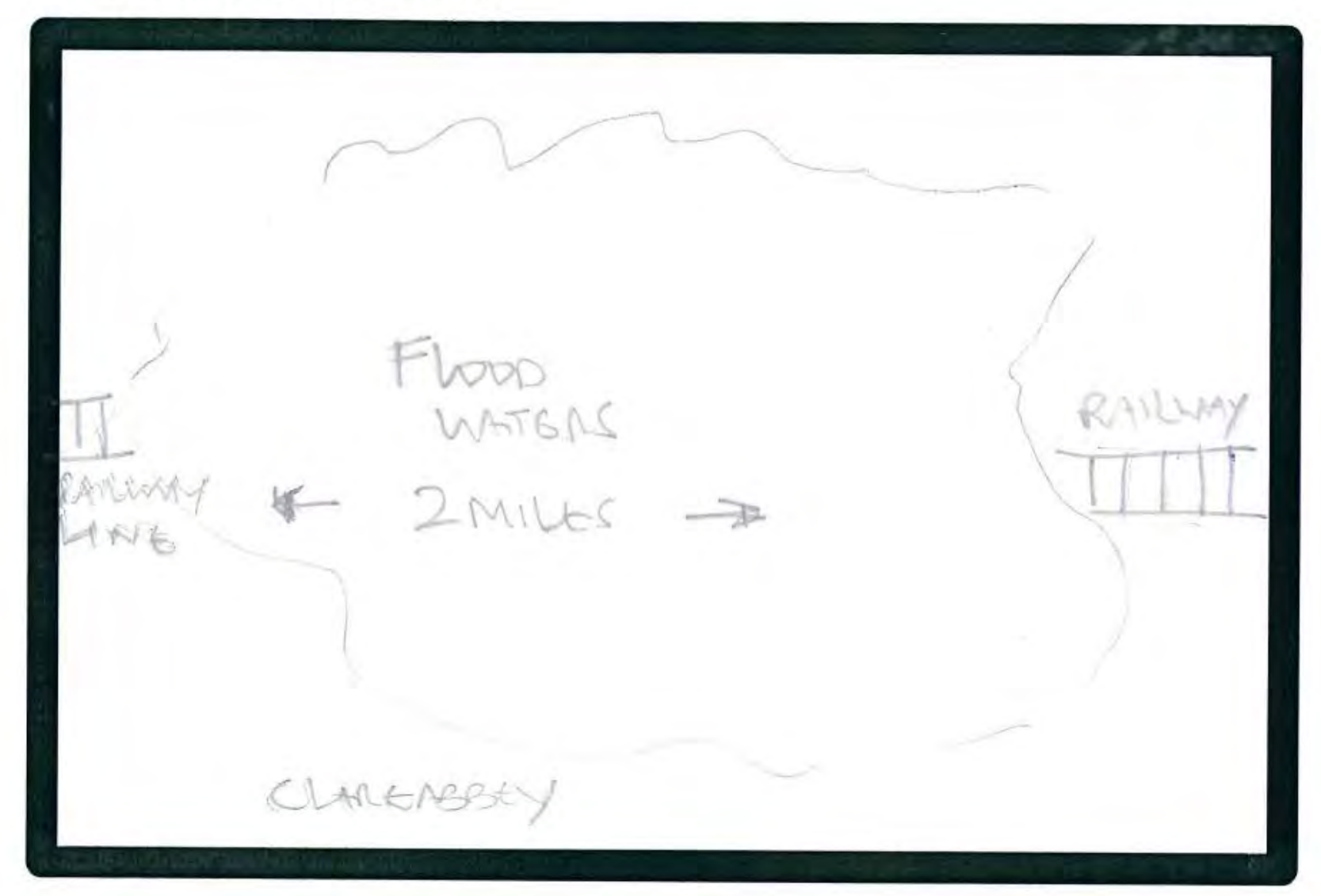




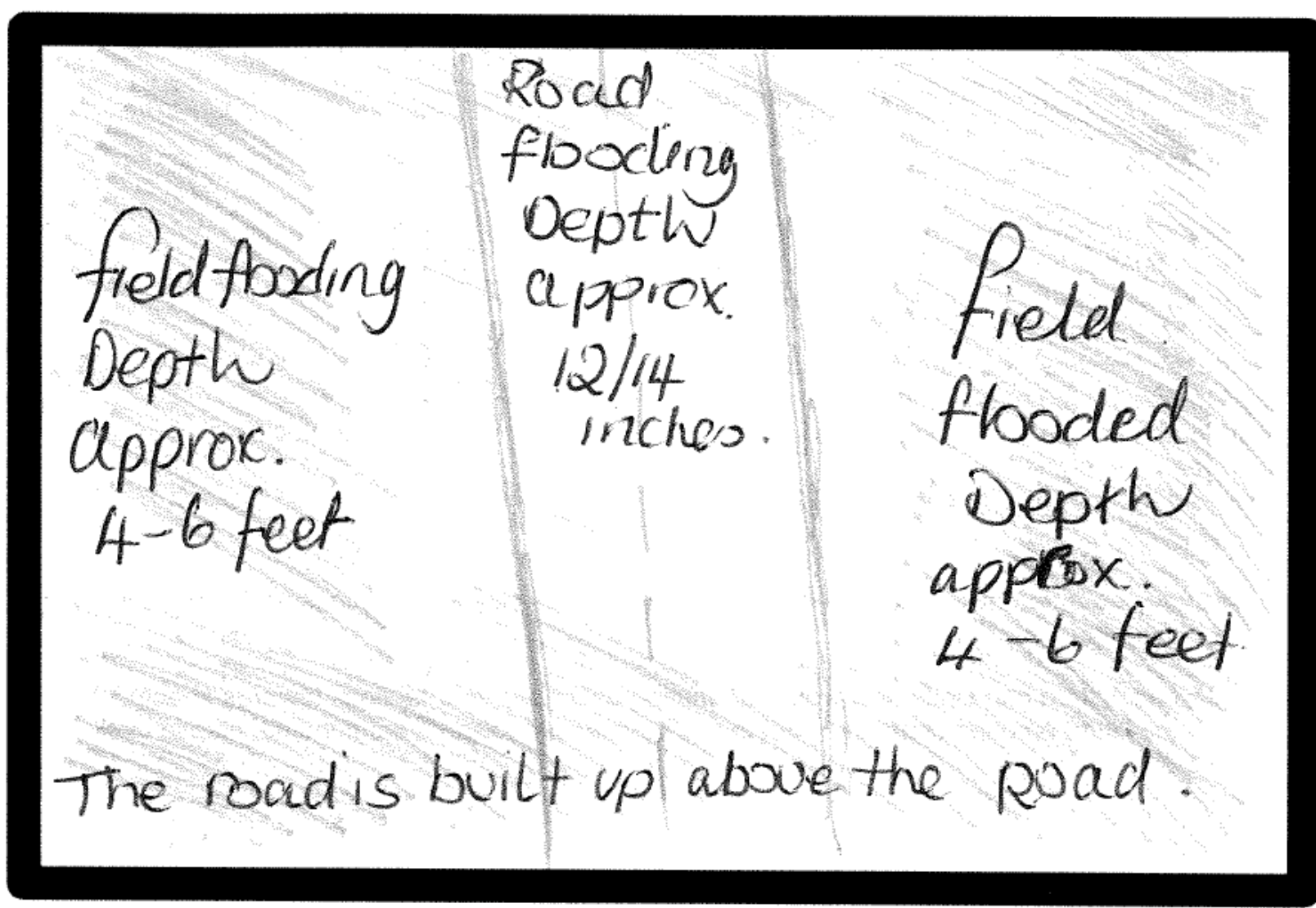


\&ing PLEASE STAY INSIDE THE BOX!

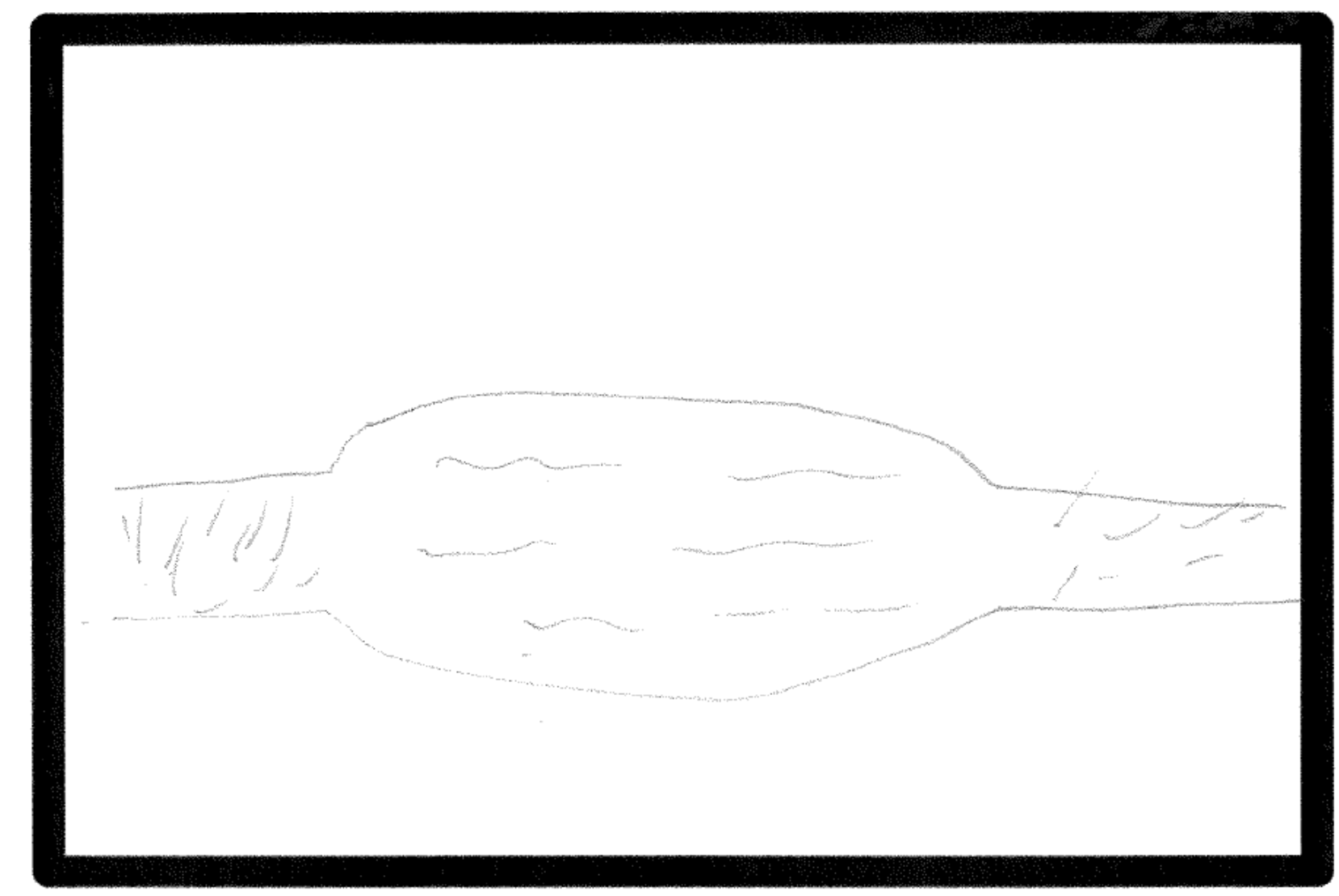




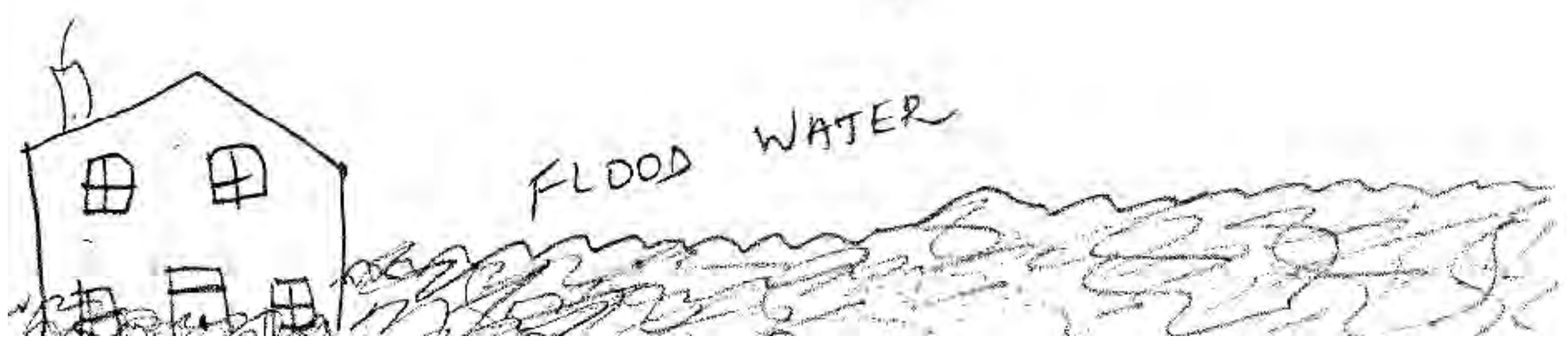

Non-expert 


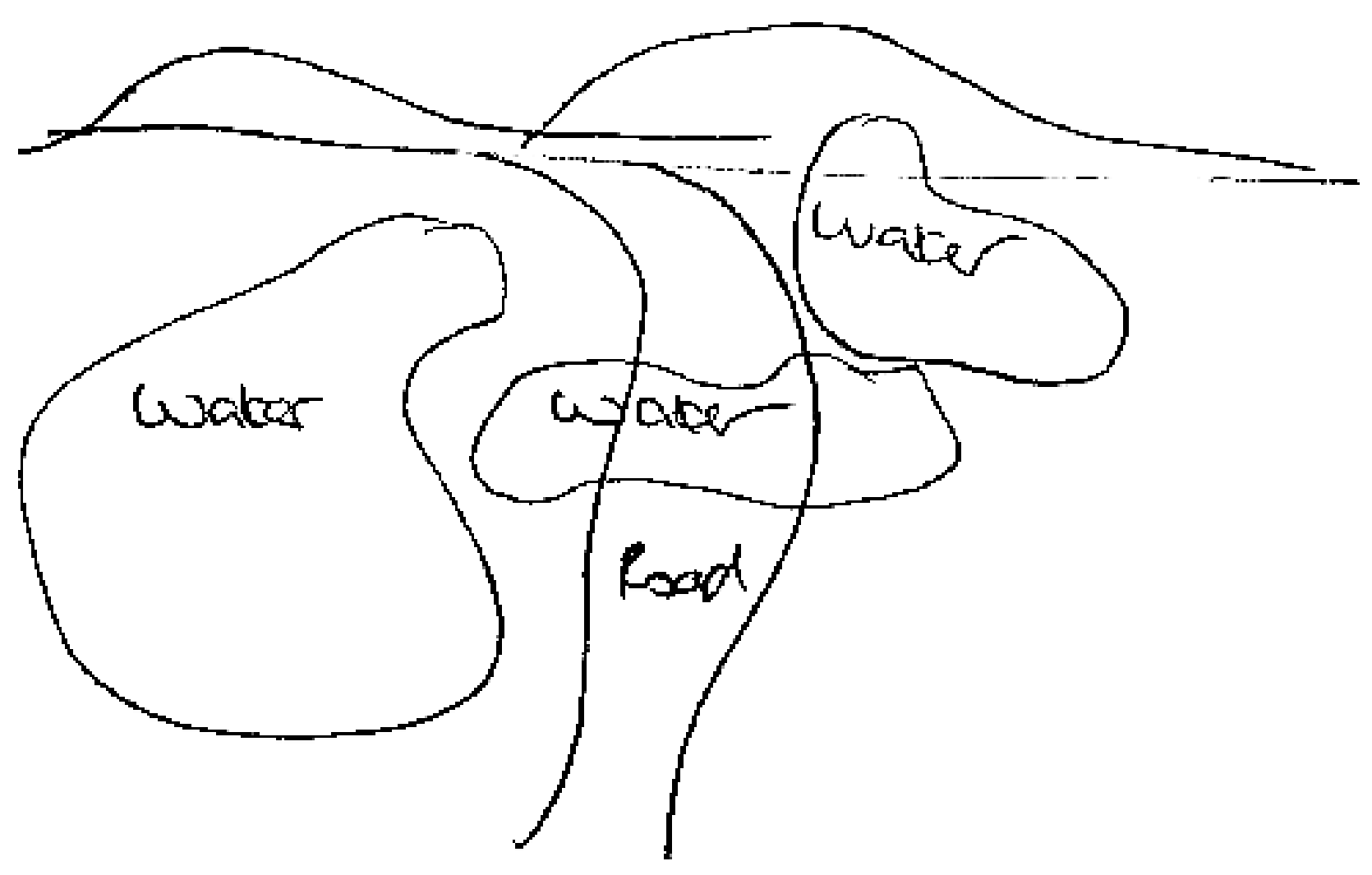

Non-expert 


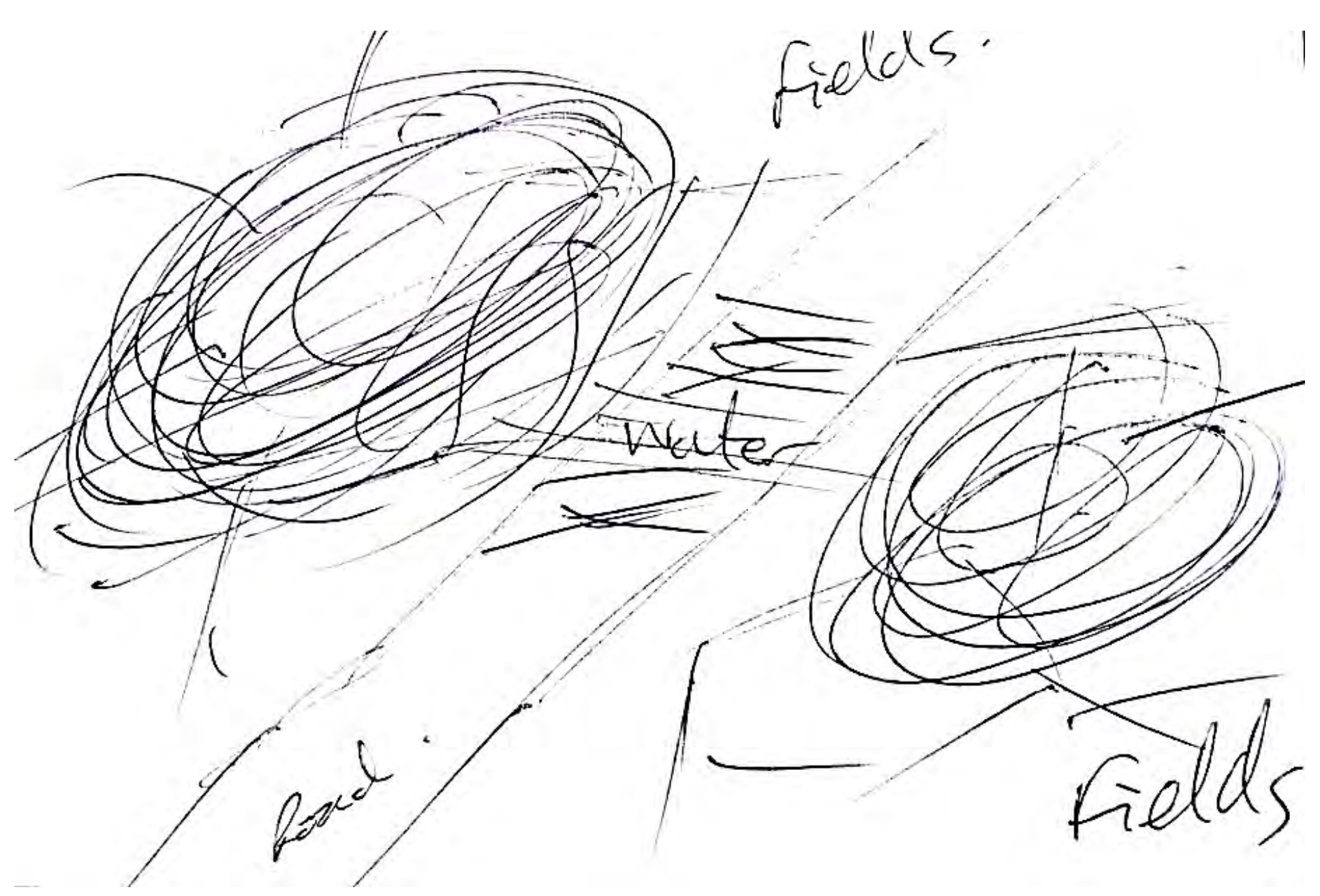

Non-expert 


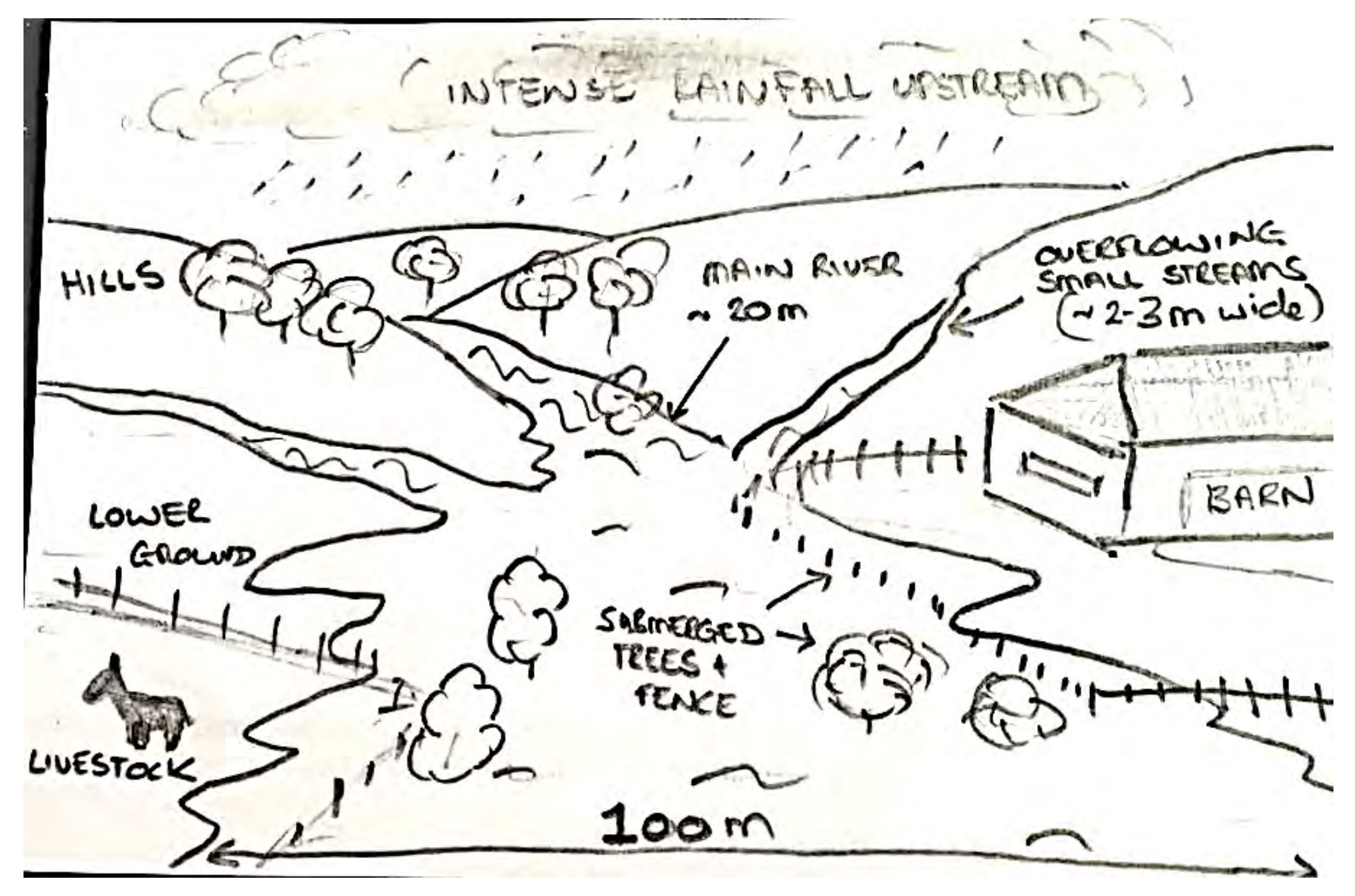

Expert 


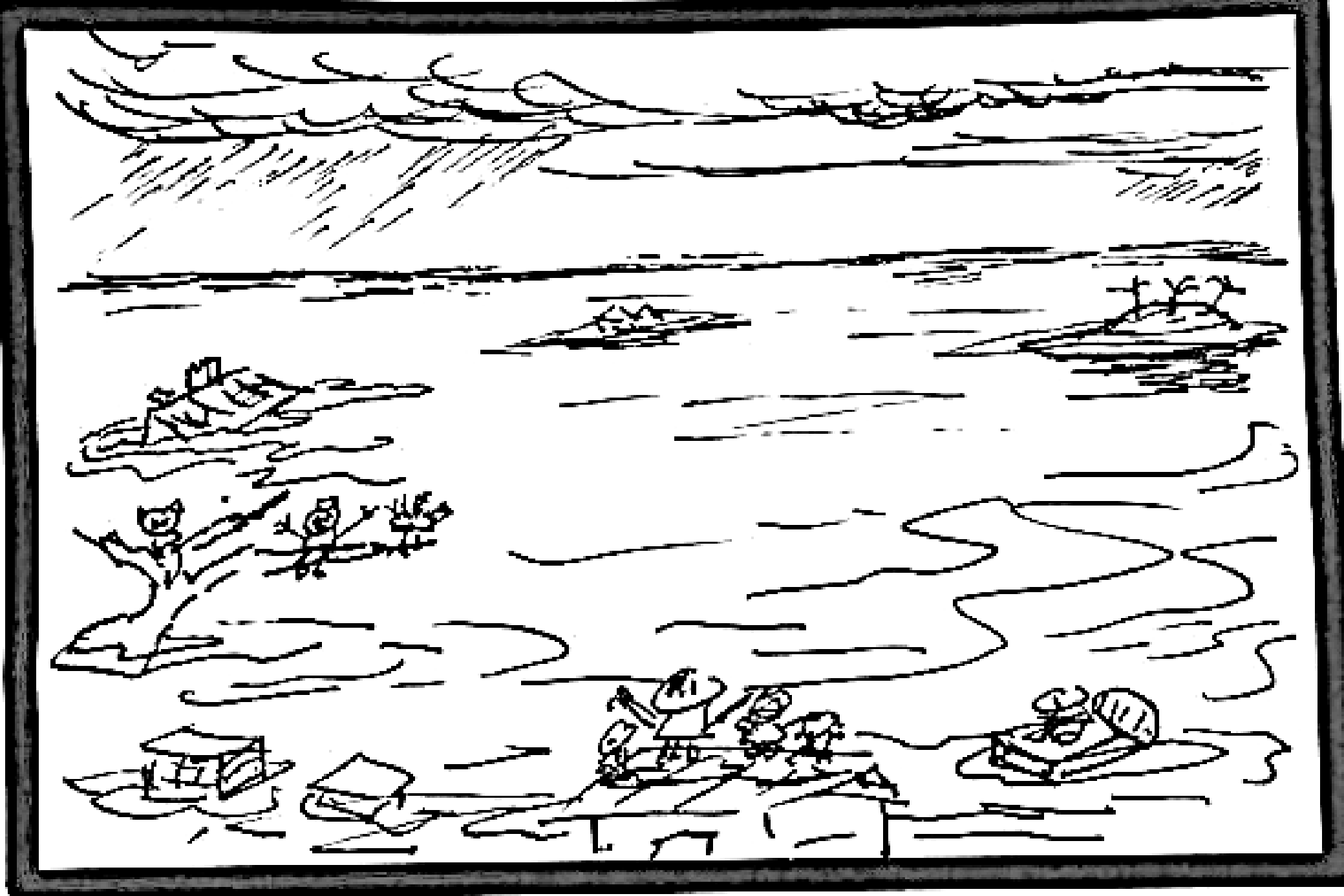




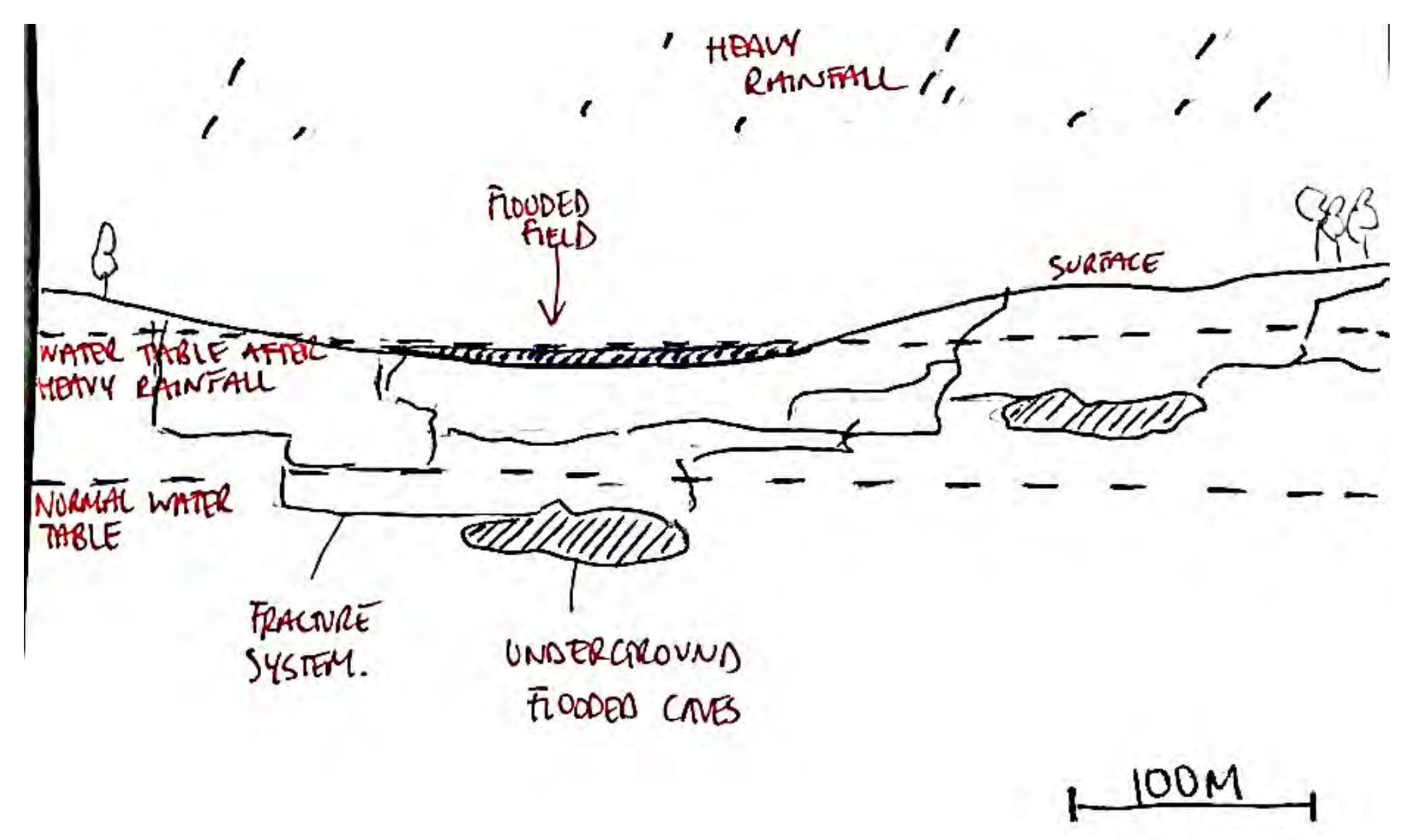

Expert 


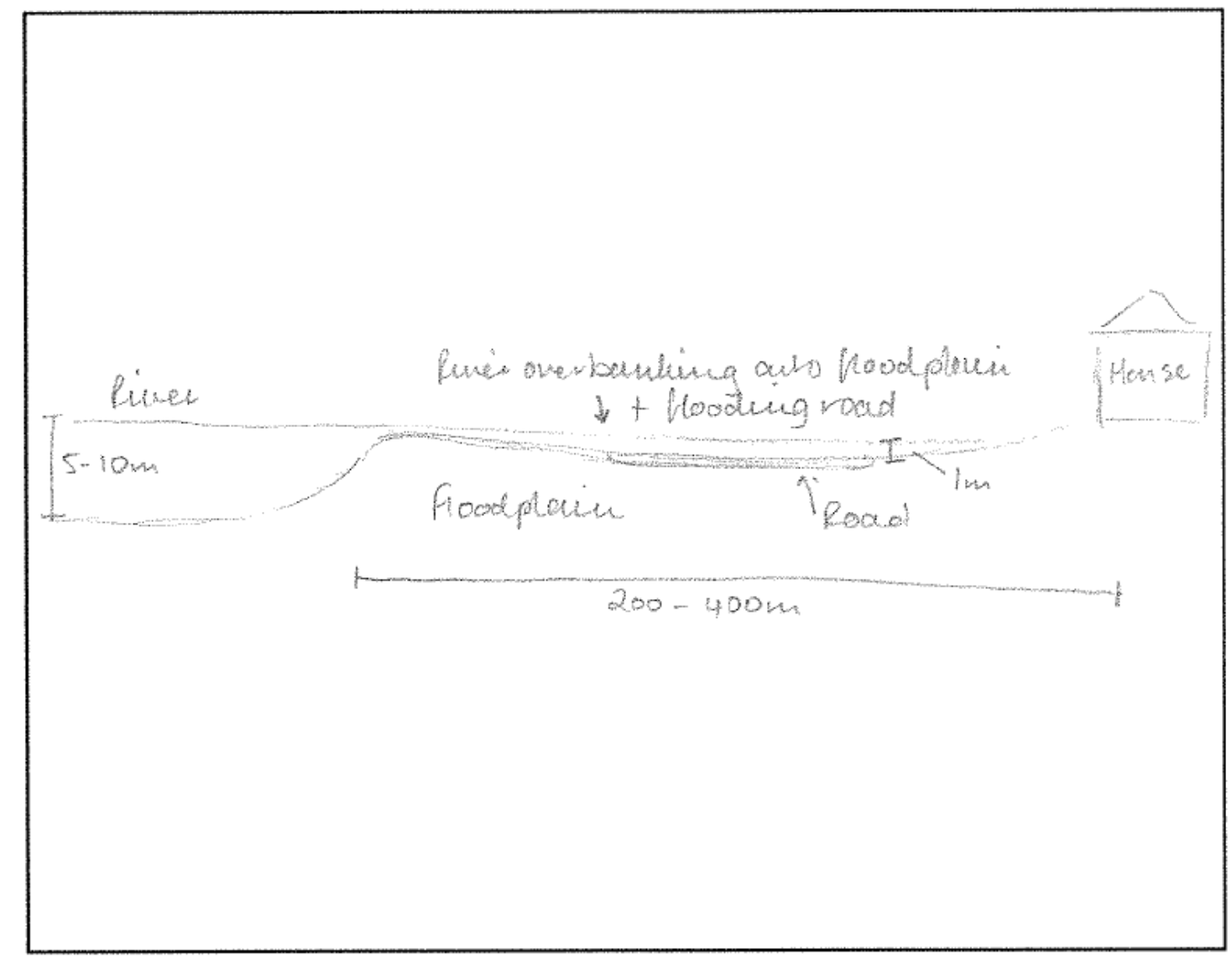


PLEASE STAY INSIDE THE BOX!

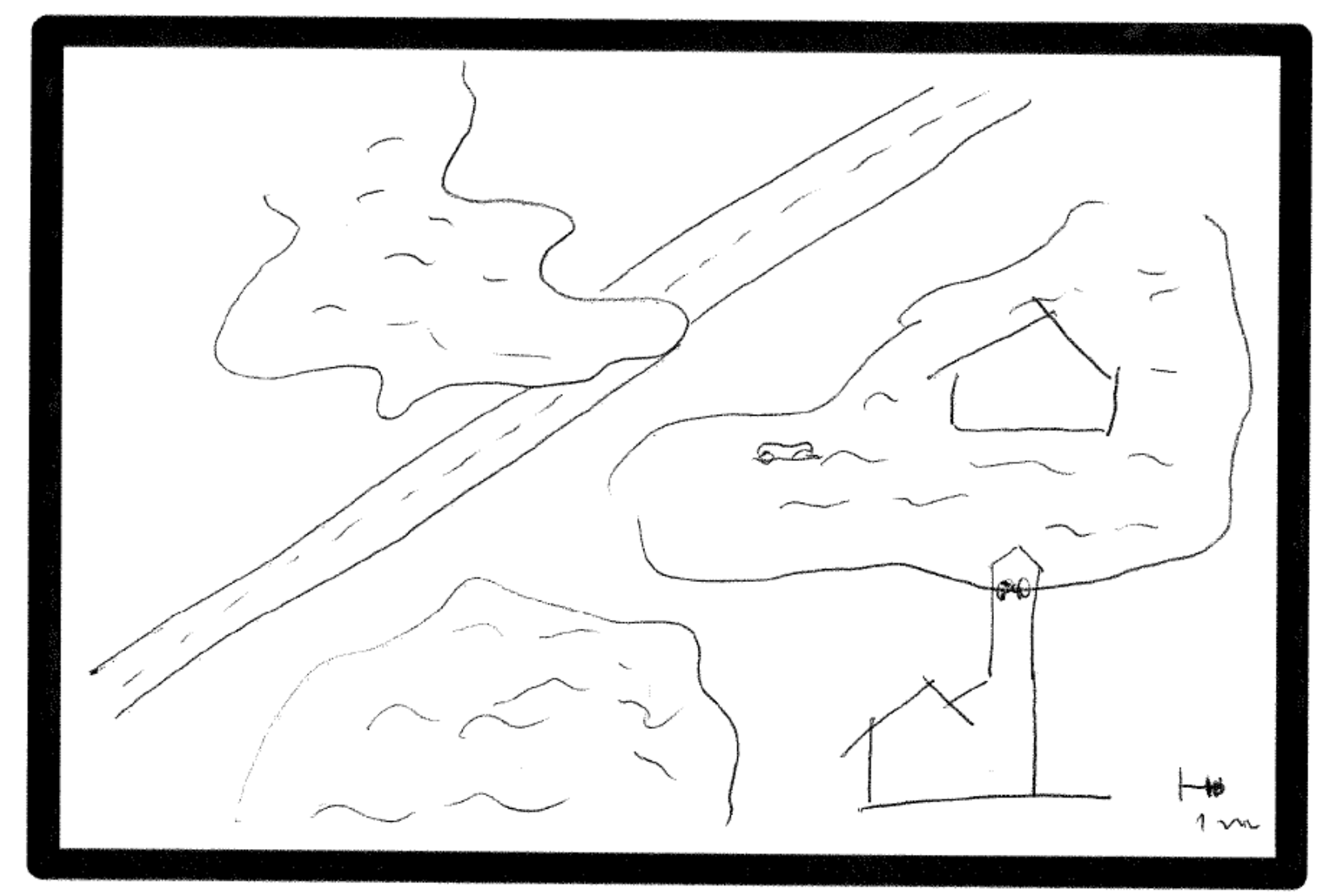




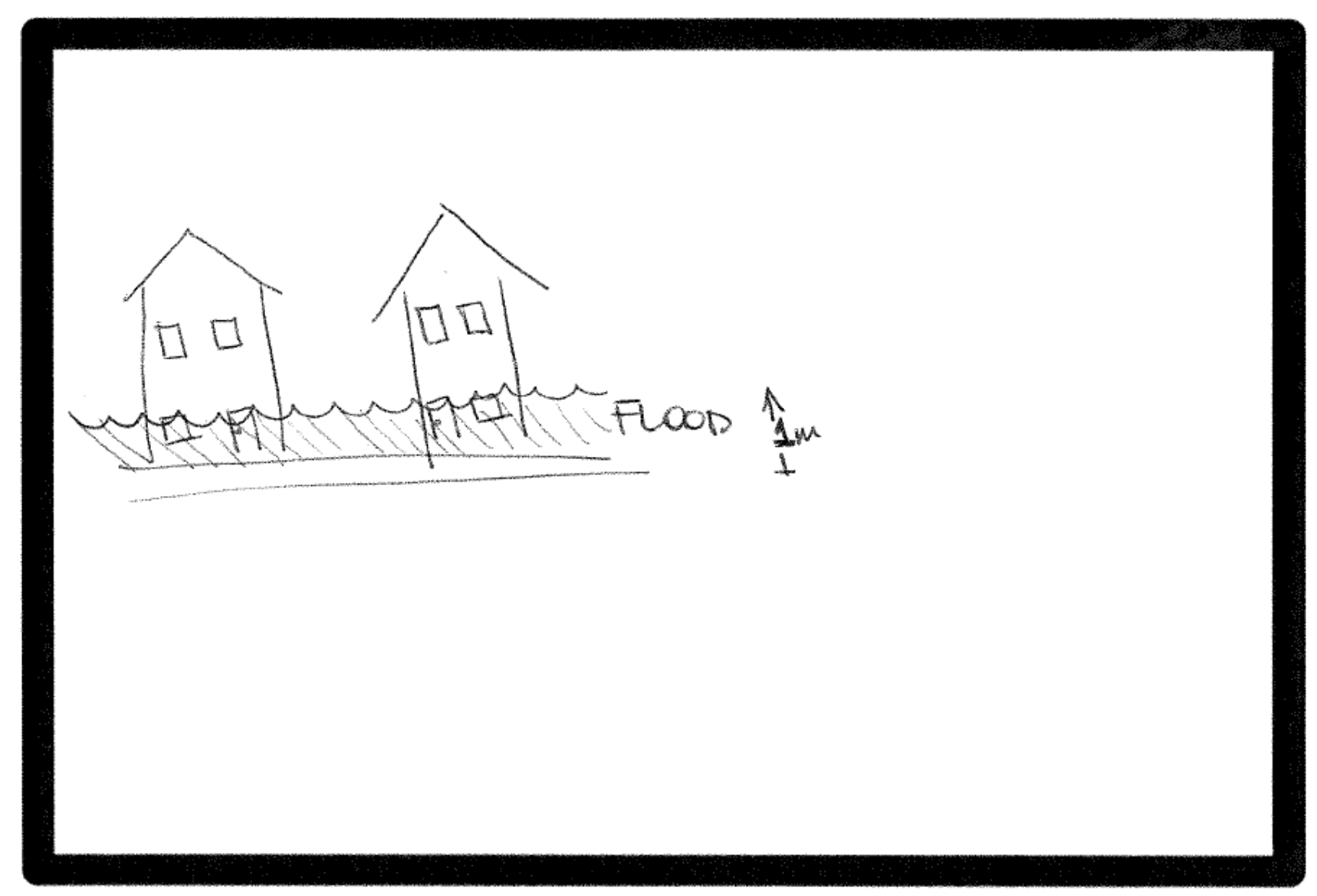


PLEASE STAY INSIDE THE BOX!

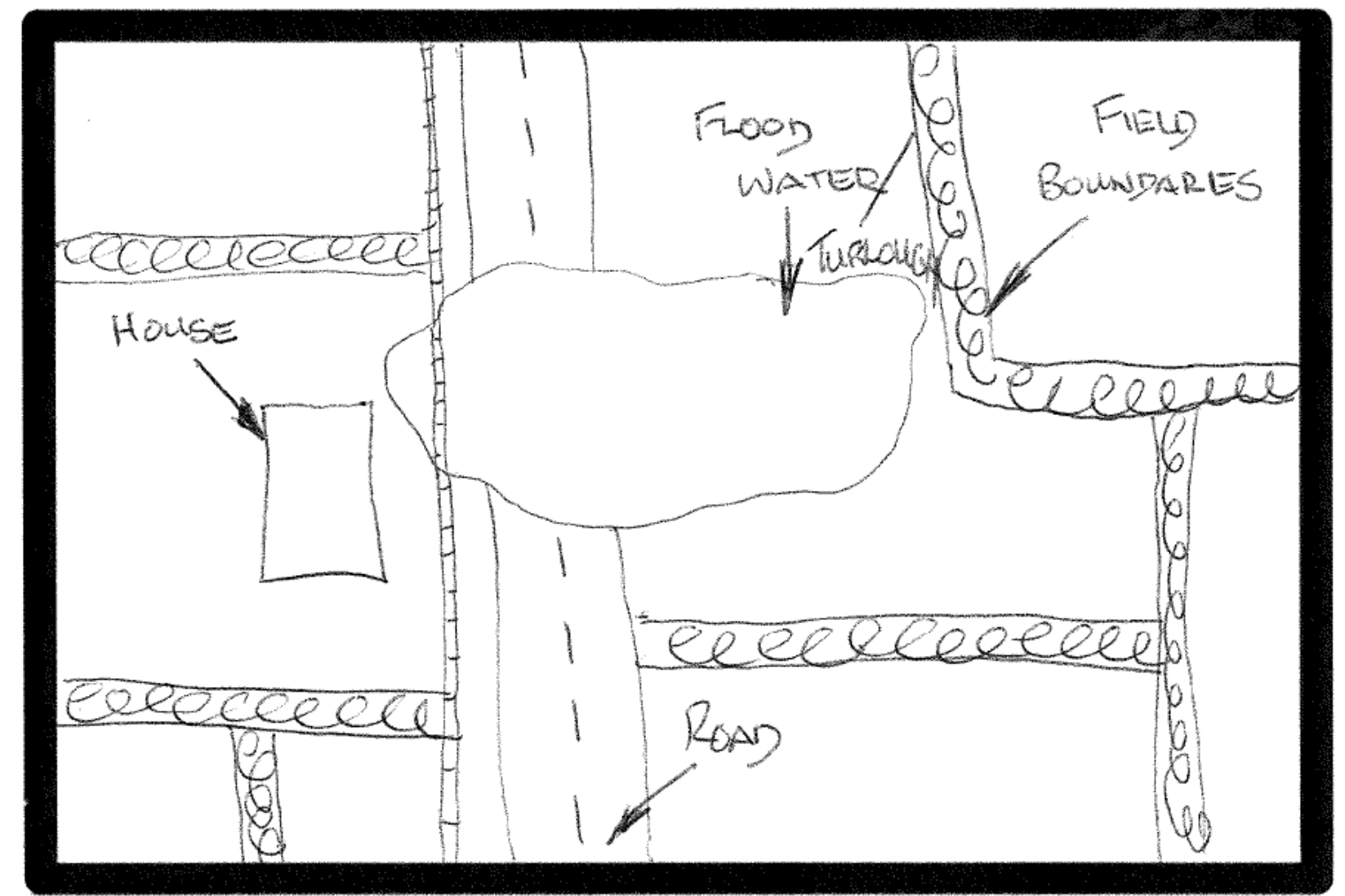

Expert 
PLEASE STAY INSIDE THE BOX!

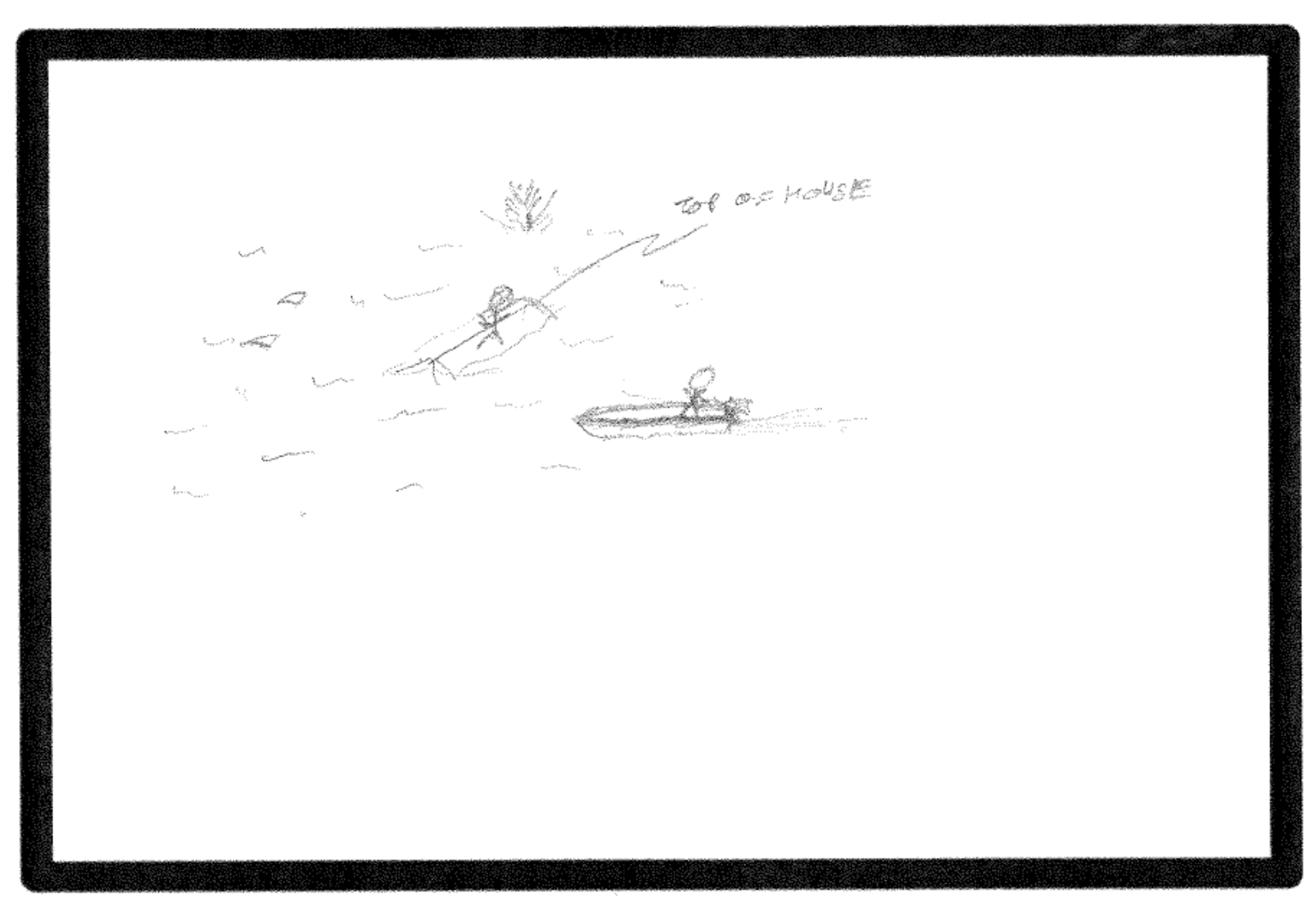




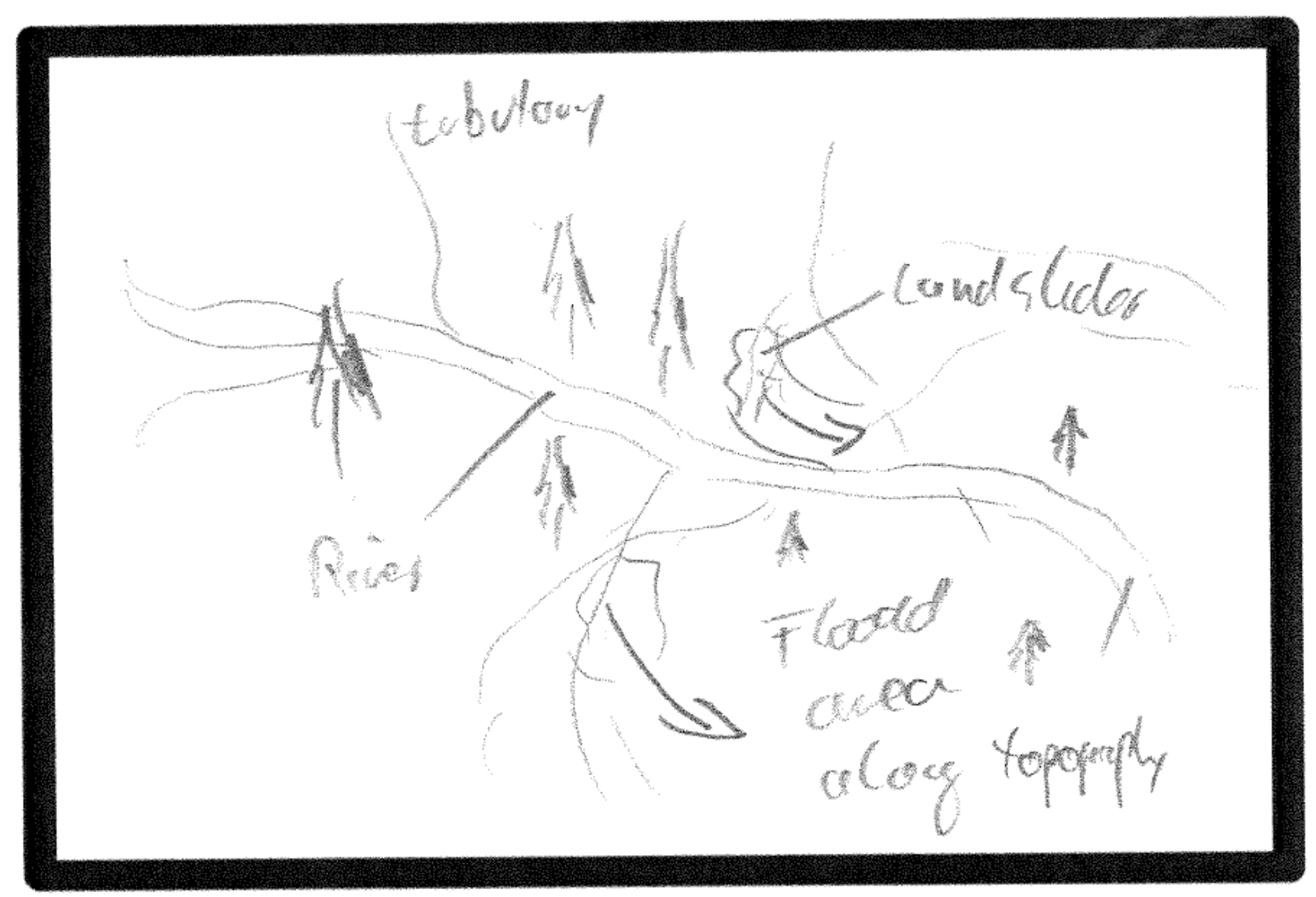




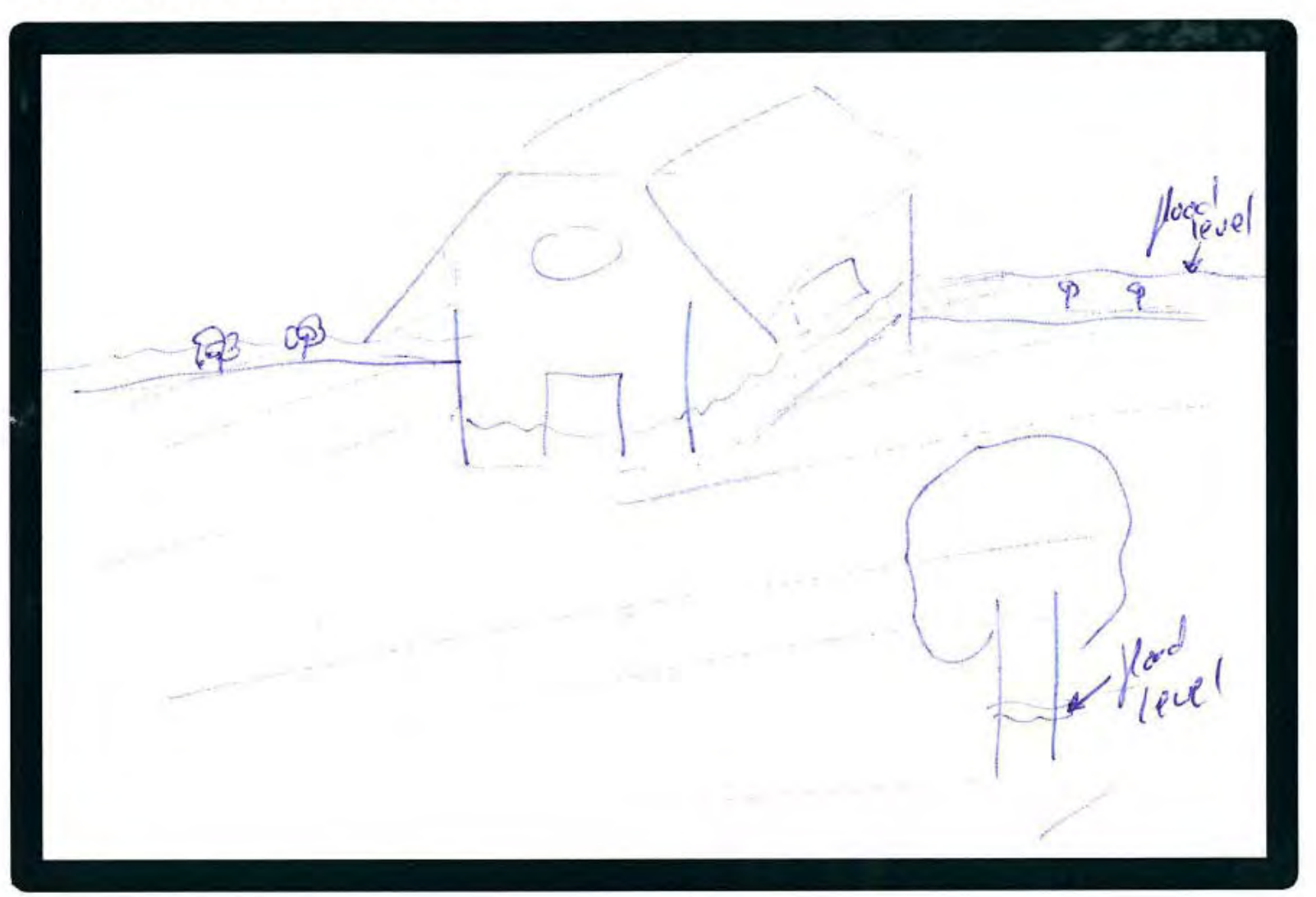


PLEASE STAY INSIDE THE BOX!

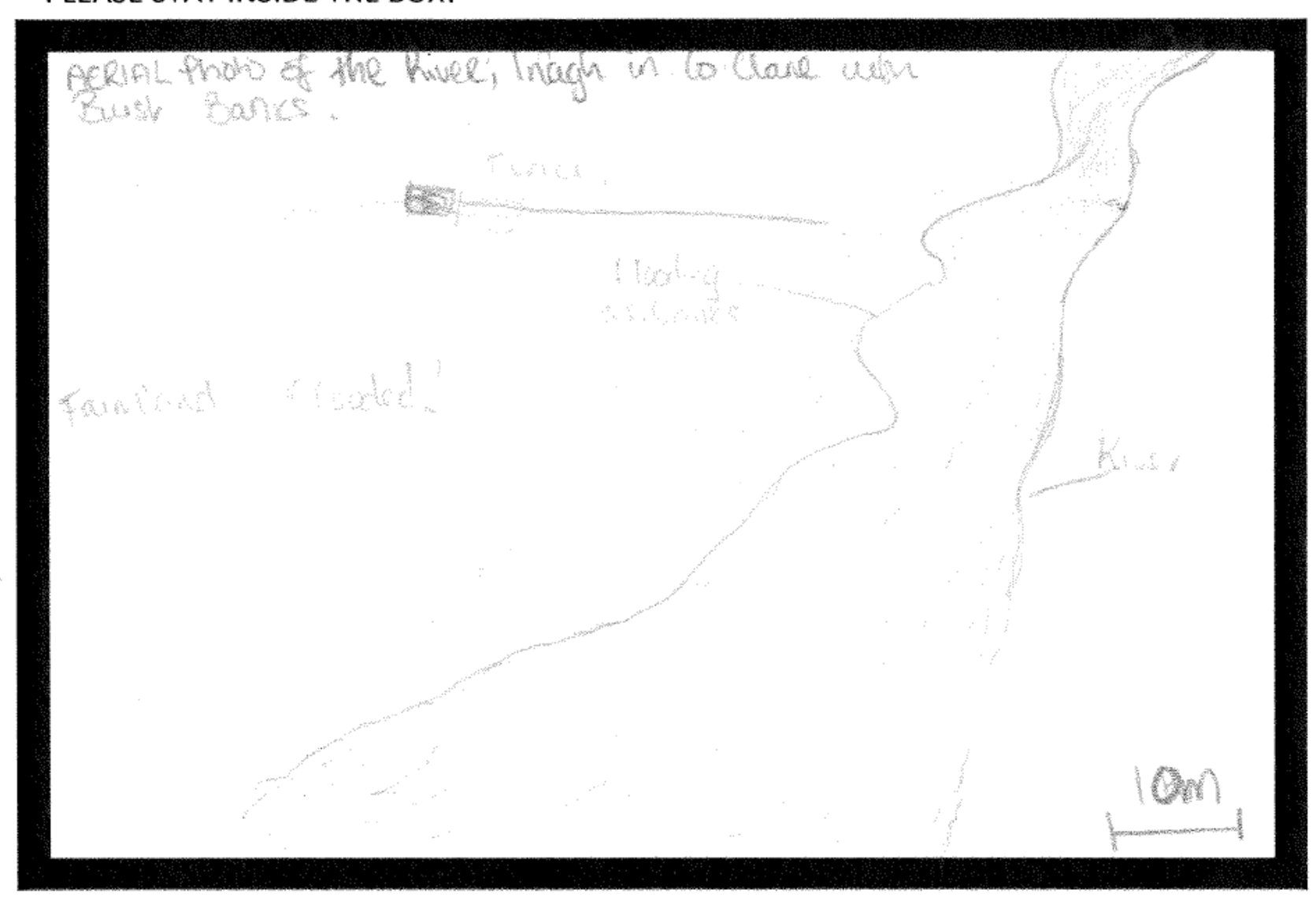


PLEASE STAY INSIDE THE BOX!

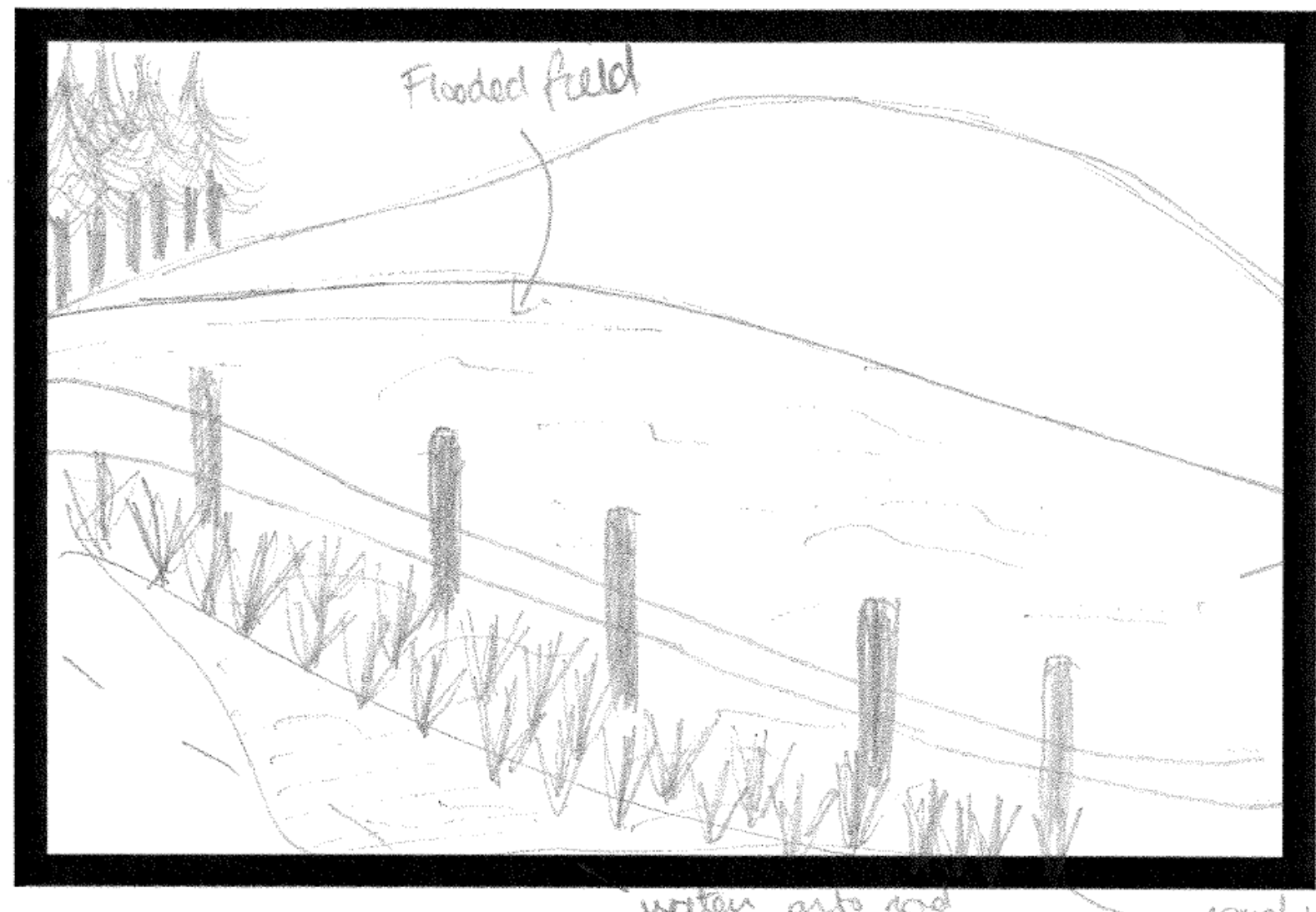

4a How realistic do vou find vou sketch on a srale from 1 tn 5 ? Pleace tirk the relevant number 


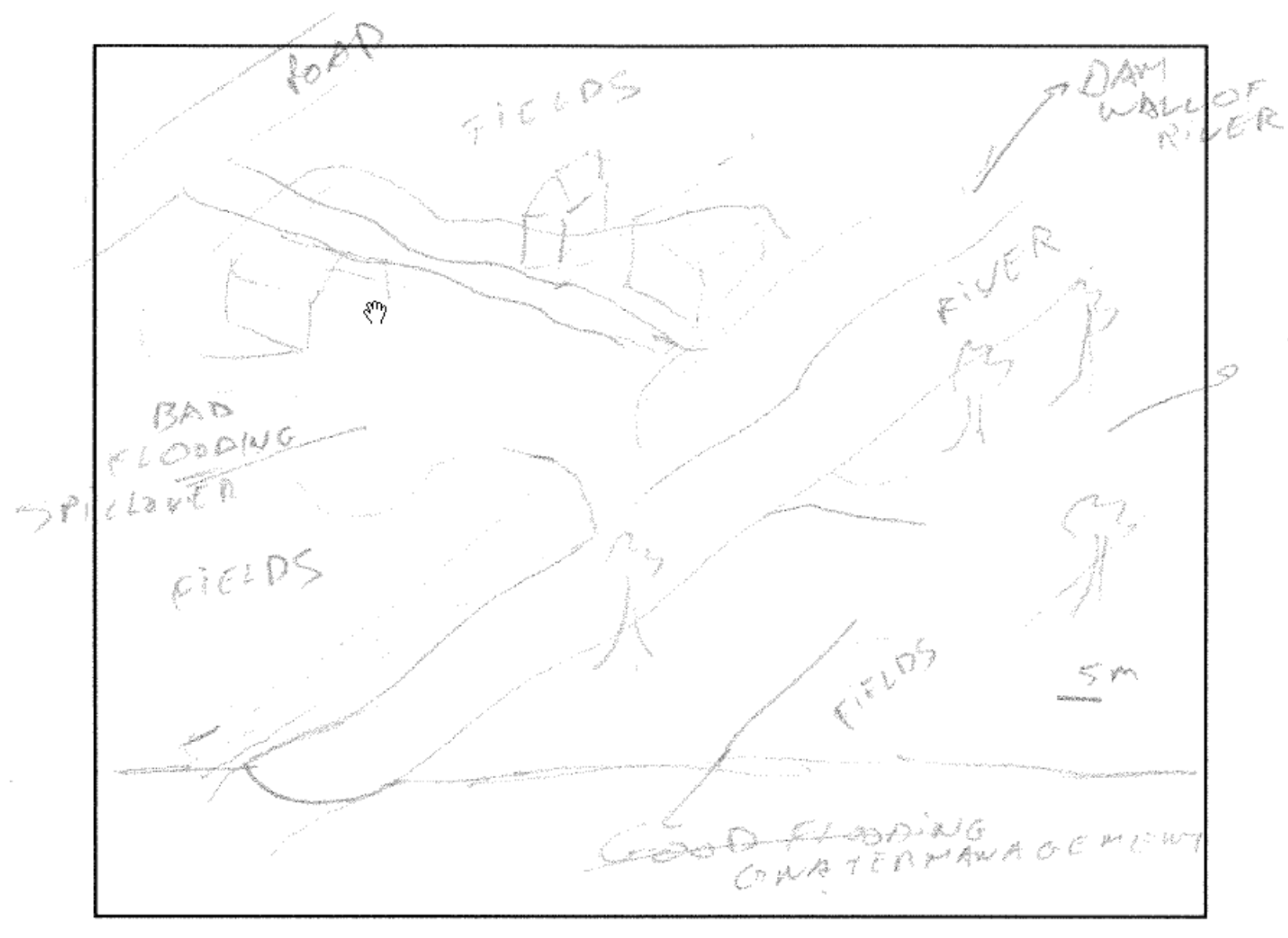

Expert 


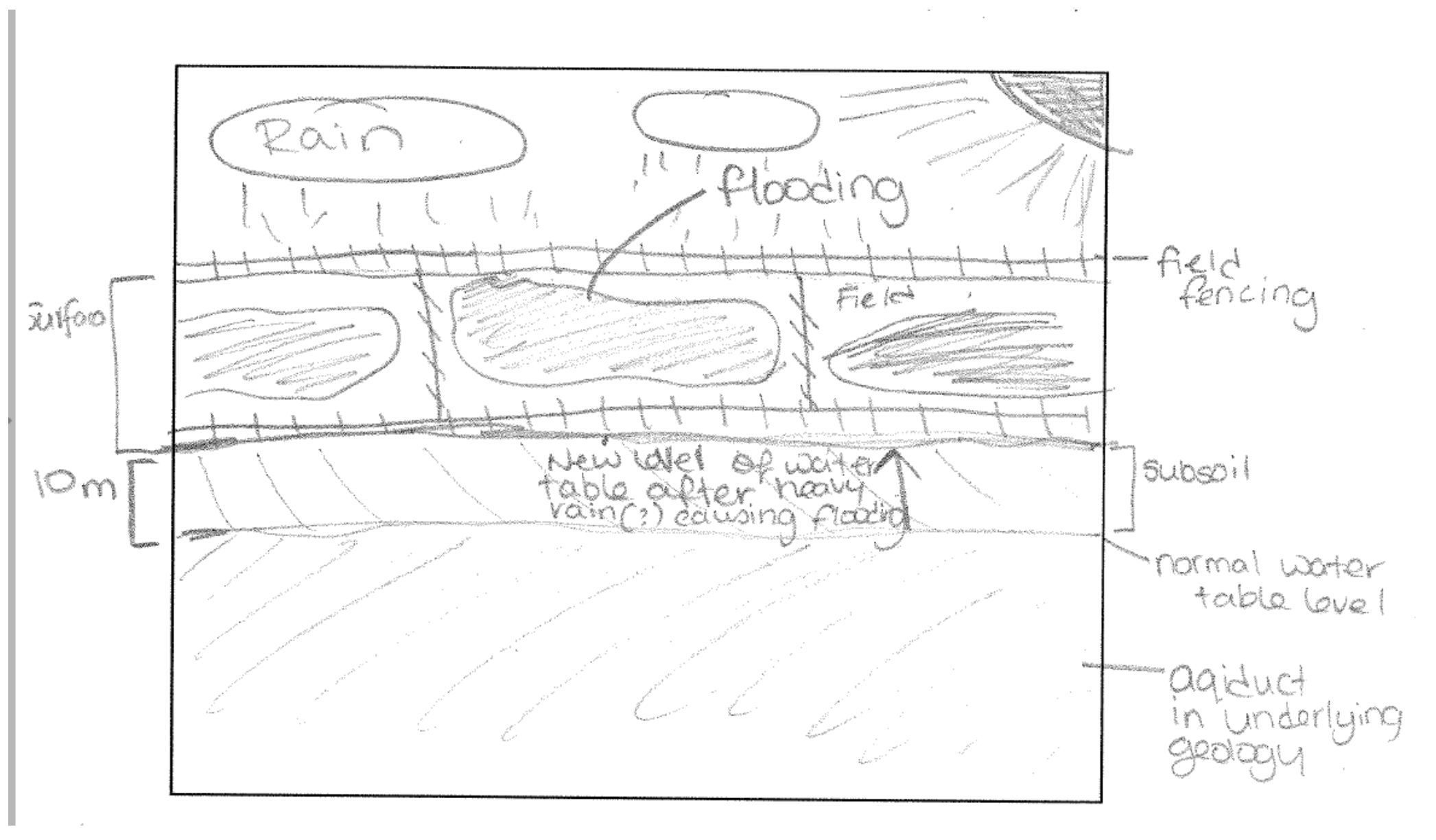




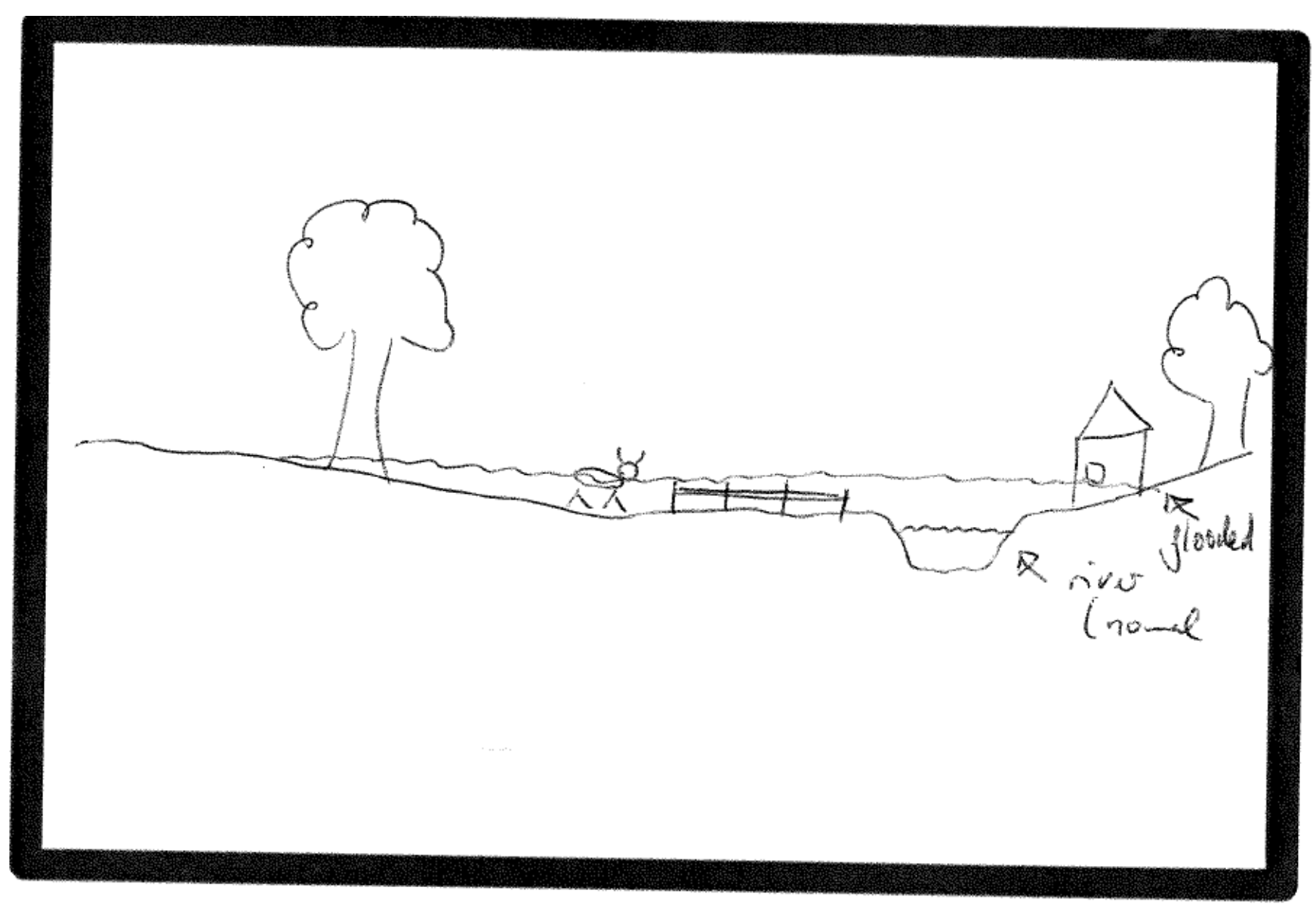




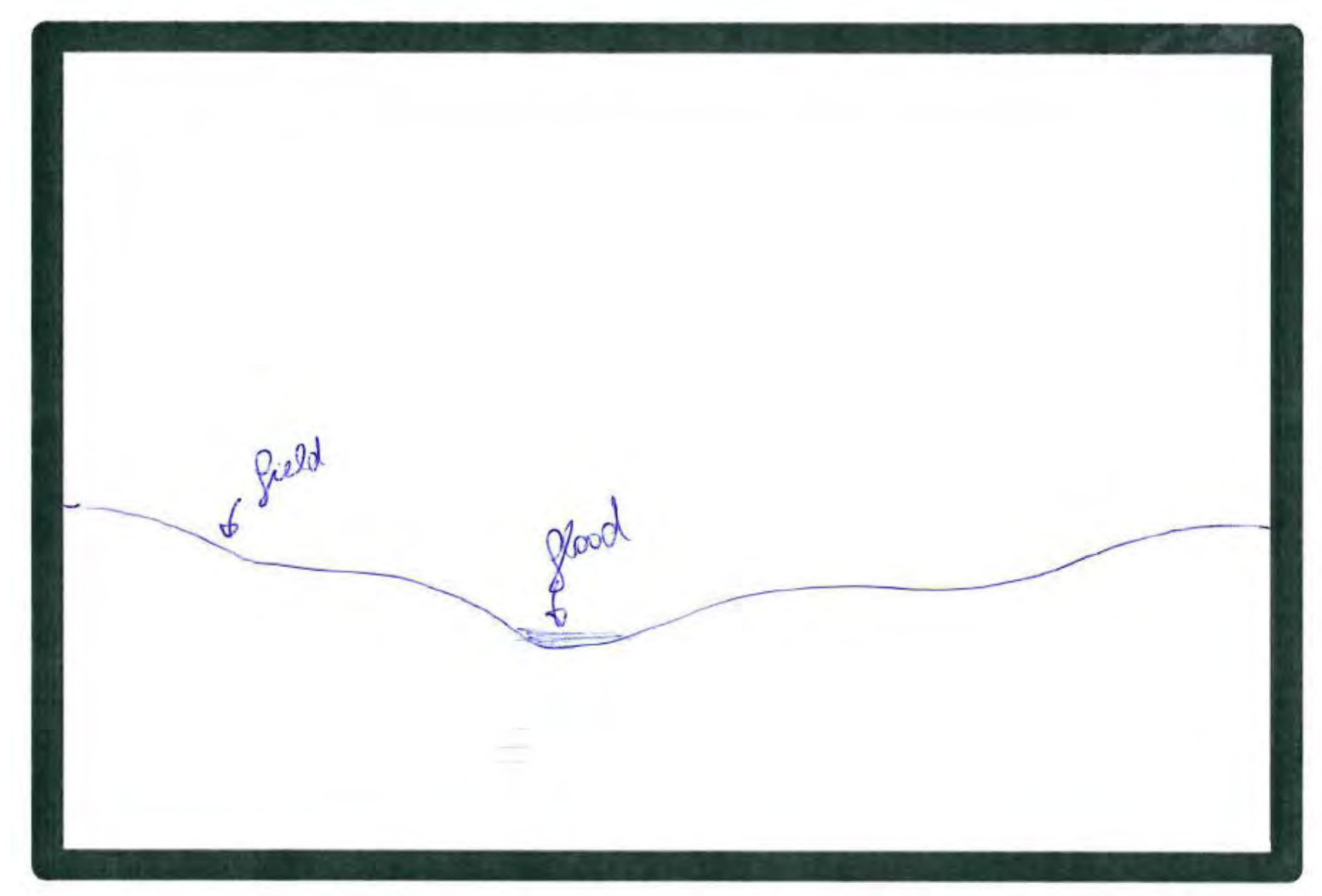


PLEASE STAY INSIDE THE BOX!

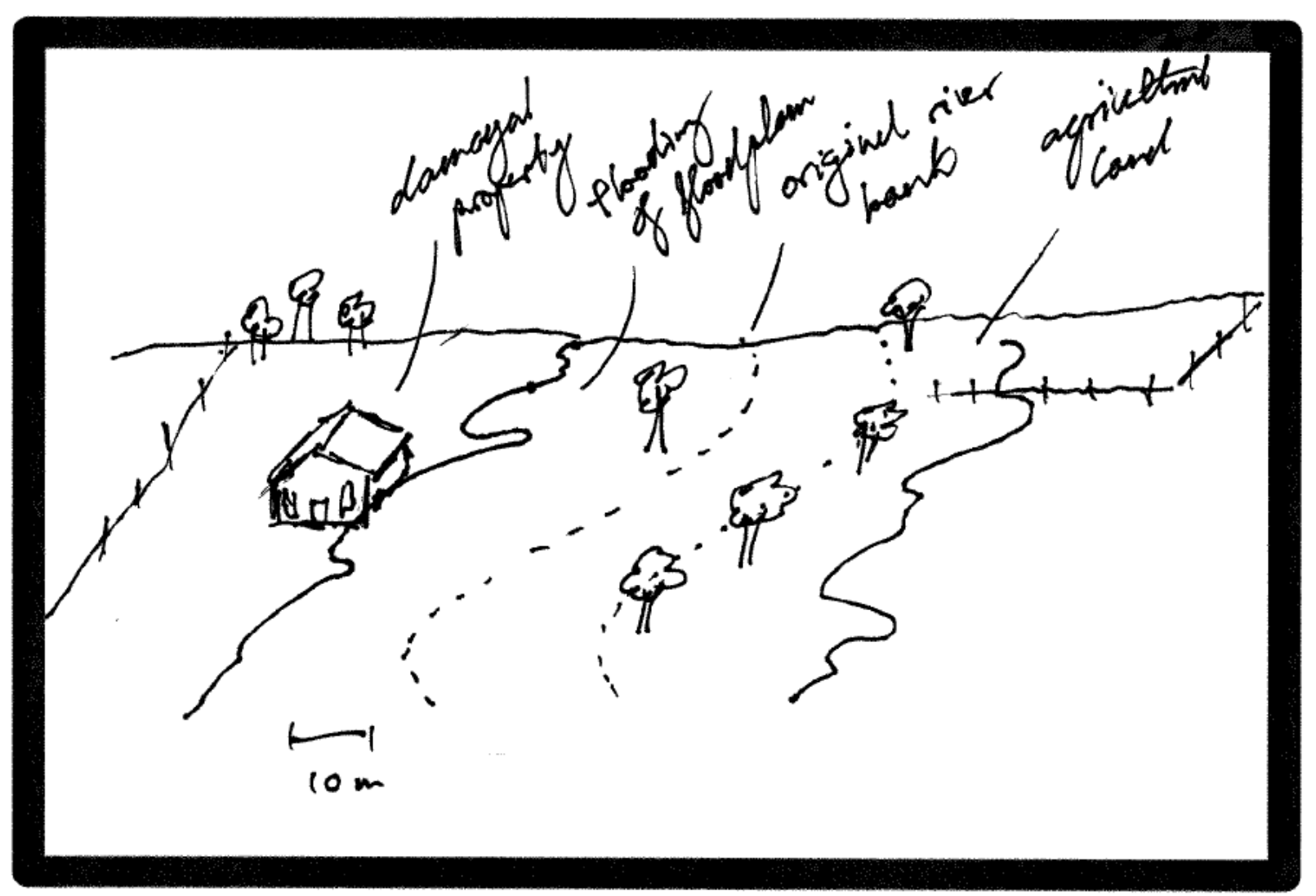




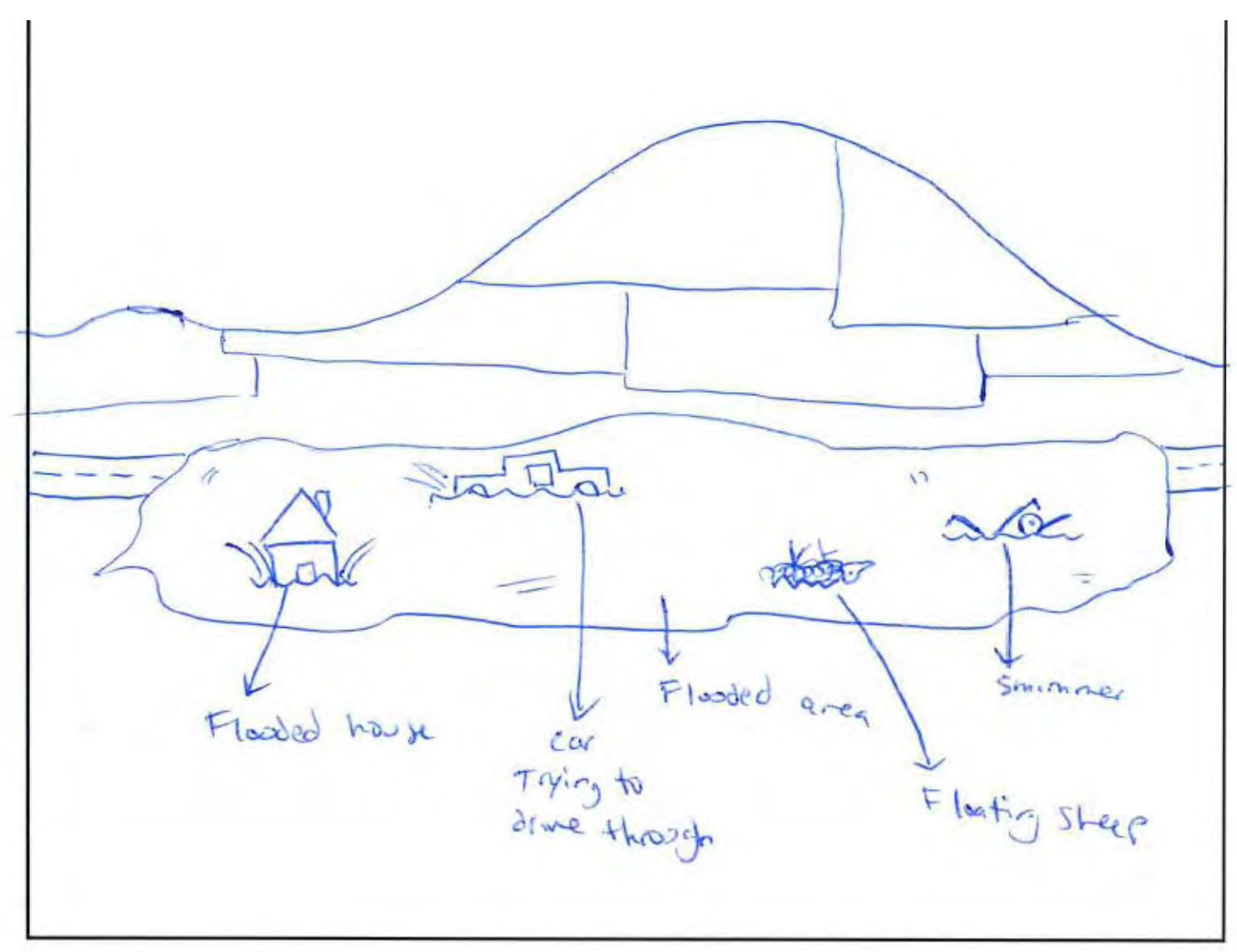




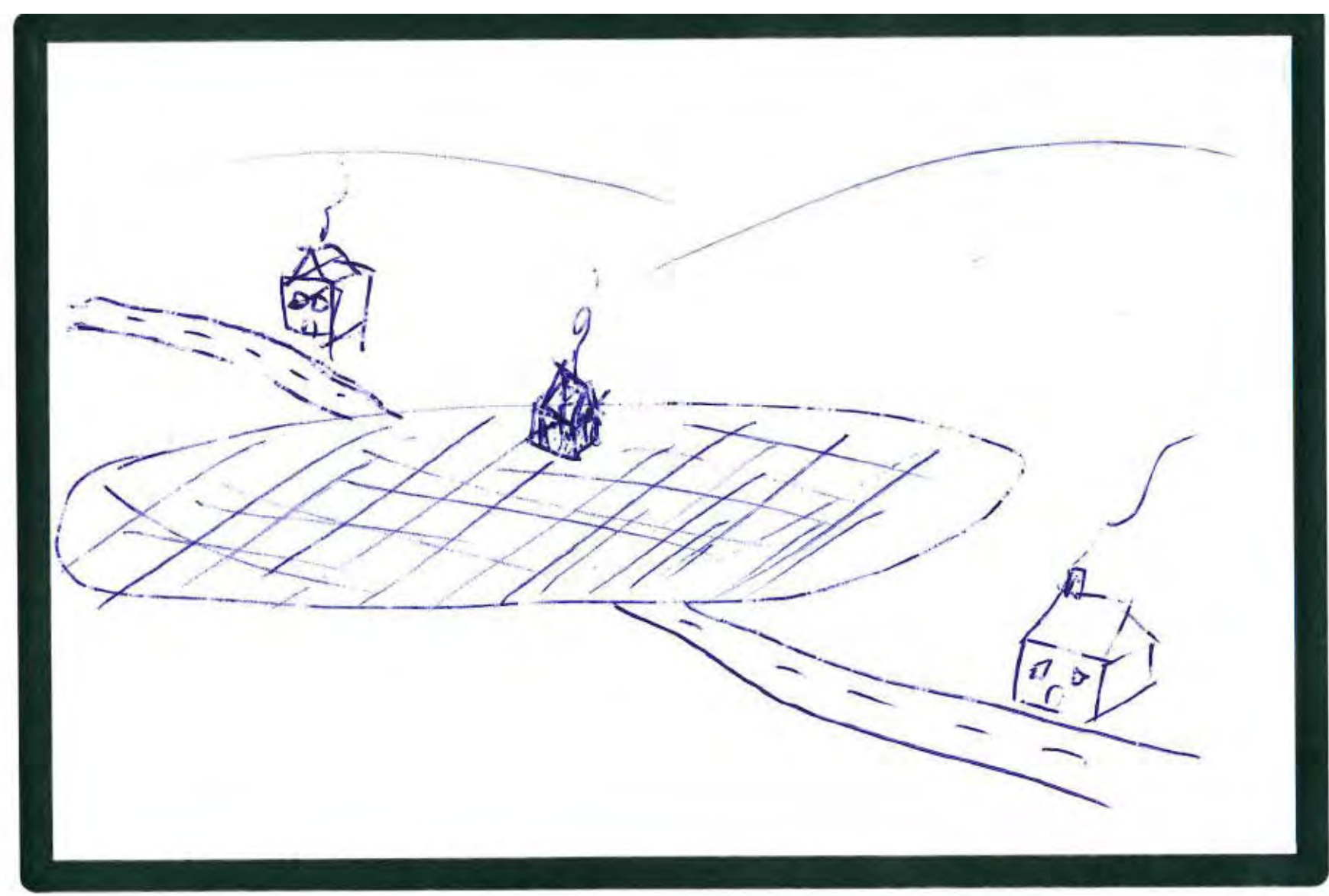


PLEASE STAY INSIDE THE BOX!

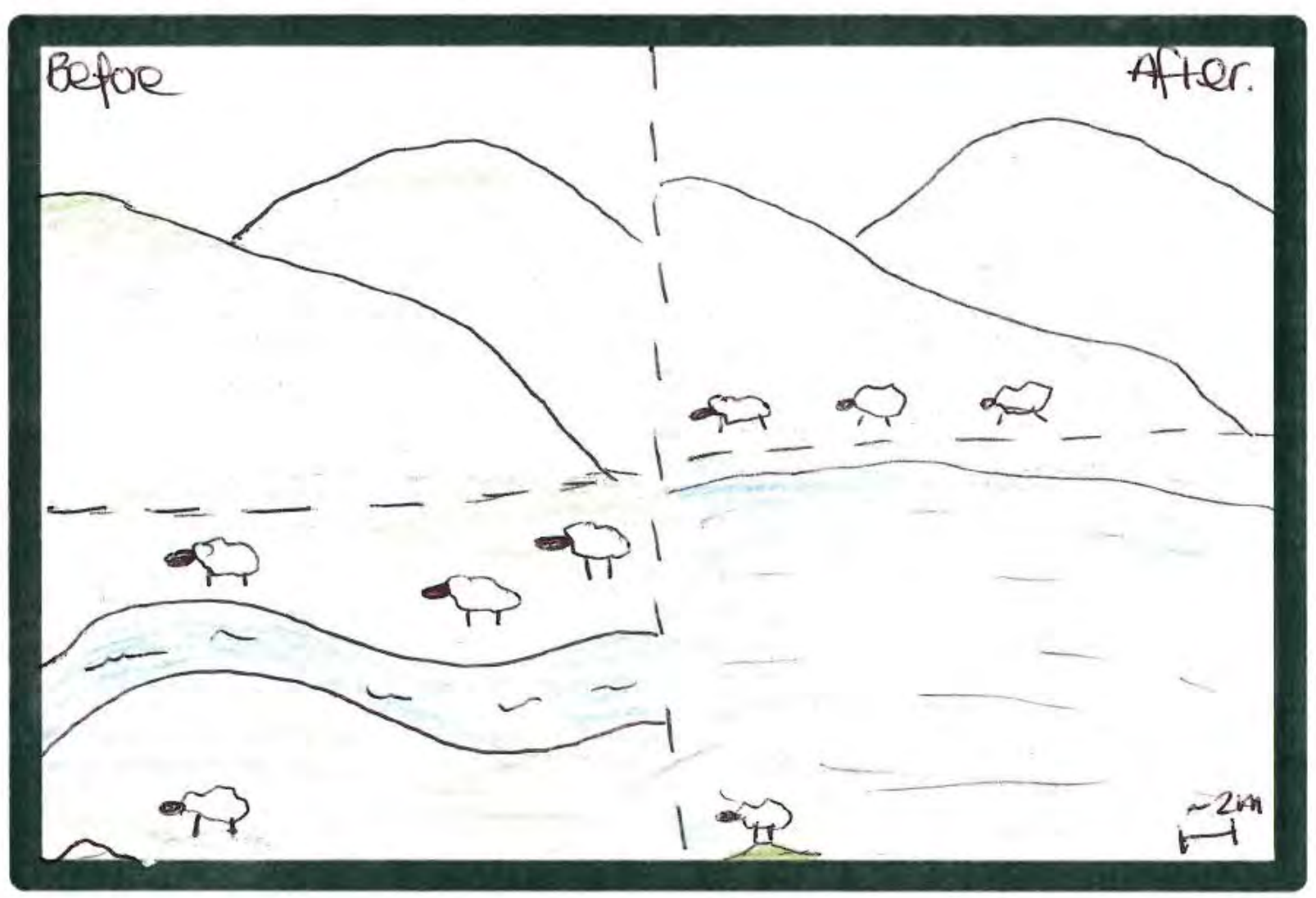


PLEASE STAY INSIDE THE BOX!

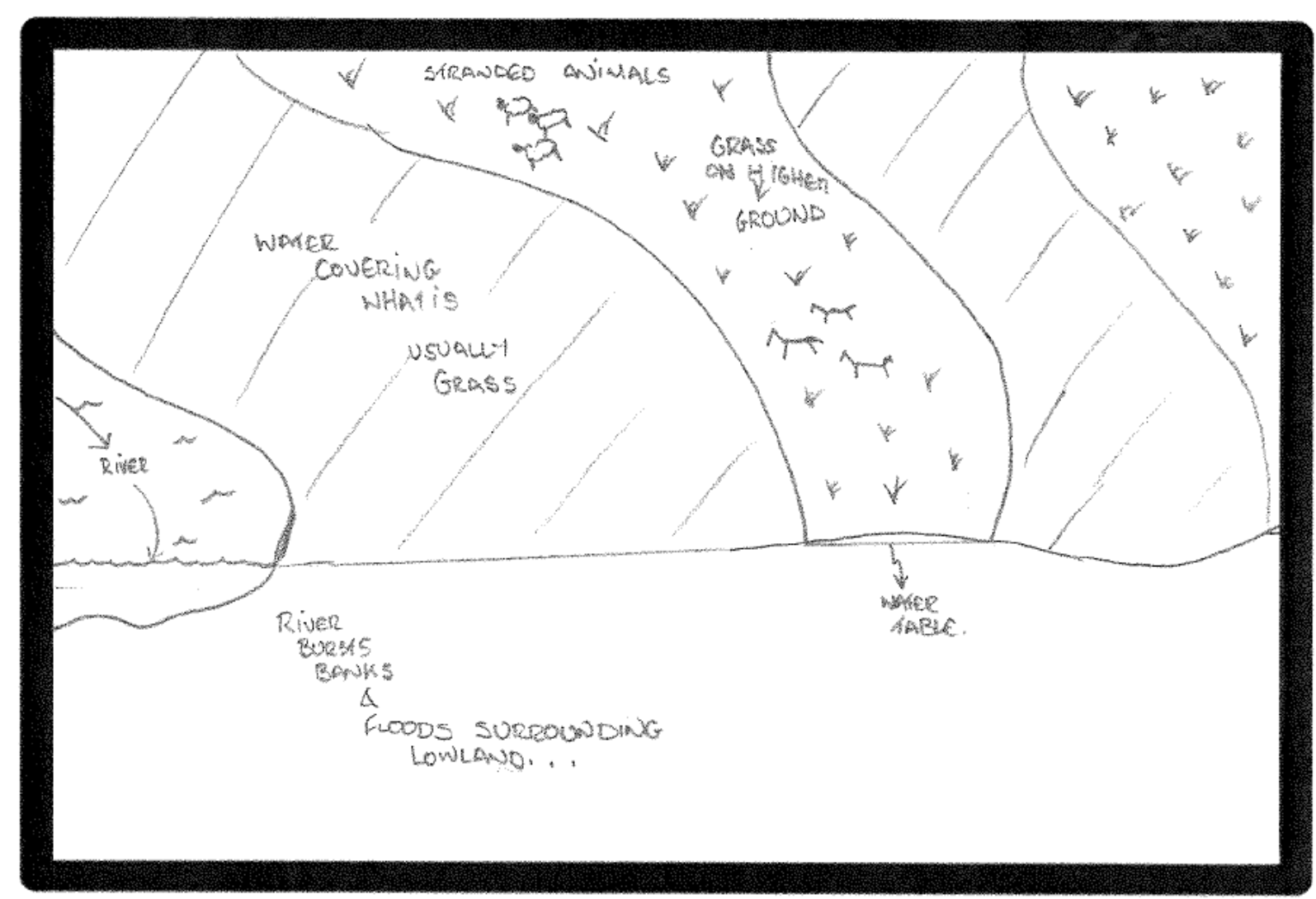




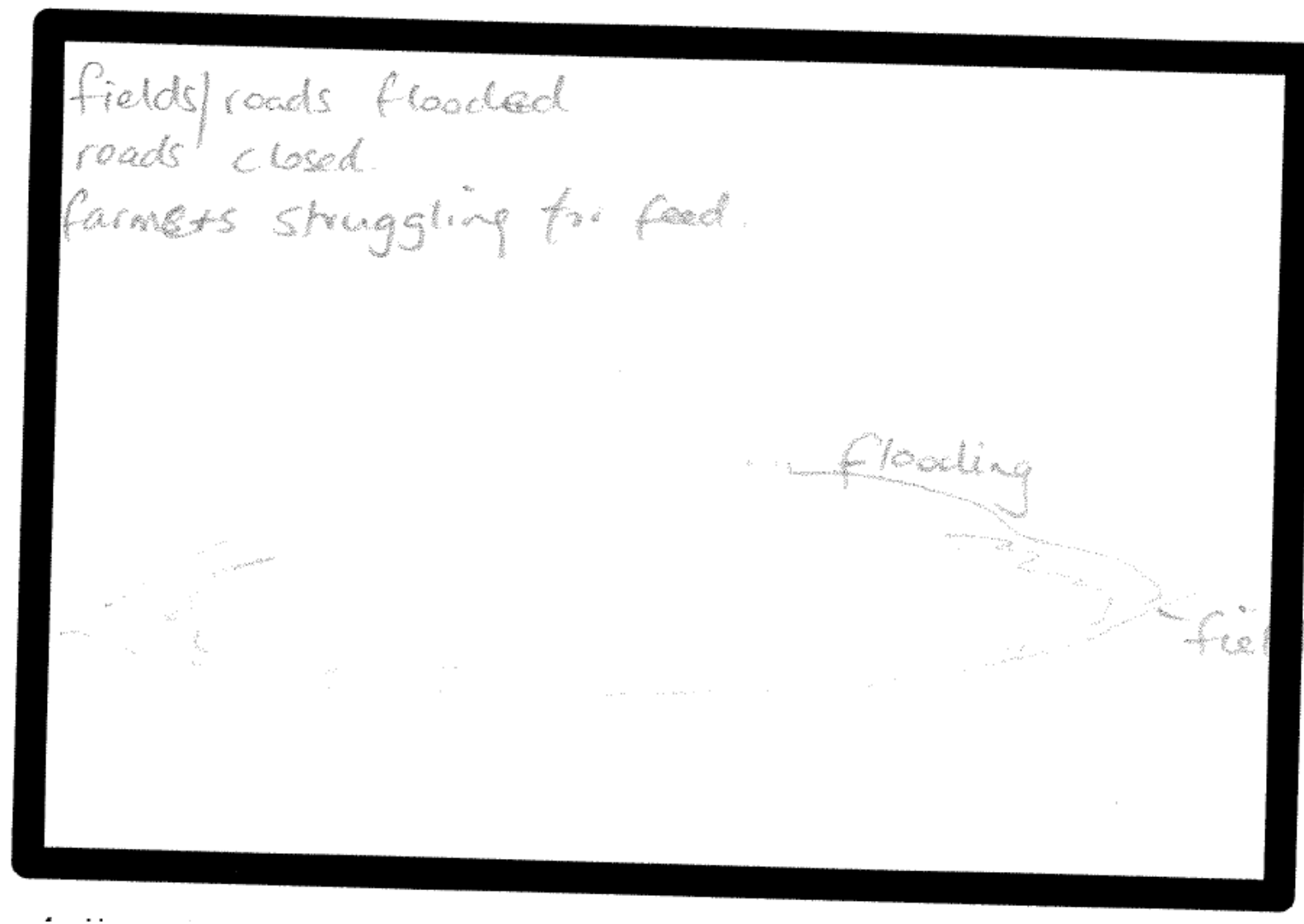




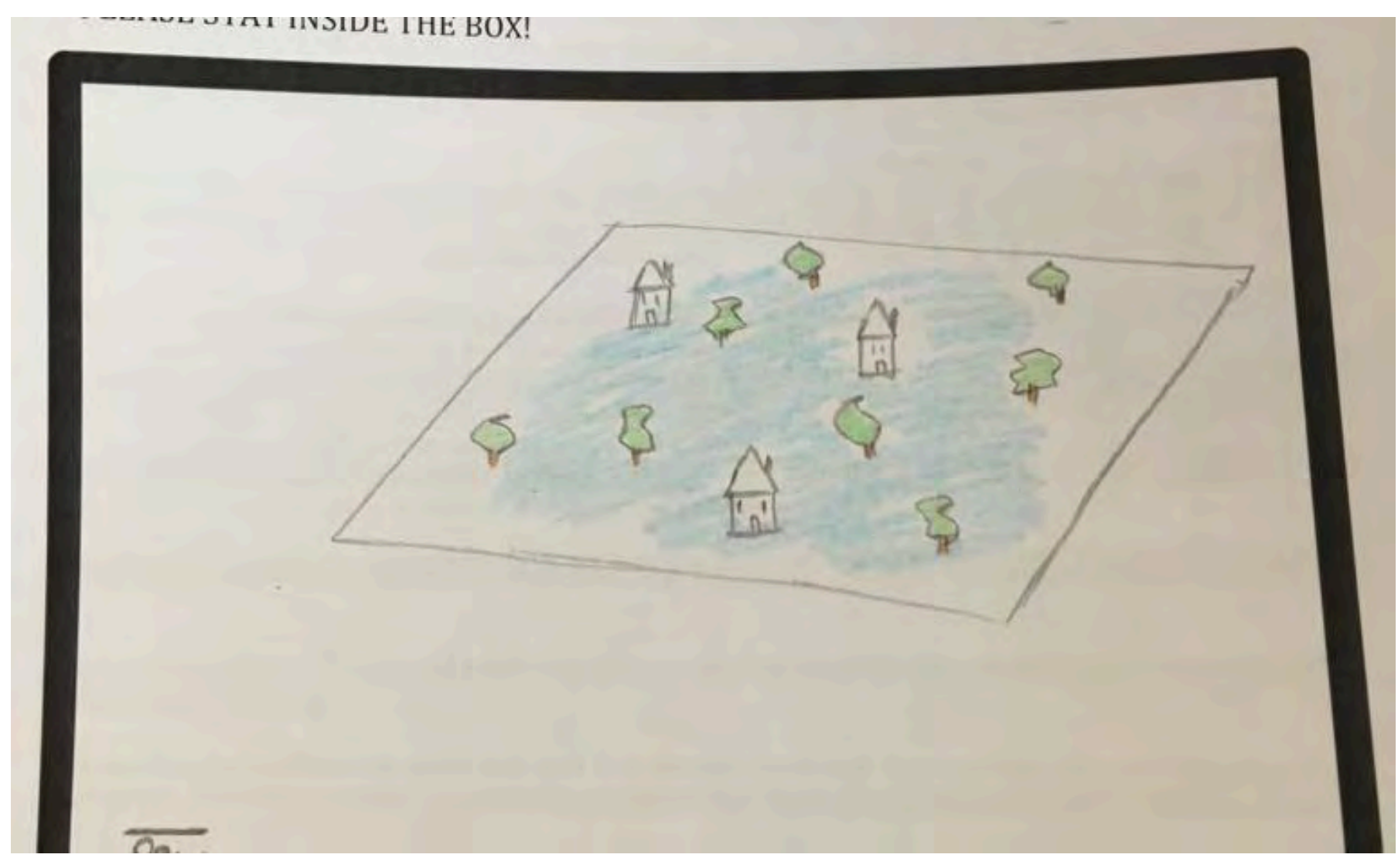

